\title{
Reduction of New Zealand Titanomagnetite Ironsand by Hydrogen Gas in a Fluidised Bed System
}

by

Sigit Wahyu Prabowo

A thesis submitted to Victoria University of Wellington in fulfilment of the requirement for the degree of Doctor of Philosophy in Engineering, and conferred as a single degree under a joint $\mathrm{PhD}$ program between Victoria University of Wellington and the University of Wollongong

Victoria University of Wellington 



\section{ACKNOWLEDGMENT}

All praises to the Almighty Allah S.W.T for His blessings, the strength, and good health throughout the process in completing this thesis. I am very grateful to all those who have helped and supported me to finish my thesis.

First of all, I would like to extend my sincere gratitude to my supervisors, Dr Chris Bumby, Professor Brian Monaghan, and Dr Raymond Longbottom for their generous support and guidance to my $\mathrm{PhD}$ work in patience. They had always provided me with invaluable inputs for during the work on this thesis. I feel fortunate to have supervisors who have always been supportive, and who responded to my questions and concerns promptly.

The most significant impact on my work must be accredited to Diego del Puerto. Thank you for continuous discussions and engineering assistance in the design and build of the fluidised bed reactor. Also, thank you for always strict on me. I know that it was to ensure my safety. Experiments in this thesis involved high amounts of hydrogen gas. One mistake could result in an explosion and an ending of my $\mathrm{PhD}$. I am very grateful that there was no incident nor accident throughout this project.

I would like to thank the Advanced Materials Group at Callaghan Innovation. Special gratitude to Martin Ryan for his time, expertise, and advice in X-ray diffraction analysis. I want to thank Dr Matthias Vest for speeding up the bureaucracy of the safety assessment for my experimental works. Dr Conrad Lendrum for allowing me to conduct experiments with hydrogen gas.

I also want to thank the team at Robinson Research Institute. Special thanks to Sarah Spencer for help in scanning electron microscopy and Joseph bailey for help with LabView. Furthermore, I want to thank Jeannie Redman and Ursula Muavae for all the administrative works. Also thank you to Dr Edward Cozens for helping me with the English language in my thesis.

I am very grateful for the scholarship and funding from the Ministry of Business, Innovation and Employment. My PhD project would not be possible without this support.

Special thanks also to my $\mathrm{PhD}$ mates in the ironsand team: Ao and Oscar for the friendship, discussions, and jokes.

At this point, I wish to thank all my former lecturers. A special thanks to my former undergraduate supervisor from Institut Teknologi Bandung (ITB), Professor Zaki 
Mubarok, who has opened an opportunity to study overseas. Also, thanks to my former supervisor in Kumamoto University, Toshiuki Kozuka Sensei and Takeshi Hashishin Sensei, for the recommendation letter for this PhD study. Without help from them, I would not be here now.

Finally, a very special thanks to my wife Yukiko and my one-year-old son Zealand, for their endless support, sacrifice, and patience. I wish to express my deepest gratitude to my parents (Sunarto Husodo and Eny Suniarti) for their love, support, and wisdom. I would like to also thank my parents-in-law (Dr Ikbal and Reny Sylvia) for their support. 


\section{ABSTRACT}

Titanomagnetite (TTM) ironsand has been used to produce steel in New Zealand (NZ) for about 40 years. However, the current steelmaking process in NZ produces high emissions of $\mathrm{CO}_{2}$ because it uses coal as a primary reducing agent. The fluidised bed (FB) process allows the use of pure hydrogen gas to reduce ironsand, and as a result, does not produce $\mathrm{CO}_{2}$ gas. However, for conventional hematite ores, reduction in a FB system is usually limited by the onset of particle sticking at temperatures $\gtrsim 800^{\circ} \mathrm{C}$. This thesis investigates the reduction of NZ TTM ironsand by hydrogen gas in the FB system with a key focus on ore sticking behaviour.

Initially, this thesis reports preliminary fluidisation tests by nitrogen and helium gases at room temperature, carried out to determine key fluidisation parameters for ironsand powder. From these results, a laboratory-scale experimental FB reactor has been designed and built for the hydrogen reduction study at high temperatures. A key feature of the reactor is a novel in-situ sampling system, which enables extraction of multiple samples during a single experimental run without interrupting operation of the FB.

Quantitative X-ray diffraction (q-XRD) has been used to determine the metallisation degree of partially reduced samples. Phase evolution during the reaction has also been analysed using q-XRD alongside scanning electron microscopy/energy dispersed spectroscopy (SEM/EDS). Additionally, the water vapour compositions in the exhaust gas were calculated from the q-XRD data and also measured in real-time using a hightemperature humidity sensor.

The effect of various parameters has been investigated within the FB reduction experiments: hydrogen gas concentrations, hydrogen gas flow rate, bed mass, particle size, and temperature. The results indicate that across the entire range of controlled studied, the FB reduction rate of TTM ironsand is simply controlled by the rate of hydrogen gas supply. Interestingly, there were no occurrences of the sticking phenomenon at any point during the reduction by hydrogen gas at high temperatures of up to $1000^{\circ} \mathrm{C}$. Sticking appears to be prevented by the formation of a protective titanium-rich oxide shell around each particle during the initial reduction stage. Importantly, this shell remains present throughout the reduction process, and as a result, the reduction reaction proceeds rapidly to completion with a metallisation degree of $\sim 93 \%$. 
The influence of temperature on the reaction progress has also been investigated. The reduction pathway appears to vary within different temperature regimes. At low temperatures $\left(750^{\circ} \mathrm{C}-800^{\circ} \mathrm{C}\right)$, TTM is directly reduced to metallic iron and ilmenite without any evidence of wüstite phase. At 'intermediate temperatures' $\left(850^{\circ} \mathrm{C}-900^{\circ} \mathrm{C}\right)$ small amount of short-lived wüstite is observed. Some of the amount of TTM appears to be reduced to wüstite, and some is directly reduced to metallic iron. At high temperatures $(\geq$ $950^{\circ} \mathrm{C}$ ), approximately half of the initial TTM phase is quickly reduced to wüstite. After that point, wüstite is then reduced to metallic iron whilst the reduction of TTM stops. This is due to the enrichment of Ti species in TTM phase, which stabilises TTM crystal. Once wüstite has been fully reduced, the reduction of TTM then resumes.

Throughout the entire experimental program for this thesis, particle sticking was observed to occur only under two specific sets of experimental conditions. These were: reduction by $100 \% \mathrm{H}_{2}$ gas at $1050^{\circ} \mathrm{C}$ (case A) and reduction by $7.5 \mathrm{~mol} . \% \mathrm{H}_{2} \mathrm{O}-92.5$ mol.\% $\mathrm{H}_{2}$ at $950^{\circ} \mathrm{C}$ (case B). In both cases, sticking occurred as a sinter which nucleated at the reactor wall surface, while most particles remained fluidised as loose powder. The mechanism of these sticking cases has been analysed by XRD and SEM. The results suggest that silica from the quartz reactor wall reacted and bonded with Fe from particles to nucleate the initial sinter.

In summary, the findings in this thesis show that the hydrogen-FB process is highly effective in reducing NZ ironsand to a direct reduced iron (DRI) product. These findings open up the possibility of developing a new industrial FB technology for the direct reduction of NZ TTM ironsand, with extremely low $\mathrm{CO}_{2}$ emissions. 


\section{CERTIFICATION}

I, Sigit Wahyu Prabowo, declare that this thesis submitted in fulfilment of the requirements for the conferral of the degree Doctor of Philosophy (PhD), from Victoria University of Wellington, New Zealand, is my own work. Any contribution made to the research by others, with whom I have worked, is explicitly acknowledged in the thesis. This thesis is being submitted under a joint PhD agreement between Victoria University of Wellington and the University of Wollongong, Australia. This degree will be conferred as a single degree. Therefore, this thesis has also been submitted to the University of Wollongong for PhD examination. This document has not been submitted for qualifications at any other academic institution.

Sigit Wahyu Prabowo

$15^{\text {th }}$ July 2020 


\section{LIST OF PUBLICATIONS}

During the course of this thesis, one journal article and two conference papers have been published. One further journal article is in preparation. Several passages and figures, that were included in these published papers, or are currently in preparation for publication, have been directly reused in this thesis. A list of publication is given below.

\section{Journal Article:}

- Prabowo, S., Longbottom, R., Monaghan, B., del Puerto, D., Ryan, M., and Bumby, C., (2019) 'Sticking-Free Reduction of Titanomagnetite Ironsand in a Fluidized Bed Reactor', Metallurgical and Materials Transactions B. Springer US, 50(4), pp. 1729-1744.

\section{Conference Papers}

- Prabowo, S., Longbottom, R., del Puerto, D., Ryan, M., Bumby, C., and Monaghan, B., (2019) 'Development of an Experimental Fluidised Bed Reactor for the Processing of New Zealand Titanomagnetite Ironsand', in Iron Ore Conference 2019 Proceedings. Perth, pp. 456-463.

- $\quad$ Prabowo, S., del Puerto, D., Ryan, M., Longbottom, R., Monaghan, B., and Bumby, C., (2018) 'Design and Commissioning of an Experimental Fluidized Bed Reactor for the Hydrogen Reduction of Titanomagnetite Ironsand', in $8^{\text {th }}$ International Congress on Science and Technology in Ironmaking. Vienna, Paper ID: 279. 


\section{LIST OF ABBREVIATIONS}

$\mathrm{BF} \quad=$ Blast furnace

BOF = Basic oxygen furnace

BSE = Back scattered electron

CFB = Circulating fluidised bed

$\mathrm{DR}=$ Direct reduction

DRI = Direct reduced iron

EDS = Energy dispersed spectroscopy

$\mathrm{FB} \quad=$ Fluidised bed

HDR = Hydrogen direct reduction

HPLC = High-Performance Liquid Chromatography

NZ = New Zealand

PSD = Particle size distribution

q-XRD = Quantitative x-ray diffraction

RPCC = Reduced primary concentrate and char

SEM = Scanning electron microscopy

TTM = Titanomagnetite

$\mathrm{TTH}=$ Titanohematite

$\mathrm{XRD}=\mathrm{X}$-ray diffraction

$\mathrm{XRF}=\mathrm{X}$-ray fluorescence 


\section{NOMENCLATURE}

$A \quad=$ Reactor inner area (bed surface area) $\left(\mathrm{cm}^{2}\right)$

$A_{b} \quad=$ Bed top surface area $\left(\mathrm{cm}^{2}\right)$

Ar = Archimedes number (dimensionless)

$D \quad=$ Reactor inner diameter $(\mathrm{cm})$

$D_{\text {bed }}=$ Bed diameter $(\mathrm{cm})$

$D_{i} \quad=$ Gas inlet inner diameter $(\mathrm{cm})$

$d_{p} \quad=$ Mean particle diameter $(\mu \mathrm{m})$

$F e^{o}=$ the amount of metallic iron in the sample (wt.\%)

$F e_{\text {Tot }}=$ total iron in the sample (wt.\%)

$\mathrm{Fe}_{T} \quad=$ total iron in the raw ironsand concentrate (wt.\%)

$\mathrm{Fr} \quad=$ Fraude number (dimensionless)

$g \quad=$ gravitational acceleration $\left(9.81 \mathrm{~m} / \mathrm{s}^{2}\right)$

$H_{\text {bed }}=$ Bed height $(\mathrm{cm})$

$H_{w} \quad=$ Windbox height $(\mathrm{cm})$

$\%$ met $=$ Metallisation degree $(\%)$

$R_{e} \quad=$ Reynold's number (dimensionless)

$\mathrm{Q}=$ Flow rate $(\mathrm{L} / \mathrm{min})$

$U_{m f}=$ Minimum fluidisation velocity $(\mathrm{cm} / \mathrm{s})$

$U_{t} \quad=$ Terminal velocity $(\mathrm{cm} / \mathrm{s})$

$W_{b} \quad=$ Weight of the bed (g)

$\Delta P \quad=$ Pressure drop $(\mathrm{Kpa})$

$P_{\mathrm{H} 2 \mathrm{O}}=$ Partial pressure of $\mathrm{H}_{2} \mathrm{O}(\mathrm{atm})$

$\varepsilon \quad=$ Bed voidage (dimensionless)

$\varepsilon_{m f} \quad=$ Bed voidage at minimum fluidisation (dimensionless)

$\varphi \quad=$ Sphericity (dimensionless)

$u_{o} \quad=$ Superficial velocity $(\mathrm{cm} / \mathrm{s})$

$\rho_{s} \quad=$ Solid density $\left(\mathrm{g} / \mathrm{cm}^{3}\right)$

$\rho_{g} \quad=$ Gas density $\left(\mathrm{g} / \mathrm{cm}^{3}\right)$

$\mu \quad=$ Viscosity $(\mathrm{g} / \mathrm{cm} \cdot \mathrm{s})$ 


\section{CONTENTS}

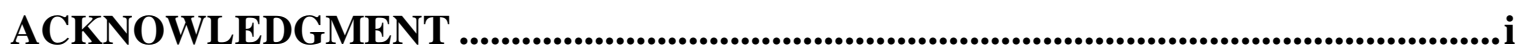

ABSTRACT ..............................................................................................................................................iii

CERTIFICATION ...................................................................................................................v

LIST OF PUBLICATIONS ..........................................................................................

LIST OF ABBREVIATIONS ...................................................................................

NOMENCLATURE ...........................................................................................................viii

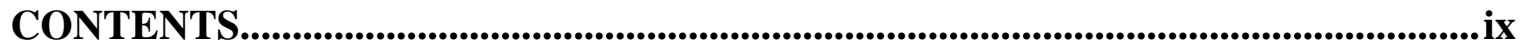

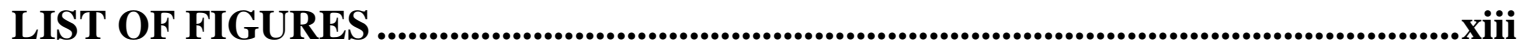

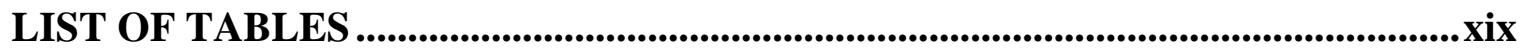

1 Introduction ........................................................................................................................ 1

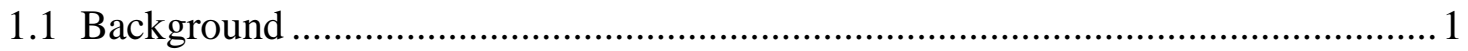

1.1.1 Current steelmaking process.................................................................. 1

1.1.2 NZ ironsand and the NZ steel process ....................................................1

1.1.3 The emerging importance of hydrogen direct reduction ..............................2

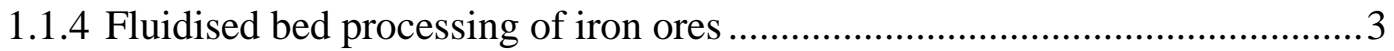

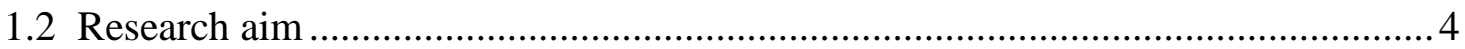

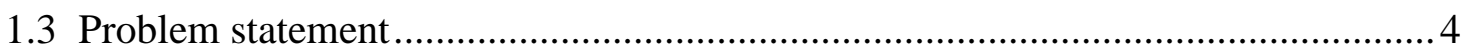

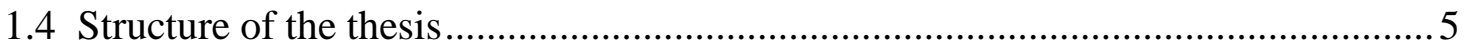

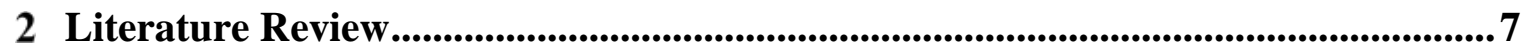

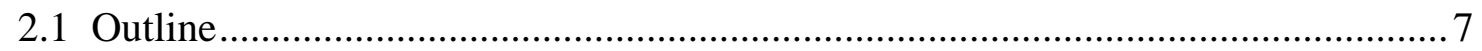

2.2 Fundamentals in iron ore reduction by $\mathrm{H}_{2}$ gas ................................................ 7

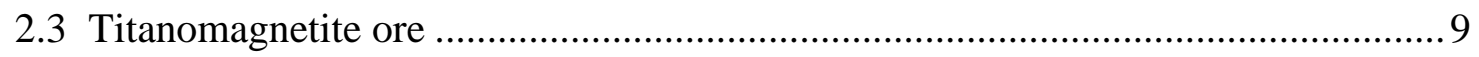

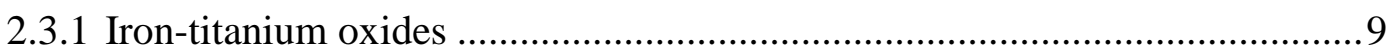

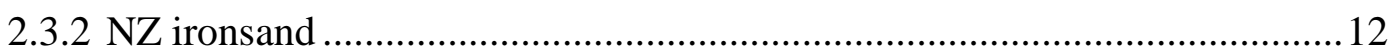

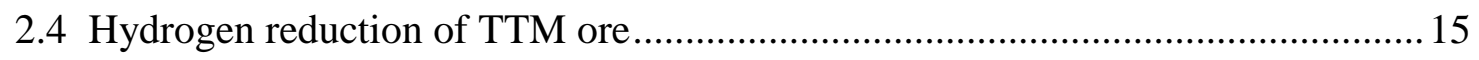

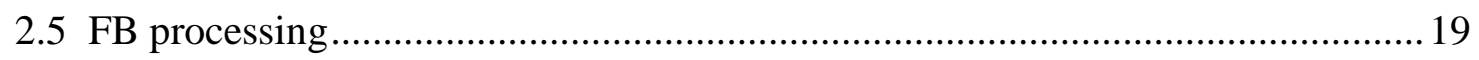

2.5.1 Theoretical considerations in designing a FB reactor ................................19

2.5.2 Previous laboratory experiments on FB reduction involving iron oxides ....26

2.6 Commercial FB technology for DR process of iron ores.....................................29

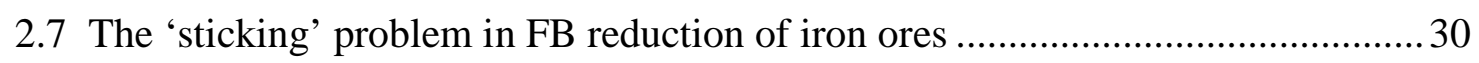

2.7.1 Particle sticking in the FB reduction of hematite ores..................................30

2.7.2 Previous reports related to the sticking in FB reduction of TTM ores.........34 
2.7.3 Previously proposed strategies to prevent sticking during FB reduction of

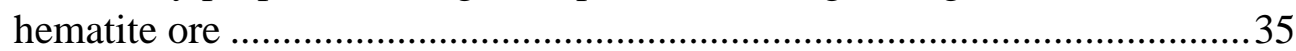

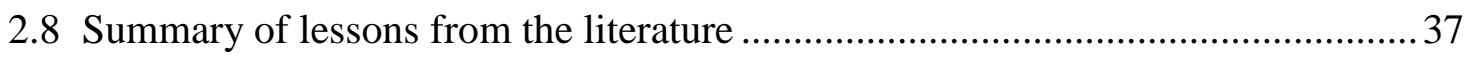

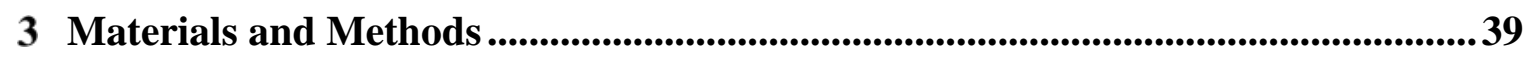

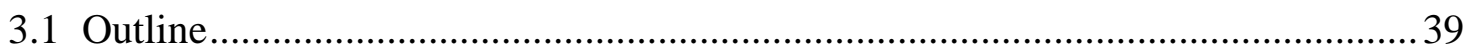

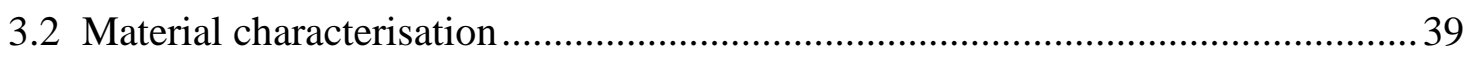

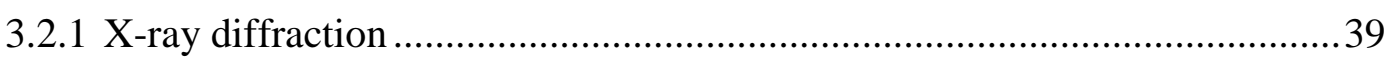

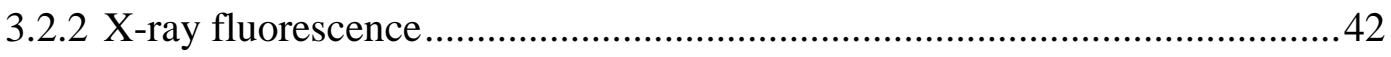

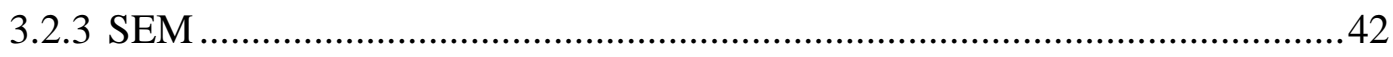

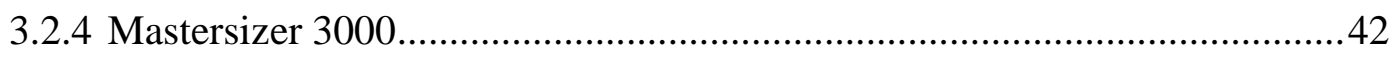

3.3 Characterisation of raw NZ ironsand concentrate ............................................... 43

3.4 Development of an analytical method for determining \%met ............................ 46

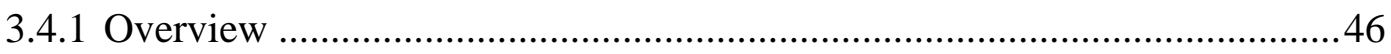

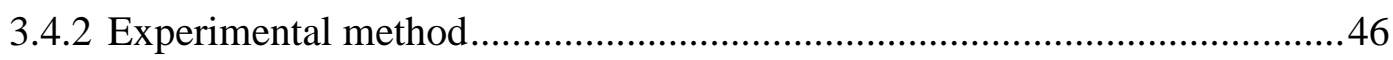

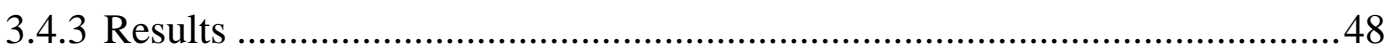

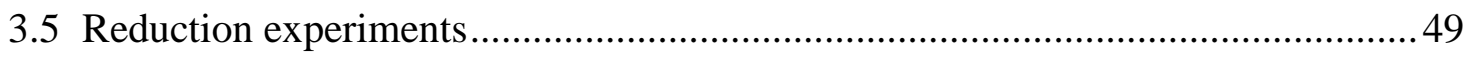

3.5.1 General procedure for the reduction experiments .......................................49

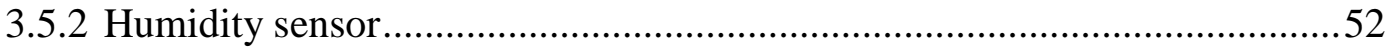

3.5.3 Introduction of steam to the FB reactor ....................................................5

4 Design and Commissioning of an Experimental FB Reactor ..................................... 57

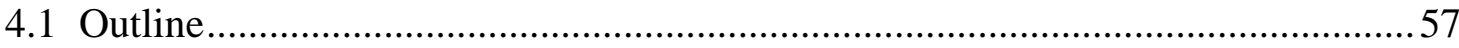

4.2 Fluidisation tests at room temperature …........................................................... 57

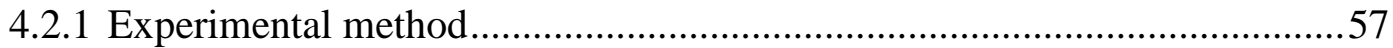

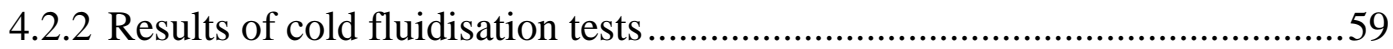

4.3 Design and build of the high-temperature FB reactor..........................................66

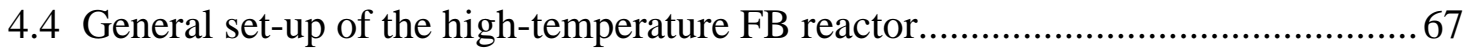

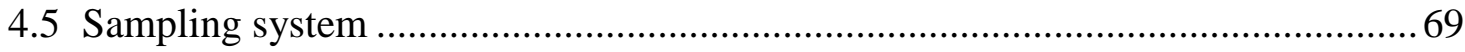

4.5.1 Initial tests in a laboratory set-up at room temperature ...............................69

4.5.2 Sampling tests using the high-temperature FB reactor set-up ......................71

4.6 Commissioning of the high-temperature FB reactor........................................... 74

4.6.1 Initial commissioning of the reactor system using an inert gas $\left(\mathrm{N}_{2}\right)$ at

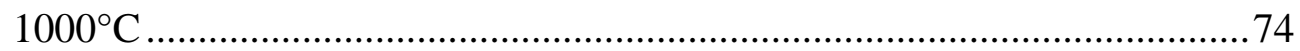

4.6.2 Commissioning of the reactor system using air at $1000^{\circ} \mathrm{C} \ldots \ldots \ldots \ldots \ldots \ldots \ldots . . . . . . . . . . . . .75$

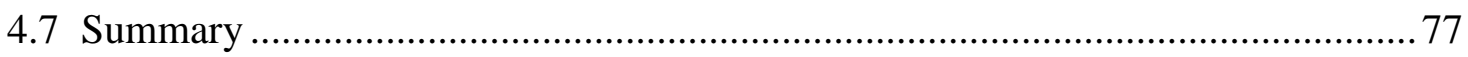

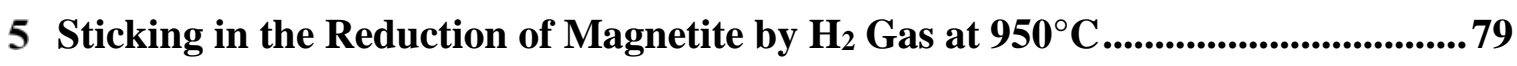




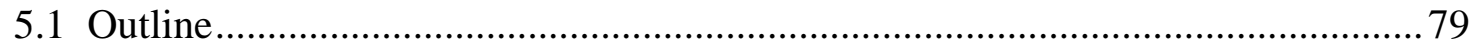

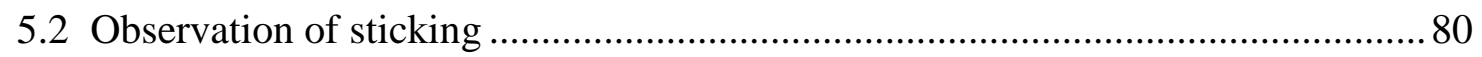

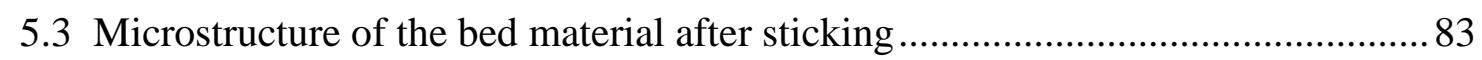

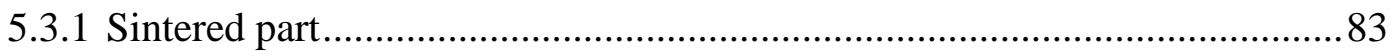

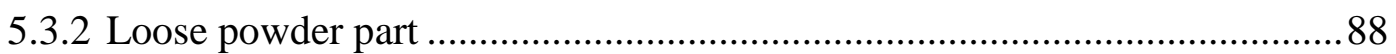

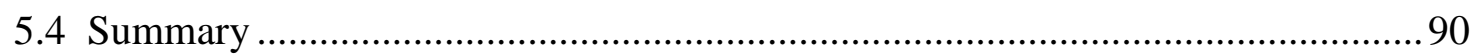

6 Reduction of NZ TTM Ironsand by Ar- $\mathrm{H}_{2}$ Gas Mixture at $950^{\circ} \mathrm{C}$............................93

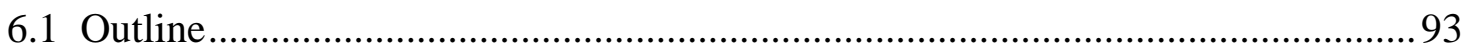

6.1.1 Description of experimental procedure ...................................................93

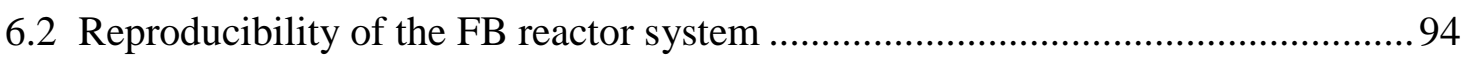

6.3 Effect of various parameters on the reduction rate of TTM ironsand....................95

6.4 Phase evolution within TTM ironsand during hydrogen reduction at $950^{\circ} \mathrm{C}$........98

6.5 The effect of experimental parameters on the water vapour emitted during the

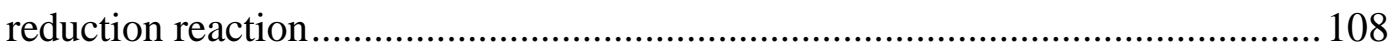

6.6 Microstructural evolution of ironsand particles during the FB reduction .............111

6.6.1 Microstructural evolution of uniform TTM particles ................................112

6.6.2 Development of the protective outer oxide shell ......................................116

6.6.3 Microstructural evolution of non-uniform lamella TTH/TTM particles ....120

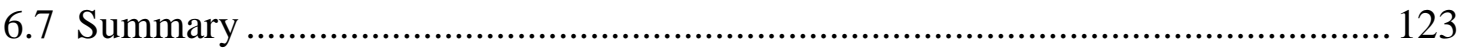

7 Reduction of NZ TTM Ironsand by $\mathrm{H}_{2}$ Gas at Different Bed Temperatures...... 126

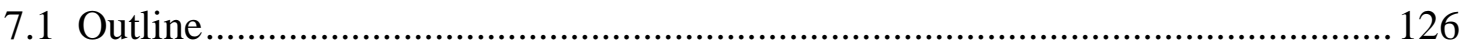

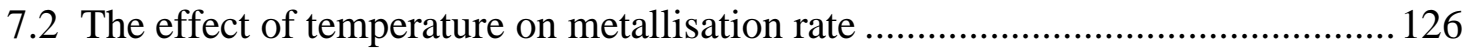

7.3 Effect of temperature on phase transition of TTM ironsand during the reduction reaction

7.4 Evolution of TTM lattice parameter during reduction at different temperature. .131

7.5 Overall reduction mechanism of TTM ironsand at different temperatures.......... 134

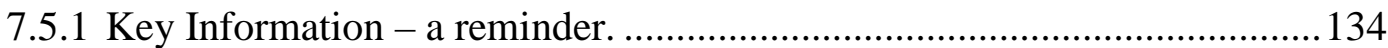

7.5.2 Reduction at high temperature regime $\left(950^{\circ} \mathrm{C}-1000^{\circ} \mathrm{C}\right)$...........................135

7.5.3 Reduction at low temperature regime $\left(750^{\circ} \mathrm{C}-800^{\circ} \mathrm{C}\right)$.............................140

7.5.4 Reduction at the intermediate temperature regime $\left(850^{\circ} \mathrm{C}-900^{\circ} \mathrm{C}\right)$............144

7.6 Thermodynamic analysis of the reduction of TTM ironsand at different temperatures.

7.6.1 Measurement of $\mathrm{H}_{2} \mathrm{O}$ (water vapour) emitted during the reduction reaction ...

7.6.2 Resulted $\mathrm{H}_{2} \mathrm{O}$ emitted during the reduction and comparison with BaurGlaessner diagram for iron oxides 
7.7 Observations of particle sticking in specific non-optimal FB reduction conditions

7.7.1 Case A: Particle sticking during the reduction at $1050^{\circ} \mathrm{C}$

7.7.2 Case B: Particle sticking during the reduction by $7.5 \mathrm{~mol} . \% \mathrm{H}_{2} \mathrm{O}$ at $950^{\circ} \mathrm{C}$...

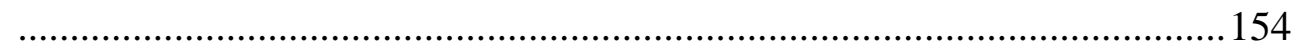

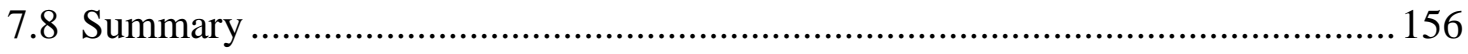

8 Conclusions and Recommendations for Future Work ....................................... 160

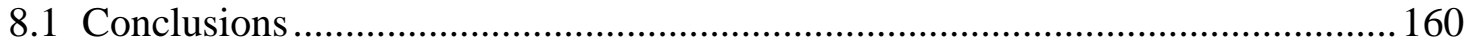

8.2 Recommendations for future work................................................................ 162

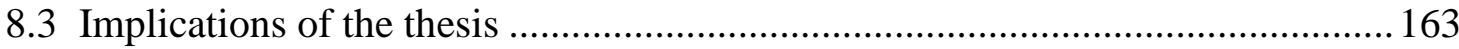

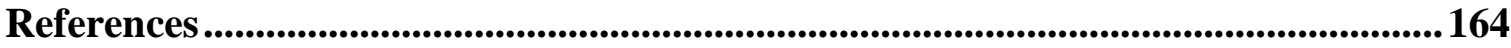

Appendix A In-situ Calibration of the Humidity Sensor .......................................... 174

Appendix B Additional SEM Images for Chapter 6 ..................................................179

B.1 SEM images of the particle reduced by 30 vol. $\% \mathrm{Ar}-70$ vol. $\% \mathrm{H}_{2}$ at $950^{\circ} \mathrm{C}-$ Section 6.6.

B.2 Low magnification images of bulk ironsand particles reduced by $5 \mathrm{Nl} / \mathrm{min} \mathrm{H}_{2}$ at

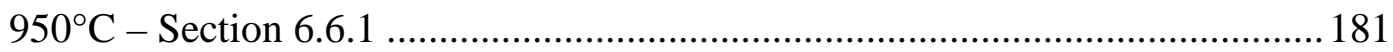

Appendix C Additional SEM Images for Chapter 7 ................................................ 184

C.1 SEM images of the particle reduced by $5 \mathrm{Nl} / \mathrm{min}_{2}$ at $800^{\circ} \mathrm{C} \ldots \ldots \ldots \ldots \ldots \ldots \ldots \ldots . . . . . . . . . . . . .184$

C.2 SEM images of the particle reduced by $5 \mathrm{Nl} / \mathrm{min} \mathrm{H}_{2}$ at $850^{\circ} \mathrm{C}$............................ 184

\section{Appendix D Additional Information for Sticking Cases Described in Section 7.7}

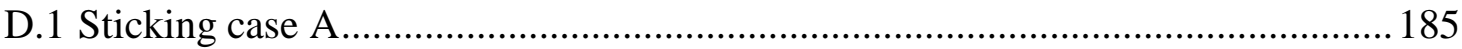

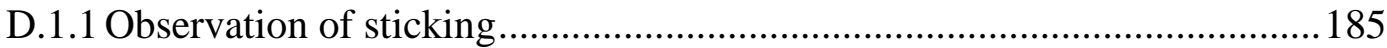

D.1.2 SEM images for the fluidised particle (loose powder) .............................187

D.1.3 SEM images for the small sinter.............................................................188

D.1.4 SEM images for large sinter ................................................................191

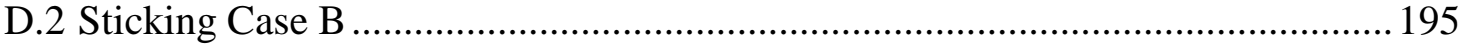

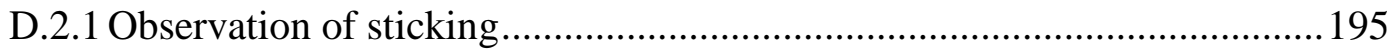

D.2.2 SEM images for fluidised particle (loose powder) ....................................197

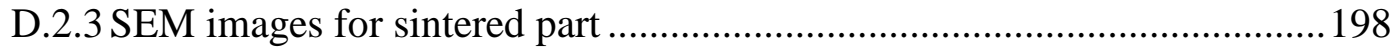




\section{LIST OF FIGURES}

Figure 1.1 Schematic diagram for the ironmaking process in the New Zealand Steel plant, re-drawn with modification from Evans (1986)..............................................................2

Figure 1.2 Schematic process flow of the hydrogen direct reduction. ...............................3

Figure 2.1 Baur-Glaessner diagram: $\mathrm{H}_{2}-\mathrm{H}_{2} \mathrm{O}$ gas mixture for $\mathrm{Fe}-\mathrm{O}-\mathrm{H}$ system at $1 \mathrm{~atm}$ total pressure.

Figure 2.2 Cross-section images of partially reduced dense particle (a) and porous

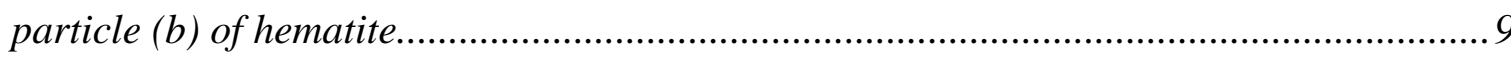

Figure 2.3 Ternary phase diagram for $\mathrm{Fe}_{2} \mathrm{O}_{3}-\mathrm{FeO}-\mathrm{TiO}_{2}$ system in mol.\%.......................10

Figure 2.4 A unit cell of magnetite crystal structure ........................................................ 12

Figure 2.5 Location of ironsand deposits in NZ (red line). ..............................................13

Figure 2.6 Cross-section images of the homogenous particle (a) and lamellar particle (b)

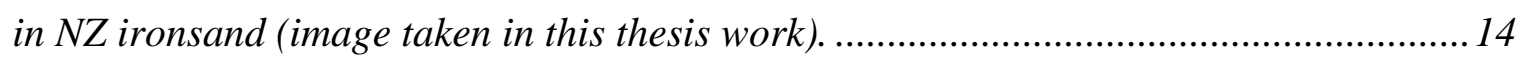

Figure 2.7 Various kinds of fluidisation states in gas-solid reaction................................20

Figure 2.8 A typical graph of pressure drop versus gas velocity. ....................................21

Figure 2.9 Geldart classification of powders. ..................................................................21

Figure 2.10 Pressure drop diagram for slugging region. ..............................................22

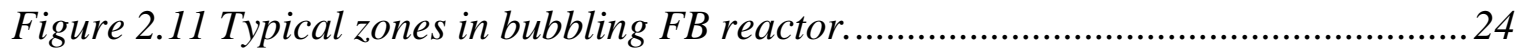

Figure 2.12 Influence of distributor type on fluidisation quality.....................................25

Figure 2.13 A typical flowsheet diagram in the operation of FB technology....................29

Figure 2.14 Fibrous and whisker structure of reduced iron reported by Hayashi, Sayama and Iguchi, 1990 (a) and Zhang, Lei and Zhu, 2014 (b)...............................................33

Figure 2.15 Schematic diagrams of spouted type FB......................................................

Figure 3.1 XRD patterns (a) and the evolution of phases (b) as a function of time for

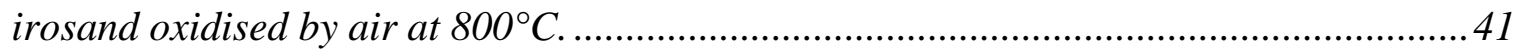

Figure 3.2 PSD of the as-received raw ironsand concentrate. D10=98 $\mu \mathrm{m}, D 50=144 \mu \mathrm{m}$, and $\mathrm{D} 90=210 \mu \mathrm{m}$.

Figure 3.3 PSD of different particle size fractions of raw ironsand concentrate. (a): 63-90 $\mu \mathrm{m},(\mathrm{b}): 106-125,(C): 125-150 \mu \mathrm{m}$, and (d): 125-150 $\mu \mathrm{m}$.

Figure 3.4 XRD patterns (CoK $\alpha$ ) of the raw ironsand concentrate for different particle size fractions. .45

Figure 3.5 BSE image of the raw ironsand concentrate with a size fraction of 106-125 $\mu m$. 
Figure 3.6 Schematic illustration of experimental set-up for fixed bed reduction of ironsand.

Figure 3.7 Calibration plot of \%met value calculated by $q-X R D$ versus titration method.

Figure 3.8 Schematic diagram of the FB reactor....

Figure 3.9 Temperature profile of the bed and the furnace during the fluidisation in $\mathrm{Ar}$ gas when the temperature is on hold at $700^{\circ} \mathrm{C}$ and $900^{\circ} \mathrm{C}$. 52

Figure 3.10 Schematic diagram of the FB reactor set-up showing the position of the humidity sensor (a).

Figure 3.11 Schematic diagram of the FB reactor set-up and the steam generator. 55

Figure 4.1 A photograph (a) and schematic diagram (b) of the experimental set up used for experiment 1 and 2.

Figure 4.2 An example photo during cold fluidisation test.

Figure 4.3 Pressure drop profile of the bed as a function of air velocity with initial bed height of $20 \mathrm{~mm}(\mathrm{a}), 40 \mathrm{~mm}(\mathrm{~b})$, and $80 \mathrm{~mm}$ (c).

Figure 4.4 An example of SEM image showing 1000 particles of raw ironsand concentrate. The size fraction of particles is 106-125 $\mu \mathrm{m}$.

Figure 4.5 Pressure drop profile as a function of helium gas velocities in cold model

fluidisation.

Figure 4.6 Bed height profile as a function of helium gas velocities in cold model

fluidisation.

Figure 4.7 A photograph (a) and schematic diagram (b) of the FB reactor. 68

Figure 4.8 A photograph (a) and schematic diagram for sampling system tests a laboratory set-up at room temperature.

Figure 4.9 A photograph (a) and a schematic diagram (b) of the sampling system installed to the high-temperature FB reactor. 72

Figure 4.10 Sampling collection at different "valve-open” times (a) and at six repetitions for every $1.5 \mathrm{~s}$ of "valve open" at $1000^{\circ} \mathrm{C}(\mathrm{b})$. 73

Figure 4.11 PSD analysis of raw ironsand concentrate and raw ironsand samples collected by the sampling system

Figure 4.12 Measured Pressure drop across the $\mathrm{FB}$ at $1000^{\circ} \mathrm{C}$ at different nitrogen gas velocities

Figure 4.13 The evolution of the crystalline phases as a function of time during the FB oxidation of ironsand in air at various temperatures. 
Figure 4.14 Oxidation degree of the TTM ironsand oxidised in air at various temperatures.

Figure 5.1 XRD pattern of the commercially-sourced Hoganas Magnetite material (106$150 \mu \mathrm{m}$ size fraction) used in the experiments reported in this chapter. .79 Figure 5.2 Profiles of gas flow rate (a), temperature (b), and $\triangle P(c)$ during the reduction of magnetite by $100 \% \mathrm{H}_{2}$ gas at $950^{\circ} \mathrm{C}$.

Figure 5.3 Photograph of samples taken from the reactor after the experiment. (a): sinter part; (b): loose powder part. .82

Figure 5.4 XRD patterns of the sintered part and powder part of the sample. .83

Figure 5.5 Photograph (a), and SEM image (65x magnification) (b), of a sample of sintered bed material.

Figure 5.6 Surface BSE-SEM images of the sticking between two particles in the sinter sample from the reduction of Hoganas magnetite by $5 \mathrm{~L} / \mathrm{min}$ at $950^{\circ} \mathrm{C}$. .85 Figure 5.7 Elemental EDS map of two sticking locations.

Figure 5.8 Photograph (a) and SEM image (300x magnification) (b) of the sintered sample.

Figure 5.9 Cross-section BSE SEM images of a particle in the sinter part from the reduction of Hoganas magnetite by $5 \mathrm{~L} / \mathrm{min}$ at $950^{\circ} \mathrm{C}$. .88

Figure 5.10 Surface BSE-SEM images of particles in the loose powder part from the reduction of Hoganas magnetite by $5 \mathrm{~L} / \mathrm{min}$ at $950^{\circ} \mathrm{C}$.

Figure 5.11 Cross-section BSE SEM images of a particle in the loose powder part from the reduction of Hoganas magnetite by $5 \mathrm{~L} / \mathrm{min}$ at $950^{\circ} \mathrm{C}$.

Figure $6.1 \%$ met curves for the five reduction runs of TTM ironsand in $80 \mathrm{vol} . \% \mathrm{H}_{2}-20$ vol.\% Ar gas mixture at $950^{\circ} \mathrm{C}$.

Figure $6.2 \%$ met as a function of time for the reduction of NZ ironsand in various conditions at a constant temperature of $950^{\circ} \mathrm{C}$. .96

Figure $6.3 \%$ met as a function of total delivered $\mathrm{H}_{2}$ volume for the reduction of TTM ironsand in various conditions at a constant temperature of $950^{\circ} \mathrm{C}$.

Figure 6.4 XRD patterns of reduced irosands showing the progression of reduction reaction by $80: 20 \mathrm{vol} . \% \mathrm{H}_{2}$ : Ar gas mixture at $950^{\circ} \mathrm{C}$.

Figure 6.5 The evolution of crystalline phases as a function of time during the reduction of ironsand at $950^{\circ} \mathrm{C}$ in various $\mathrm{H}_{2}$ gas compositions. 101 
Figure 6.6 The evolution of crystalline phases as a function of time during the reduction of ironsand by different $\mathrm{H}_{2}$ gas flow rate at $950^{\circ} \mathrm{C}$.

Figure 6.7 The evolution of crystalline phases as a function of time during the reduction of ironsand by $4 \mathrm{~L} / \mathrm{min} \mathrm{H}_{2}$ at $950^{\circ} \mathrm{C}$ for different sample mass. 103

Figure 6.8 The evolution of crystalline phases as a function of time during the reduction of ironsand by $3 \mathrm{~L} / \mathrm{min} \mathrm{H}_{2}$ at $950^{\circ} \mathrm{C}$ for different particle size. 104 Figure 6.9 The proportions of the minority Ti-containing phases (ilmenite (a), rutile (b), and pseudobrookite (c)) as a function of time during the reduction of ironsand by various $\mathrm{H}_{2}$ gas compositions.

Figure 6.10 Calculated $\mathrm{H}_{2} \mathrm{O} / \mathrm{H}_{2}+\mathrm{H}_{2} \mathrm{O}$ ratio as a function of total delivered $\mathrm{H}_{2}$ volume during the reduction process at $950^{\circ} \mathrm{C}$ for different $\mathrm{H}_{2}$ gas concentration (a), $\mathrm{H}_{2}$ gas flow rate (b), initial bed mass (c), and particle size (d). 109

Figure 6.11 Calculated $\mathrm{H}_{2} \mathrm{O} /\left(\mathrm{H}_{2}+\mathrm{H}_{2} \mathrm{O}\right)$ ratio as a function of \%met during the reduction process at $950^{\circ} \mathrm{C}$ for different $\mathrm{H}_{2}$ gas concentration (a), $\mathrm{H}_{2}$ gas flow rate (b), initial bed mass (c), and particle size (d). Numbered spans at the top of each plot indicate the \%met corresponding to each reduction stage.

Figure 6.12 SEM micrographs for unreduced ironsand particles (a, $c$ ) and ironsand particles reduced in $5 \mathrm{~L} / \mathrm{min} \mathrm{H}_{2}$ at $950^{\circ} \mathrm{C}$ for 60 minutes $(b, d)$. Red markers indicate the location of magnified image. 112

Figure 6.13 The microstructural evolution of the uniform grain during the reduction by 5 $\mathrm{L} / \mathrm{min} \mathrm{H}_{2}$ at $950^{\circ} \mathrm{C}$ : (a) raw ironsand, (b) 5 minutes (stage 1), (c) 10 minutes (stage 2), (d) 20 minutes (stage 3), (e) 40 minutes (stage 4), (f) 60 minutes (stage 4).

Figure 6.14 High magnification back scatter SEM images of cross-sectioned uniform particles after reduction by $5 \mathrm{~L} / \mathrm{min} \mathrm{H}_{2}$ at $950^{\circ} \mathrm{C}$. The magnification is $8,000 \mathrm{X}$.

Figure 6.15 Elemental EDS map of a TTM ironsand uniform grain reduced by $5 \mathrm{~L} / \mathrm{min} \mathrm{H}_{2}$ at $950^{\circ} \mathrm{C}$ for 5 minutes. 115

Figure 6.16 SEM cross-section micrographs of unreduced ironsand particles sample taken after fluidisation in Ar gas at $950^{\circ} \mathrm{C}$ for 30 mins.

Figure 6.17 Elemental EDS map of the TTM ironsand uniform grain in Figure 6.16(b) from fluidisation in Ar gas at $950^{\circ} \mathrm{C}$ for 30 mins.

Figure 6.18 Plot showing relative change in ratios of key metallic elements within the shell, as a function of time during the reduction by $100 \mathrm{vol} . \% \mathrm{H}_{2}$ at $950^{\circ} \mathrm{C}$.

Figure 6.19 Elemental EDS map of the TTM ironsand uniform grain reduced by $5 \mathrm{~L} / \mathrm{min}$ $\mathrm{H}_{2}$ at $950^{\circ} \mathrm{C}$ for 60 minutes. 
Figure 6.20 The microstructural evolution of non-uniform lamella particles during the reduction by $5 \mathrm{~L} / \mathrm{min} \mathrm{H}_{2}$ at $950^{\circ} \mathrm{C}$.

Figure 6.21 High magnification image (16,000X) of non-uniform lamella particles during the reduction by $5 \mathrm{~L} / \mathrm{min} \mathrm{H}_{2}$ at $950^{\circ} \mathrm{C}$ : (a) after 5 minutes reduction; (b) after 10 minutes reduction; (c) after 20 minutes reduction; (d) after 60 minutes reduction. 122 Figure $7.1 \%$ met as a function of time for the reduction of TTM ironsand by $5 \mathrm{~L} / \mathrm{min}_{2}$ at different temperatures. 127 Figure 7.2 The change in wt.\% for the amount of (a) TTM, (b) wüstite, and (c) ilmenite as a function of time during the reduction by $5 \mathrm{~L} / \mathrm{min} \mathrm{H}_{2}$ at different temperatures. 128 Figure 7.3 Plot showing the estimated $\Delta$ value at the peak wüstite composition (in Figure 7.2) for different temperatures. 131

Figure 7.4 Close up of a TTM XRD peak obtained from the sample reduced at $750^{\circ} \mathrm{C}(\mathrm{a})$,

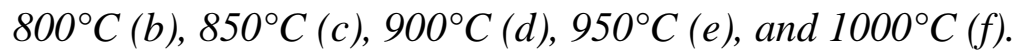

Figure 7.5 Fitted lattice parameter of TTM phase as a function of time during the reduction by $5 \mathrm{~L} / \mathrm{min} \mathrm{H}_{2}$ at different temperatures.

Figure 7.6 Measured lattice parameter values for TTM at different $\Delta$ values taken from literature.

Figure 7.7 BSE-SEM image of the ironsand particle reduced by $5 \mathrm{~L} / \mathrm{min} \mathrm{H}_{2}$ gas at $950^{\circ} \mathrm{C}$ for 10 minutes.

Figure 7.8 Phase evolution as a function of time during the reduction of ironsand in 5 $\mathrm{L} / \mathrm{min} \mathrm{H}_{2}$ at (a) $950^{\circ} \mathrm{C}$ and (b) $1000^{\circ} \mathrm{C}$.

Figure 7.9 BSE-SEM images of a typical TTM ironsand particle during reduction by 5 $\mathrm{L} / \mathrm{min} \mathrm{H}_{2}$ at $1000^{\circ} \mathrm{C}$.

Figure 7.10 High magnification BSE SEM images of the TTM ironsand particle reduced by $5 \mathrm{~L} / \mathrm{min} \mathrm{H}_{2}$ at $1000^{\circ} \mathrm{C}$ for 1.5 minutes (a) and 5 minutes (b). The magnification is $16000 x$

Figure 7.11 Plot showing the average shell thickness as a function of time during the reduction by $5 \mathrm{~L} / \mathrm{min} \mathrm{H}_{2}$ at $950^{\circ} \mathrm{C}$ and $1000^{\circ} \mathrm{C}$.

Figure 7.12 Phase evolution as a function of time during the reduction of ironsand in 5 $\mathrm{L} / \mathrm{min} \mathrm{H}_{2}$ at (a) $750^{\circ} \mathrm{C}$ and (b) $800^{\circ} \mathrm{C}$.

Figure 7.13 BSE-SEM images of the TTM ironsand particle from samples taken during the reduction by $5 \mathrm{~L} / \mathrm{min} \mathrm{H}_{2}$ at $750^{\circ} \mathrm{C}$ : (a) raw ironsand, (b) 5 minutes, (c) 20 minutes, (d) 
60 minutes. Images $(e-h)$ are the right side are respective high magnification images of the red markers.

Figure 7.14 Elemental EDS map of a TTM ironsand particle reduced by $5 \mathrm{~L} / \mathrm{min} \mathrm{H}_{2}$ at $750^{\circ} \mathrm{C}$ for 20 minutes.

Figure 7.15 BSE SEM image of the ironsand particle during the reduction at $900^{\circ} \mathrm{C}$ : (a) 5 minutes, (b) 10 minutes, and (c \& d) 60 minutes. Image (d) is the high magnification of image (c).

Figure 7.16 Elemental EDS map of a TTM ironsand particle reduced at $900^{\circ} \mathrm{C}$ for 60 minutes.

Figure 7.17 Plots of the measured PH2O in the outlet gas for the three reduction runs of TTM ironsand in $5 \mathrm{~L} / \mathrm{min}$ of $\mathrm{H}_{2}$ at $950^{\circ} \mathrm{C}$.

Figure 7.18 Plots of PH2O as a function of time for the reduction of TTM ironsand by 5

$\mathrm{L} / \mathrm{min}$ of $\mathrm{H}_{2}$ at different temperatures: (a) $750^{\circ} \mathrm{C}$, (b) $800^{\circ} \mathrm{C}$, (c) $850^{\circ} \mathrm{C}$, (d) $900^{\circ} \mathrm{C}$, (e) $950^{\circ} \mathrm{C}$, and (f) $1000^{\circ} \mathrm{C}$.

Figure 7.19 Equilibrium diagram for $\mathrm{H}_{2}-\mathrm{H}_{2} \mathrm{O}$ gas mixture for iron oxides system (plotted from thermodynamic data in Kubaschewski, Alcock and Spencer, 1993) containing estimated gas compositions at each temperature during the reduction.

Figure 7.20 Photograph showing sintered part that was stuck to the wall (a), stuck to the sampling tube (b), and reduced ironsand powder. 153

Figure 7.21 BSE-SEM cross-section images for the particle in the loose powder (a) and the sintered part that stuck to the wall (b) found in Figure 7.20, after the reduction experiment in $5 \mathrm{~L} / \mathrm{min} \mathrm{H}_{2}$ at $1050^{\circ} \mathrm{C}$ for 20 minutes

Figure 7.22 Photograph of the sintered sample (a). (b) is the loose powder. 155

Figure 7.23 BSE-SEM micrographs for the surface morphology of particles in the sintered part (in Figure 7.22). 156 


\section{LIST OF TABLES}

Table 2.1 Key information on crystal structure for iron-titanium oxides in this thesis.....11

Table 2.2 Chemical composition of ironsand at different locations in NZ........................13

Table 2.3 Summary table of the literature dealing with hydrogen reduction of ironsand.17

Table 2.4 Summary table for FB reactors and experimental conditions from the literature

Table 2.5 Sticking tendency for different types of ore and associated reduction conditions.

Table 2.6 Sticking tendency for different shapes of ores (Hayashi and Iguchi, 1992)......32

Table 2.7 Summary of the sticking prevention methods investigated at different reducing conditions.

Table 3.1 Chemical composition of the raw ironsand concentrate for different particle size fractions in the oxidized state as measured by XRF

Table 3.2 Chemical composition of Hoganas magnetite. .................................................48

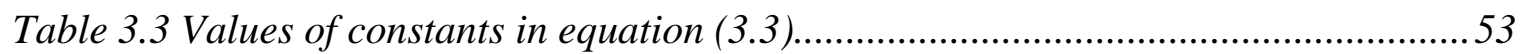

Table 4.1 Calculated parameters for different materials and fluidising gas.

Table 4.2 Selected criteria for the high-temperature FB reactor and the reasons for the selection

Table 4.3 Comparison of the minimum flow rate and vacuum needed for different tube sizes.

Table 5.1 Elemental spot EDS analysis of points shown in Figure 5.6. Red coloured fonts are for the bright light grey phase. .86

Table 5.2 Elemental spot EDS analysis of points shown in Figure 5.9. Red coloured fonts are for the bright phase. .88

Table 5.3 Elemental spot EDS analysis of points shown in Figure 5.10. Red coloured fonts are for the bright phase.

Table 5.4 Elemental spot EDS analysis of points shown in Figure 5.11. Red coloured fonts are for the bright phase. .90

Table 6.1 Elemental spot EDS analysis of points shown in Figure 6.13 and 6.14. Red coloured fonts indicate points in the shell. 118

Table 6.2 Elemental spot EDS analysis of points shown in Figure 6.21 123

Table 7.1 Elemental spot EDS analysis of points shown in Figure 7.9 138 
Table 7.2 Elemental spot EDS analysis of points shown in Figure 7.13. Red coloured fonts indicate points in the grey region. Blue coloured fonts indicate points in the dark region. Black coloured fonts indicate points in the bright phase.

Table 7.3 Elemental spot EDS analysis of points shown in Figure 7.23. Red coloured fonts are for the dark flakes. 


\section{Chapter 1}

\section{Introduction}

\subsection{Background}

Steel is one of the most used materials in the world. Steel is a fundamental component for buildings, bridges, vehicles, railway, dams, ships, pipelines, and much more. Over the past ten years, global steel production has increased by about 30\% (Worldsteel, 2020). The steel industry directly contributes about 500 billion USD to the global economy $(0.7 \%$ global GDP) and employs about 6.1 million people (Askerov, 2019). Future changes in iron and steelmaking industry are therefore likely to have a significant impact on the future global economy.

\subsubsection{Current steelmaking process}

At present, the dominant steelmaking process is the blast furnace $(\mathrm{BF})+$ basic oxygen furnace (BOF) route (75\% of global steel production) (Worldsteel, 2019). The main advantage of this route is the high production rate of steel. A modern blast furnace can produce up to 14,000 tonnes of molten iron per day (Spanlang, Wukovits and Weiss, 2016). Feedstock materials for the BF are lump iron ore, sinter (a mix of iron ore, coke breeze, and limestone), and iron ore pellet. These forms of iron ore along with coking coal and limestone are then charged to the BF. Here, iron ore is reduced to iron and melted to from liquid iron (hot metal). Most impurities in the ore react with limestone to form a slag, which floats on top of the hot metal. The slag is then separated, and the hot metal is transferred to the BOF. In BOF, most of the carbon in the hot metal is removed by oxygen blowing, and the hot metal is converted to steel.

\subsubsection{NZ ironsand and the NZ steel process}

Worldwide, the primary iron sources for steel production are hard-rock hematite and magnetite ores. The major iron ore producers are Australia, Brazil, China, and India. However, in New Zealand (NZ), the iron source for domestic steel production is titanomagnetite ironsand. This ironsand is magnetic black beach sand which is composed mainly of titanomagnetite. The mining process for ironsand is relatively simple, and it can be easily concentrated by magnetic separators without the need for complicated 
beneficiation processes (New Zealand Steel). Ironsand has been used to produce steel in NZ by New Zealand Steel Ltd. for about 40 years (New Zealand Steel).

NZ ironsand is different from conventional iron ores around the world. A key difference is the ironsand titanium content, which is typically $~ 8 \mathrm{wt} \%$ as $\mathrm{TiO}_{2}$ (McAdam, 1974; Park and Ostrovski, 2003; Brathwaite, Gazley and Christie, 2017). NZ ironsand can only be used in small quantities as a feedstock material for the BF process. This is because titanium in ironsand forms $\mathrm{TiN}, \mathrm{TiC}$, and $\mathrm{TiO}$ in the slag, which have high melting points (Park et al., 2004). As a result, the viscosity of the slag is increased; hence it does not flow (Park et al., 2004).

Currently, the TTM ironsand is commercially processed in NZ through coal-based reduction in a rotary-kiln (Evans, 1986). Figure 1.1 shows a schematic ironmaking process in the New Zealand Steel plant. In brief, ironsand alongside with coal and limestone are first heated and dried in a multi-hearth furnace. After that, the mixture is fed to a rotary kiln. Here, ironsand is converted at $\sim 900^{\circ} \mathrm{C}$ to form a product called reduced primary concentrate and char (RPCC), which is a mixture of reduced of ironsand ( $80 \%$ metallisation) and carbon (New Zealand Steel). Air is blown into the kiln for the combustion of coal to produce heat and CO gas, which acts as a reducing agent. The direct reduced iron is then transferred to an electric furnace to produce molten pig iron, which is then transferred to the steelmaking furnace.

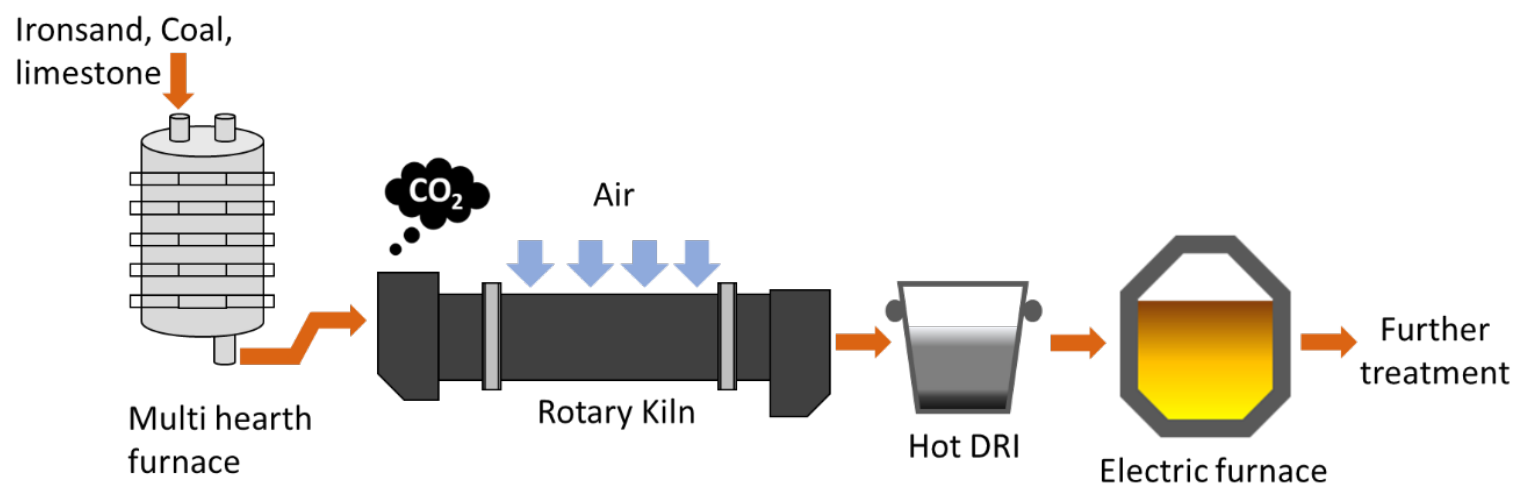

Figure 1.1 Schematic diagram for the ironmaking process in the New Zealand Steel plant, re-drawn with modification from Evans (1986).

\subsubsection{The emerging importance of hydrogen direct reduction}

A major problem for the steel industry is that the current steelmaking process emits large volumes of carbon dioxide $\left(\mathrm{CO}_{2}\right)$. This is because the steelmaking process requires coal as a primary reducing agent. In 2017, the steel industry alone accounted for about $9 \%$ 
of the total global $\mathrm{CO}_{2}$ emissions (IEA, 2020). In New Zealand (NZ), it accounted for about 5\% of gross national $\mathrm{CO}_{2}$ emissions in 2018 (Ministry for the Environment NZ, 2020). The Paris Agreement implies that this sector must reach zero $\mathrm{CO}_{2}$ emission by 2060-2080 (Åhman, Nilsson and Johansson, 2017). As a result, stricter environmental regulations are putting pressure on the steel industry (Vogl, Åhman and Nilsson, 2018). In NZ, the Climate Change Response (Zero Carbon) Amendment Act (2019) stated that NZ is committed to reaching zero net $\mathrm{CO}_{2}$ emissions by 2050. Therefore, an alternative steelmaking process which does not require coal needs to be developed.

In recent years, hydrogen direct reduction (HDR) has attracted increased attention globally as a possible means for reducing $\mathrm{CO}_{2}$ emissions from the steelmaking process (Vogl, Åhman and Nilsson, 2018; Spreitzer and Schenk, 2019a). Figure 1.2 shows the concept of HDR system. In brief, HDR uses hydrogen gas to convert iron oxides to direct reduced iron in a direct reduction (DR) reactor. The only by-product gas is steam $\left(\mathrm{H}_{2} \mathrm{O}\right)$, which is 'clean'. The hydrogen gas can be produced by splitting hydrogen and oxygen atom from water in an electrolyser, with the electricity required for this process generated from renewable sources.

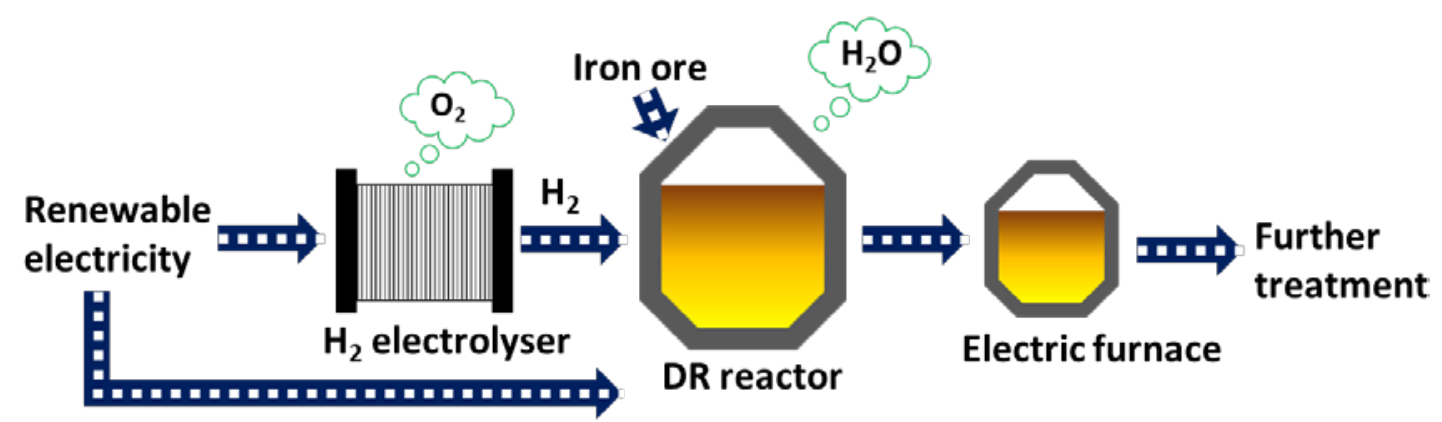

Figure 1.2 Schematic process flow of the hydrogen direct reduction.

HDR is still in development for commercial application at industrial scale. One of the most promising projects for the realisation of HDR is the HYBRIT project that is owned by Svenskt Stål AB (SSAB), Luossavaara-Kiirunavaara Aktiebolag (LKAB), and Vattenfall. HYBRIT project aims to build a demonstration plant in 2025-2035 (SSAB, LKAB and Vattenfall, circa 2018). At present, the work has started building a pilot plant (SSAB, LKAB and Vattenfall, circa 2018).

\subsubsection{Fluidised bed processing of iron ores}

There are two broad types of technologies that allow the use of hydrogen gas for the DR process: shaft processes and fluidised bed (FB) processes (Feinman, 1999; Spreitzer 
and Schenk, 2019b). Among these, the FB process provides potential advantages as it enables fast processing times and direct use of iron ore fines. This eliminates the need for additional pelletising and sintering plants associated with conventional ironmaking routes (Schenk, 2011; Zhang, Lei and Zhu, 2014; Spreitzer and Schenk, 2019a).

NZ ironsand ore particles are approximately spherical in shape with a naturally occurring particle size distribution at about 50-200 $\mu \mathrm{m}$ (Shannon, Kitt and Marshall, 1960). According to the classification of DR process presented in (Skorianz, 2012), NZ ironsand is well suited to be processed in a FB reactor. However, at present there is only one historic report available that deals with reduction of NZ ironsand in a FB reactor (Shannon, Kitt and Marshall, 1960).

\subsection{Research aim}

The purpose of this research is to investigate the reduction of NZ ironsand by hydrogen gas in a FB reactor with a key focus on the ore sticking behaviour.

\subsection{Problem statement}

A key problem to the high through-put FB reduction of iron ores is particle sticking (Hayashi and Iguchi, 1992; Gong et al., 2014, 2016). "Sticking" refers to the agglomeration of particles in the whole bed during the reduction process. After agglomeration, fluidisation is lost, and the process operation stops. This results in a stuck bed which cannot be conveyed between reactors (Hayashi and Iguchi, 1992; Zhong et al., 2011; Guo et al., 2016). In the FB reduction of conventional hematite and magnetite ores by hydrogen gas, particle sticking has been reported to occur at high temperatures ( $800^{\circ} \mathrm{C}$ ) (Gransden and Sheasby, 1974; Zhang, Lei and Zhu, 2014). It should be noted that whilst reduction at lower temperatures reduces the chance of sticking, it also substantially decreases the reaction rate to produce iron metal.

Questions that need to be addressed in this thesis are:

a. Do NZ ironsand particles stick during FB reduction in hydrogen at high temperatures?

b. If ironsand particles do not stick, why?

c. If ironsand particles do stick, how to prevent the particle sticking?

d. What are the key parameters that affect the reduction rate of NZ ironsand in a hydrogen-FB system? 


\subsection{Structure of the thesis}

The structure of this thesis is as follows:

Chapter 2 presents a literature review relevant to the reduction of NZ ironsand and FB reduction of iron ores, as well as fundamental knowledge necessary for designing a FB reactor. The main focus of the chapter is on the existing literature that address the "sticking" problem in FB reduction of iron ores.

Chapter 3 describes material characterization techniques used for samples obtained from experiments and presents the characterization of raw NZ ironsand used for experiments in this thesis. Finally, this chapter briefly describes the general procedure for the reduction experiment.

Chapter 4 presents preliminary work on the design and commissioning of the FB reactor set-up. This includes cold fluidisation experiments as well as commissioning work at high temperature to assess the reactor set-up and its sampling system.

Chapter 5 presents experimental results for the reduction of conventional magnetite ore at $950^{\circ} \mathrm{C}$. This chapter presents evidence for the "sticking” problem during hydrogen reduction of titanium free-magnetite at $950^{\circ} \mathrm{C}$.

Chapter 6 presents experimental results for the high temperature reduction $\left(950^{\circ} \mathrm{C}\right)$ of TTM ironsand under various parameters: hydrogen gas composition, hydrogen gas flow rate, initial ironsand bed mass, and ironsand particle size. The final section discusses the unusual absense of the particle sticking during the hydrogen reduction of NZ ironsand by at $950^{\circ} \mathrm{C}$.

Chapter 7 presents experimental results for the reduction of TTM ironsand by $100 \%$ $\mathrm{H}_{2}$ gas at temperatures ranging from $750^{\circ} \mathrm{C}$ to $1000^{\circ} \mathrm{C}$. This chapter mainly discusses the characterization of the phase evolution stages of the TTM ironsand at different temperatures. This chapter also dicusses the thermodynamic analysis of the reduction process at different temperatures. The final section presents a discussion of two particle sticking incidences which were encountered during the course of this project in two nonoptimal specific conditions.

Chapter 8 presents conclusions and suggestions for future works. 


\section{Chapter 2}

\section{Literature Review}

\subsection{Outline}

This chapter describes the necessary background knowledge for the reduction of iron oxides. This chapter has six sections. The first section gives an overview of fundamentals in the hydrogen reduction of iron oxides. The second introduces the TTM ore, important Ti-Fe oxides that is associated with TTM ore, and NZ TTM ironsand. The third describes important points for the hydrogen reduction of TTM ore. The fourth gives an overview the fundamental theories in designing an FB reactor. This includes summaries of previous labscale reactors for the reduction of iron oxides. The fifth describes briefly some existing commercial FB technologies for reduction of iron oxide. The final section describes the commonly known "sticking” problem in the FB reduction of iron ores.

\subsection{Fundamentals in iron ore reduction by $\mathrm{H}_{2}$ gas}

DR process is classified as the reduction of iron ores to metallic iron (by removing oxygen atoms) at temperatures below the melting point of iron (Feinman, 1999; Skorianz, 2012). Reducing agents for the $\mathrm{DR}$ process can be coal or gases such as $\mathrm{CO}, \mathrm{CH}_{4}$ or $\mathrm{H}_{2}$. As mentioned in Chapter 1, hydrogen reduction has gained much interest as it is possible to greatly reduce the $\mathrm{CO}_{2}$ emissions of the entire steelmaking process. This chapter only reviews some fundamentals in the hydrogen reduction of iron oxide.

The reduction of iron oxide typically proceeds in multiple stages at temperatures $>$ $560^{\circ} \mathrm{C}$ : hematite $\left(\mathrm{Fe}_{2} \mathrm{O}_{3}\right)$ to magnetite $\left(\mathrm{Fe}_{3} \mathrm{O}_{4}\right)$ to wüstite $(\mathrm{FeO})$ to metallic iron $(\mathrm{Fe})$. Reactions involved during the reduction process and the corresponding standard Gibbs free energy (Joule/mole) are given in reactions (2.1-2.3) (Ross, 1980). 


$$
\begin{array}{ll}
3 \mathrm{Fe}_{2} \mathrm{O}_{3(\mathrm{~s})}+\mathrm{H}_{2(\mathrm{~g})} \rightarrow 2 \mathrm{Fe}_{3} \mathrm{O}_{4(\mathrm{~s})}+\mathrm{H}_{2} \mathrm{O}_{(\mathrm{g})}, & \Delta \mathrm{G}^{\circ}=3012.5-85.86 \mathrm{~T} \\
\mathrm{Fe}_{3} \mathrm{O}_{4(\mathrm{~s})}+\mathrm{H}_{2(\mathrm{~g})} \rightleftharpoons 3 \mathrm{FeO}_{(\mathrm{s})}+\mathrm{H}_{2} \mathrm{O}_{(\mathrm{g}),} & \Delta \mathrm{G}^{\circ}=65772.5-70.29 \mathrm{~T} \\
\mathrm{FeO}_{(\mathrm{s})}+\mathrm{H}_{2(\mathrm{~g})} \rightleftharpoons \mathrm{Fe}_{(\mathrm{s})}+\mathrm{H}_{2} \mathrm{O}_{(\mathrm{g})}, & \Delta \mathrm{G}^{\circ}=13179.6-7.74 \mathrm{~T}
\end{array}
$$

At temperatures $<570^{\circ} \mathrm{C}$, wüstite is not stable. So, the reduction stage is from hematite to magnetite to metallic iron. The direct conversion of magnetite to metallic iron is given in reaction (2.4) (Ross, 1980).

$$
1 / 4 \mathrm{Fe}_{3} \mathrm{O}_{4(\mathrm{~s})}+\mathrm{H}_{2(\mathrm{~g})} \rightleftharpoons 3 / 4 \mathrm{Fe}_{(\mathrm{s})}+\mathrm{H}_{2} \mathrm{O}_{(\mathrm{g})} \quad \Delta \mathrm{G}^{\circ}=26325.7-23.39 \mathrm{~T}
$$

Reaction (2.1) is irreversible, whereas reactions (2.2-2.4) are reversible and temperature dependent (Ross, 1980; Skorianz, 2012).

Figure 2.1 shows "Baur-Glaessner diagram” describing equilibrium conditions for reactions (2.2-2.4) at different temperatures and $\mathrm{H}_{2}-\mathrm{H}_{2} \mathrm{O}$ compositions. In general, reduction of iron oxide (via the conversion of $\mathrm{H}_{2}$ to water vapour) is favoured by high temperatures $\left(\gtrsim 600^{\circ} \mathrm{C}\right.$ ) and $\mathrm{H}_{2}$ gas concentrations ( $\gtrsim 70 \%$ ). The diagram was plotted with an assumption that the activity of $\mathrm{FeO}$ and Fe phases is 1. This is because the solubility of hydrogen atom in metallic iron is extremely low (Ross, 1980).

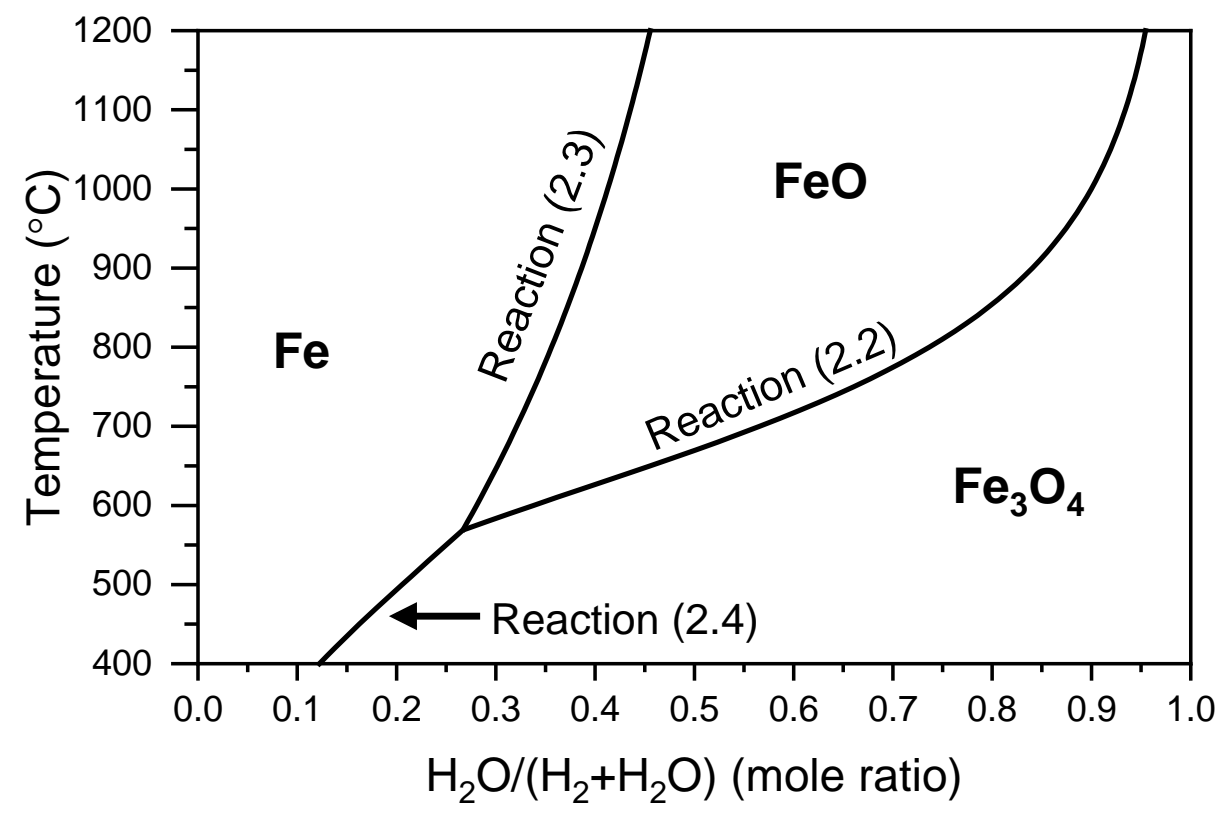

Figure 2.1 Baur-Glaessner diagram: $\mathrm{H}_{2}-\mathrm{H}_{2} \mathrm{O}$ gas mixture for $\mathrm{Fe}-\mathrm{O}-\mathrm{H}$ system at $1 \mathrm{~atm}$ total pressure. The diagram is re-plotted from thermochemical data in Kubaschewski, Alcock and Spencer, 1993. 
The gaseous reduction of solid iron oxide particles usually proceeds in a topochemical manner (occurring at the interface between phases), with the reaction starting from the particle surface (Ross, 1980; Kaushik and Fruehan, 2006; Weiss et al., 2010, 2011; Spreitzer and Schenk, 2019b). Figure 2.2 shows example of cross-section images of two types of partially reduced iron oxide particles: (a) dense particles, and (b) porous particles (from Pichler et al., 2016). Partially reduced dense iron oxide particles typically show a central unreacted region of iron oxide surrounded by metallic iron on the outer surface. However, for porous iron oxide particles, the reaction can nucleate from pores within the particle, and the microstructure of the partially reduced porous particle does not show a topochemical type boundary (Pichler et al., 2016).

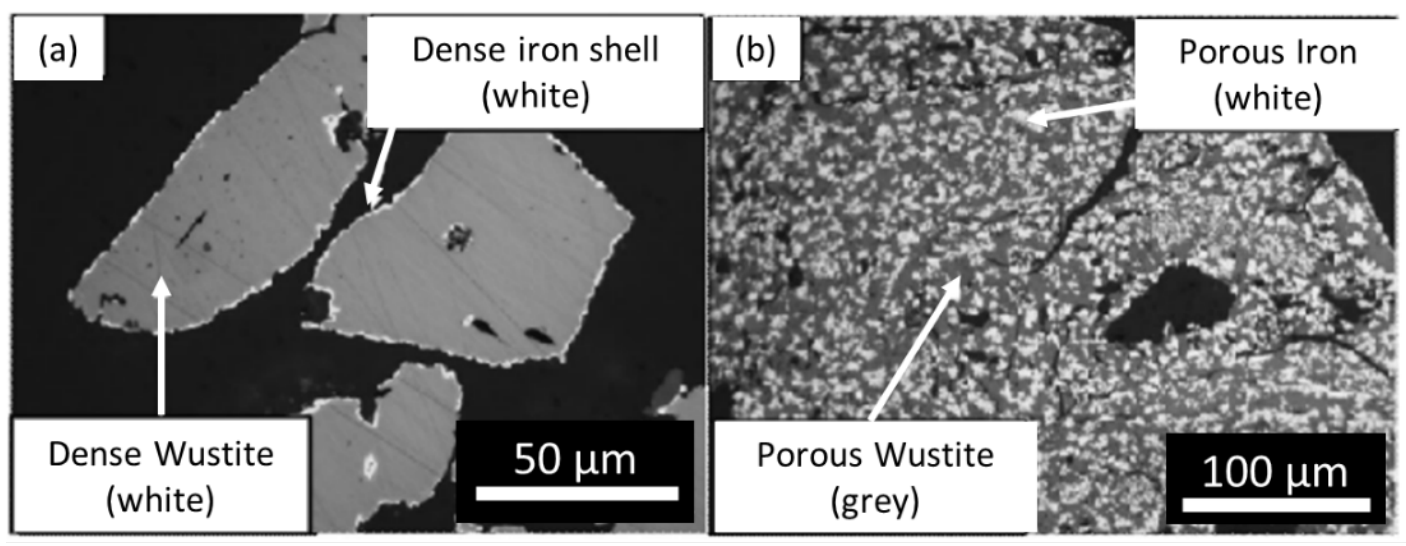

Figure 2.2 Cross-section images of partially reduced dense particle (a) and porous particle (b) of hematite. Images reproduced from Pichler et al. (2016) with permission of John Wiley and Sons through Copyright Clearance Centre.

\subsection{Titanomagnetite ore}

NZ ironsand is predominantly composed of titanomagnetite (TTM) ore. TTM ore is different from conventional magnetite ore because of the presence of titanium in the crystal lattice.

\subsubsection{Iron-titanium oxides}

Some iron-titanium oxides associated with TTM ore have been encountered over the course of this thesis work. Figure 2.3 presents the ternary phase diagram for $\mathrm{Fe}_{2} \mathrm{O}_{3}-\mathrm{FeO}$ $\mathrm{TiO}_{2}$ system. In the figure, the major oxides in this system are hematite $\left(\mathrm{Fe}_{2} \mathrm{O}_{3}\right)$, wüstite (FeO), rutile $\left(\mathrm{TiO}_{2}\right)$, magnetite $\left(\mathrm{Fe}_{3} \mathrm{O}_{4}\right)$, ilmenite $\left(\mathrm{FeTiO}_{3}\right)$, ulvospinel $\left(\mathrm{Fe}_{2} \mathrm{TiO}_{4}\right)$, pseudobrookite $\left(\mathrm{Fe}_{2} \mathrm{TiO}_{5}\right)$, and ferro-pseudobrookite $\left(\mathrm{FeTi}_{2} \mathrm{O}_{5}\right)$. Key information on crystal structures for these oxides are presented in Table 2.1 


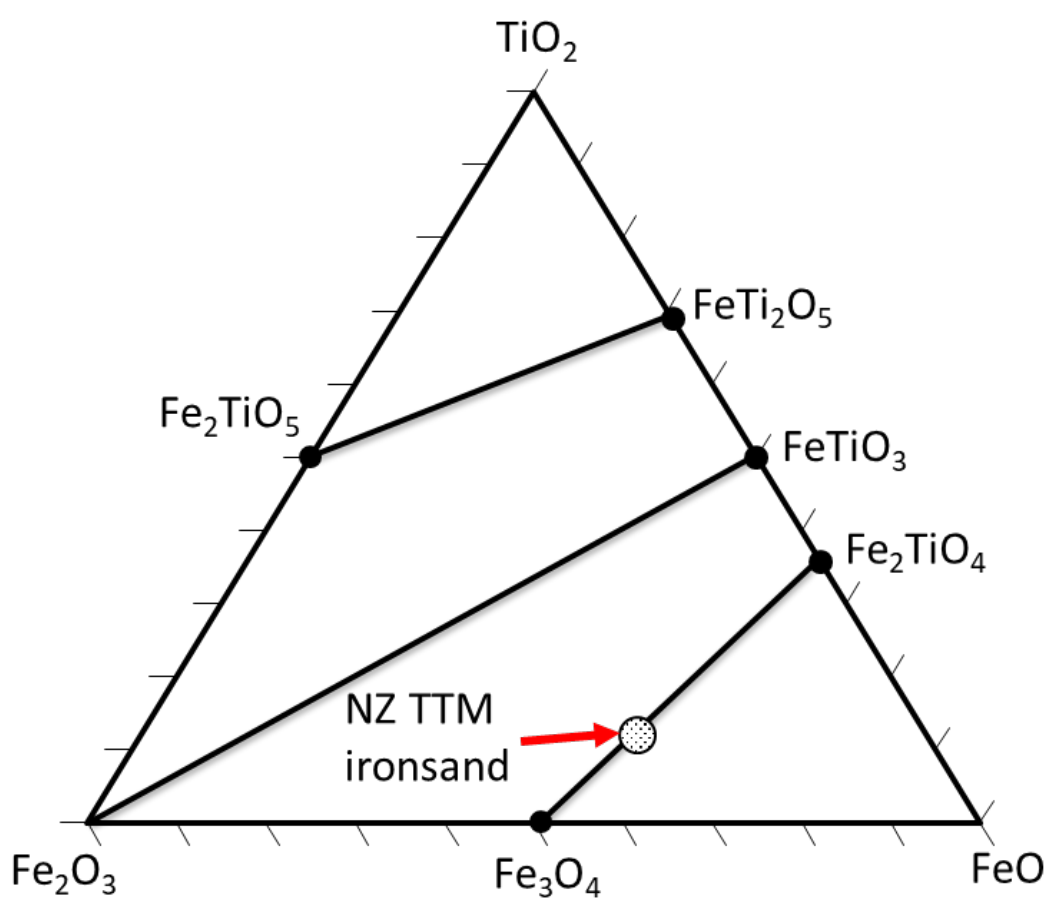

Figure 2.3 Ternary phase diagram for $\mathrm{Fe}_{2} \mathrm{O}_{3}-\mathrm{FeO}-\mathrm{TiO}_{2}$ system in mol.\%. The diagram is re-plotted from the data in Buddington and Lindsley, 1964. The diagram is plotted using code developed by Graham and Midgley, 2000.

Three important solid-solution series are formed in the system, as shown by the three tie lines in Figure 2.3. These solid solutions are between magnetite and ulvöspinel (TTM) hematite and ilmenite (titanohematite), and pseudobrookite and ferro-pseudobrookite solid solution. The stoichiometric composition of NZ TTM ironsand is $\mathrm{Fe}_{3-x} \mathrm{Ti}_{x} \mathrm{O}_{4}$, where $x=0.27 \pm 0.02$ (Park and Ostrovski, 2003). The approximate composition of NZ TTM ironsand is indicated by the red arrow in the phase diagram (Figure 2.3). 
Table 2.1 Key information on crystal structure for iron-titanium oxides in this thesis

\begin{tabular}{|c|c|c|c|c|c|c|c|}
\hline \multirow{2}{*}{ Oxide } & \multirow{2}{*}{$\begin{array}{l}\text { Stoichiometric } \\
\text { Equation }\end{array}$} & \multirow{2}{*}{$\begin{array}{c}\text { Crystal } \\
\text { Structure }\end{array}$} & \multirow{2}{*}{$\begin{array}{l}\text { Density } \\
\left(\mathrm{g} / \mathrm{cm}^{3}\right)\end{array}$} & \multicolumn{3}{|c|}{ Lattice constant $(\AA)$} & \multirow{2}{*}{ Reference } \\
\hline & & & & $\mathrm{a}$ & $\mathrm{b}$ & C & \\
\hline Magnetite & $\mathrm{Fe}_{3} \mathrm{O}_{4}$ & Cubic & 5.2 & 8.397 & & & $\begin{array}{l}\text { Anthony, } \\
\text { Bideaux, et } \\
\text { al., } 2001\end{array}$ \\
\hline Hematite & $\mathrm{Fe}_{2} \mathrm{O}_{3}$ & Hexagonal & 5.3 & 5.038 & & 13.722 & $\begin{array}{l}\text { Anthony, } \\
\text { Bideaux, et } \\
\text { al., } 2001\end{array}$ \\
\hline Wüstite & $\mathrm{FeO}$ & Cubic & 5.3 & 4.296 & & & $\begin{array}{c}\text { McCammon, } \\
1992\end{array}$ \\
\hline Ulvöspinel & $\mathrm{Fe}_{2} \mathrm{TiO}_{4}$ & Cubic & 4.9 & 8.537 & & & $\begin{array}{l}\text { Tanaka and } \\
\text { Kono, } 1987 \\
\end{array}$ \\
\hline Ilmenite & $\mathrm{FeTiO}_{3}$ & Hexagonal & 4.8 & 5.088 & & 14.092 & $\begin{array}{c}\text { Wechsler } \\
\text { and Prewitt, } \\
1984 \\
\end{array}$ \\
\hline Rutile & $\mathrm{TiO}_{2}$ & Tetragonal & 4.2 & 4.594 & & 2.959 & $\begin{array}{l}\text { Anthony, } \\
\text { Bideaux, et } \\
\text { al., } 2001\end{array}$ \\
\hline Pseudobrookite & $\mathrm{Fe}_{2} \mathrm{TiO}_{5}$ & Orthorhombic & 4.4 & 9.757 & 9.942 & 3.726 & $\begin{array}{c}\text { Guo et al., } \\
1999\end{array}$ \\
\hline $\begin{array}{c}\text { Ferro- } \\
\text { pseudobrookite }\end{array}$ & $\mathrm{FeTi}_{2} \mathrm{O}_{5}$ & Orthorhombic & 4.3 & 9.808 & 10.071 & 3.75 & $\begin{array}{c}\text { Guo et al., } \\
1999\end{array}$ \\
\hline $\begin{array}{l}\text { Titanomagnetite } \\
\text { in NZ ironsand }\end{array}$ & $\begin{array}{c}\mathrm{Fe}_{3-x} \mathrm{Ti}_{x} \mathrm{O}_{4} \\
x=0.27 \pm 0.02\end{array}$ & Cubic & $\begin{array}{c}5.1 \\
\text { (measured) }\end{array}$ & 8.402 & & & $\begin{array}{c}\text { Wright, } \\
1964\end{array}$ \\
\hline
\end{tabular}

In magnetite crystal structure, all $\mathrm{Fe}^{2+}$ ions occupy the octahedral sites, whereas $\mathrm{Fe}^{3+}$ ions occupy both tetrahedral and octahedral sites of the spinel lattice. Figure 2.4 shows the position of octahedral and tetrahedral sites in a unit cell of magnetite crystal.

In $\mathrm{TTM}, \mathrm{Ti}^{4+}$ ions prefer to occupy octahedral sites of the magnetite spinel lattice (Richards et al., 1973; Wechsler, Lindsley and Charles T. Prewitt, 1984; Okube et al., 2018). The substitution of $\mathrm{Ti}^{4+}$ to octahedral $\mathrm{Fe}^{3+}$ site yields to an equivalent conversion of $\mathrm{Fe}^{3+}$ to $\mathrm{Fe}^{2+}$ to maintain charge neutrality, i.e. one $\mathrm{Ti}^{4+}$ ion plus one $\mathrm{Fe}^{2+}$ for two $\mathrm{Fe}^{3+}$ ions. Most TTM ore contains other impurities, such as aluminium and magnesium (Park, 2002). $\mathrm{Al}^{3+}$ ions can substitute into octahedral sites, whereas $\mathrm{Mg}^{2+}$ ions can substitute into both octahedral and tetrahedral sites (Richards et al., 1973). 


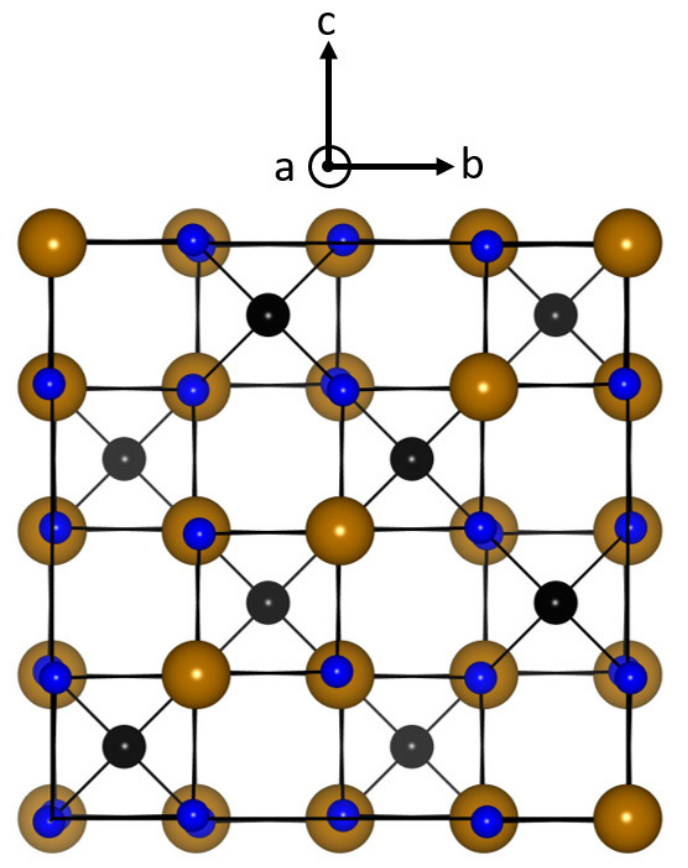

(a)

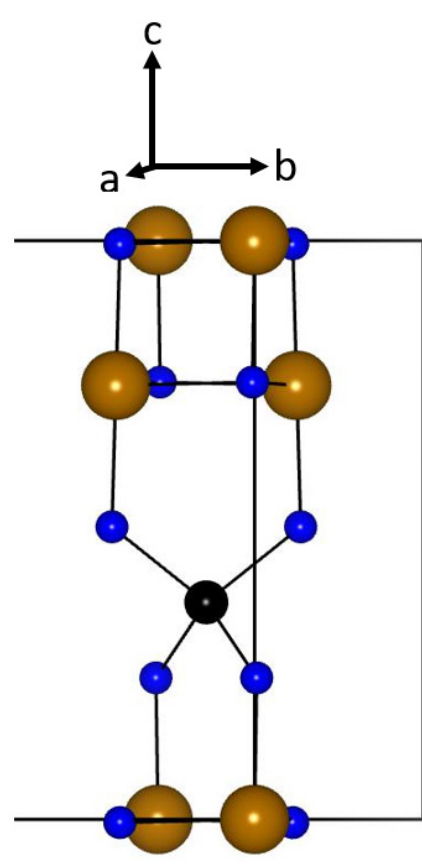

(b)
- Octahedral site

- Tetrahedral site

- Oxygen

Figure 2.4 A unit cell of magnetite crystal structure (a). Image (b) is a section of the unit crystal showing the position of octahedral site, tetrahedral site, and oxygen atom. The figure is drawn using a software developed by Momma and Izumi, 2011 based on the data in Okamura et al., 1995

\subsubsection{NZ ironsand}

Figure 2.5 shows the location of ironsand deposit in NZ. Large deposits of ironsand are found along the west coast of the North Island of NZ (red line). There are two commercial ironsand mines in NZ: Waikato North Head mine and Taharoa mine. Waikato North Head mine has been supplying ironsand concentrate to be processed in the New Zealand Steel plant at Glenbrook for domestic steel production. On the other hand, the ironsand deposit in Taharoa mine has been exported overseas. 


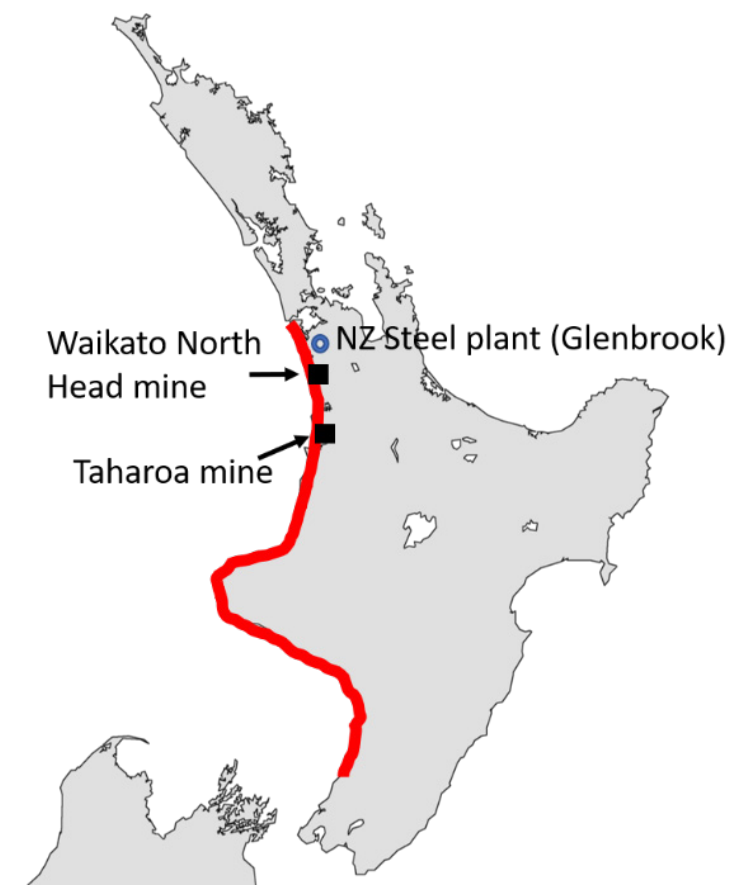

Figure 2.5 Location of ironsand deposits in NZ (red line). Black squares indicate the location of two commercial ironsand mine in NZ. The blue circle indicates the location of the NZ steel plant. The image has been modified from a license-free image created by commons.wikimedia.org/wiki/User:Kahuroa.

Table 2.2 presents the chemical composition of ironsand deposits in some locations along the west coast of the North island of NZ. From the table, the titanium content in NZ ironsand is broadly similar in all locations, typically $\sim 8 \mathrm{wt} . \%$ as $\mathrm{TiO}_{2}$.

Table 2.2 Chemical composition of ironsand at different locations in NZ

\begin{tabular}{|c|c|c|c|c|c|c|}
\hline \multirow{2}{*}{ Deposit location ${ }^{-}$} & \multicolumn{5}{|c|}{ Compositions (equivalent mass\%) } & \multirow{2}{*}{ Reference } \\
\hline & $\mathrm{Fe}$ & $\mathrm{TiO}_{2}$ & $\mathrm{Al}_{2} \mathrm{O}_{3}$ & $\mathrm{MgO}$ & $\mathrm{MnO}$ & \\
\hline $\begin{array}{c}\text { Waikato North } \\
\text { Head }\end{array}$ & 61.4 & 8.0 & 3.5 & 2.8 & 0.6 & $\begin{array}{c}\text { Brathwaite, } \\
\text { Gazley and } \\
\text { Christie, } 2017 \\
\end{array}$ \\
\hline Raglan & 60.7 & 8.2 & 3.6 & 2.6 & 0.7 & Wright, 1964 \\
\hline Taharoa & 60.9 & 7.9 & 3.5 & 2.8 & 0.5 & $\begin{array}{c}\text { Brathwaite, } \\
\text { Gazley and } \\
\text { Christie, } 2017\end{array}$ \\
\hline New Plymouth & 60.7 & 8.5 & 3.2 & 2.7 & 0.7 & $\begin{array}{c}\text { Brathwaite, } \\
\text { Gazley and } \\
\text { Christie, } 2017 \\
\end{array}$ \\
\hline $\begin{array}{l}\text { Whanganui- } \\
\text { Waikawau }\end{array}$ & 61.0 & 8.3 & 3.2 & 2.8 & 0.6 & $\begin{array}{l}\text { Brathwaite, } \\
\text { Gazley and } \\
\text { Christie, } 2017\end{array}$ \\
\hline
\end{tabular}


The titanium content in NZ ironsand is typically lower than other TTM ore deposits in the world. TTM ironsand deposits in Indonesia has a titanium content between 9 and 12 wt.\% as $\mathrm{TiO}_{2}$ (Hilman et al., 2014; Yong-qi, Han-jie and Lin, 2015). Other TTM ores are found in the form of rock. South African TTM ore was reported to have a titanium content of $\sim 12$ wt. $\% \mathrm{TiO}_{2}$ (Sun et al., 2016). Panzhihua TTM ore was reported to have a titanium content 13 wt.\% $\mathrm{TiO}_{2}$ (Hu et al., 2013).

Previous publications have reported that NZ ironsand is typically composed of two kinds of grain. These are "homogeneous particles" and "lamellar particles", the latter containing lamellar structures. Most of the particles are uniform homogeneous grains of TTM. The small minority (< $10 \%$ of particles) are non-uniform particles containing lamellar structures of TTH, $\left(\mathrm{Fe}_{2-\mathrm{y}} \mathrm{Ti}_{\mathrm{y}} \mathrm{O}_{3}\right)$ exsolved in a TTM matrix (Wright, 1964; Park and Ostrovski, 2003; Wang et al., 2016). Figure 2.6 shows the typical cross-section images for these grains.

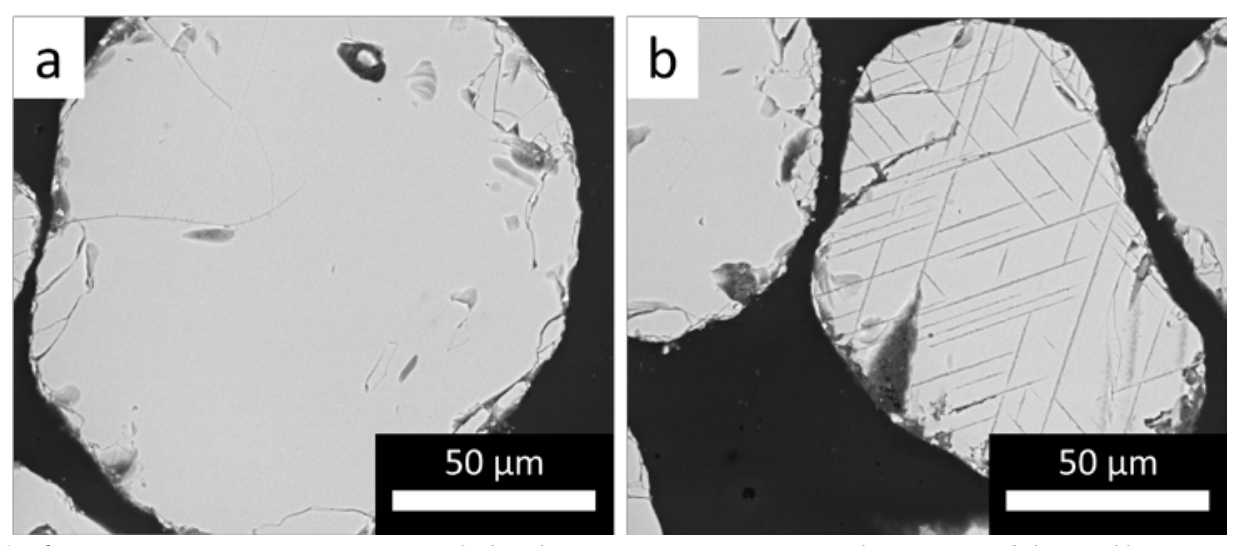

Figure 2.6 Cross-section images of the homogenous particle (a) and lamellar particle (b) in NZ ironsand (image taken in this thesis work).

The homogeneous particle is composed of TTM solid solution. Iron and titanium elements within the solid solution are distributed broadly uniformly within the particle (McAdam, 1974; Park and Ostrovski, 2003). Aluminium and magnesium elements can also be contained within the solid solution but the concentration of these elements vary within a particle (Park and Ostrovski, 2003).

In the lamellar particle, each lamella meets at an angle of $\sim 60^{\circ}$ to each other (Park and Ostrovski, 2003; Bjäreborn et al., 2018). The titanium content in the lamellae is typically higher than in the surrounding TTM matrix (Wright and Lovering, 1965; Park and Ostrovski, 2003; Bjäreborn et al., 2018). In contrast, the aluminium and magnesium 
elemental content in the surrounding TTM matrix is typically higher than in the lamellae (Wright and Lovering, 1965; Park and Ostrovski, 2003; Bjäreborn et al., 2018).

\subsection{Hydrogen reduction of TTM ore}

Although there are a small number of reports on the FB reduction of TTM ore, there are several reports on the hydrogen reduction of TTM ore in the form of pellets or fixed beds (Park and Ostrovski, 2003; Park and Ostrovski, 2004b; Sun et al., 2013; Wang, Zhang, Ma, et al., 2017). Previous literature has reported that the reduction of NZ TTM ironsand by $\mathrm{H}_{2}$ gas is much faster than by CO (Shannon, Kitt and Marshall, 1960; McAdam, Dall and Marshall, 1969; Park, 2002). This chapter only reviews literature concerning the hydrogen reduction of TTM ore.

It is commonly accepted that the gaseous reduction of TTM ore occurs in several steps. In equilibrium state, the sequence of the reduction path for TTM in the Fe-Ti-O system is given in equation (2.5) (Inoue, Itoh and Azakami, 1996):

$\mathrm{Fe}_{3-x} \mathrm{Ti}_{x} \mathrm{O}_{4} \rightarrow \mathrm{FeO}+\mathrm{Fe}_{2} \mathrm{TiO}_{4} \rightarrow \mathrm{Fe}+\mathrm{Fe}_{2} \mathrm{TiO}_{4} \rightarrow \mathrm{Fe}+\mathrm{FeTiO}_{3} \rightarrow \mathrm{Fe}+\mathrm{FeTi}_{2} \mathrm{O}_{5} \rightarrow \mathrm{Fe}+\mathrm{TiO}_{2}$

Although TTM ore is different from conventional magnetite ore, reduction reactions for pure magnetite in equations (2.1-2.3) are considered to be the basis for the reduction process of TTM (Park, 2002). Some additional reactions of iron-titanium oxides that may also occur are given in reactions (2.6-2.8) (Park, 2002).

$$
\begin{aligned}
& \mathrm{FeTiO}_{3(\mathrm{~s})}+\mathrm{H}_{2(\mathrm{~g})} \rightarrow \mathrm{Fe}_{(\mathrm{s})}+\mathrm{TiO}_{2(\mathrm{~s})}+\mathrm{H}_{2} \mathrm{O}_{(\mathrm{g})} \\
& \mathrm{Fe}_{2} \mathrm{TiO}_{4(\mathrm{~s})}+2 \mathrm{H}_{2(\mathrm{~g})} \rightarrow 2 \mathrm{Fe}_{(\mathrm{s})}+\mathrm{TiO}_{2(\mathrm{~s})}+2 \mathrm{H}_{2} \mathrm{O}_{(\mathrm{g})} \\
& 2 \mathrm{Fe}_{2} \mathrm{TiO}_{5(\mathrm{~s})}+6 \mathrm{H}_{2(\mathrm{~g})} \rightarrow 2 \mathrm{Fe}_{(\mathrm{s})}+2 \mathrm{TiO}_{2(\mathrm{~s})}+6 \mathrm{H}_{2} \mathrm{O}_{(\mathrm{g})}
\end{aligned}
$$

Previous studies on pellet or fixed bed reduction reported a slightly different behaviour between NZ TTM ironsand and other TTM ores during the reduction by $\mathrm{H}_{2}$ at $900^{\circ} \mathrm{C}$. In reduction studies for TTM ores by Sun et al., 2013 and Wang et al., 2017, significant levels of wüstite X-ray diffraction (XRD) peaks were observed during the initial reduction steps. On the other hand, in a reduction study for NZ TTM ore by Park and Ostrovski, 2004b, only a trace level of wüstite XRD peak was reported during the initial reduction steps. The authors concluded that the reduction of TTM to wüstite is much slower than the subsequent reduction of wüstite to metallic iron in the reduction at $900^{\circ} \mathrm{C}$. In the final step, all these studies reported the formation of Ti-bearing oxides: ilmenite $\left(\mathrm{FeTiO}_{3}\right)$, 
rutile $\left(\mathrm{TiO}_{2}\right)$, and pseudobrookite $\left(\mathrm{Fe}_{2} \mathrm{TiO}_{5}\right)$, which are consistent with equation (2.5). It should be noted that these studies have only reported the phase evolution during the reduction of $\mathrm{TTM}$ at $900^{\circ} \mathrm{C}$. There is no information on whether this phase evolution may change at different reduction temperatures.

Table 2.3 presents a brief summary of some literature dealing with the hydrogen reduction of TTM ore, both for TTM ironsand and TTM in solid rock. Some important points from the Table are that temperature and reducing gas composition affect both the reaction rate and the final microstructure of a fully reduced TTM ore. In general, the reduction rate of TTM ores increases with the increasing temperature and $\mathrm{H}_{2}$ concentration in the gas mixtures. Needle-shaped ( $\lesssim 50 \mu \mathrm{m})$ metallic iron structures were reported to result from reduction at low temperatures $\leq 800^{\circ} \mathrm{C}$ (Park and Ostrovski, 2004b). By contrast, porous metallic iron structures were produced by the reduction at low temperatures $\geq 900^{\circ} \mathrm{C}$.

NZ TTM ironsand is typically reduced more slowly than conventional hematite and magnetite ores as reported in McAdam (1974), Park and Ostrovski (2004b), and Longbottom, Ostrovski and Park (2006). They stated that this is due to the presence of $\mathrm{Ti}^{4+}$ in the TTM crystal lattice which stabilises the cubic spinel structure. The activity of $\mathrm{Fe}^{3+}$ becomes lower, and the reduction of $\mathrm{Fe}^{3+}$ to $\mathrm{Fe}^{2+}$ is then retarded. As a result, favoured reaction becomes the reduction of $\mathrm{Fe}^{2+}$ to $\mathrm{Fe}^{0}$ (metallic iron).

Another important point to note is that the reduction of lamellar particles has been observed to proceed faster than homogeneous particles (McAdam, 1974; Park and Ostrovski, 2003; Park and Ostrovski, 2004b). This is due to the presence and the fast reduction of TTH lamellae. During the reduction of TTH to TTM, the transformation of the crystal structure from hexagonal TTH to cubic TTM, results in atomic rearrangement in the crystal. For every oxygen taken out, interstitial $\mathrm{Fe}^{3+}$ atoms in the hexagonal structure of TTH will move to tetrahedral sites of the cubic structure of TTM and as a result, the lattice stretches (Dey, 1981; Ünal and Bradshaw, 1983). This results in an increase of relative crystal volume of the lattice of iron atoms in the crystal by about 4\% (calculated from the change in density and equivalent mass from hematite to magnetite). This increase results in stress and formation of cracks in the particle which provide spaces for the diffusion of reducing gases. This result agrees well with the effect of pre-oxidisation of TTM to TTH. Pre-oxidisation of the NZ TTM ironsand has been demonstrated to increase the overall reduction rate (Park and Ostrovski, 2004a; Longbottom, Ostrovski and Park, 2006). 
Table 2.3 Summary table of the literature dealing with hydrogen reduction of ironsand.

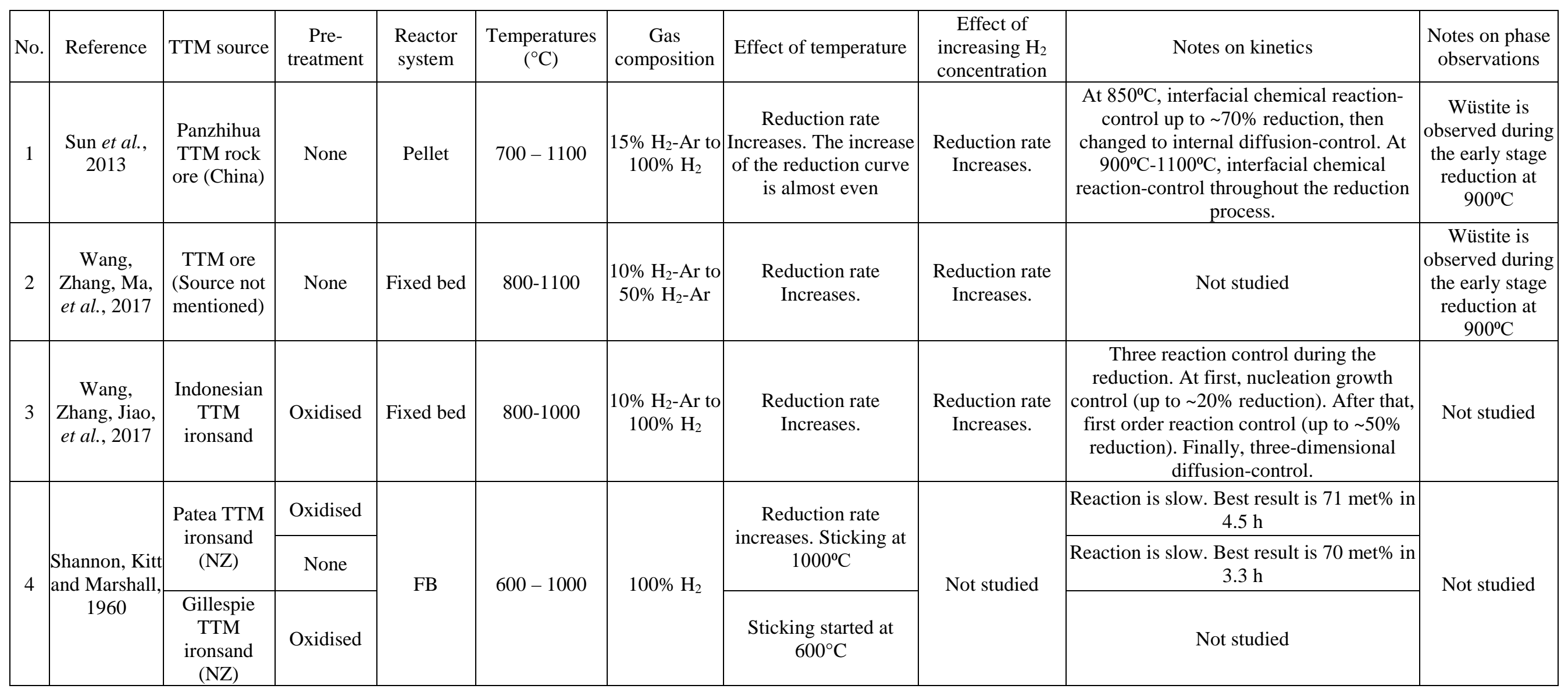


Table 2.3 (continued)

\begin{tabular}{|c|c|c|c|c|c|c|c|c|c|c|}
\hline No. & Reference & TTM source & Pre-treatment & $\begin{array}{c}\text { Reactor } \\
\text { system }\end{array}$ & $\begin{array}{c}\text { Temperatures } \\
\left({ }^{\circ} \mathrm{C}\right)\end{array}$ & $\begin{array}{c}\text { Gas } \\
\text { composition }\end{array}$ & $\begin{array}{c}\text { Effect of } \\
\text { temperature }\end{array}$ & $\mid \begin{array}{c}\text { Effect of } \mathrm{H}_{2} \\
\text { concentration }\end{array}$ & Notes on kinetics & $\begin{array}{c}\text { Notes on phase } \\
\text { observations }\end{array}$ \\
\hline 5 & $\begin{array}{l}\text { G. D } \\
\text { McAdam, } \\
1969\end{array}$ & $\begin{array}{l}\text { Waikato } \\
\text { North Head } \\
\text { TTM } \\
\text { ironsand } \\
\text { (NZ) }\end{array}$ & None & Pellet & $800-1100$ & $100 \% \mathrm{H}_{2}$ & $\begin{array}{l}\text { Reduction rate } \\
\text { Increases }\end{array}$ & Not studied & $\begin{array}{l}\text { Rate controlling step is the reduction } \\
\text { wüstite to metallic iron }\end{array}$ & Not studied \\
\hline \multirow[b]{2}{*}{6} & \multirow[b]{2}{*}{$\begin{array}{l}\text { Park and } \\
\text { Ostrovski, } \\
\text { 2004b }\end{array}$} & \multirow[b]{2}{*}{$\begin{array}{l}\text { Waikato } \\
\text { North Head } \\
\text { TTM } \\
\text { ironsand } \\
\text { (NZ) }\end{array}$} & Oxidised & \multirow[b]{2}{*}{ Fixed bed } & 900 & $\begin{array}{l}25 \% \mathrm{H}_{2}-\mathrm{Ar} \\
\text { to } 100 \% \mathrm{H}_{2}\end{array}$ & Not studied & \begin{tabular}{|c|} 
Reduction rate \\
Increases.
\end{tabular} & \multirow[b]{2}{*}{$\begin{array}{l}\text { Rate-controlling step is the reduction } \\
\text { TTM to wüstite }\end{array}$} & Not studied \\
\hline & & & None & & $700-1100$ & $\begin{array}{l}25 \% \mathrm{H}_{2}-\mathrm{Ar} \\
\text { to } 100 \% \mathrm{H}_{2}\end{array}$ & $\begin{array}{c}\text { Reduction rate } \\
\text { increases up to } \\
1000^{\circ} \mathrm{C} \text {. Small } \\
\text { increase when } \\
\text { increasing to } \\
1100^{\circ} \mathrm{C} \\
\end{array}$ & $\begin{array}{c}\text { Reduction rate } \\
\text { Increases. }\end{array}$ & & $\begin{array}{l}\text { Trace level of a } \\
\text { wüstite peak } \\
\text { (reduction at } \\
900^{\circ} \mathrm{C} \text { ) }\end{array}$ \\
\hline 7 & $\begin{array}{c}\text { Zhang et al., } \\
2020\end{array}$ & $\begin{array}{l}\text { Waikato } \\
\text { North Head } \\
\text { TTM } \\
\text { ironsand } \\
\text { (NZ) }\end{array}$ & Oxidised & \multirow[t]{2}{*}{ Pellet } & $707-1170$ & $100 \% \mathrm{H}_{2}$ & $\begin{array}{c}\text { Significant } \\
\text { increase from } \\
707^{\circ} \mathrm{C} \text { to } 870^{\circ} \mathrm{C} . \\
\text { Small increase } \\
\text { from } 870^{\circ} \mathrm{C} \text { to } \\
1170^{\circ} \mathrm{C}\end{array}$ & Not studied & $\begin{array}{l}\text { At } 770^{\circ} \mathrm{C} \text {, combination between gas } \\
\text { diffusion and chemical reaction- } \\
\text { control. At } 870^{\circ} \mathrm{C}-1170^{\circ} \mathrm{C} \text {, chemical } \\
\text { reaction-control. }\end{array}$ & $\begin{array}{l}\text { XRD analysis on } \\
\text { fully reduced } \\
\text { samples. Rutile is } \\
\text { observed in the } \\
\text { final product } \\
\text { reduced at } 770^{\circ} \mathrm{C} \\
\text { and } 870^{\circ} \mathrm{C} \text {. }\end{array}$ \\
\hline 8 & $\begin{array}{l}\text { Longbottom } \\
\text { et al., } 2018\end{array}$ & \begin{tabular}{|} 
Waikato \\
North Head \\
TTM \\
ironsand \\
(NZ)
\end{tabular} & None & & $900-1100$ & $3.5 \% \mathrm{H}_{2}-\mathrm{Ar}$ & $\begin{array}{l}\text { Reduction rate } \\
\text { Increases. }\end{array}$ & Not studied & $\begin{array}{l}\text { The reaction is controlled by the mass } \\
\text { transport of water vapor in the bulk } \\
\text { gas. This is likely because of the low } \\
\mathrm{H}_{2} \text { content in the gas mixture. }\end{array}$ & $\begin{array}{l}\text { Wüstite is } \\
\text { observed during } \\
\text { the early stage } \\
\text { reduction at } \\
900^{\circ} \mathrm{C} \text { to } 1100^{\circ} \mathrm{C} .\end{array}$ \\
\hline
\end{tabular}




\subsection{FB processing}

In this thesis work, a laboratory-scale FB reactor is initially built for the hydrogen reduction study at high temperatures. The next section will give necessary theoretical background relevant for designing an FB reactor.

\subsubsection{Theoretical considerations in designing a FB reactor}

\subsubsection{Fluidisation Behaviour in Gas-solid System}

Kunii and Levenspiel (1977) reported that there are five different states in the gassolid fluidisation system. A schematic illustration of these various fluidisation states is presented in Figure 2.7. The fixed bed is a state in which a very low flow of gas merely percolates through the bed materials and flows through the void spaces between immobile stacked particles. A small increase in the flow rate results in vibrations between particles moving in a restricted area, like a "fluid" flowing in a restricted container. This state is called the minimum fluidisation state. Neither a fixed bed nor minimum fluidisation regimes are desirable for $\mathrm{FB}$ operation, because the gas flow rate is too low and therefore produces inefficient mixing of the bed. At higher flow rates, agitation and movement of particles becomes more vigorous, accompanied by the appearance of bubbles. This state is called a bubbling FB. The bubbling FB region is desirable because it delivers excellent gassolid mixing during the reaction. This ensures good heat transfer between particles, gas, and the vessel, and any localized "hot spots" are expected to vanish. If the gas flow rate is further substantially increased, the bubbles become larger and cover the inner reactor diameter whilst moving in the upward direction. This state is called the slugging state as 'slugs' of powder are pushed up the reactor in a pulsing motion. The slugging state is generally not considered desirable for gas-solid reactions, because of the high amounts of carryover solid with non-uniform solid contact. In an actual operation, slugging also results in a high vibration of the reactor vessel which can lead to safety risks. A further increase in gas flow rate eventually results in the particles becoming entrained in the gas flow and being pushed out of the reactor, causing the disappearance of the dense bed. This state is called pneumatic transport fluidisation, and can be desirable in the operation of a circulating FB (CFB) reactor where excessive flow rates are needed to circulate particles during the reaction. 


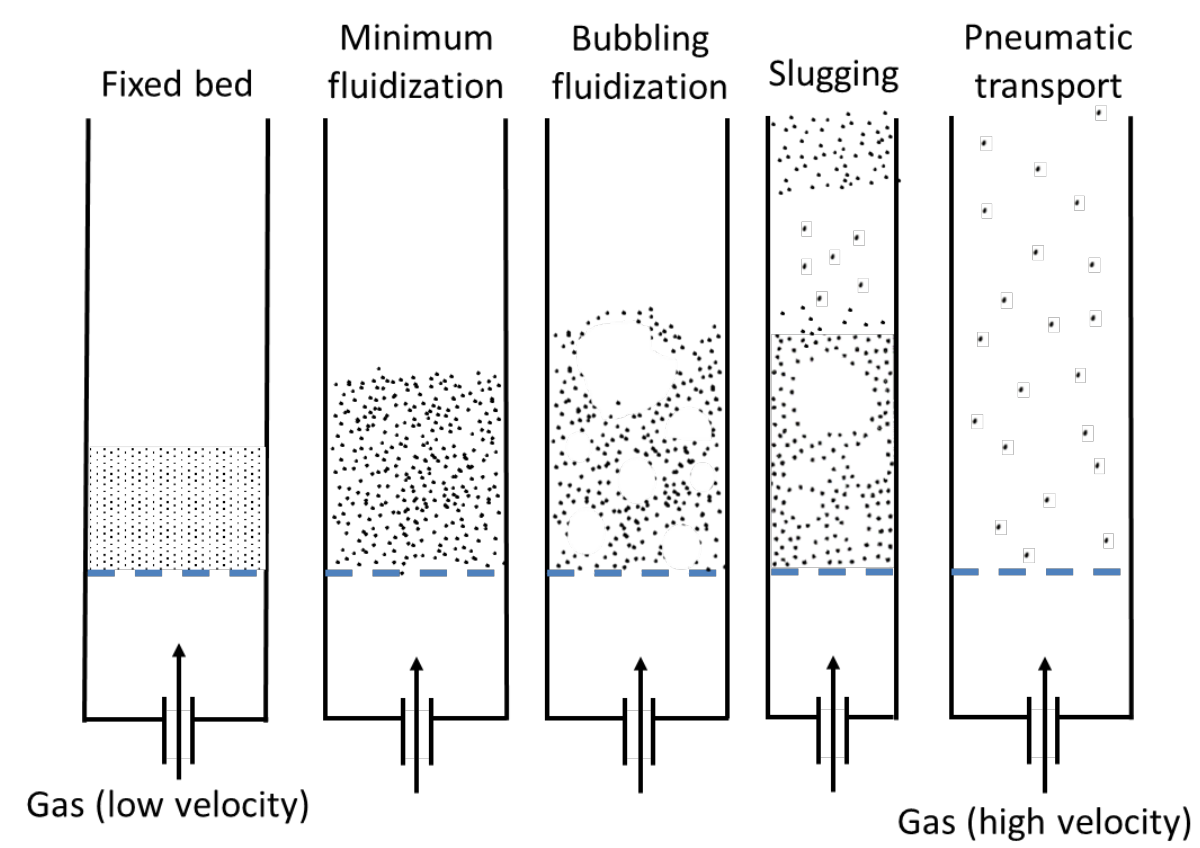

Figure 2.7 Various kinds of fluidisation states in gas-solid reaction (redrawn from Kunii and Levenspiel, 1977). Copyright (C) 1977 from Fluidization Engineering. Re-drawn with permission of John Wiley and Sons Ltd. through PLSclear.

The fluidisation regimes can be easily determined by visual observation. This is usually possible at room temperature fluidisation or in a transparent FB reactor. In certain circumstances, such as at high temperatures and in a covered reactor vessel, visual observation is not possible. Plotting the pressure drop $(\Delta P)$ across the bed versus gas velocity is a well-known method to estimate the fluidisation region. As reported by Kunii and Levenspiel (1977), the minimum fluidisation velocity $\left(U_{m f}\right)$ can be determined from the sudden change of this curve, as in Figure 2.8. Based on the Geldart classification of powders (Geldart, 1973), NZ ironsand belongs to a 'B-type’ (sand-like) powder, see Figure 2.9. For B-type powder, bubbles start to initiate as soon as the velocity exceeds the $U_{m f}$. The bubbling fluidisation region is the flow range for which $\Delta P$ across the bed remains nearly constant. Within this region, the $\Delta P$ value is about equal to $\frac{W_{b}}{A_{b}}$, where $W_{b}$ is the weight of the bed and $A_{b}$ is the bed top surface area. When a slugging state occurs, large fluctuations in $\Delta P$ are observed (Figure 2.10).

At even higher gas velocities, $\Delta P$ starts to increase again (although this need not be a big effect), as shown in Figure 2.8. This point indicates that particles start to be entrained. Beyond a peak point, $\Delta P$, then continuously decreases with increasing gas flow, as more and more particles are entrained in the gas and leaving the reactor. 


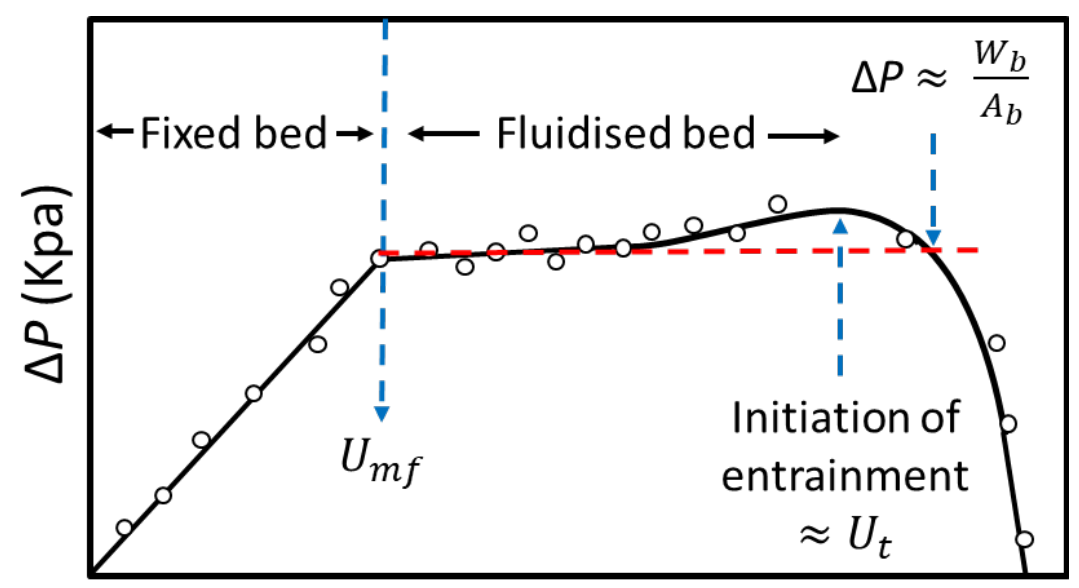

\section{Gas velocity $(\mathrm{cm} / \mathrm{s})$}

Figure 2.8 A typical graph of pressure drop versus gas velocity (re-drawn from Kunii and Levenspiel, 1977). Copyright (C) 1977 from Fluidization Engineering. Re-drawn with permission of John Wiley and Sons Ltd. through PLSclear.

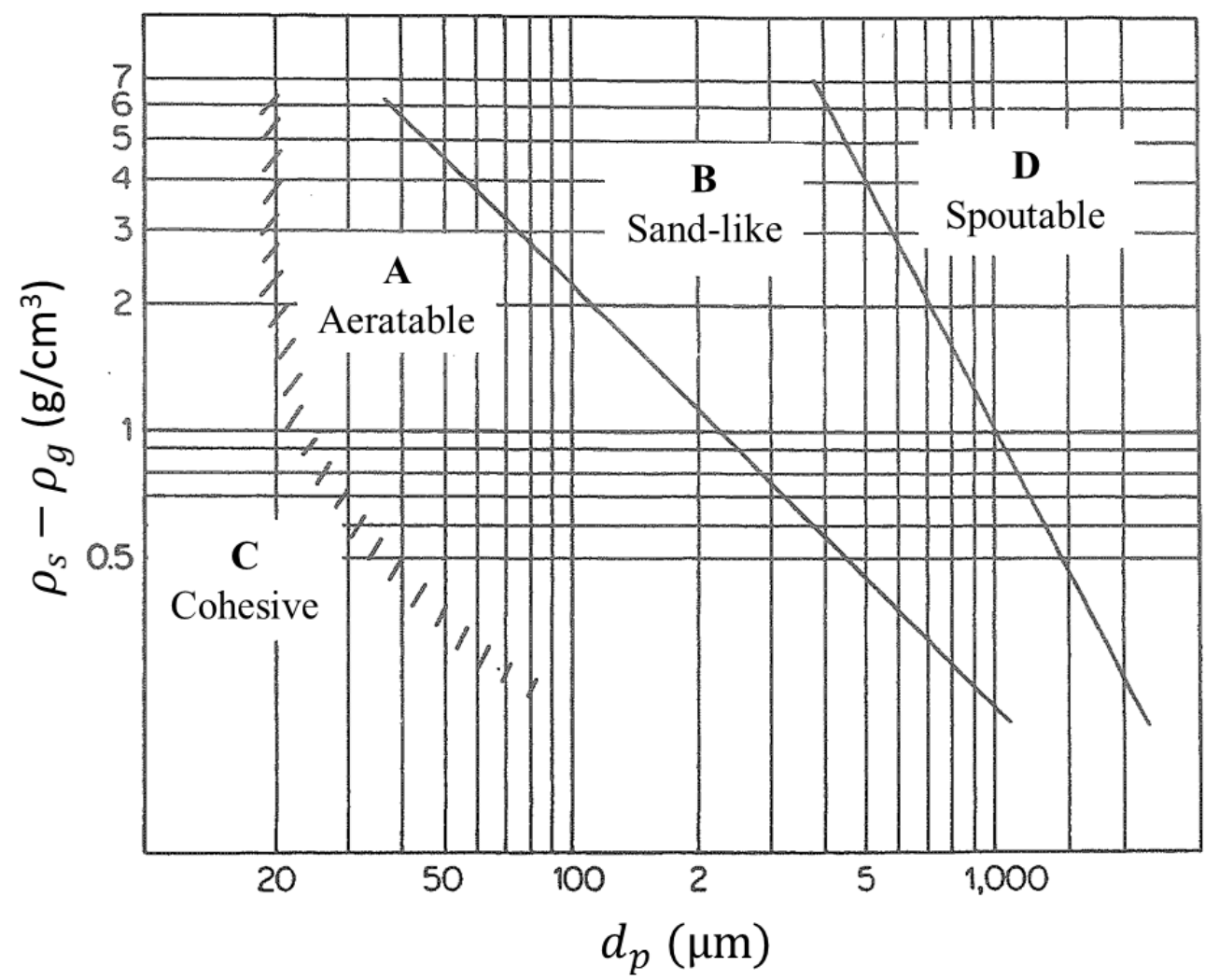

Figure 2.9 Geldart classification of powders (Reproduced from Yang, 2003). Copyright (C) 2003 from Handbook of fluidization and fluid-particle systems. Reproduced with permission of Taylor and Francis Group, LLC, a division of informa plc. 


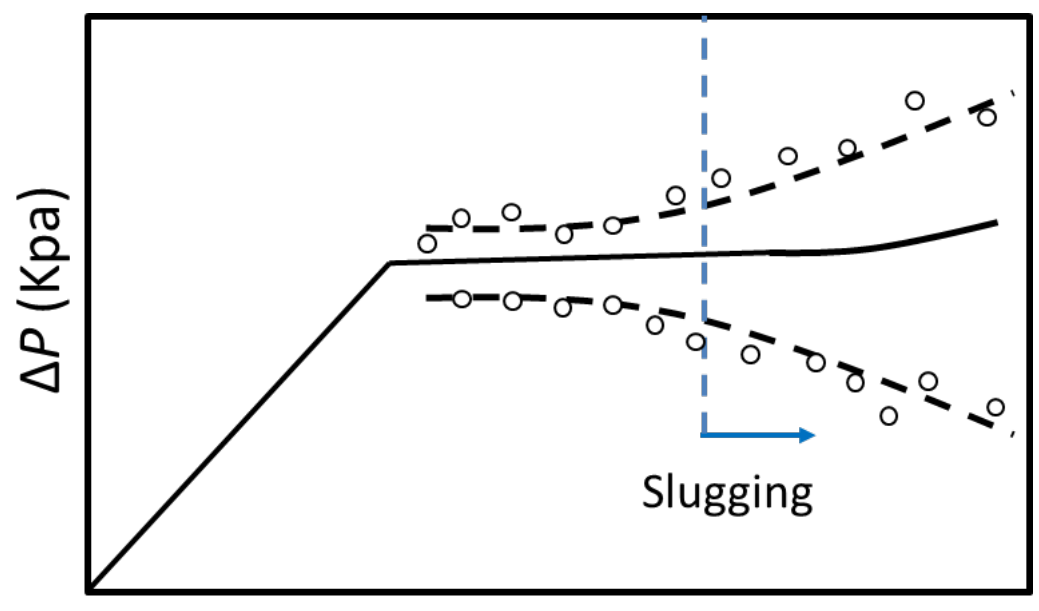

Gas velocity $(\mathrm{cm} / \mathrm{s})$

Figure 2.10 Pressure drop diagram for slugging region (re-drawn from Kunii and Levenspiel, 1977). Copyright (C) 1977 from Fluidization Engineering. Re-drawn with permission of John Wiley and Sons Ltd. through PLSclear.

\subsubsection{Correlations for Equations in Hydrodynamic Parameters}

In the gas-solid FB, particles start to fluidise when the superficial gas velocity reaches the point at which the drag force (pressure drop or $\Delta P$ ) on the bed of particles from the upward gas is equal to the gravitational force exerted on the particles $\left(\frac{W_{b}}{A_{b}}\right)$, as shown in Figure 2.8(a) (Kunii and Levenspiel, 1977). The net gravitational force needed in the fluidised vessel follows equation (2.9). The definition of all symbols in this section are presented in Nomenclature.

$$
\frac{W_{b}}{A_{b}}=\Delta P=g\left(\rho_{s}-\rho_{g}\right)(1-\varepsilon) H_{b e d}
$$

The $\Delta P$ across the bed follows the Ergun equation as presented in equation (2.10),

$$
\frac{\Delta P \cdot g}{H_{b e d}}=150 \frac{\left(1-\varepsilon_{m f}\right)^{2}}{\varepsilon_{m f}{ }^{3}} \cdot \frac{\mu \cdot u_{o}}{\left(\varphi d_{p}\right)^{2}}+1.75 \frac{1-\varepsilon_{m f}}{\varepsilon_{m f}{ }^{3}} \frac{\rho_{g} \cdot u_{o}^{2}}{\varphi \cdot d_{p}}
$$

where the $\varepsilon_{m f}$ value is defined in equations (2.11),

$$
\varepsilon_{m f}=0.586 \varphi^{-0.72} \cdot\left(\frac{\mu^{2}}{\rho_{g} \cdot \eta \cdot d_{p}{ }^{3}}\right)^{0.029} \cdot\left(\frac{\rho_{g}}{\rho_{s}}\right)^{0.021}
$$

where the $\eta$ value is defined in equations (2.12).

$$
\eta=g\left(\rho_{s}-\rho_{g}\right)
$$


Wen and Yu (1966) reported the correlation to get an approximation of the $\varepsilon_{m f}$ value as presented in equation (2.13).

$$
\frac{1}{\varphi \cdot \varepsilon_{m f}{ }^{3}} \approx 14 \text { and } \frac{1-\varepsilon_{m f}}{\varphi^{2} \cdot \varepsilon_{m f}{ }^{3}} \approx 11
$$

The correlation for minimum fluidisation velocity are presented in equations (2.14) and (2.15).

$$
\begin{aligned}
U_{m f} & =\frac{\left(\varphi \cdot d_{p}\right)^{2}}{150} \cdot \frac{\eta \cdot \varepsilon_{m f}{ }^{3}}{\mu\left(1-\varepsilon_{m f}\right)} ; R_{e}<20 \\
U_{m f}{ }^{2} & =\frac{\varphi \cdot d_{p}}{1.75} \cdot \frac{\mathrm{\eta} \cdot \varepsilon_{m f^{3}}}{\rho_{g}} ; R_{e}>1000
\end{aligned}
$$

where the $\mathrm{R}_{\mathrm{e}}$ is defined in equation (2.16).

$$
R_{e}=\frac{d_{p} \cdot \rho_{g} \cdot u_{o}}{\mu}
$$

The maximum fluidisation velocity is usually denoted as terminal velocity $\left(U_{t}\right)$ when the gas velocity exceeds the free-fall terminal velocity of particle. The correlations for $U_{t}$ are presented in equations (2.17) and (2.18).

$$
\begin{gathered}
U_{t}=\frac{\eta \cdot d_{p}^{2}}{18 \cdot \mu} ; R_{e}<0.4 \\
U_{t}=\left(\frac{4}{225} \cdot \frac{\eta^{2}}{\mu \cdot \rho_{g}}\right)^{1 / 3} \cdot d p ; 0.4<R_{e}>500
\end{gathered}
$$

The non-entrainment regime is presented in equation (2.19).

$$
U_{m f}<u_{o}<U_{t}
$$

\subsubsection{Minimum freeboard height}

A FB reactor can usually be divided into distinct 'dense bed' and 'freeboard' regions (Werther and Hartge, 2003). The dense bed zone extends from the bottom of the bed to the highest bursting bubble, whereas the freeboard zone extends from the upper surface of the dense bed to the highest particle, as shown in Figure 2.11. At a high superficial gas velocity, the dense bed fluctuates greatly, resulting in large errors in the determination of the bed height. This zone is usually called the splash zone. The distance between the splash zone and the point where the solids holdup concentration becomes nearly constant is called the transport disengagement height (TDH). An estimation of TDH is important for the reactor design, as the total freeboard height should be at least higher than TDH to minimize the entrainment of particles at the gas outlet. However, there is no commonly accepted method 
for calculation of TDH (Werther and Hartge, 2003). Practically, the freeboard height and TDH should be observed in preliminary experiments before designing the reactor

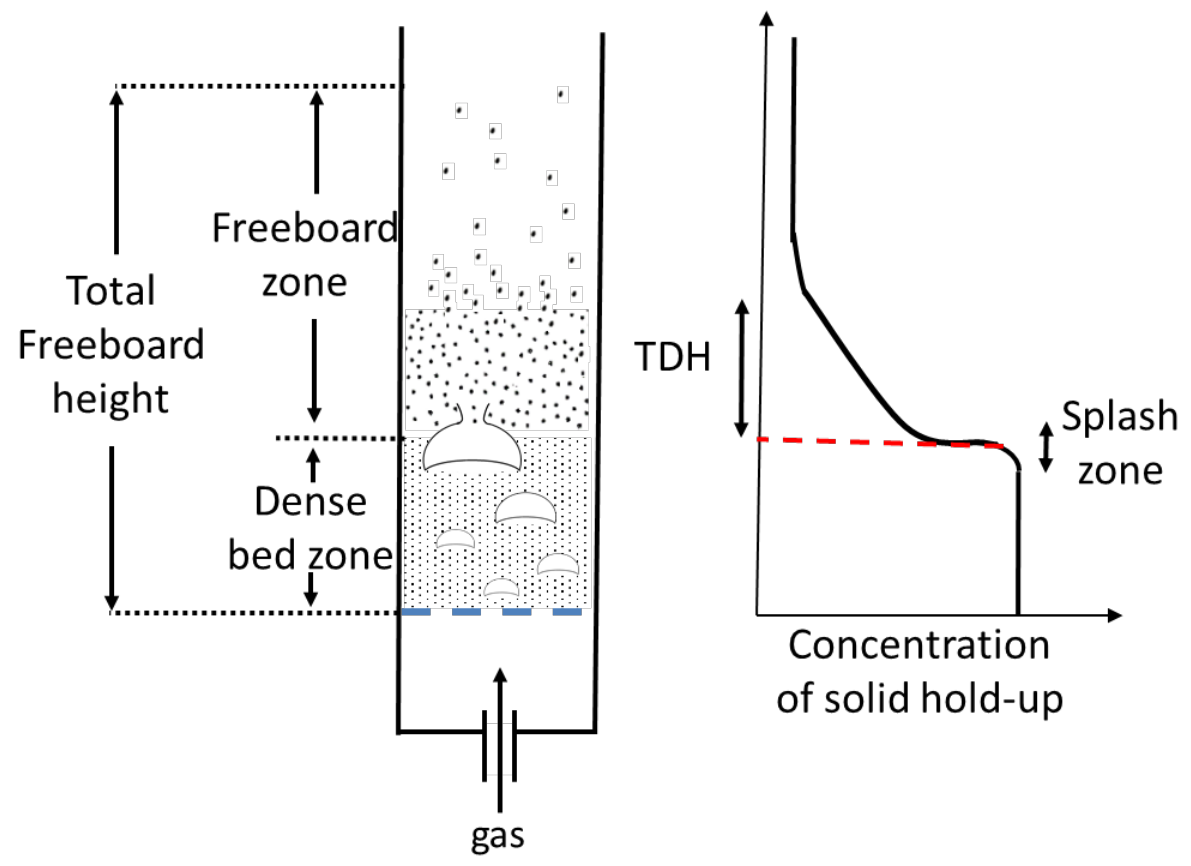

Figure 2.11 Typical zones in bubbling FB reactor (re-drawn from Werther and Hartge, 2003). Copyright (C) 2003 from Handbook of fluidization and fluid-particle systems. Redrawn with permission of Taylor and Francis Group, LLC, a division of informa plc.

\subsubsection{Choice of Distributor Type}

Grohse, 1955 reported that the quality of fluidisation is strongly influenced by the distributor type. His findings are summarised in Figure 2.12. Using a single orifice opening, channelling and slugging are likely to occur as one bubble produced at a time. This becomes severe at high flow rates so that the bubble can become larger, and eventually cover the inner reactor (Grohse, 1955; Kunii and Levenspiel, 1977). Using a sintered plate diffuser, which has many inlet openings, the distribution of bubbles is more uniform throughout the bed. The bubbles are smaller and there is a much higher possibility for gas-solid contact. Channelling and slugging are less likely to occur. 


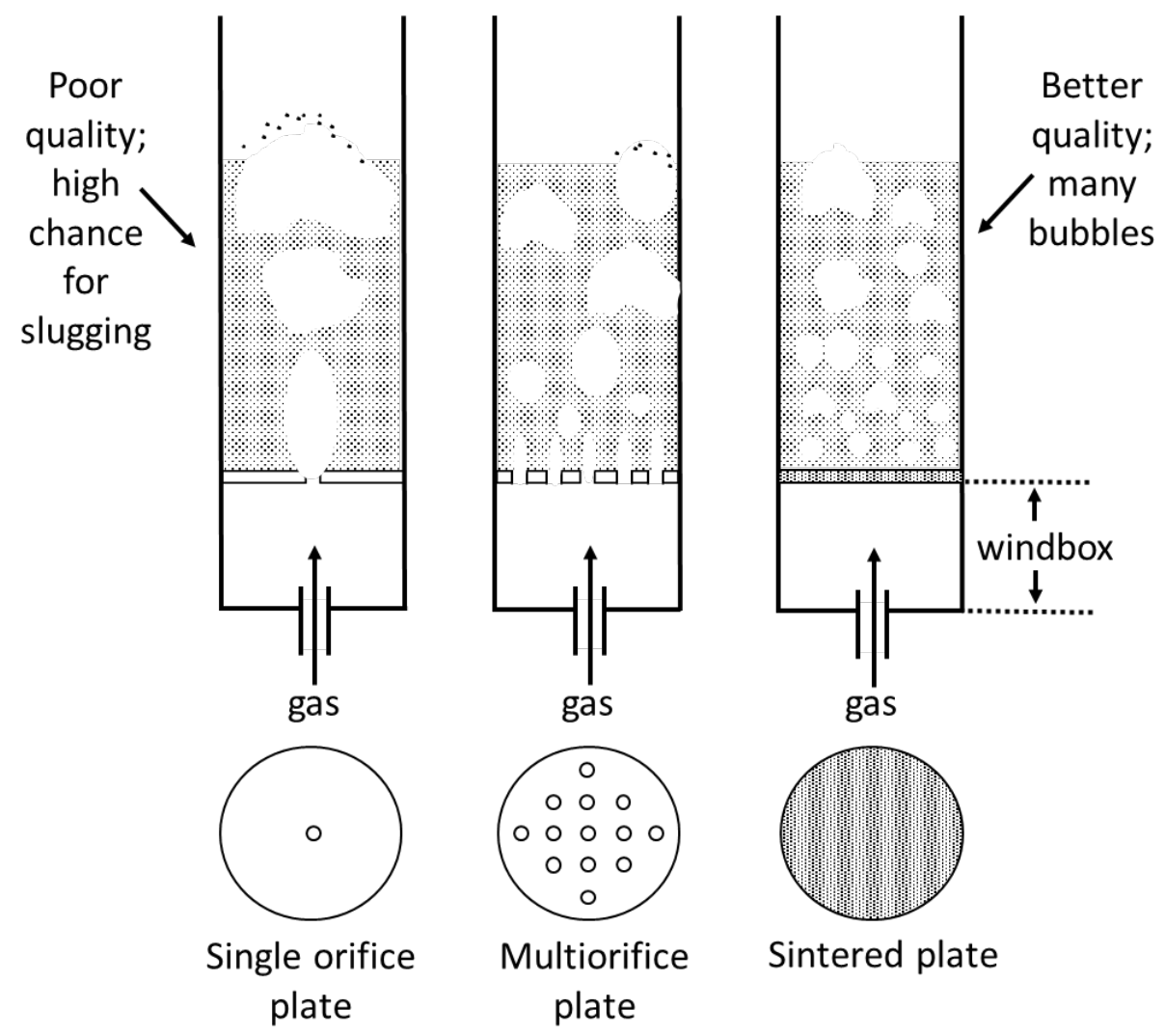

Figure 2.12 Influence of distributor type on fluidisation quality (re-drawn from Kunii and Levenspiel, 1977). Copyright (C) 1977 from Fluidization Engineering. Re-drawn with permission of John Wiley and Sons Ltd. through PLSclear.

\subsubsection{Windbox}

The bottom part under the distributor, where the gas enters the reactor, is called the windbox (Figure 2.12). The distributor needs to be separated at a certain distance from the gas entry point to the reaction vessel. This is to ensure the gas is distributed upward uniformly into the bed. Litz (1972) developed correlations for the gas inlet in horizontal and vertical directions to the reactor. If there is not enough distance between the distributor and gas inlet, the inlet gas expansion can cause an uneven distribution of gas. The minimum windbox height $\left(H_{w}\right)$ is based on the criteria defined in equation (2.20) and (2.21) (Litz, 1972).

$$
\begin{array}{ll}
H_{w}=3\left(D-D_{i}\right) ; & \text { for } D_{i}>\frac{D}{36} \\
H_{w}=100 D_{i} ; & \text { for } D_{i}<\frac{D}{36}
\end{array}
$$




\subsubsection{Previous laboratory experiments on FB reduction involving iron oxides}

When designing a laboratory scale FB reactor, it is important to refer to and consider the works of previous authors. Instruments required may vary on the sample materials, experimental conditions, and gas atmosphere. For experiments to be conducted at high temperatures, the construction materials should have a high melting point, good heat resistance, and dimensional stability at high temperatures. The dimensions of the reactor also need to be considered. If the diameter is too small, the possibility of slugging will be higher. Different sample materials will result in a different fluidisation velocity. A larger bed weight means that greater $\Delta P$ will be generated. These are all general problems for FB reactor design which have also been faced by previous authors. Table 2.4 summarises some previous laboratory scale FB works involving iron oxides for consideration and reference in designing a lab-scale reactor. 
Table 2.4 Summary table for FB reactors and experimental conditions from the literature

\begin{tabular}{|c|c|c|c|c|c|c|c|c|c|c|c|c|c|}
\hline \multirow{2}{*}{ Author } & \multirow{2}{*}{$\begin{array}{c}\text { Tube } \\
\text { material }\end{array}$} & \multirow{2}{*}{$\begin{array}{c}\text { Operating } \\
\text { temperature } \\
(\mathrm{C})\end{array}$} & \multirow{2}{*}{$\begin{array}{l}\text { Gas } \\
\text { mixture }\end{array}$} & \multirow{2}{*}{$\begin{array}{c}\text { Gas } \\
\text { velocity } \\
(\mathrm{cm} / \mathrm{s})\end{array}$} & \multicolumn{2}{|c|}{ Reactor dimension (mm) } & \multirow{2}{*}{$\begin{array}{c}\text { Sample } \\
\text { material }\end{array}$} & \multicolumn{2}{|c|}{ Bed weight (g) } & \multirow{2}{*}{$\begin{array}{c}\text { Particle } \\
\text { size } \\
(\mu \mathrm{m})\end{array}$} & \multirow{2}{*}{$\begin{array}{l}\text { Sampling } \\
\text { type }\end{array}$} & \multirow{2}{*}{$\begin{array}{c}\text { Pre-heating } \\
\text { process }\end{array}$} & \multirow{2}{*}{ Step } \\
\hline & & & & & Diameter & Height & & Silica & sample & & & & \\
\hline $\begin{array}{c}\text { Shannon, } \\
\text { Kitt and } \\
\text { Marshall, } \\
1960\end{array}$ & Inconel & $700-900$ & $\begin{array}{c}\mathrm{H}_{2}-\mathrm{CO}, \\
\mathrm{H}_{2} \text {, and } \\
\mathrm{CO}\end{array}$ & $6-13$ & 88.9 & 482.6 & $\begin{array}{c}\mathrm{NZ} \\
\text { ironsand }\end{array}$ & 0 & 2041 & $\begin{array}{l}70- \\
200\end{array}$ & continuous & $\begin{array}{l}\text { Bed sample } \\
\text { is pre- } \\
\text { heated with } \\
\text { inert gas in } \\
\text { the reactor }\end{array}$ & 1 \\
\hline $\begin{array}{c}\text { Zhang, Lei } \\
\text { and Zhu, } \\
2014\end{array}$ & Quartz & $600-800$ & $\begin{array}{c}\mathrm{H}_{2}-\mathrm{CO}, \\
\mathrm{H}_{2} \text {, and } \\
\mathrm{CO}\end{array}$ & $30-50$ & 16 & 860 & $\begin{array}{c}\text { Hematite } \\
\text { ore }\end{array}$ & 0 & 8 & $\begin{array}{c}106- \\
150\end{array}$ & batch & $\begin{array}{l}\text { Bed sample } \\
\text { is pre- } \\
\text { heated with } \\
\text { inert gas in } \\
\text { the reactor }\end{array}$ & 2 \\
\hline $\begin{array}{l}\text { Zhong et } \\
\text { al., } 2013\end{array}$ & Quartz & $700-800$ & $\mathrm{~N}_{2}-\mathrm{CO}$ & $10-30$ & 25 & $\begin{array}{c}\text { Not } \\
\text { mentioned }\end{array}$ & $\begin{array}{c}\text { Iron } \\
\text { powder }\end{array}$ & 0 & 10 & $\begin{array}{c}50- \\
74,74 \\
-149, \\
\text { and } 149 \\
-210\end{array}$ & batch & $\begin{array}{l}\text { Bed sample } \\
\text { is pre- } \\
\text { heated with } \\
\text { inert gas in } \\
\text { the reactor }\end{array}$ & 1 \\
\hline $\begin{array}{c}\text { Hayashi, } \\
\text { Sayama and } \\
\text { Iguchi, } \\
1990\end{array}$ & Quartz & 900 & $\begin{array}{c}\mathrm{N}_{2}-\mathrm{H}_{2} \text {, } \\
\text { containing } \\
\mathrm{H}_{2} \mathrm{~S}\end{array}$ & $43-48$ & 22 & $\begin{array}{c}\text { Not } \\
\text { mentioned }\end{array}$ & $\begin{array}{l}\text { Hematite } \\
\text { ore }\end{array}$ & 0 & 20 & $\begin{array}{c}149- \\
210\end{array}$ & batch & $\begin{array}{l}\text { Bed sample } \\
\text { is pre- } \\
\text { heated with } \\
\text { inert gas in } \\
\text { the reactor }\end{array}$ & 1 \\
\hline $\begin{array}{l}\text { Habermann } \\
\text { et al., } 2000\end{array}$ & $\begin{array}{l}\text { Heat } \\
\text { resistant } \\
\text { steel }\end{array}$ & $550-840$ & $\begin{array}{c}\mathrm{H}_{2}, \mathrm{CO}- \\
\mathrm{CO}_{2} \text {, and } \\
\mathrm{H}_{2}-\mathrm{CO}\end{array}$ & 25 & $\begin{array}{c}\text { Not } \\
\text { mentioned }\end{array}$ & $\begin{array}{c}\text { Not } \\
\text { mentioned }\end{array}$ & $\begin{array}{c}\text { Hematite } \\
\text { ore }+ \\
\text { silica }\end{array}$ & 270 & 30 & $\begin{array}{c}125- \\
500 \text { and } \\
>500\end{array}$ & batch & $\begin{array}{l}\text { Gas is pre- } \\
\text { heated } \\
\text { before } \\
\text { coming to } \\
\text { the bed }\end{array}$ & 1 \\
\hline
\end{tabular}


Table 2.4 (continued)

\begin{tabular}{|c|c|c|c|c|c|c|c|c|c|c|c|c|c|}
\hline \multirow{2}{*}{ Author } & \multirow{2}{*}{$\begin{array}{c}\text { Tube } \\
\text { material }\end{array}$} & \multirow{2}{*}{$\begin{array}{l}\text { Operating } \\
\text { temperature } \\
\left({ }^{\circ} \mathrm{C}\right)\end{array}$} & \multirow{2}{*}{$\begin{array}{l}\text { Gas } \\
\text { mixture }\end{array}$} & \multirow{2}{*}{$\begin{array}{c}\text { Gas } \\
\text { velocity } \\
(\mathrm{cm} / \mathrm{s})\end{array}$} & \multicolumn{2}{|c|}{$\begin{array}{l}\text { Reactor dimension } \\
(\mathrm{mm})\end{array}$} & \multirow{2}{*}{$\begin{array}{l}\text { Sample } \\
\text { material }\end{array}$} & \multicolumn{2}{|c|}{ Bed weight (g) } & \multirow{2}{*}{$\begin{array}{l}\text { Particle } \\
\text { size } \\
(\mu \mathrm{m})\end{array}$} & \multirow{2}{*}{$\begin{array}{l}\text { Sampling } \\
\text { type }\end{array}$} & \multirow{2}{*}{$\begin{array}{l}\text { Pre-heating } \\
\text { process }\end{array}$} & \multirow{2}{*}{ Step } \\
\hline & & & & & Diameter & Height & & Silica & sample & & & & \\
\hline $\begin{array}{l}\text { Shao, Guo } \\
\text { and Tang, } \\
2013\end{array}$ & Quartz & 900 & $\mathrm{H}_{2}-\mathrm{CO}$ & 15 & 30 & $\begin{array}{c}\text { Not } \\
\text { mentioned }\end{array}$ & $\begin{array}{l}\text { Hematite } \\
\text { ore }\end{array}$ & 0 & 50 & $74-150$ & batch & $\begin{array}{l}\text { Gas is pre-heated } \\
\text { before coming to } \\
\text { the bed }\end{array}$ & 1 \\
\hline $\begin{array}{l}\text { Lei et al., } \\
\quad 2014\end{array}$ & Quartz & $800-900$ & $\mathrm{H}_{2}-\mathrm{CO}$ & 44 & 16 & 860 & $\begin{array}{l}\text { Hematite } \\
\text { ore }\end{array}$ & 0 & 6 & $\begin{array}{c}106- \\
150\end{array}$ & batch & $\begin{array}{l}\text { Reactor is pre- } \\
\text { heated with inert } \\
\text { gas, then iron ore } \\
\text { is fed at } \\
\text { temperature }\end{array}$ & 2 \\
\hline $\begin{array}{l}\text { Shao, Guo } \\
\text { and Tang, } \\
2011\end{array}$ & Quartz & $25-750$ & $\mathrm{~N}_{2}$ & 20 & 30 & $\begin{array}{c}\text { Not } \\
\text { mentioned }\end{array}$ & $\begin{array}{c}\text { Iron } \\
\text { powder }\end{array}$ & 0 & 70 & $38-75$ & batch & $\begin{array}{l}\text { Gas pre-heat in } \\
\text { outer layer of } \\
\text { reactor, before } \\
\text { coming to bed } \\
\text { sample } \\
\end{array}$ & 1 \\
\hline $\begin{array}{l}\text { Chen, } \\
\text { Zheng, } \\
\text { Chen and } \\
\text { Bi, } 2017\end{array}$ & Quartz & $700-850$ & $\mathrm{CO}$ & $3.5-10$ & 20 & 15 & $\begin{array}{l}\text { Hematite } \\
\text { ore }+ \\
\text { silica }\end{array}$ & 4 & $\begin{array}{c}0.03- \\
0.04\end{array}$ & $\begin{array}{c}100- \\
150\end{array}$ & batch & $\begin{array}{l}\text { Reactor is pre- } \\
\text { heated of inert } \\
\text { gas with silica, } \\
\text { then samples are } \\
\text { injected to } \\
\text { reactor }\end{array}$ & 1 \\
\hline $\begin{array}{l}\text { Miyagawa, } \\
\text { Kamijo } \\
\text { and } \\
\text { Deguchi, } \\
1992\end{array}$ & $\begin{array}{l}\text { Heat } \\
\text { resistant } \\
\text { steel }\end{array}$ & 850 & $\mathrm{H}_{2}-\mathrm{CO}$ & 40 & 50 & $\begin{array}{c}\text { Not } \\
\text { mentioned }\end{array}$ & $\begin{array}{l}\text { Hematite } \\
\text { ore }\end{array}$ & 0 & 500 & $45-500$ & continuous & $\begin{array}{l}\text { Gas is pre-heated } \\
\text { in a chamber } \\
\text { filled with } \\
\text { alumina balls } \\
\text { before coming to } \\
\text { bed }\end{array}$ & 1 \\
\hline
\end{tabular}




\subsection{Commercial FB technology for DR process of iron ores}

Several existing FB technologies have been commercially developed for the direct reduction of iron ores to produce direct reduced iron (DRI) powder with high metallisation degrees ( 90\%). Three well-known patents of this technology are Finmet ${ }^{\circledR}$, FIOR ${ }^{\circledR}$ and Circored ${ }^{\circledR}$ (Plaul, Böhm and Schenk, 2009; Schenk, 2011). In these processes, the reducing gas is a mixture of $\mathrm{H}_{2}, \mathrm{CH}_{4}$, and $\mathrm{CO}$ gases which is reformed from natural gas by steam. Finmet ${ }^{\circledR}$ and FIOR ${ }^{\circledR}$ operate with a bubbling fluidisation system while Circored ${ }^{\circledR}$ operates the circulating FB system. However, these processes are known to face serious problems at high temperatures ( $\gtrsim 800^{\circ} \mathrm{C}$ ), due to particle sticking. At present, none of these processes operate at an industrial scale (Nuber, Eichberger and Rollinger, 2006; Schenk, 2011).

In general, the FB technology operates in multi-reactors with a counter-current flow of raw materials and reducing gases (Kunii and Levenspiel, 1977; Schenk, 2011; Pichler et al., 2016). Figure 2.13 shows a typical schematic diagram for a FB reactor system.

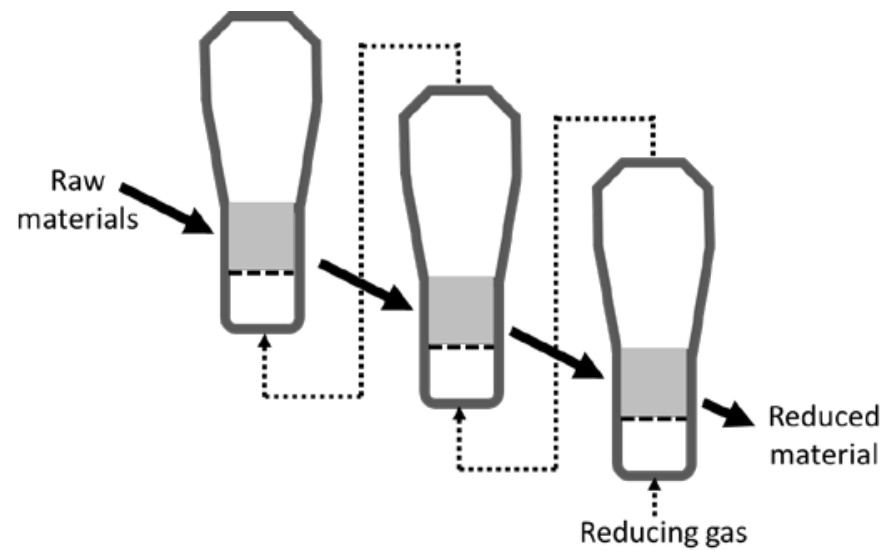

Figure 2.13 A typical flowsheet diagram in the operation of FB technology. Dotted arrow indicates the gas stream. Solid arrow indicates the iron ore stream.

There are two other direct reduction technologies that use FB process in their system, FINEX $^{\circledR}$ and HIsmelt ${ }^{\circledR}$ (Schenk, 2011; Yi, Cho and Yi, 2018; Goodman, 2019). In these processes, the FB process is only used as a pre-reduction stage. In HIsmelt ${ }^{\circledR}$, iron ores are pre-reduced to contain only magnetite and wüstite, without metallic iron. In FINEX ${ }^{\circledR}$, the output from the FB pre-reduction stage is direct reduced iron with a metallisation of $\sim 60 \%$ (Yi, Cho and Yi, 2018). The pre-reduced ores are then finally reduced by coal in a smeltingreduction furnace (for FINEX ${ }^{\circledR}$, it is specifically called melter-gasifier).

HIsmelt ${ }^{\circledR}$ uses a CFB system at temperatures $\sim 800^{\circ} \mathrm{C}$ with natural gas as the reducing gas. The application of the CFB in HIsmelt ${ }^{\circledR}$ faced many problems during the 
commissioning period in Kwinana, Australia. One of the problems was particles sticking to the walls in the thinner section of the pipe. The operation started from 2005 and stopped in 2008.

By contrast, the application of the bubbling FB in the FINEX ${ }^{\circledR}$ has been a success. FINEX ${ }^{\circledR}$ use four sequential reactors of the bubbling FB system at temperatures $\sim 700^{\circ} \mathrm{C}$. The reducing gas in a mixture of $\mathrm{CH}_{4}, \mathrm{CO}$, and $\mathrm{H}_{2}$ gases. From 2008 to 2017, the commercial FINEX ${ }^{\circledR}$ plant has reached a total production of 20 million tons of hot metal (Yi, Cho and Yi, 2018). The key point of success for FINEX ${ }^{\circledR}$ seems to be the operating temperature, which is controlled at temperatures $\sim 700^{\circ} \mathrm{C}$. The reduction is incomplete ( $60 \%$ metallisation), but this is not a problem as the final reduction takes place in the melter-gasifier.

\subsection{The 'sticking' problem in FB reduction of iron ores}

\subsubsection{Particle sticking in the FB reduction of hematite ores}

'Sticking' is a serious problem for the industrial application of FB iron ore reduction. When sticking occurs, particles become agglomerated during FB operation, resulting in a fixed bed which retards the movement of adjacent particles. Fluidisation is then interrupted, no longer mixing particles, and the operation needs to be shut down. Sticking is a 'runaway' effect, which can build up across the entire bed in a short time. Its onset can be identified from the rapid decrease of $\Delta P$ across the bed.

Sticking behaviour is strongly affected by the operating temperature, superficial gas velocity, and ore type. Previous literature has reported that sticking occurs with hematite ore at temperatures $\geq 800^{\circ} \mathrm{C}$ (Gransden and Sheasby, 1974; Komatina and Gudenau, 2004; Zhang, Lei and Zhu, 2014). In the case of gas velocity, the sticking temperature increases with an increase in superficial gas velocity (Gudenau et al., 1989; Hayashi, Sayama and Iguchi, 1990), probably because the particles experience more collisions between each other during fluidisation with an increased superficial velocity.

In the case of ore type, iron ore containing low levels of gangue material has been reported to have a high sticking tendency (Hayashi and Iguchi, 1992; Miyagawa, Kamijo and Deguchi, 1992). Table 2.5 presents a brief summary from literature regarding the sticking tendency for different ores. 
Table 2.5 Sticking tendency for different types of ore and associated reduction conditions.

\begin{tabular}{|c|c|c|c|c|c|c|c|}
\hline Author & Sample material & Pre-treatment & Gas mixture & Temperature $\left({ }^{\circ} \mathrm{C}\right)$ & $\begin{array}{l}\text { Reduction time } \\
\text { (min) }\end{array}$ & $\begin{array}{l}\text { Metallisation } \\
(\%)\end{array}$ & Sticking \\
\hline \multirow{5}{*}{$\begin{array}{l}\text { Hayashi and } \\
\text { Iguchi, } 1992\end{array}$} & $\begin{array}{l}\text { Low gangue content } \\
\text { iron ore } \\
\end{array}$ & \multirow{5}{*}{ None } & \multirow{5}{*}{$\mathrm{H}_{2}$} & \multirow{5}{*}{900} & - & - & Yes \\
\hline & $\begin{array}{c}\text { High } \mathrm{Al}_{2} \mathrm{O}_{3} \text { content } \\
\text { iron ore }\end{array}$ & & & & \multirow{4}{*}{15} & \multirow{2}{*}{$\begin{array}{c}\text { Varied } \\
\text { between 50\% } \\
\text { and } 90 \%\end{array}$} & No \\
\hline & $\begin{array}{l}\text { High } \mathrm{Al}_{2} \mathrm{O}_{3} \text { and } \mathrm{MgO} \\
\text { content iron ore }\end{array}$ & & & & & & No \\
\hline & $\begin{array}{c}\text { High } \mathrm{SiO}_{2} \text { content iron } \\
\text { ore }\end{array}$ & & & & & - & Yes \\
\hline & $\begin{array}{c}\text { High MgO content } \\
\text { iron ore }\end{array}$ & & & & & - & Yes \\
\hline \multirow{3}{*}{$\begin{array}{c}\text { Miyagawa, } \\
\text { Kamijo and } \\
\text { Deguchi, } 1992\end{array}$} & $\begin{array}{l}\text { Low gangue content } \\
\text { iron ore } \\
\end{array}$ & \multirow{3}{*}{ None } & \multirow{3}{*}{$\mathrm{H}_{2} \& \mathrm{CO}$} & \multirow{3}{*}{850} & - & - & Yes \\
\hline & $\begin{array}{c}\text { High } \mathrm{Al}_{2} \mathrm{O}_{3} \text { content } \\
\text { iron ore }\end{array}$ & & & & \multirow{2}{*}{120} & \multirow{2}{*}{$\begin{array}{c}\text { Varied } \\
\text { between } 70 \% \\
\text { and } 90 \%\end{array}$} & No \\
\hline & $\begin{array}{c}\text { High } \mathrm{Al}_{2} \mathrm{O}_{3} \text { and } \mathrm{MgO} \\
\text { content iron ore }\end{array}$ & & & & & & No \\
\hline \multirow{7}{*}{$\begin{array}{c}\text { Shannon, Kitt } \\
\text { and Marshall, } \\
1960\end{array}$} & \multirow{7}{*}{ Patea ironsand } & \multirow{4}{*}{ Oxidized } & \multirow{2}{*}{$\mathrm{H}_{2}$} & 900 & 198 & 70 & No \\
\hline & & & & 1000 & - & - & Yes \\
\hline & & & \multirow{2}{*}{$\mathrm{CO}$} & 750 & 360 & 45 & No \\
\hline & & & & 900 & - & - & Yes \\
\hline & & \multirow{3}{*}{ None } & \multirow{2}{*}{$\mathrm{H}_{2}$} & 900 & 270 & 71 & No \\
\hline & & & & 1000 & - & - & Yes \\
\hline & & & $\mathrm{CO}$ & 800 & 480 & $<15$ & Yes \\
\hline \multirow{2}{*}{$\begin{array}{l}\text { H. Sun et al. } \\
\text { (Sun et al., } \\
\text { 2016, 2017) }\end{array}$} & \multirow[b]{2}{*}{ South African TTM } & Oxidized & $\mathrm{CO}$ & 850 & \multirow[b]{2}{*}{120} & $\sim 90$ & No \\
\hline & & None & $\mathrm{CO}$ & 950 & & $\sim 90$ & No \\
\hline
\end{tabular}

The hyphen sign in the table means that the reduction is stopped, as a result of the particle sticking 
The shape of ore particles also influences the sticking tendency (Hayashi and Iguchi, 1992). Spheroidal shapes have been reported to show less sticking tendency than rectangular prism and angular types in the reduction by $\mathrm{H}_{2}$ gas at $900^{\circ} \mathrm{C}$, as shown in Table 2.6 (Hayashi and Iguchi, 1992). Particles with high sphericity have a lower bed voidage than rectangular prism and angular type particles. In that work, the $U_{m f}$ of spheroid particles was found to be approximately half that of the rectangular prisms and angular types (Hayashi and Iguchi, 1992). Non-spheroidal particles have more complex shapes and a lower drag coefficient than the spheroid type. This results in a higher surface area for particles to contact each other and a higher friction between particles during the fluidisation (Hayashi and Iguchi, 1992).

Table 2.6 Sticking tendency for different shapes of ores (Hayashi and Iguchi, 1992).

Reproduced with permission of The Iron and Steel Institute of Japan.

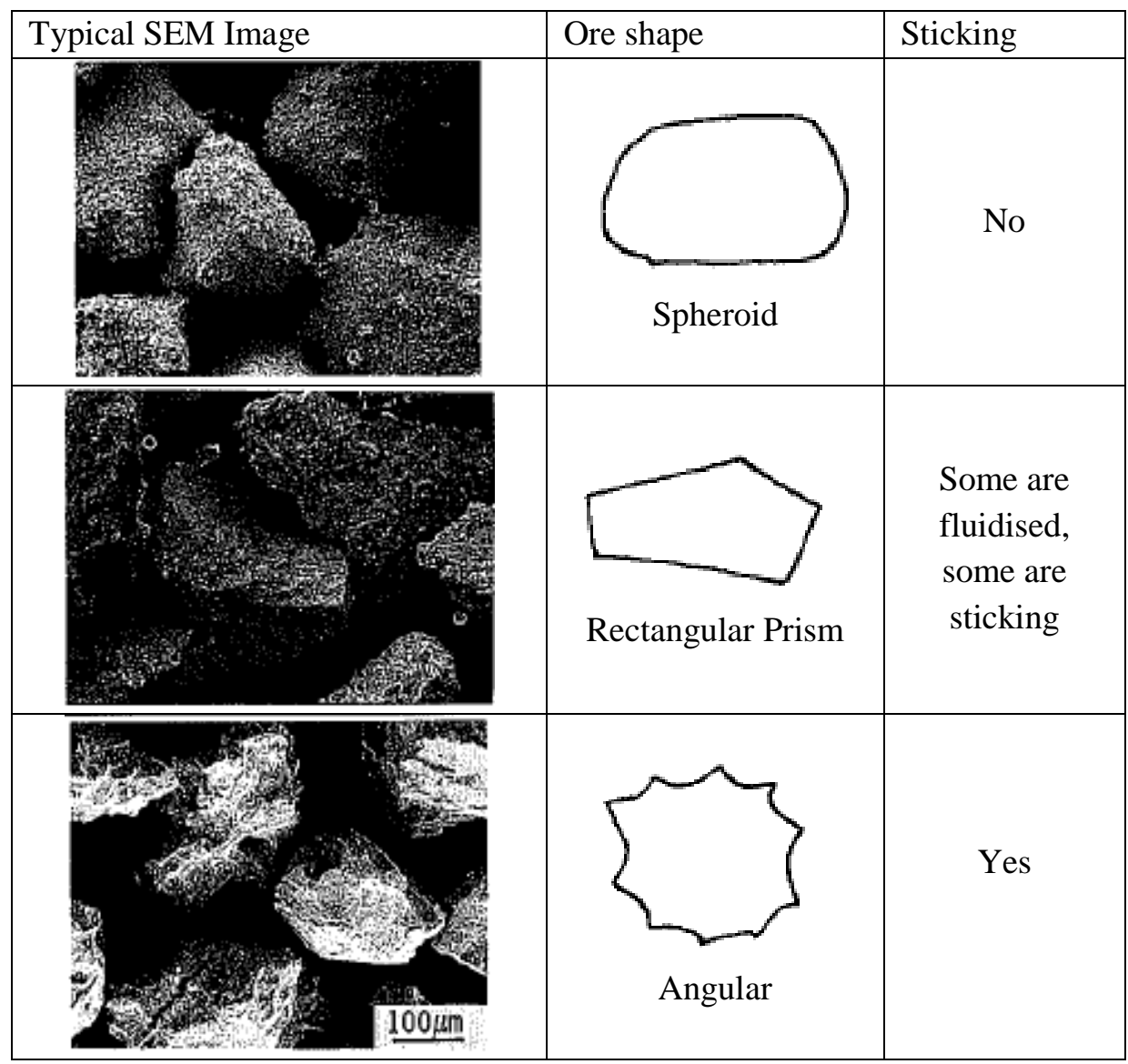

Sticking of hematite iron ore particles has been reported to occur due to the following three distinct differing causes:

\section{Formation of fibrous iron}

This 'sticking' usually occurs in the reduction by $\mathrm{H}_{2}$ or $\mathrm{CO}$ gas at temperatures $\geq 700^{\circ} \mathrm{C}$ (Gransden and Sheasby, 1974; Hayashi and Iguchi, 1992; Zhang, Lei and Zhu, 2014). A 
number of researchers have reported that the microstructure of this precipitate has a fibrous shape - with whisker-like structures observed on the surface of particles (Gransden and Sheasby, 1974; Hayashi, Sayama and Iguchi, 1990; Hayashi and Iguchi, 1992; Zhang, Lei and Zhu, 2014). Figure 2.14 shows two SEM image examples of whisker structure on a reduced iron particle. These fibrous particles can become entangled with each other upon contact between particles. As the metallisation is proceeding, the iron grains grow on the particle surface. The particles then become agglomerated and this effect spreads across the whole bed.
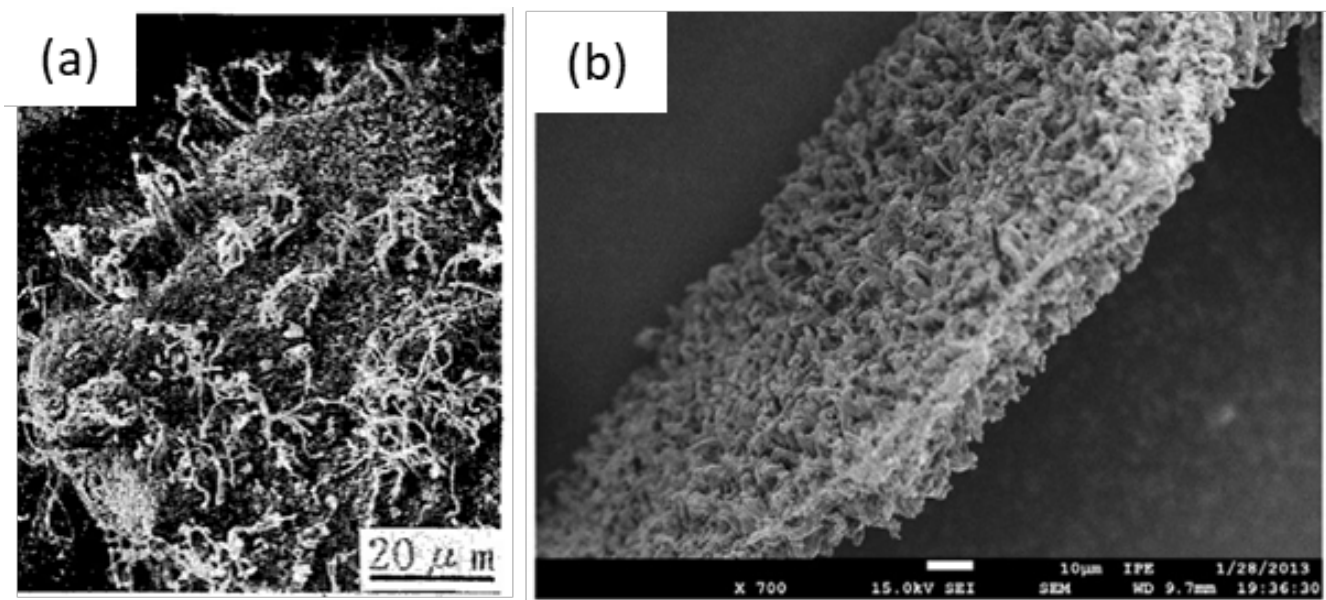

Figure 2.14 Fibrous and whisker structure of reduced iron reported by Hayashi, Sayama and Iguchi, 1990 (a) and Zhang, Lei and Zhu, 2014 (b). Image (a) is reproduced with permission of The Iron and Steel Institute of Japan. Image (b) is reproduced with permission of Elsevier through Copyright Clearance Centre.

\section{Formation of newly formed metallic iron without the fibrous structure}

The main cause for this case is the sintering of metallic iron upon contact between particles. This is reported to occur as a result of the high surface energy of newly formed metallic iron from wüstite (Nicolle and Rist, 1979; Hayashi and Iguchi, 1992; Komatina and Gudenau, 2004; Guo et al., 2020). The higher the surface energy, the stronger the adhesive properties of iron. This phenomenon is mainly observed at high temperatures $\left(\geq 900^{\circ} \mathrm{C}\right)$, high metallisation ratios, and prolonged time frames. Zhang et al., 2011 also reported the surface energy of the iron crystal increases above the Tamman temperature $\left(\sim 550^{\circ} \mathrm{C}\right)$, where the solidphase reaction starts to begin. Shao, Guo and Tang, 2011 reported that sticking occurred in the high temperature fluidisation of iron powders, even without a fibrous or whisker structure. Their findings indicated that the iron powder does not agglomerate at temperatures below $650^{\circ} \mathrm{C}$. The iron powder slowly agglomerates at $650^{\circ} \mathrm{C}$, and then rapidly agglomerates at temperatures above $650^{\circ} \mathrm{C}$. 
3. Formation of a low melting point multi-component phase between wüstite and gangue materials in the ore.

In this case, sticking is initiated when the ore is converted to wüstite. Wüstite with gangue contents like $\mathrm{CaO}$ and $\mathrm{SiO}_{2}$, may form a low temperature multi-component phase of $\mathrm{CaO}-\mathrm{SiO}_{2}$ FeO (Ross, 1980; Komatina and Gudenau, 2004; Zhang et al., 2011). This phase can soften, melt, and stick together in iron ore particles at high temperature $\left(\geq 900^{\circ} \mathrm{C}\right)$. If this phase is formed on the surface of the iron ore particles during FB reduction, it can soften and "glue" the particles together, and eventually spreads across the whole bed.

\subsubsection{Previous reports related to the sticking in FB reduction of TTM ores.}

As far as the author is aware, there are only two reports dealing with FB reduction of TTM ore. The first is an old paper which studied the FB reduction NZ TTM ironsand by $\mathrm{H}_{2}$ and CO gas separately (Shannon, Kitt and Marshall, 1960). The second is a more recent paper which studied the FB reduction of South African TTM ore (lump rock) by CO gas (Sun et al., 2016).

In the case of CO reduction study of South African TTM ore by Sun et al. (2016), the reactor is the bubbling-type FB reactor made from quartz. The titanium content in the South African TTM ore is 13.7 wt.\% as $\mathrm{TiO}_{2}$. The authors did not report any sticking behaviour during the reduction by $\mathrm{CO}$ gas at temperatures up to $950^{\circ} \mathrm{C}$. However, the reason why the TTM ore particles did not stick was not identified.

In the study by Shannon, Kitt and Marshall (1960), they used Patea TTM ironsand with a titanium content of 8.2 wt.\% as $\mathrm{TiO}_{2}$. The reactor used is a spouted-type FB reactor constructed from Inconel, as illustrated in Figure 2.15(a). In this study, no sticking was reported in the hydrogen reduction of ironsand at temperatures up to $900^{\circ} \mathrm{C}$. This temperature is higher from the onset sticking temperature for hematite ores (see Section 2.7.2). However, the reason why TTM ore particles did not stick was not identified.

The particle sticking started to occur during the reduction by $\mathrm{H}_{2}$ at $1000^{\circ} \mathrm{C}$, with particles adhered to the reactor wall, as illustrated in Figure 2.15(b). In the reduction by CO gas, the particle sticking started to occur at $800^{\circ} \mathrm{C}$. However, the sticking mechanism in these cases are not clearly understood as there was no clear microstructure analysis for the sintered ironsands. Therefore, the sticking behaviour for NZ TTM ironsand during the FB reduction requires further investigation 


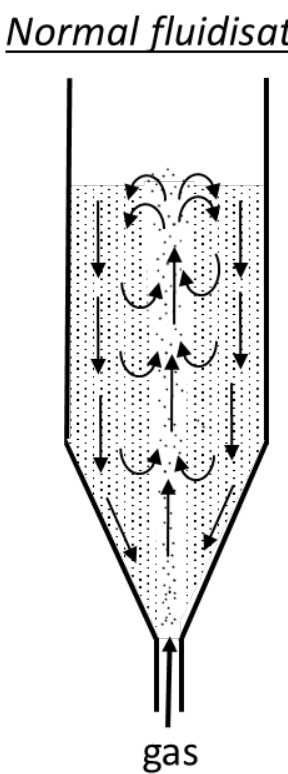

(a)

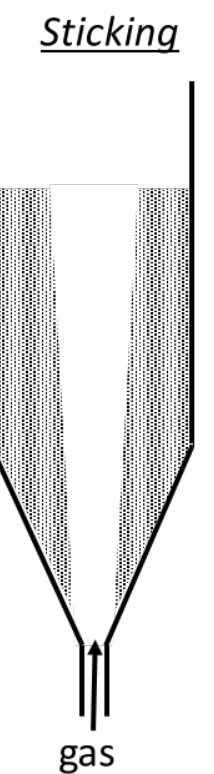

(b)

Figure 2.15 Schematic diagrams of spouted type FB (re-drawn from Shannon, Kitt and Marshall, 1960). Image (a) is the condition when the bed is fluidised normally. Image (b) is the condition when the bed stuck. Black arrows indicate the flow of particles.

\subsubsection{Previously proposed strategies to prevent sticking during FB reduction of hematite ore}

There have been investigations on various methods to prevent sticking in FB reduction of hematite iron ore. This section presents some particle sticking prevention methods that could be applied if particle sticking occurs during the reduction of NZ TTM ironsand. Table 2.7 presents a summary of various methods which have been experimentally demonstrated by researchers. In brief, the coating of ore particles with either inert oxides or carbon has been reported to be effective for preventing particle sticking at a selected temperature range. The purpose of these methods is to provide a protective layer at the particle surface which prevents iron to iron contact between particles. Coating hematite ores with inert oxides such as $\mathrm{MgO}$ and $\mathrm{CaO}$ has been reported to effectively prolong the fluidisation at temperatures up to $800^{\circ} \mathrm{C}$ (Shao, Guo and Tang, 2013; Zhong et al., 2013). At temperatures up to $900^{\circ} \mathrm{C}$, coating hematite ores with alumina $\left(\mathrm{Al}_{2} \mathrm{O}_{3}\right)$ was reported to prevent particle sticking (Hayashi, Sawai and Iguchi, 1993). Coating of hematite ores with carbon was also reported to effectively resist sticking at temperatures up to $900^{\circ} \mathrm{C}$. There were three carbon sources for this method; coal, heavy oil, and CO (Watanabe et al., 1986; Miyagawa, Kamijo and Deguchi, 1992; Zhang, Lei and Zhu, 2014). 
Table 2.7 Summary of the sticking prevention methods investigated at different reducing conditions.

\begin{tabular}{|c|c|c|c|c|c|c|c|c|c|c|}
\hline \multirow{2}{*}{ Author } & \multirow{2}{*}{ Sample material } & \multirow{2}{*}{ Pre-treatment } & \multirow{2}{*}{ Gas mixture } & \multirow{2}{*}{$\begin{array}{l}\text { Reduction } \\
\text { time (min) }\end{array}$} & \multicolumn{3}{|c|}{ Metallisation (\%) } & \multicolumn{3}{|c|}{ Sticking } \\
\hline & & & & & $700^{\circ} \mathrm{C}$ & $800^{\circ} \mathrm{C}$ & $900^{\circ} \mathrm{C}$ & $700^{\circ} \mathrm{C}$ & $800^{\circ} \mathrm{C}$ & $900^{\circ} \mathrm{C}$ \\
\hline \multirow{9}{*}{$\begin{array}{c}\text { Hayashi, } \\
\text { Sawai and } \\
\text { Iguchi, } 1993\end{array}$} & \multirow{3}{*}{ Carajas hematite ore } & None & \multirow{9}{*}{$\begin{array}{c}33 \% \mathrm{~N}_{2}-67 \% \\
\mathrm{H}_{2}\end{array}$} & \multirow{9}{*}{15} & \multirow{9}{*}{$\begin{array}{c}\text { Not } \\
\text { performed }\end{array}$} & \multirow{9}{*}{$\begin{array}{c}\text { Not } \\
\text { performed }\end{array}$} & - & \multirow{9}{*}{$\begin{array}{c}\text { Not } \\
\text { performed }\end{array}$} & \multirow{9}{*}{$\begin{array}{c}\text { Not } \\
\text { performed }\end{array}$} & Yes \\
\hline & & $\mathrm{Al}_{2} \mathrm{O}_{3}$ powder addition & & & & & $\sim 90$ & & & No \\
\hline & & Slurry coating by $\mathrm{Al}_{2} \mathrm{O}_{3}$ & & & & & $\sim 90$ & & & No \\
\hline & \multirow{3}{*}{ Carajas hematite ore } & None & & & & & - & & & Yes \\
\hline & & $\mathrm{Al}_{2} \mathrm{O}_{3}$ powder addition & & & & & - & & & Yes \\
\hline & & Slurry coating by $\mathrm{Al}_{2} \mathrm{O}_{3}$ & & & & & $\sim 90$ & & & No \\
\hline & \multirow{3}{*}{$\begin{array}{l}\text { Yampi Sound } \\
\text { hematite ore }\end{array}$} & None & & & & & - & & & Yes \\
\hline & & $\mathrm{Al}_{2} \mathrm{O}_{3}$ powder addition & & & & & $\sim 90$ & & & No \\
\hline & & Slurry coating by $\mathrm{Al}_{2} \mathrm{O}_{3}$ & & & & & $\sim 90$ & & & No \\
\hline \multirow{2}{*}{$\begin{array}{l}\text { Zhong et al., } \\
2013\end{array}$} & \multirow{2}{*}{ Hematite powder } & Solution coating by MgO & \multirow{2}{*}{$\begin{array}{c}50 \% \mathrm{~N}_{2}-50 \% \\
\mathrm{CO}\end{array}$} & \multirow{2}{*}{$50-83$} & \multirow{2}{*}{$\begin{array}{c}\text { Not } \\
\text { mentioned }\end{array}$} & \multirow{2}{*}{$\begin{array}{c}\text { Not } \\
\text { mentioned }\end{array}$} & - & No & No & Yes \\
\hline & & Solution coating by $\mathrm{CaO}$ & & & & & - & No & No & Yes \\
\hline \multirow{3}{*}{$\begin{array}{l}\text { Shao, Guo } \\
\text { and Tang, } \\
2013\end{array}$} & \multirow{3}{*}{ Hematite ore } & None & \multirow{3}{*}{$\begin{array}{c}30 \% \mathrm{H}_{2}-70 \% \\
\mathrm{CO}\end{array}$} & - & \multirow{3}{*}{$\begin{array}{c}\text { Not } \\
\text { performed }\end{array}$} & - & \multirow{3}{*}{$\begin{array}{c}\text { Not } \\
\text { performed }\end{array}$} & \multirow{3}{*}{$\begin{array}{c}\text { Not } \\
\text { performed }\end{array}$} & Yes & \\
\hline & & MgO Powder addition & & \multirow{2}{*}{83} & & $\sim 80$ & & & No & $\begin{array}{l}\text { Not } \\
\text { Norformed }\end{array}$ \\
\hline & & Solution coating by $\mathrm{MgO}$ & & & & $\sim 80$ & & & No & \\
\hline & & None & & - & - & - & - & Yes & Yes & Yes \\
\hline al., 1986 & $\begin{array}{l}\text { Rio Doce nematile } \\
\text { ore }\end{array}$ & $\begin{array}{c}\text { Carbon coated by heavy } \\
\text { oil cracking }\end{array}$ & $100 \% \mathrm{H}_{2}$ & $40-70$ & $\sim 90$ & $\sim 90$ & $\sim 90$ & No & No & No \\
\hline Miyagawa, & & None & & & - & - & - & & Yes & Yes \\
\hline $\begin{array}{l}\text { Kamijo and } \\
\text { Deguchi, } \\
1992\end{array}$ & Hematite ore & Carbon coated by coal & $\begin{array}{c}20 \% \mathrm{H}_{2}-80 \% \\
\text { CO }\end{array}$ & 120 & - & $\sim 90$ & $\sim 90$ & $\begin{array}{c}\text { Not } \\
\text { performed }\end{array}$ & No & No \\
\hline & & & $100 \% \mathrm{H}_{2}$ & & - & - & & Yes & Yes & \\
\hline & & None & $\begin{array}{c}80 \% \mathrm{H}_{2}-20 \% \\
\mathrm{CO}\end{array}$ & 60 & $\sim 80$ & - & $\begin{array}{c}\text { Not } \\
\text { performed }\end{array}$ & No & Yes & $\begin{array}{c}\text { Not } \\
\text { performed }\end{array}$ \\
\hline Zhang, Lei & Brazil hematite ore & & $100 \%$ CO & & - & - & & Yes & Yes & \\
\hline $\begin{array}{l}\text { and Znu, } \\
2014\end{array}$ & Brazı nematite ore & $\begin{array}{c}\text { Carbon coated by carbon } \\
\text { deposition }\end{array}$ & $100 \% \mathrm{H}_{2}$ & 30 & & $\sim 90$ & - & & Yes & Yes \\
\hline & & $\begin{array}{c}\text { Carbon coated by carbon } \\
\text { deposition }\end{array}$ & $\begin{array}{c}80 \% \mathrm{H}_{2}-20 \% \\
\mathrm{CO} \\
\end{array}$ & 60 & performed & $\sim 90$ & $\sim 90$ & performed & No & No \\
\hline $\begin{array}{l}\text { Zhang et al., } \\
2013\end{array}$ & Hematite powder & $\begin{array}{c}\text { Carbon coated by carbon } \\
\text { deposition }\end{array}$ & $100 \% \mathrm{CO}$ & 60 & $\begin{array}{c}\text { Not } \\
\text { performed }\end{array}$ & $\sim 90$ & $\begin{array}{c}\text { Not } \\
\text { performed }\end{array}$ & $\begin{array}{c}\text { Not } \\
\text { performed }\end{array}$ & No & $\begin{array}{c}\text { Not } \\
\text { performed }\end{array}$ \\
\hline $\begin{array}{l}\text { Lei et al., } \\
\quad 2015\end{array}$ & Brazil hematite ore & $\begin{array}{c}\text { Carbon coated by carbon } \\
\text { deposition }\end{array}$ & $100 \%$ CO & 20 & $\begin{array}{c}\text { Not } \\
\text { performed }\end{array}$ & $\sim 90$ & $\begin{array}{c}\text { Not } \\
\text { performed }\end{array}$ & $\begin{array}{c}\text { Not } \\
\text { performed }\end{array}$ & No & $\begin{array}{c}\text { Not } \\
\text { performed }\end{array}$ \\
\hline
\end{tabular}

The hyphen sign in the table means that the reduction is stopped, as a result of the particle sticking 


\subsection{Summary of lessons from the literature}

A key difference between the TTM ores and conventional hematite and magnetite ores is the titanium content. This makes the reduction rate of TTM ores slower than hematite ores because the titanium in TTM stabilises the spinel structure. In general, the reduction rate of TTM ores can be increased by either increasing the temperature or concentration of hydrogen gas.

In designing a FB reactor, three important points need to be considered. First, fluidisation needs to be operated with a gas velocity between the $U_{m f}$ and the $U_{t}$. Second, a sintered porous distributor is a preferred choice as it has many gas pathways which can result in many small bubbles and a higher possibility for gas-solid contact. Third, the total freeboard height of a reactor must be at least higher than the TDH to minimize the entrainment of particles.

Particle sticking is the key obstacle to the application of FB technology in direct reduction of iron ores. Operating temperature and ore type strongly affect the sticking behaviour of ore particles. Hematite ore particles stick during FB reduction in $\mathrm{H}_{2}$ gas at temperatures $\geq 800^{\circ} \mathrm{C}$. A previous study reported that NZ ironsand particles do not stick at during the $\mathrm{FB}$ reduction in $\mathrm{H}_{2}$ gas at up to $900^{\circ} \mathrm{C}$. However, the reason for this is not clear, and the report on sticking behaviour is incomplete.

Most proposed sticking prevention methods use the idea of coating the ore particles with either inert oxides or carbon. Coating with $\mathrm{MgO}$ or $\mathrm{CaO}$ was effective to prevent the particle sticking at up to $800^{\circ} \mathrm{C}$ in $\mathrm{CO}$ gas, while coating with $\mathrm{Al}_{2} \mathrm{O}_{3}$ or carbon was effective at up to $900^{\circ} \mathrm{C}$ in $\mathrm{H}_{2}$ gas. Once the reduction temperature exceeds $900^{\circ} \mathrm{C}$, the growth of iron at the particle surface are the leading cause of sticking regardless of the pre-treatment. While all methods have been experimentally demonstrated for hematite ores, none of them have been investigated using TTM ironsand. 


\section{Chapter 3}

\section{Materials and Methods}

\subsection{Outline}

This chapter describes the raw materials, characterisation methods, and experimental procedures used in this thesis. First, the analysis of particle size, chemical composition, and phases in the raw NZ ironsand concentrate is described. Second, the material characterisation techniques used are presented. In this thesis, X-ray diffraction (XRD) and scanning electron microscopy (SEM) are used to characterise the samples. XRD is used to analyse phases contained in the samples. SEM is used to characterise the microstructure of the samples. Finally, the procedures for the reduction experiments are described. This subsection only provides an overview of the procedure used to perform FB reduction experiments in this thesis. Full details of the FB reactor itself are described in Chapter 4. Specific parameters applied for the reduction experiments are explained in detail in Chapter 6 and Chapter 7, which also present results of the experiments.

\subsection{Material characterisation}

\subsubsection{X-ray diffraction}

The crystal phases within the reduced ironsand were characterized using $\mathrm{x}$-ray diffraction (XRD) (Bruker D8 Advance) with Co $\mathrm{K} \alpha$ radiation, at $0.05^{\circ}$ step size and 2 s/step collection time.

Quantitative XRD analysis (q-XRD) was used to determine the crystal phase composition of each sample by applying Rietveld refinement, and this was performed using Topas 4.2 (Bruker) software. Variables such as specimen background, peak profile (width, shape, asymmetry), crystal size, crystal strain, and preferred orientation of each separate crystal phase were refined. The wt.\% error for each phase in each sample using the Rietvield method was determined to be less than $1 \mathrm{wt} . \%$. The standard deviation for four repeats of the sample analysis was also found to be approximately $\pm 1 \mathrm{wt}$.\%.

The q-XRD analysis has been used to obtain composition changes of the crystalline phases in the samples throughout the FB experiments. Figure 3.1(a) shows an example of a series of XRD patterns obtained from ironsand samples oxidised in air at $800^{\circ} \mathrm{C}$. The 
wt.\% of each crystalline phase was then calculated by the Topas 4.2 software based on fittings of each of the XRD patterns obtained in Figure 3.1(a). Figure 3.1(b) shows an example of the time evolution of each crystalline phase during oxidation by air at $800^{\circ} \mathrm{C}$.

The q-XRD method was also used to determine the metallisation degree of the TTM ironsand during reduction experiments. The metallisation degree (\%met) was calculated from the q-XRD data using equation (3.1).

$$
\% m e t=F e^{o} / F e_{T o t} x 100 \%
$$

The total iron $\left(F e_{T o t}\right)$ is determined as the total iron within all iron-containing phases, whilst the metallic iron $\left(F e^{o}\right)$ is determined as the independent metallic iron phase as detected by XRD. The $F e_{T o t}$ and $F e^{o}$ content was calculated by q-XRD analysis. The accuracy of the q-XRD technique was confirmed by comparisons with standard titration tests (ISO 16878:2016, 2016) on a series of partially reduced magnetite and ironsand samples. The details of the preliminary test results for the comparison between the q-XRD and titration techniques are presented in Section 3.4. This comparison showed close agreement between the q-XRD and titration methods (to within $3 \%$ met), across the full measurement range considered in this work. 


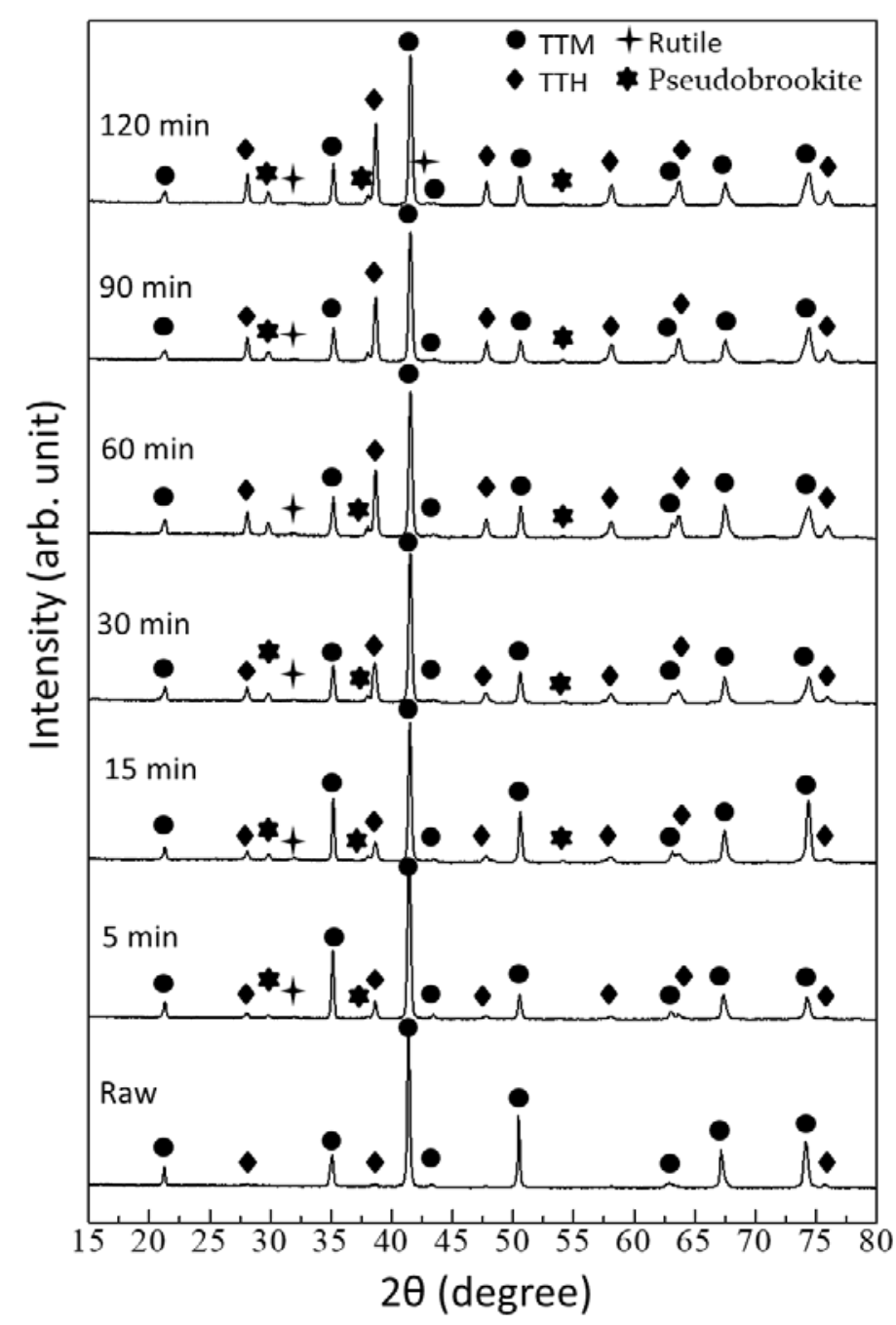

(a)

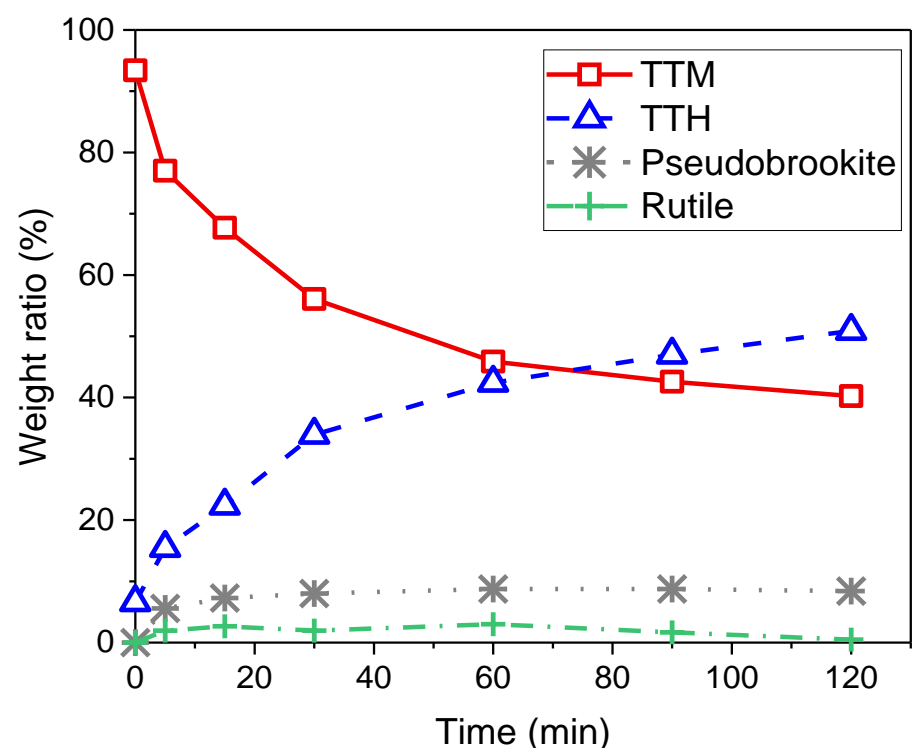

(b)

Figure 3.1 XRD patterns (a) and the evolution of phases (b) as a function of time for irosand oxidised by air at $800^{\circ} \mathrm{C}$. 


\subsubsection{X-ray fluorescence}

The chemical composition of raw ironsand samples was analysed by XRF. The XRF anaysis were performed by CRL Energy Ltd (now Verum Group). XRF samples were prepared following a standard procedure in CRL Energy Ltd. In brief, the sample was oxidized in air at $1000^{\circ} \mathrm{C}$ for one hour prior to analysis. The sample was then mixed with a lithium tetraborate melt as a standard calibration matrix.

\subsubsection{SEM}

Samples for the SEM study were prepared through two methods depending on the purpose of the sample observation. For the observation of the sample's surface morphology, powder samples were put directly on adhesive carbon tape mounted on a sample stage.

For the observation of the sample's cross-section morphology, the powder samples were mounted into an epoxy resin mould. The samples were then ground using SiC paper from \#220 to \#4000 grade, and then polished with $3 \mu \mathrm{m}$ and $1 \mu \mathrm{m}$ diamond paste. The polished samples were then carbon coated before placing in the SEM.

The microstructures of the samples were examined using a field-emission scanning electron microscope (FEG-SEM, FEI, Nova 450) at $20 \mathrm{kV}$. Elemental spot analysis and mapping were analyzed using an integrated energy dispersed spectroscopy (EDS) detector at $15 \mathrm{kV}$.

\subsubsection{Mastersizer $\mathbf{3 0 0 0}$}

Particle size distributions (PSD) of raw ironsand samples were analysed using Malvern Mastersizer 3000 with a wet dispersion unit, Hydro-EV. The instrument uses laser diffraction to analyse particle size in the sample. The light sources are a $632.8 \mathrm{~nm}$ red light and a $470 \mathrm{~nm}$ blue light. The instrument is capable of analysing particle sizes in the range 0.01-3500 $\mu \mathrm{m}$.

For PSD analysis, a bulk sample of $1 \mathrm{~kg}$ of the raw ironsand concentrate was riffled by a large riffler, and subsequently a rotary micro riffler, to obtain a representative sample of about $5 \mathrm{~g}$. The sample is then dispersed in de-ionised water by the Hydro-EV unit. During the PSD measurement, ultrasound from the Hydro-EV unit was used to break any agglomerated particles. 


\subsection{Characterisation of raw NZ ironsand concentrate}

The ironsand material studied in this work was TTM ironsand concentrate from Waikato North Head (WNH) mine. It has a density of about $5102 \mathrm{~kg} / \mathrm{m}^{3}$, which was measured with a pycnometer. The PSD analysis of the raw ironsand concentrate is presented in Figure 3.2. In the Figure, D10 is the diameter at which $10 \%$ of the cumulative mass is comprised of particles with a diameter less than this value, D50 is the diameter at which $50 \%$ of the cumulative mass is comprised of particles with a diameter less than this value, and D90 is the diameter at which $90 \%$ of the cumulative mass is comprised of particles with a diameter less than this value. The figure shows that the PSD of the raw concentrate is in the range of about $60-250 \mu \mathrm{m}$.

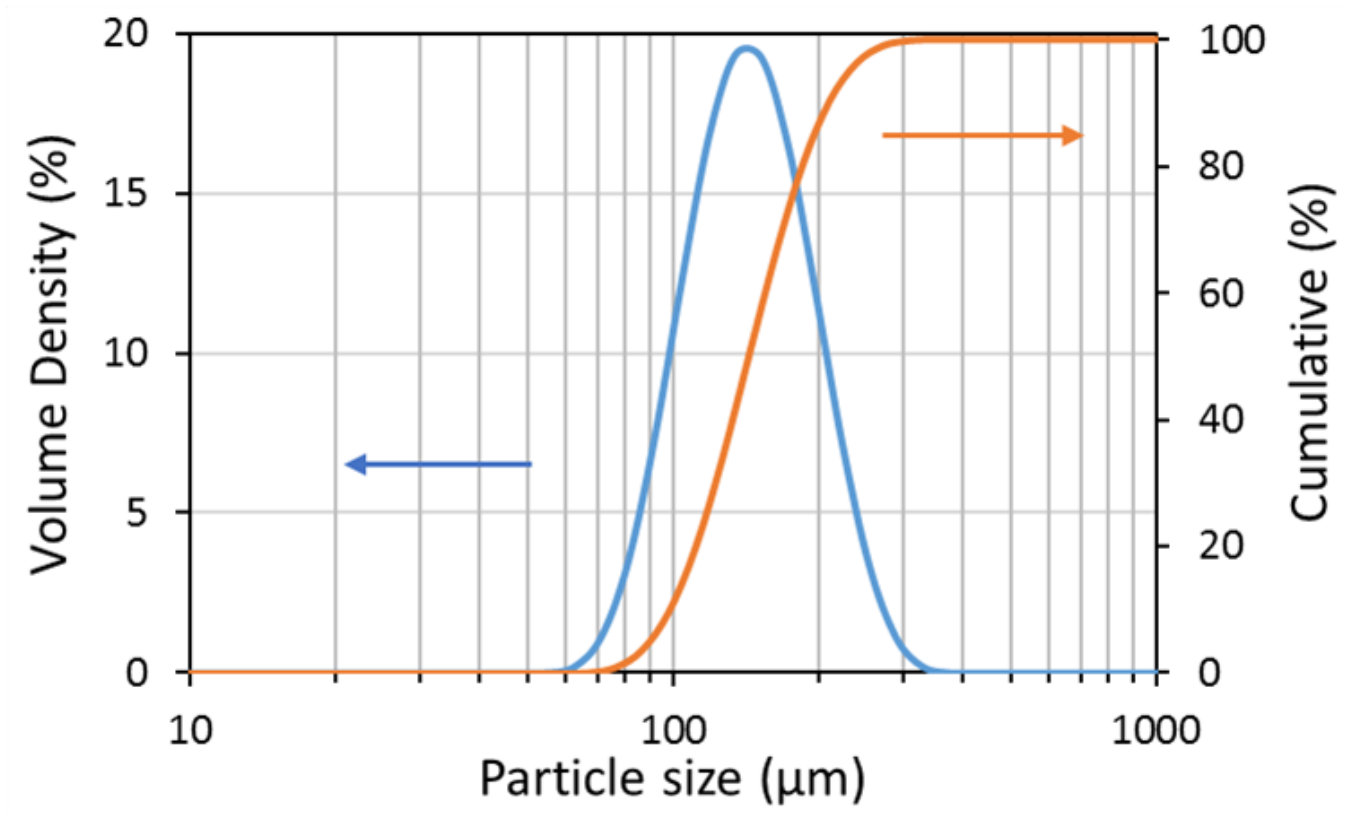

Figure 3.2 PSD of the as-received raw ironsand concentrate. D10=98 $\mu \mathrm{m}, D 50=144 \mu \mathrm{m}$, and $\mathrm{D} 90=210 \mu \mathrm{m}$.

The particle size of ironsand concentrate samples used for most of the experiments in this thesis was a size sieved fraction screened between 106 and $125 \mu \mathrm{m}$. This size fraction corresponds to the average particle size of the as-received raw concentrate (see Figure 3.2). Other size fractions of 63-90 $\mu \mathrm{m}, 125-150 \mu \mathrm{m}$, and 150-180 $\mu \mathrm{m}$ were also used for experiments in Chapter 6. The preparation and the procedure of the PSD analysis is the same as that used for the as-received raw concentrate. The results of the PSD analysis for ironsand concentrate for all of these size fractions is presented in Figure 3.3. 


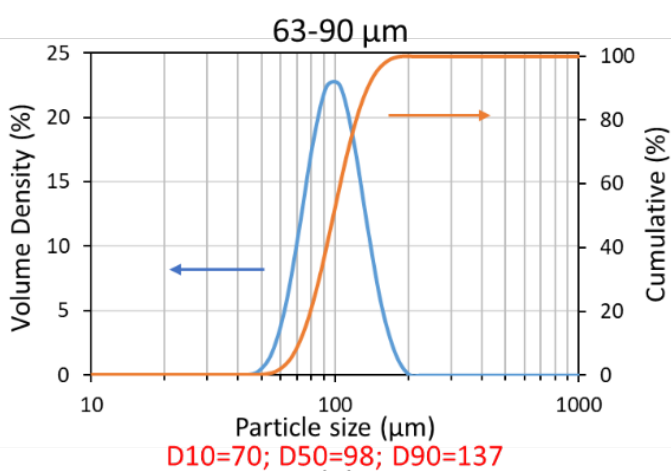

(a)

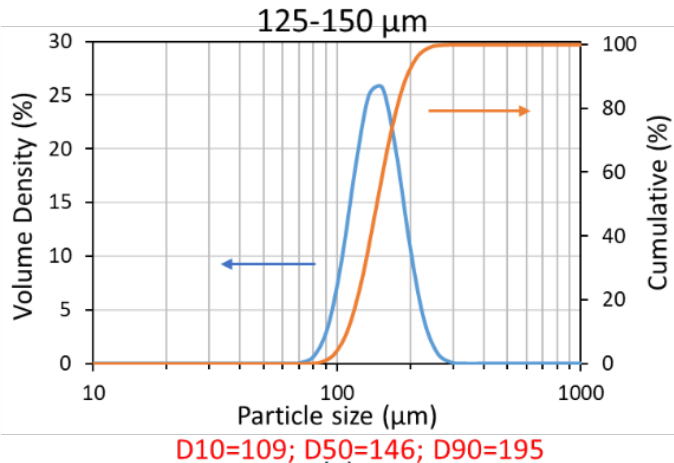

(c)

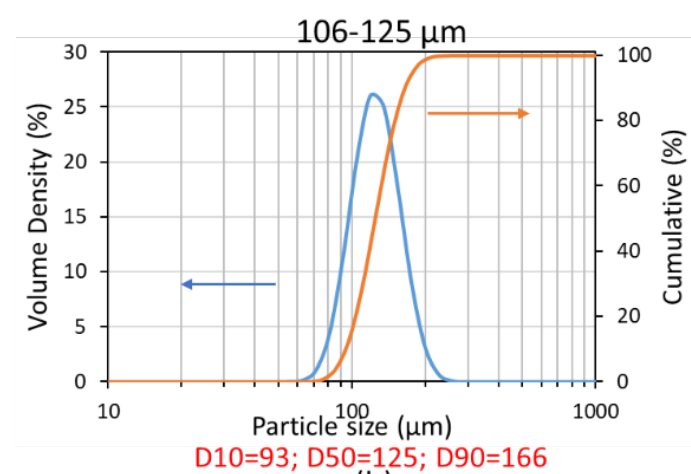

(b)

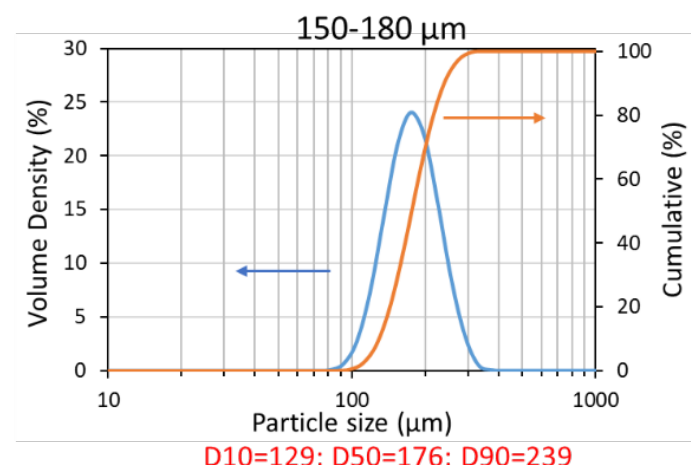

(d)

Figure 3.3 PSD of different particle size fractions of raw ironsand concentrate. (a): 63-90 $\mu \mathrm{m},(\mathrm{b}):$ 106-125, (C): 125-150 $\mu \mathrm{m}$, and (d): 125-150 $\mu \mathrm{m}$.

Table 3.1 presents the XRF results for the composition of the raw concentrate for different particle size fractions. The XRF approach reports as mass\% of equivalent oxides. This has been converted to an Fe mass\% in the unoxidized sample by assuming that all mass change is due solely to oxygen uptake resulted from the oxidation (during sample preparation). From the table, the chemical composition of the raw ironsand is similar for each particle size fraction.

Table 3.1 Chemical composition of the raw ironsand concentrate for different particle size fractions in the oxidized state as measured by XRF

\begin{tabular}{cccccccccc}
\hline \multicolumn{7}{c}{ Compositions (equivalent mass\%) } \\
\hline Sample & $\mathrm{Fe}$ & $\mathrm{TiO}_{2}$ & $\mathrm{Al}_{2} \mathrm{O}_{3}$ & $\mathrm{MgO}$ & $\mathrm{MnO}$ & $\mathrm{V}_{2} \mathrm{O}_{5}$ & $\mathrm{P}_{2} \mathrm{O}_{5}$ & $\mathrm{SiO}_{2}$ & $\mathrm{CaO}$ \\
\hline $\begin{array}{c}\text { Non- } \\
\text { sieved }\end{array}$ & 59.1 & 7.9 & 3.8 & 2.8 & $\sim 0.6$ & $\sim 0.6$ & $\sim 0.1$ & $\sim 1.9$ & $\sim 0.4$ \\
\hline $\begin{array}{c}106- \\
125 \mu \mathrm{m}\end{array}$ & 60.7 & 8.1 & 3.4 & 2.6 & $\sim 0.7$ & $\sim 0.6$ & $\sim 0.1$ & $\sim 0.8$ & $\sim 0.2$ \\
\hline $\begin{array}{c}125- \\
150 \mu \mathrm{m}\end{array}$ & 60.5 & 8.1 & 3.5 & 2.6 & $\sim 0.6$ & $\sim 0.6$ & $\sim 0.1$ & $\sim 0.9$ & $\sim 0.2$ \\
\hline $\begin{array}{c}150- \\
180 \mu \mathrm{m}\end{array}$ & 58.7 & 7.9 & 3.7 & 3 & $\sim 0.6$ & $\sim 0.6$ & $\sim 0.1$ & $\sim 2.3$ & $\sim 0.6$ \\
\hline
\end{tabular}


As mentioned in Chapter 2, TTM is a solid solution of magnetite and ulvöspinel. Magnetite and ulvöspinel exhibit identical crystal structures, with only a small change in lattice constant (1.6 \%) (Tanaka and Kono, 1987; Bosi, Hålenius and Skogby, 2009). As such, it is not generally possible to resolve the peak-shift between XRD patterns from TTM containing small differences in $\mathrm{Ti}$ composition, using a standard laboratory XRD instrument. Figure 3.4 shows the XRD patterns obtained from the raw ironsand concentrate for different particle size fractions. It can be seen from this figure that XRD patterns obtained from all particle size fractions are almost identical. The majority of peaks in the ironsand concentrate are from the TTM phase with some small peaks for the TTH phase.

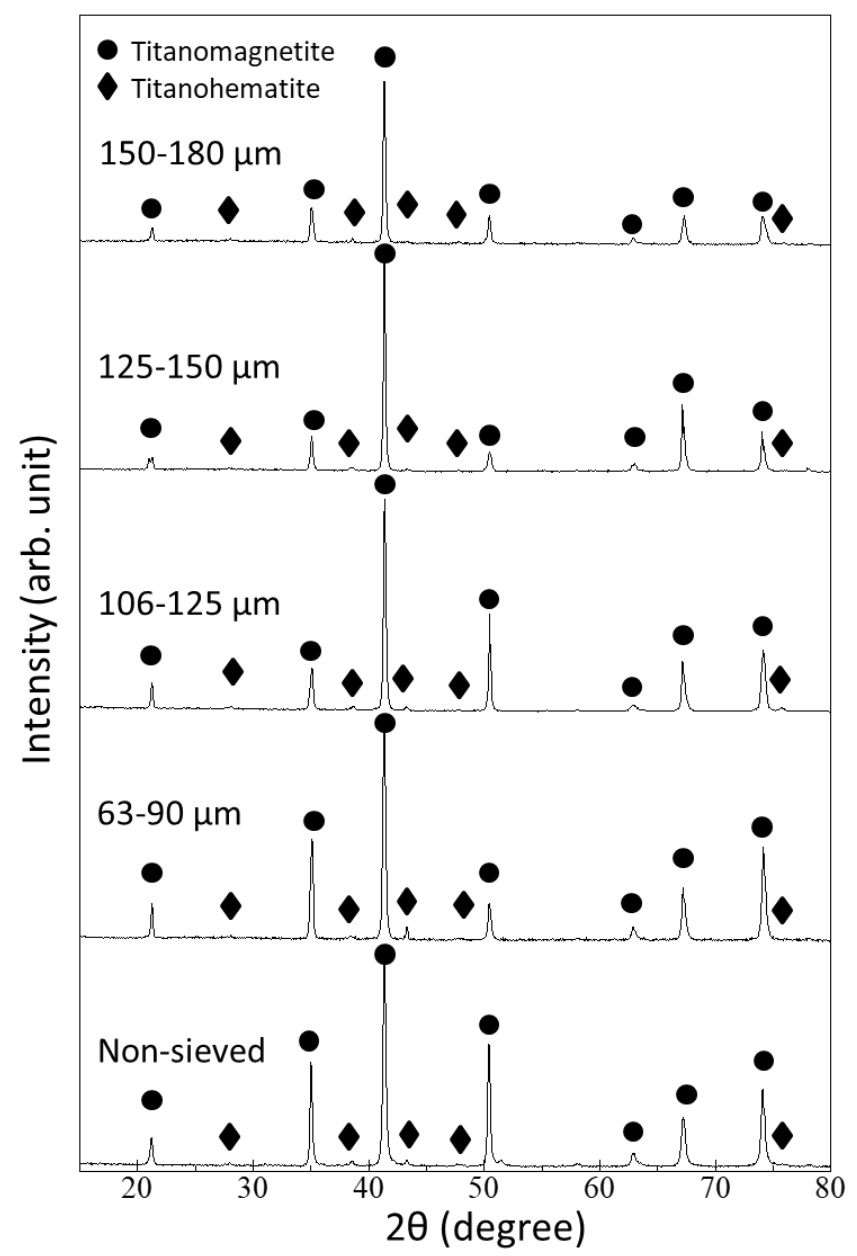

Figure 3.4 XRD patterns (CoK $\alpha$ ) of the raw ironsand concentrate for different particle size fractions.

A typical back-scattered electron (BSE) image of the raw NZ ironsand particles with a size fraction of 106-125 $\mu \mathrm{m}$ is shown in Figure 3.5. From this figure, it can be seen that most particles are rounded and approximately spheroidal in shape. 


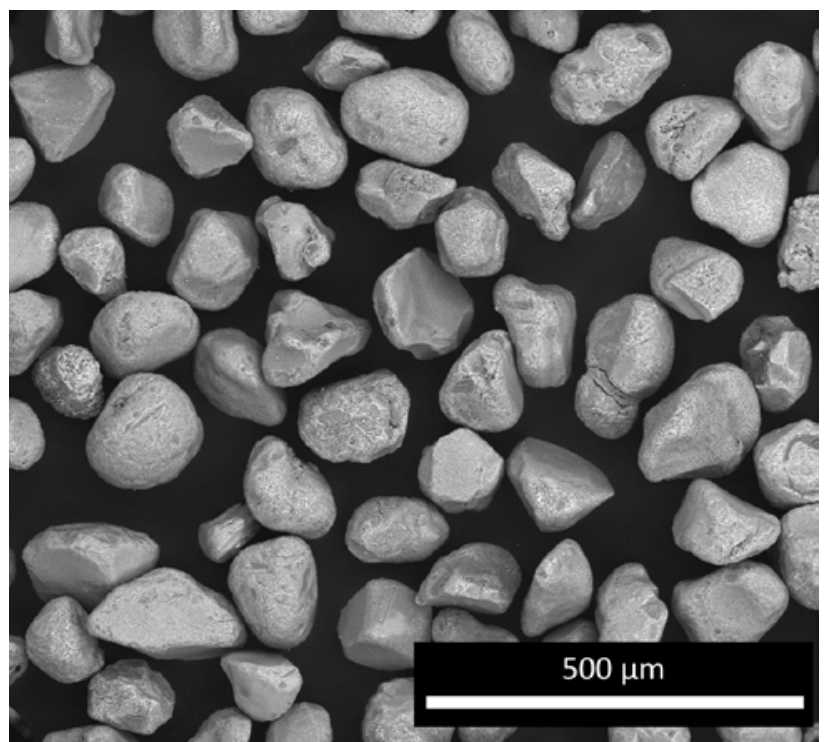

Figure 3.5 BSE image of the raw ironsand concentrate with a size fraction of 106-125 $\mu m$.

\subsection{Development of an analytical method for determining \%met}

\subsubsection{Overview}

An important parameter when analysing the reduction of iron ores (such as TTM ironsand) is the \%met, which is calculated by equation (3.1).

The q-XRD method offers the advantage of quick and accurate analysis of the \%met of multiple samples (König, Gobbo and Reiss, 2012). However, standard approaches often rely on wet chemistry titrations to determine the level of $\mathrm{Fe}^{0}$ in a sample. In order to validate the use of q-XRD in subsequent experimental analysis, preliminary tests were performed to compare the \%met values determined by the q-XRD and wet chemistry methods.

\subsubsection{Experimental method}

\subsubsection{Titration vs $q-X R D$ for partially reduced samples}

Partially reduced samples for titration and q-XRD analysis were obtained by reducing $5 \mathrm{~g}$ of ironsand powder in a horizontal tube reactor. The experimental set-up for the fixed bed reduction of ironsand is illustrated in Figure 3.6. Sample material was a 1:1 mass ratio mix of ironsand, with particle size fraction of 106-125 $\mu \mathrm{m}$, and alumina powder. Alumina powder was added to prevent sintering of ironsand particles during reduction. Reduction was performed using $100 \mathrm{~mL} / \mathrm{min}$ of $\mathrm{H}_{2}$ at $950^{\circ} \mathrm{C}$ for $20,25,30$, and 40 minutes. 


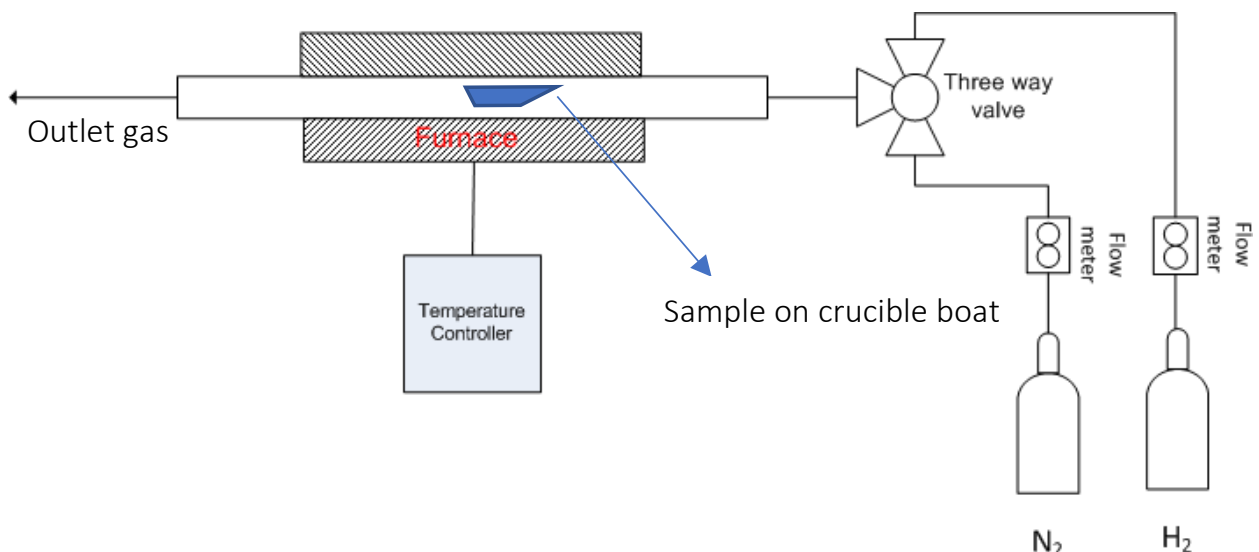

Figure 3.6 Schematic illustration of experimental set-up for fixed bed reduction of ironsand.

The titrations were performed following the standard wet chemistry technique, ISO 16878:2016, which is specified to determine the amount of metallic iron in the sample. The solid sample was initially dissolved in an iron (III) chloride solution (250 g/l) for about 45 minutes. Here, metallic iron $\left(\mathrm{Fe}^{0}\right)$ is dissolved into the solution and oxidised to $\mathrm{Fe}^{2+}$, according to reaction (3.2).

$$
\mathrm{Fe}^{0}+2 \mathrm{Fe}^{3+} \rightarrow 3 \mathrm{Fe}^{2+}
$$

It is important to note that only $\mathrm{Fe}^{0}$ enters solution. Any $\mathrm{Fe}^{2+}$ and $\mathrm{Fe}^{3+}$ species in oxides remain bound in the solid state (not dissolved). A low flow of $\mathrm{N}_{2}$ gas was purged during the dissolution to prevent oxidation of the sample. The $\mathrm{Fe}^{2+}$ ions in the solution were then titrated with potassium dichromate solution.

The standard titration technique, ISO 2597-1:2006, was not used to determine the total iron in the sample because of two reasons. The first is because mercury chloride was not allowed in the laboratory at Callaghan Innovation. The second is because ISO 25971:2006 does not cover the full iron range in reduced ironsand (only for 30-70 wt.\% total iron). Instead, the total iron in the sample was determined based on the XRF data for the total iron in the raw concentrate (Table 3.1). The total iron of the partially reduced sample was calculated by equation (3.3).

$$
F e_{T o t}=\frac{m_{0}}{m_{f}} x F e_{T} \text { in the raw ironsand }
$$


The $m_{0}$ value indicates the initial mass of the sample and the $m_{f}$ value indicates the final mass of the sample. The $\mathrm{Fe}_{T}$ value indicates the total iron in the raw ironsand.

\subsubsection{Mixed synthetic samples to obtain known low \%met values}

For the purposes of this validation, the \%met values obtained from the titration method were considered as "true values". However, the ISO titration method is not applicable to samples with metallic iron $\left(\mathrm{Fe}^{0}\right)$ content lower than $57.5 \mathrm{wt}$ \%, which would correspond to \%met lower than $70 \%$ for ironsand. In order to compare the results from ISO method with q-XRD for a \%met range of below 70\%, the partially reduced (with > $57.5 \%$ metallic iron) samples were diluted with either unreduced ironsand or Hoganas magnetite. The metallic iron content after mixing corresponds to \%met values of 10-60 \%. The chemical composition of the unreduced ironsand and Hoganas magnetite is presented in Table 3.1 and Table 3.2, respectively. Mixing of samples was conducted by grinding them gently in ethanol.

Table 3.2 Chemical composition of Hoganas magnetite.

\begin{tabular}{|c|c|c|c|c|c|c|c|c|}
\hline \multirow{2}{*}{ Sample } & \multicolumn{7}{|c|}{ Compositions (equivalent mass\%) } \\
\cline { 2 - 9 } & $\begin{array}{c}\text { Calc. } \\
\mathrm{Fe}\end{array}$ & $\mathrm{TiO}_{2}$ & $\mathrm{Al}_{2} \mathrm{O}_{3}$ & $\mathrm{MgO}$ & $\mathrm{CaO}$ & $\mathrm{SiO}_{2}$ & $\mathrm{~V}_{2} \mathrm{O}_{5}$ & $\mathrm{MnO}$ \\
\hline $\begin{array}{c}\text { Hoganas } \\
\text { magnetite }\end{array}$ & 72 & 0.15 & 0.15 & - & - & 0.1 & 0.1 & 0.03 \\
\hline
\end{tabular}

\subsubsection{Results}

Figure 3.7 plots the comparison of \%met values obtained from q-XRD versus the titration method. Close agreement is observed as the linear fit shows an error on slope of only $1 \%$. These results show that the $\mathrm{q}-\mathrm{XRD}$ method is a reliable method to analyse \%met, at an appropriate level of accuracy for the reduction process experiments performed in this thesis. More importantly, q-XRD method is a much quicker method than the ISO wet chemistry method. The q-XRD method took about 30 minutes for one sample, including sample preparation. In comparison, the ISO method is very labour intensive. It took about one hour for one sample, and this does not include the time needed for preparation, cleaning, etc, which constitutes most of the labour. 


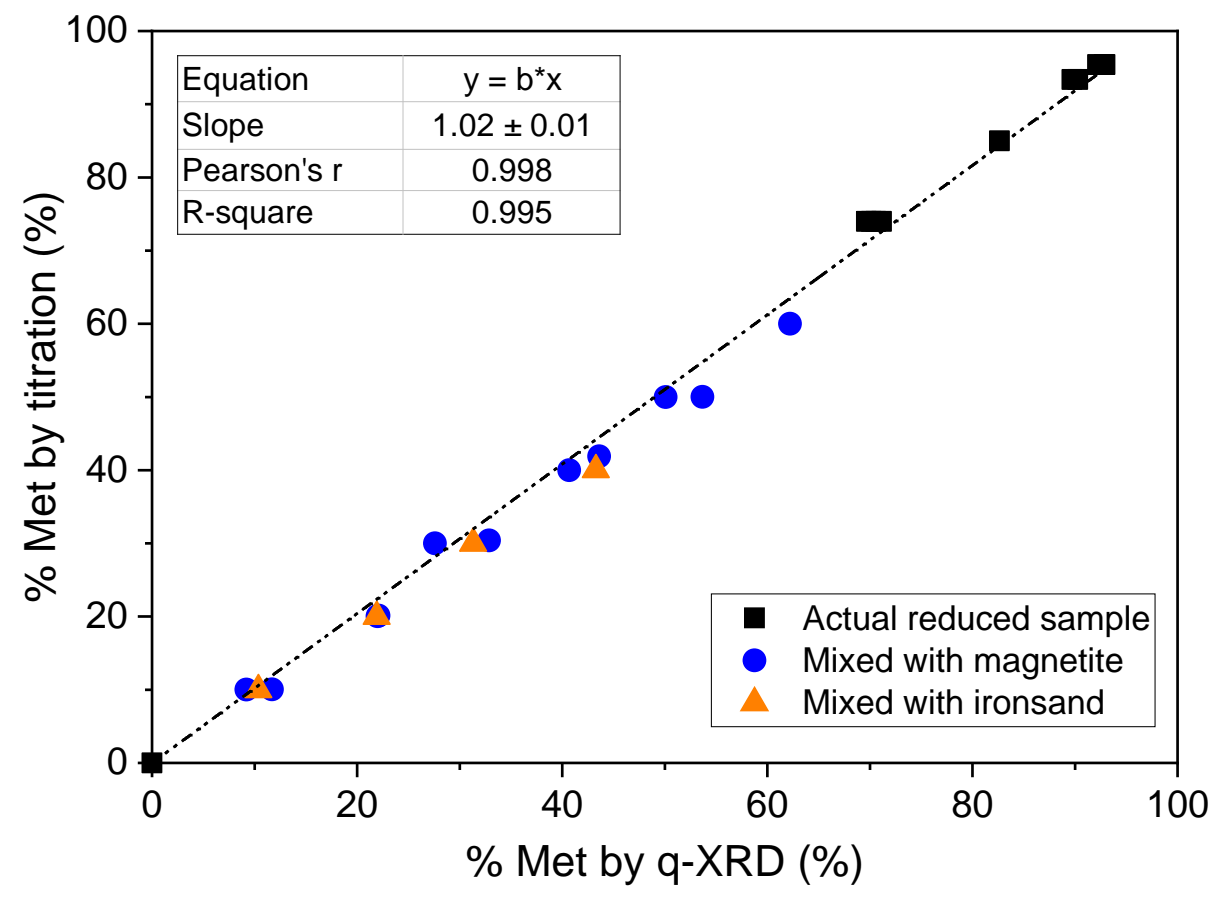

Figure 3.7 Calibration plot of \%met value calculated by $q-X R D$ versus titration method.

\subsection{Reduction experiments}

\subsubsection{General procedure for the reduction experiments}

A series of reduction experiments was performed using a laboratory-scale FB reactor set-up, as illustrated in Figure 3.8. The details of the reactor set-up are described in Chapter 4. In brief, the system comprises a vertical quartz tube mounted within a radiant high temperature furnace. $\mathrm{H}_{2}$ gas passes through a quartz frit (40-90 $\mu \mathrm{m}$ pore size) mounted within the tube, and supports a bubbling bed comprising $100 \mathrm{~g}$ of ironsand. The top part of the reactor is wrapped with an alumina fibre and the top flange is wrapped with a band heater to prevent water condensation at the reactor outlet. A key feature of the reactor setup is a custom-made venturi sampling system, which enables multiple samples to be extracted during a single experimental run without interrupting operation of the FB. 


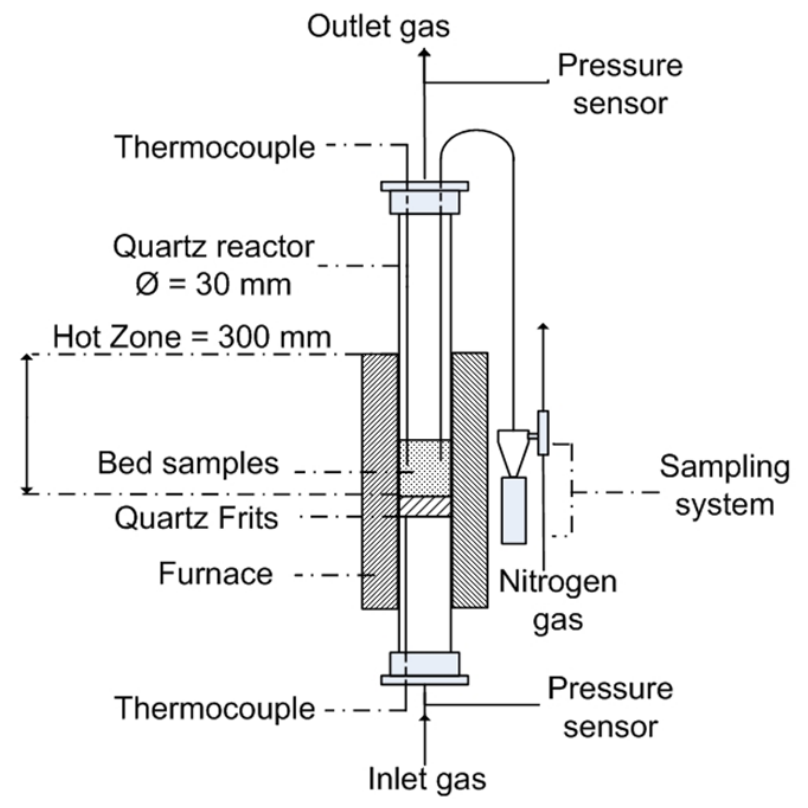

Figure 3.8 Schematic diagram of the FB reactor

During sample collection, a high flow rate of nitrogen gas ( $\geq 75 \mathrm{~L} / \mathrm{min})$ is introduced to the inlet of the Venturi nozzle, and then the valves are activated by the software to an “open” state. A small mass ( 2 g) can be extracted directly from the bed by activating the "open" state of the valves for one second.

In most reduction experiments, the ironsand sample weight used is 100 g. For experiments in Chapter 6, the sample weight was varied from $50 \mathrm{~g}$ to $250 \mathrm{~g}$. The ironsand sample was initially charged to the reactor at room temperature. The sample bed was then purged by Ar gas with a flow rate of $3 \mathrm{~L} / \mathrm{min}$ while heating up the bed (at $10^{\circ} \mathrm{C}$ per minute) to the experimental temperature. For experiments in Chapter 7, the experimental temperature was varied from $750^{\circ} \mathrm{C}$ to $1000^{\circ} \mathrm{C}$ in $50^{\circ} \mathrm{C}$ intervals. After the bed reached the desired reduction temperature, the inert fluidising gas was then switched to a reducing gas of varying composition. The total gas flow rate $\left(\mathrm{H}_{2}-\mathrm{Ar}\right)$ for the reduction was set to a maximum of $5 \mathrm{~L} / \mathrm{min}$. This ensured that the ironsand in the reactor was in the bubbling fluidisation regime (Yang, 2003) for every temperature studied.

At predetermined sampling times, samples of partially reduced ironsand ( 2 g per sample) were extracted into the sample container. The sample container was quench cooled in a water pot. When exchanging the sample container, a low flow rate of Ar gas was introduced to purge the container opening and prevent re-oxidation of the sample. The partially reduced samples taken during the reduction experiments were then stored in a desiccator to minimize re-oxidation of the samples. 


\subsubsection{Measurement of the bed temperature}

For all reduction experiments, the operating temperature was taken as the bed temperature, which was measured by an external thermocouple that is inserted from the top of the reactor (Figure 3.8). The tip of the thermocouple is in contact with the particles in the bed - located $20 \mathrm{~mm}$ above the frit, and approximately between the center and the wall of the reactor. This thermocouple was used as the input to the furnace temperature controller to control the heating power and bed temperature. As the reactor wall is transparent, the radiant heat from the furnace heating element is mostly absorbed by the black body of ironsand particles, and the heat is transferred from fluidized bed to the gas and the reactor wall. As long as particles are fluidized, particles bounce vigorously, and therefore the temperature gradient within the fluidised bed itself can be assumed to be minimal. However, if the bed becomes stuck (defluidised), heat transfer in the bed is more complicated. There is a possible radial gradient heat within the bed, with the centre of the bed is likely colder than the bed close to the wall. The heat is transferred through the sintered bed close to the wall to the centre of the bed. This may be relevant to the sintered bed in sections 5.2 and 7.7.

Originally, the furnace thermocouple was connected to the controller. However, the bed temperature was not appropriately controlled when the furnace thermocouple was used to control the heat. An initial fluidization test of ironsand was carried out in Ar gas to compare the bed temperature and the furnace temperature when the heating program is held at $700^{\circ} \mathrm{C}$ and $900^{\circ} \mathrm{C}$. The result of this test is presented in Figure 3.9. The figure clearly shows that the bed temperature is always higher than the furnace temperature. More importantly, the bed temperature keeps increasing during the holding at both temperatures. This may be because ironsand is black; hence absorbs more heat from the furnace. Therefore, the thermocouple in the reactor was connected to the temperature controller, and by doing this, the heating power is controlled based on the actual bed temperature. 


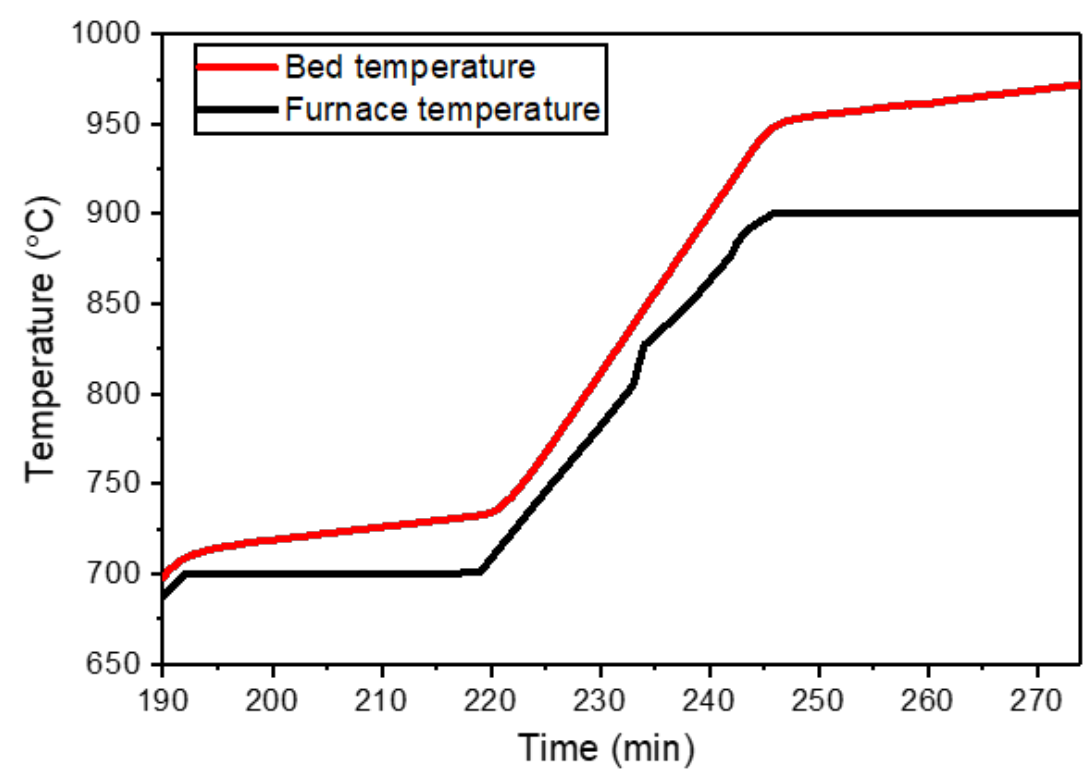

Figure 3.9 Temperature profile of the bed and the furnace during the fluidisation in Ar gas when the temperature is on hold at $700^{\circ} \mathrm{C}$ and $900^{\circ} \mathrm{C}$.

\subsubsection{Humidity sensor}

In Chapter 7, the partial pressure of $\mathrm{H}_{2} \mathrm{O}\left(P_{\mathrm{H}_{2} \mathrm{O}}\right)$ in the outlet gas was measured realtime during the reduction reaction. For this purpose, a humidity sensor, Vaisala HMT337, manufactured by Vaisala (Vantaa, Finland), was installed in the gas outlet line downstream from the reactor. This humidity sensor is rated for high-temperature applications at up to $180^{\circ} \mathrm{C}$. Figure 3.10 (a) presents the schematic configuration of the sensor position in the reactor set-up. Figure 3.10(b) shows the schematic set-up of a 'humidity chamber', where the humidity sensor probe and temperature probe measured dew point temperature $\left(T_{d}\right)$ and temperature (T) of the outlet gas, respectively. A cyclone was installed between the reactor and the sensor to collect any fine ironsand particles $(<106 \mu \mathrm{m})$, which could otherwise damage the sensor and block the gas line. The outlet gas line (red line in Figure 3.10), the cyclone, and the sensor were heated by heating tape to $\geq 120^{\circ} \mathrm{C}$ to prevent water condensation. 


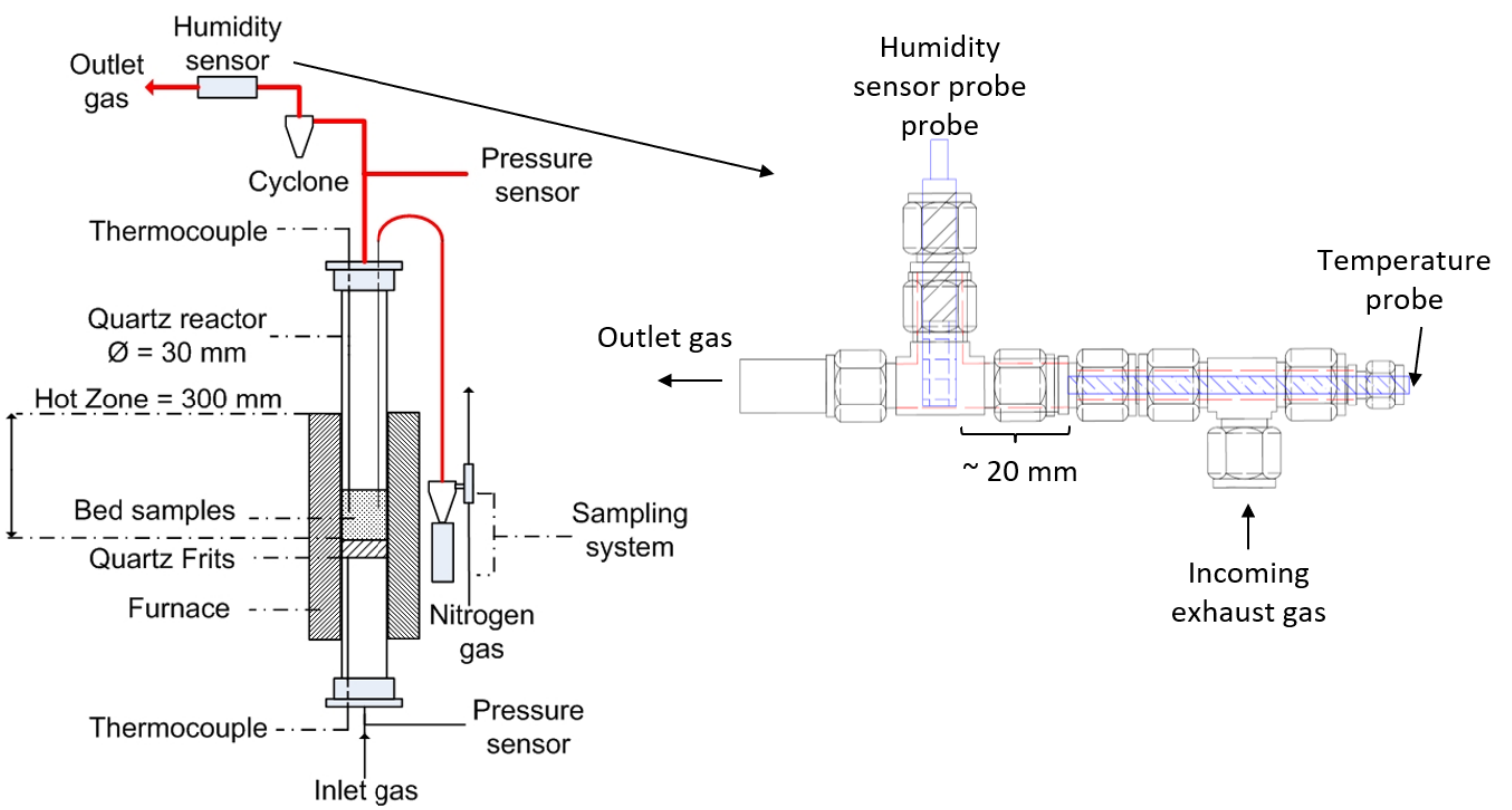

(a)

(b)

Figure 3.10 Schematic diagram of the FB reactor set-up showing the position of the humidity sensor (a). Image (b) is the close-up image for the 'humidity chamber' set-up, where the humidity sensor and temperature probe measure the $T$ and $T_{d}$ of the outlet gas.

The $T_{d}$ values measured by the sensor was then used to calculate $P_{H 2 O}$ according to equation (3.4) (from the Vaisala Operating Manual).

$$
P_{H 2 O}=A \cdot 10^{\left(\frac{m \cdot T_{d}}{T_{d}+T_{n}}\right)} \quad(\mathrm{hPa}),
$$

where $T_{d}$ is the dew point temperature, $A, m$, and $T_{n}$ are constants presented in Table 3.3.

Table 3.3 Values of constants in equation (3.3)

\begin{tabular}{ccccc}
\hline \multicolumn{5}{c}{ Constants } \\
\hline$A$ & $m$ & $T_{n}$ & max error $(\%)$ & $T_{d}$ range $\left({ }^{\circ} \mathrm{C}\right)$ \\
\hline 6.116441 & 7.591386 & 240.7263 & 0.083 & -20 to 50 \\
\hline 6.004918 & 7.337936 & 229.3975 & 0.017 & 50 to 100 \\
\hline 5.856548 & 7.2773 & 225.1033 & 0.003 & 100 to 150 \\
\hline 6.002859 & 7.290361 & 227.1704 & 0.007 & 150 to 200 \\
\hline 9.980622 & 7.388931 & 263.1239 & 0.395 & 200 to 350 \\
\hline
\end{tabular}


From the Vaisala Operating Manual, the accuracy for temperature (T) and $T_{d}$ reading by the sensor decreases with increasing temperature. At temperatures $\geq 120^{\circ} \mathrm{C}$, the accuracy for $\mathrm{T}$ and $T_{d}$ is about $\pm 0.5^{\circ} \mathrm{C}$ and $\pm 5^{\circ} \mathrm{C}$, respectively. Initial tests were conducted to test the consistency reading of the sensor in our laboratory set-up. The tests were conducted using air- $\mathrm{H}_{2} \mathrm{O}, \mathrm{N}_{2}-\mathrm{H}_{2} \mathrm{O}$, and $\mathrm{He}-\mathrm{H}_{2} \mathrm{O}$ gas mixtures at different mol.\% ratio and at temperatures between $120^{\circ} \mathrm{C}$ and $140^{\circ} \mathrm{C}$. The results of these tests showed that the $T_{d}$ readings were consistent for all gas mixtures. Although reproducible, the $T_{d}$ reading did differ from the actual value. However, the deviation was within the error margin stated in the manual.

Knowing that the sensor reading deviated from the true value, the sensor was calibrated in-situ using the set-up in Figure 3.10. The calibration was conducted in $\mathrm{N}_{2}-\mathrm{H}_{2} \mathrm{O}$ and $\mathrm{H}_{2}-\mathrm{H}_{2} \mathrm{O}$ gas mixtures at different mol.\% ratio and at temperatures between $120^{\circ} \mathrm{C}$ and $135^{\circ} \mathrm{C}$. The details and results of the calibration are presented in Appendix A. In brief, the results obtained were consistent for all gas mixtures. The $T_{d}$ values output by the sensor are linear for different mol.\% of $\mathrm{H}_{2} \mathrm{O}$ within the measurement range considered in this study, and hence calibrated equations for $T_{d}$ were obtained. The delay of the sensor response to moisture changes is within 15 seconds.

\subsubsection{Introduction of steam to the $\mathrm{FB}$ reactor}

For reduction experiments in Section 7.7.2, the inlet gas is a mixture of steam and $\mathrm{H}_{2}$ gas. A steam generation system was installed to introduce steam in the inlet gas, see Figure 3.11. A High-Performance Liquid Chromatography (HPLC) pump was used to deliver the required flow rate of water. Furnace 1 was used to heat the water delivered by the HPLC pump into steam. The gas tubing in Furnace 1 was coiled to provide a high surface area for heating water. The temperature in Furnace 1 was maintained stable at $350^{\circ} \mathrm{C} \pm 5^{\circ} \mathrm{C}$ and was monitored by an external K-type thermocouple. The gas line which connects between Furnace 1 and the FB reactor was heated by heating tape to $\geq 120^{\circ} \mathrm{C}$ (red line in Figure 3.11). 


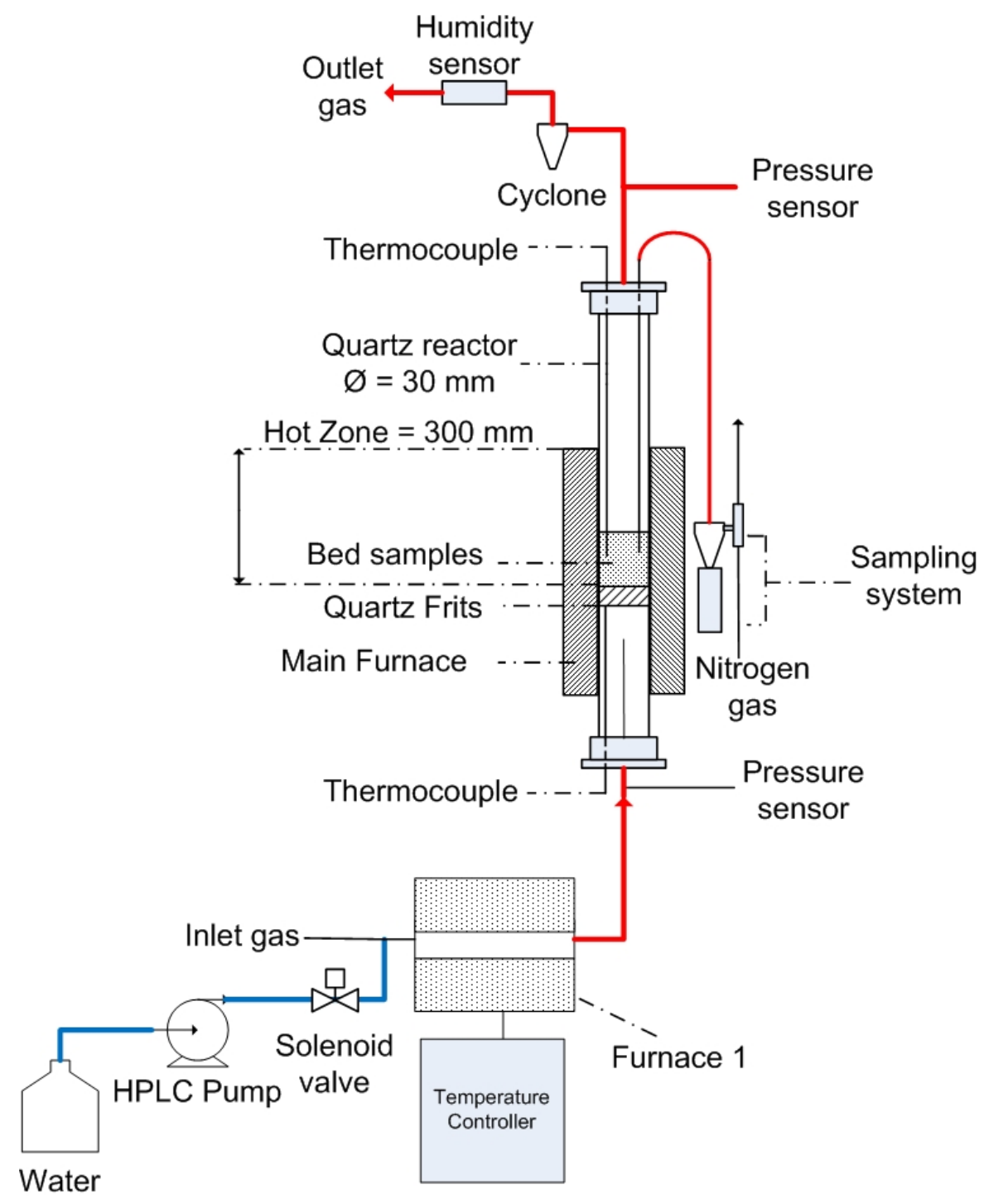

Figure 3.11 Schematic diagram of the FB reactor set-up and the steam generator. 


\section{Chapter 4}

\section{Design and Commissioning of an Experimental FB Reactor}

\subsection{Outline}

This chapter reports the design and experimental work undertaken to build and commission a laboratory FB reactor for this work. Design criteria for this reactor were that it should be capable of reducing samples of up to at least $100 \mathrm{~g}$ of ironsand in a FB using $\mathrm{H}_{2}$ or $\mathrm{H}_{2}$ - $\mathrm{Ar}$ gas at temperatures up to $1000^{\circ} \mathrm{C}$. The chapter is divided into five sections:

4.2 - Fluidisation tests at room temperature,

4.3 - Design and build of the high-temperature reactor,

4.4 - High-temperature FB reactor set-up,

4.5 - Sampling system,

4.6 - Commissioning of the reactor set-up at high temperatures.

\subsection{Fluidisation tests at room temperature}

The purpose of cold fluidisation experiments is to establish key parameters for the high-temperature FB and experimental program. Key parameters which influence final reactor design are gas flow rate, pressure drop, ironsand particle shape (sphericity), and the freeboard height.

\subsubsection{Experimental method}

Two different experiments were carried out at room temperature using an experimental set-up shown in Figure 4.1. Experiment 1 used air as the fluidising gas and ironsand powder with a size fraction of 106-125 $\mu \mathrm{m}$. The purpose of experiment 1 was to validate calculated fluidisation parameters from equation (2.10) to (2.17) against actual fluidisation data. This was carried out by recording pressure drop $(\Delta P)$ data at different air flow rates. Three different initial bed heights (20,40, and $80 \mathrm{~mm}$ ) were investigated to confirm the consistency of the experimental $U_{m f}$ value obtained (using the same ironsand material in each case). 
Experiment 2 used helium as the fluidising gas. The bed materials in this experiment were ironsand samples with size fractions of 106-125 $\mu \mathrm{m}$ and 63-90 $\mu \mathrm{m}$, and iron powder. The purpose of experiment 2 was to assess the fluidisation behaviour using a low-density gas that more closely represents the fluidisation conditions at $1000^{\circ} \mathrm{C}$. Additionally, the maximum freeboard height profile was also recorded to estimate the minimum height of the high-temperature reactor. Figure 4.2 shows a photograph example of the condition during the fluidisation. Dense bed was measured from the bottom of the bed to the highest burst of bubbles. Maximum freeboard height was measured from the bottom of the bed to the highest point of particles that were flung upward during the fluidisation.

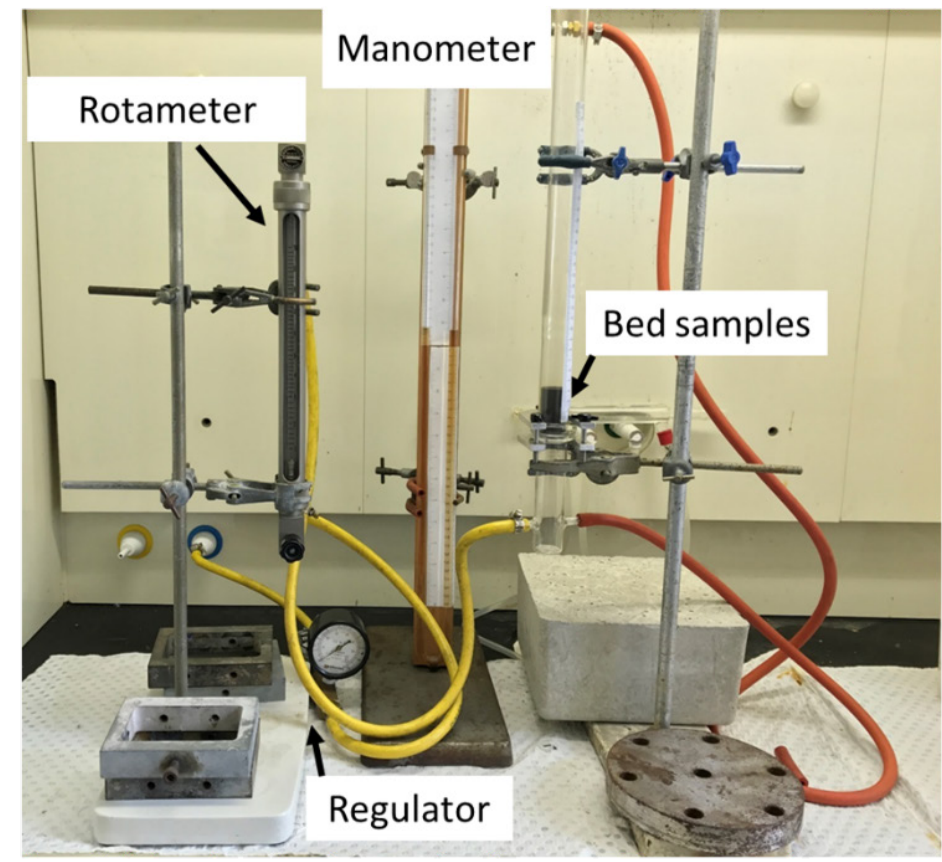

(a)

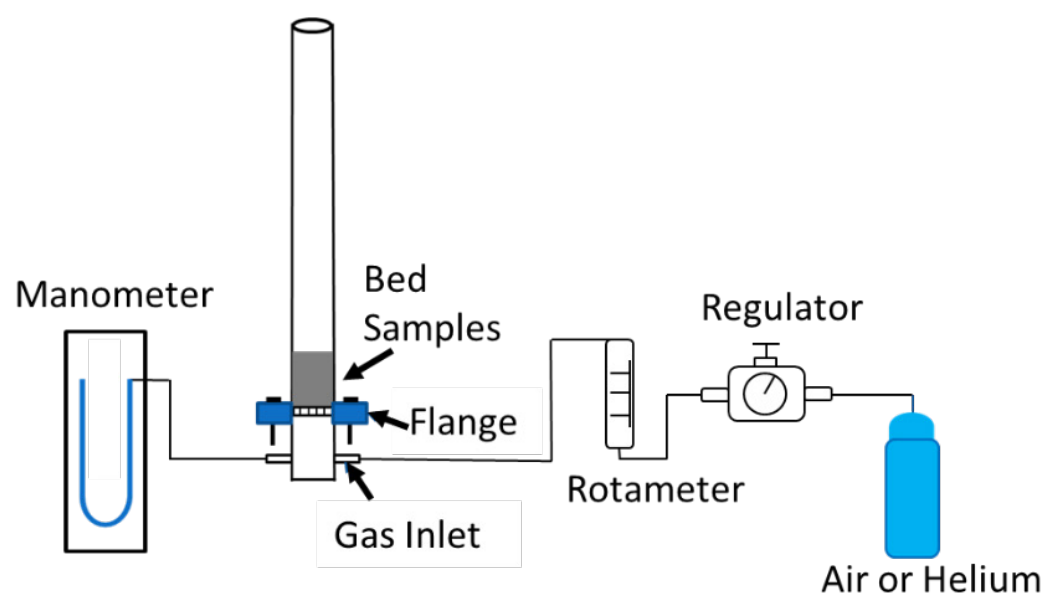

(b)

Figure 4.1 A photograph (a) and schematic diagram (b) of the experimental set up used for experiment 1 and 2. 


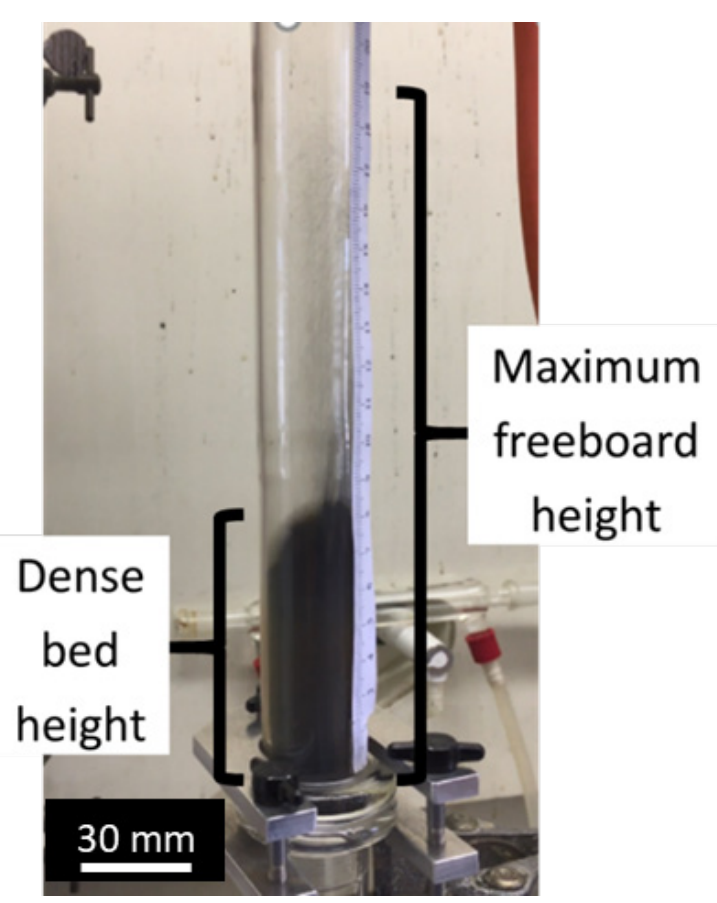

Figure 4.2 An example photo during cold fluidisation test.

\subsubsection{Results of cold fluidisation tests}

\subsubsection{Experiment 1}

For experiment 1 , the $\Delta P$ profiles at low flow rates $(\leq 2 \mathrm{~L} / \mathrm{min})$ were recorded. This enabled the $U_{m f}$ and $\Delta P$, calculated based on theory (Kunii and Levenspiel, 1977) to be compared to the actual experimental data. The $\Delta P$ profiles as a function of air velocity are presented in Figure 4.3. In the Figures, the initial slope at low flow velocities indicates the fixed bed condition. The point where the $\Delta P$ curve starts to plateau indicates that the bed starts to fluidise. This point is the $U_{m f}$. From the Figures, the $U_{m f}$ value for ironsand fluidisation for all three bed heights studied ( $H_{b e d}$ equals to $20 \mathrm{~mm}, 40 \mathrm{~mm}$, or $80 \mathrm{~mm}$ ) is within the range of $2-2.5 \mathrm{~cm} / \mathrm{s}$. From equation (2.14), a calculated $U_{m f}$ value of $2.31 \mathrm{~cm} / \mathrm{s}$ is obtained, which fits comfortably within this range. This calculation assumes an approximate sphericity value ( $\varphi$ ) of 0.6 for ironsand particles (Kunii and Levenspiel, 1977). Based on the Geldart classification of powders (Geldart, 1973), NZ TTM ironsand is expected to be a 'B-type' (sand-like) powder. In these cold tests, bubbles start to appear as soon as the velocity exceeded the $U_{m f}$ value, which is in good agreement with the behaviour of a B-type powder (Geldart, 1973). 


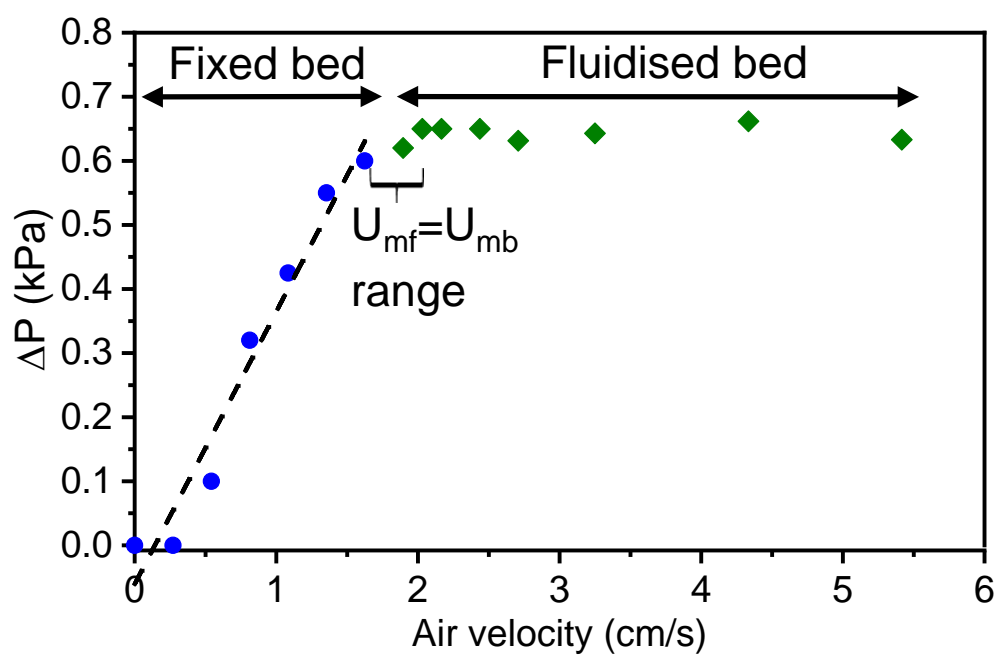

(a)

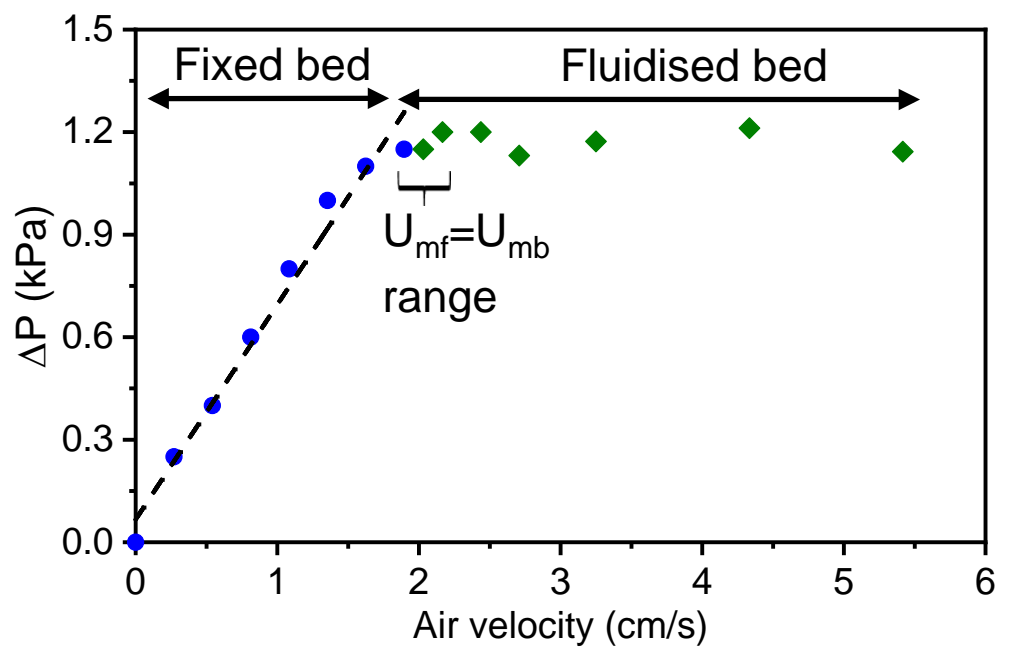

(b)

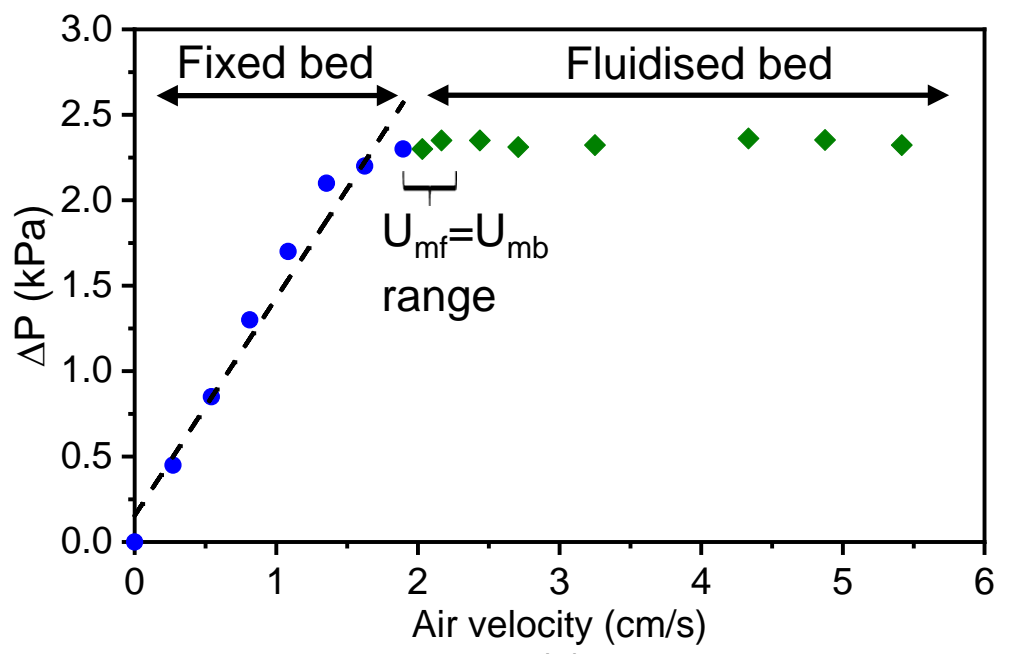

(c)

Figure 4.3 Pressure drop profile of the bed of ironsand with a particle size fraction of 106-125 $\mu \mathrm{m}$ as a function of air velocity with initial bed height of $20 \mathrm{~mm}$ (a), $40 \mathrm{~mm}$ (b), and $80 \mathrm{~mm}$ (c). Dashed line in all Figures indicates the slope when the bed is in the fixed bed state. 
More values for the ironsand sphericity $(\varphi)$ were calculated from both the cold fluidisation experiments and from SEM images of ironsand particles. The sphericity value from fluidisation experiments was obtained from equation (2.14) by substituting in the measured $U_{m f}$ value from each experiment. This yielded a mean value of $\sim 0.7$.

The circularity value from SEM images was obtained by applying equation (4.1) to measurements obtained from 20 different SEM images.

$$
4 \pi x \frac{\text { area of the top cross-section view of a particle }}{(\text { perimeter of the top cross-section view of a particle })^{2}}
$$

Figure 4.4 shows an example of SEM image containing about 1000 particles of raw ironsand with a size fraction of 106-125 $\mu \mathrm{m}$. The circularity value was measured by ImageJ software. The average circularity value from the SEM data is 0.706 with a standard deviation of 0.25 .

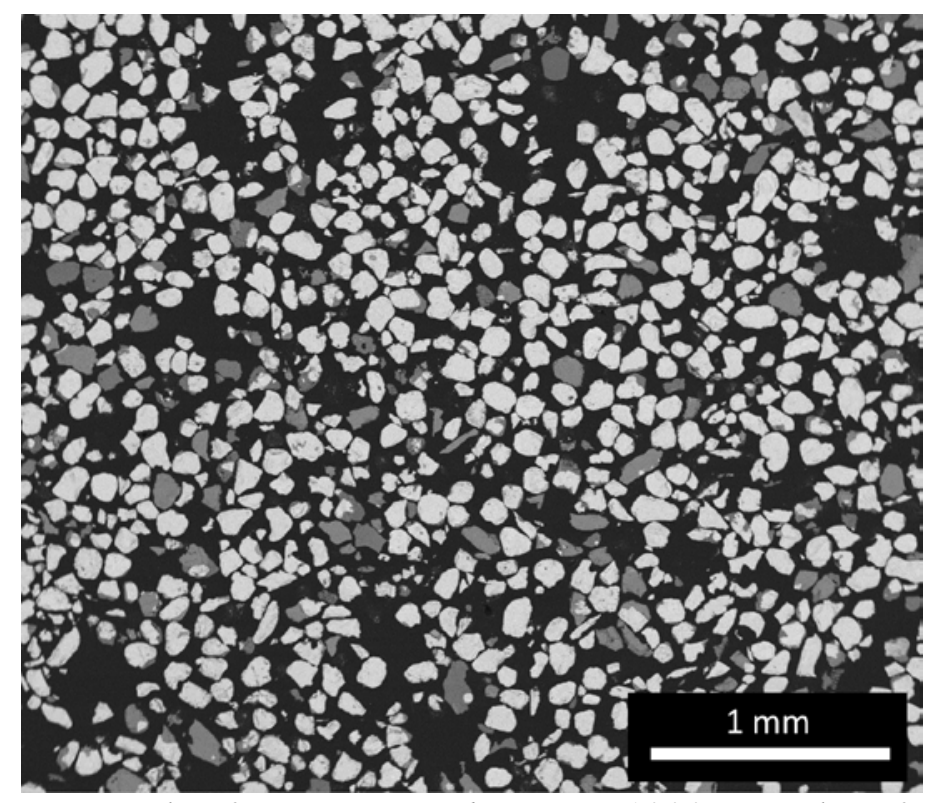

Figure 4.4 An example of SEM image showing 1000 particles of raw ironsand concentrate. The size fraction of particles is 106-125 $\mu \mathrm{m}$

\subsubsection{Experiment 2}

In experiment 2, the considerations for mimicking high-temperature fluidisation were based on the scaling rule of the simplified Glicksman's equation (Glicksman, 1988; Glicksman, Hyre and Woloshun, 1993). The full set of non-dimensional scaling parameters 
for a FB are given in equation (4.2). The definition for the symbols is listed in Nomenclature.

$$
\frac{U_{o}^{2}}{g^{2}}, \frac{\rho_{s}}{\rho_{g}}, \frac{U_{O}}{U_{m f}}, \frac{H_{\text {bed1 }}}{H_{\text {bed }}}, F r, A r, \text { sphericity }
$$

where the $F r$ and $A r$ values are defined in equations (4.3) and (4.4),

$$
\begin{aligned}
& F r=\frac{U_{o}^{2}}{g \cdot d_{p}} \\
& A r=\frac{d_{p}^{3} g \cdot \rho_{g}\left(\rho_{s}-\rho_{g}\right)}{\mu^{2}}
\end{aligned}
$$

Values for $U_{o}, g, H_{b e d}, F r, \rho_{s}$ and sphericity are the same for the room temperature cold model and high-temperature conditions. This means that $A r, U_{m f}$ and $\rho_{g}$ values for the cold model need to be close to the high-temperature condition. Helium gas (He) was chosen as the fluidising gas because its density is low and close to the estimated density of an $\mathrm{N}_{2}-\mathrm{CH}_{4}-\mathrm{H}_{2}$ gas mixture at $1000^{\circ} \mathrm{C}$. It should be noted that at the beginning of the experimental program it was still envisaged that $\mathrm{N}_{2}-\mathrm{CH}_{4}-\mathrm{H}_{2}$ gas mixtures would be a possible target for the reduction studies.

Three different samples were used in this section: 63-90 $\mu \mathrm{m}$ size fraction ironsand, 106-125 $\mu \mathrm{m}$ size fraction ironsand, and a commercially sourced 38-125 $\mu \mathrm{m}$ iron metal powder. Cold fluidisation tests of these samples were carried out to give information on what would be the flow-rate range for anticipated high-temperature fluidisation condition. The 63-90 $\mu \mathrm{m}$ size fraction ironsand was chosen because it would give a closer $A r$ value to the hot condition. The iron metal powder was chosen to give a closer $\frac{\rho_{s}}{\rho_{g}}$ ratio to the hot condition (to meet the scaling laws in equation (4.2)), as the density of each gas in the cold tests is also higher than at high temperature. Table 4.1 presents the calculated scaling parameters for these samples and three gas mixture examples of anticipated hightemperature fluidisation.

The experimental pressure drop profiles for all three samples are presented in Figure 4.5. From the Figures, the values for $U_{m f}$ and $U_{t}$ are broadly consistent with the calculated values in Table 4.1, except $U_{t}$ value in Figure 4.5(b). The experimental $U_{t}$ is lower than the calculated $U_{t}$ might be because some residual fine particles could still have been retained in this sieved size fraction, hence these fines came out of the reactor at gas a velocity lower than the calculated $U_{t}$. It is important that all pressure drop profiles are consistent with the typical pressure drop profile associated with the FB condition in Figure 2.8 (in Chapter 2). 
Table 4.1 Calculated parameters for different materials and fluidising gas.

\begin{tabular}{|c|c|c|c|c|c|c|c|c|c|c|}
\hline Material & $\begin{array}{c}\text { Particle size } \\
(\mu \mathrm{m})\end{array}$ & $\begin{array}{c}\text { Temperature } \\
\left({ }^{\circ} \mathrm{C}\right)\end{array}$ & $\begin{array}{c}\text { Helium } \\
(\mathrm{mol} . \%)\end{array}$ & $\begin{array}{c}\text { Methane } \\
(\mathrm{mol} . \%)\end{array}$ & $\begin{array}{c}\text { Hydrogen } \\
(\mathrm{mol} . \%)\end{array}$ & $\begin{array}{c}\text { Nitrogen } \\
(\mathrm{mol. \%})\end{array}$ & $\frac{\rho_{s}}{\rho_{g}}$ & $A r$ & $\begin{array}{c}U_{m f} \\
(\mathrm{~cm} / \mathrm{s})\end{array}$ & $\begin{array}{c}U_{t} \\
(\mathrm{~cm} / \mathrm{s})\end{array}$ \\
\hline Iron powder & $38-125$ & 25 & 100 & 0 & 0 & 0 & 45644 & 7.0 & 1.1 & 19.0 \\
\hline iron sand & $106-125$ & 25 & 100 & 0 & 0 & 0 & 30310 & 32.6 & 2.1 & 140.2 \\
\hline iron sand & $63-90$ & 25 & 100 & 0 & 0 & 0 & 30310 & 9.0 & 1.3 & 55.6 \\
\hline iron sand & $106-125$ & 1000 & 0 & 25 & 50 & 25 & 38346 & 8.4 & 1.2 & 80.1 \\
\hline iron sand & $106-125$ & 1000 & 0 & 25 & 60 & 15 & 49294 & 7.7 & 1.3 & 86.9 \\
\hline iron sand & $106-125$ & 1000 & 0 & 0 & 0 & 100 & 29017 & 9.8 & 0.9 & 64.3 \\
\hline
\end{tabular}

*note: In the beginning, it was originally planned to use methane gas as a sticking prevention method before knowing the results observed in Chapter 6. 


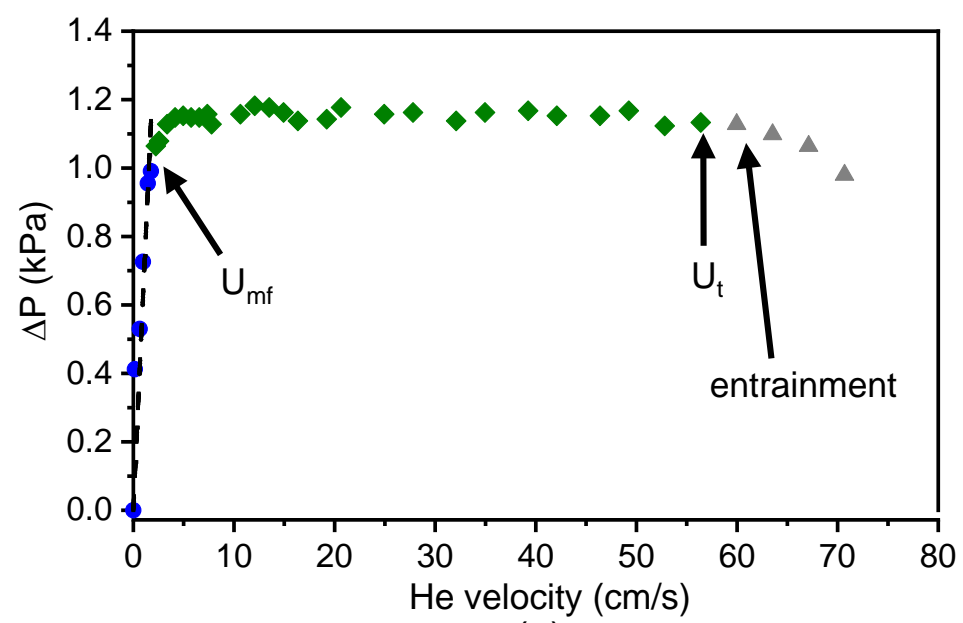

(a)

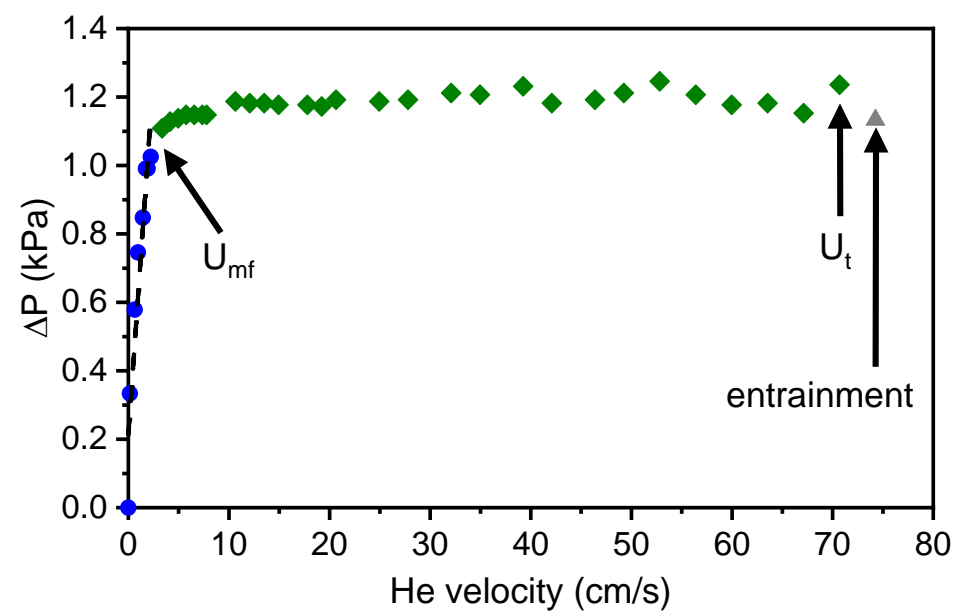

(b)

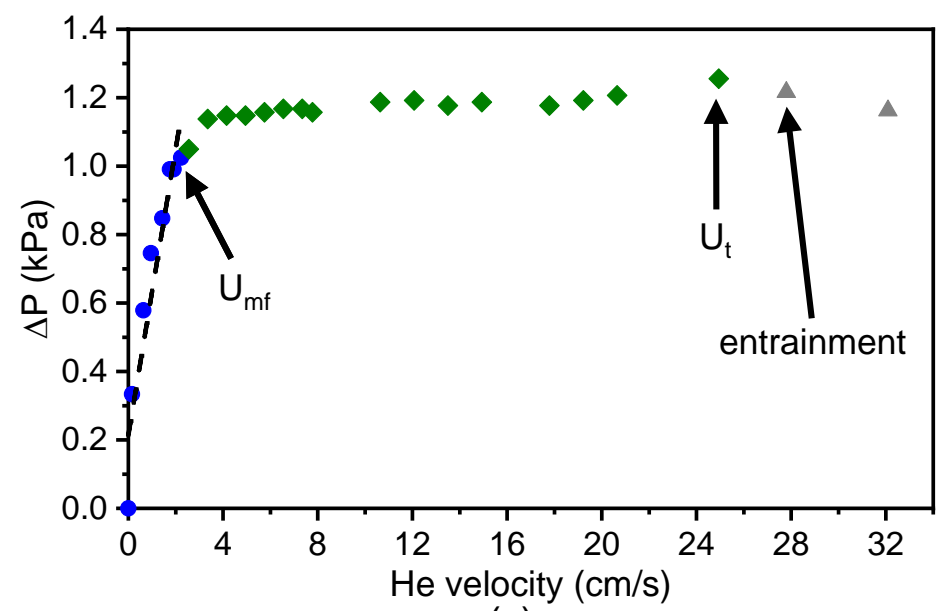

(c)

Figure 4.5 Pressure drop profile as a function of helium gas velocities in cold model fluidisation. (a) for ironsand with a particle size fraction of 63-90 $\mu \mathrm{m}$. (b) for ironsand with a particle size fraction of 106-125 $\mu \mathrm{m}$. (c) for iron powder with a particle size fraction of 38-125 $\mu \mathrm{m}$. 
To estimate the minimum dimensions for the high-temperature reactor, the bed height profile at different helium gas velocities was recorded and this is presented in Figure 4.6. The maximum freeboard height before entrainment started for 63-90 $\mu \mathrm{m}$ iron sands, 106$125 \mu \mathrm{m}$ iron sands, and iron powder was observed to be about $25 \mathrm{~cm}$. Based on these experimental results, a design value of $30 \mathrm{~cm}$ was selected as the minimum permissible freeboard height for the high-temperature FB reactor.

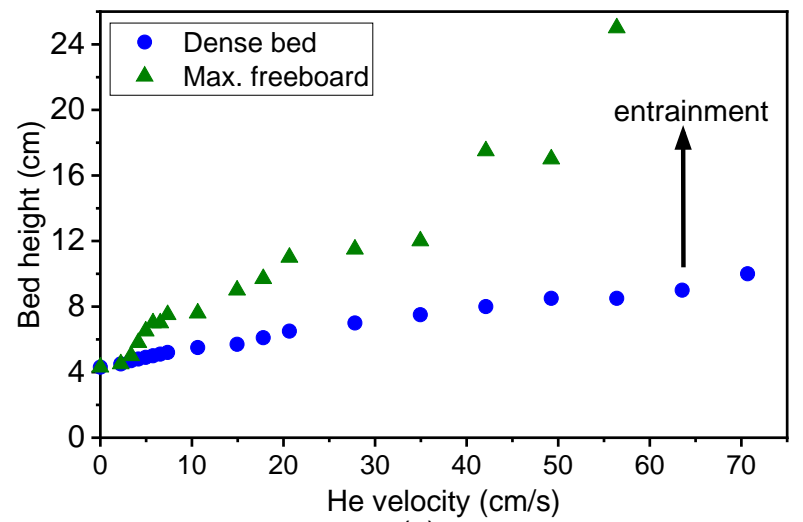

(a)

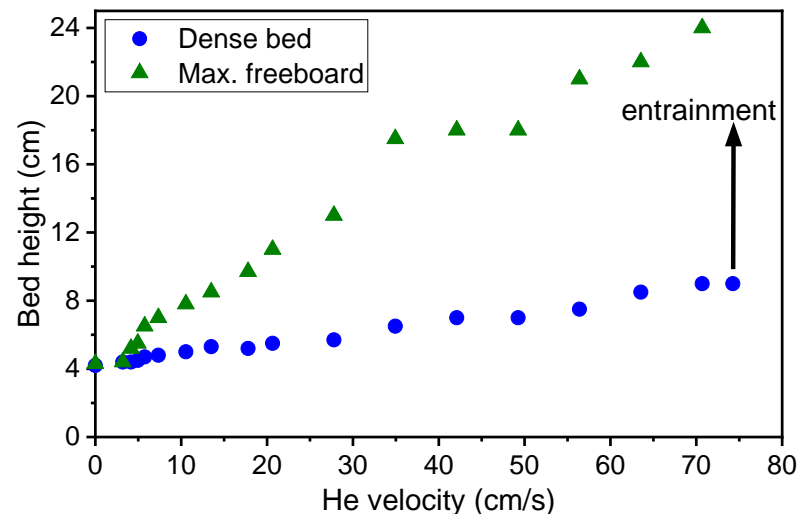

(b)

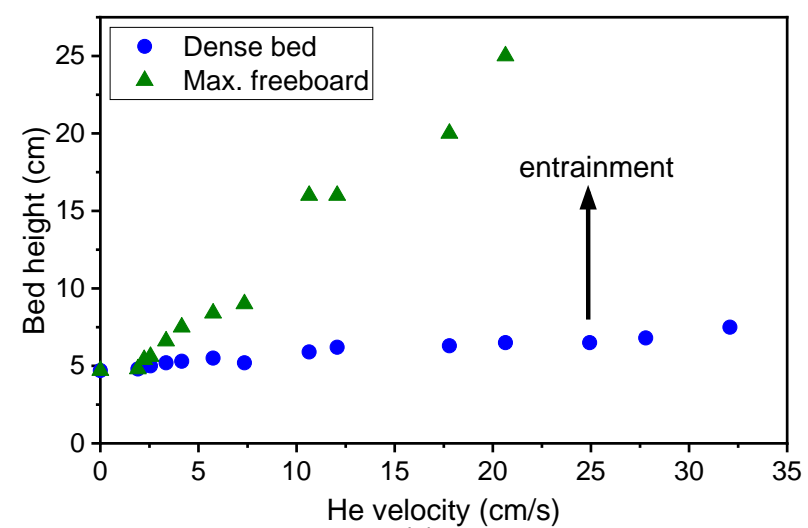

(c)

Figure 4.6 Bed height profile as a function of helium gas velocities in cold model fluidisation. (a) for ironsand with a particle size fraction of 63-90 $\mu \mathrm{m}$. (b) for ironsand with a particle size fraction of 106-125 $\mu \mathrm{m}$. (c) for iron powder with a particle size fraction of 38-125 $\mu \mathrm{m}$ 


\subsection{Design and build of the high-temperature FB reactor}

The values for the key design criteria of the FB reactor for high-temperature experiments were obtained from the results of cold fluidisation tests in Section 4.2 and literature survey. Table 4.2 presents the list of the selected design criteria values and the reason for choosing them.

Table 4.2 Selected criteria for the high-temperature FB reactor and the reasons for the selection

\begin{tabular}{|c|c|c|}
\hline & Selected criteria & Reasons \\
\hline $\begin{array}{l}\text { Reactor } \\
\text { material }\end{array}$ & Quartz & $\begin{array}{l}\text { It has an excellent thermal shock resistance. It is } \\
\text { rated for temperatures up to } 1100^{\circ} \mathrm{C} \text {. A } \\
\text { glassblower can easily fit a quartz frit to the quartz } \\
\text { tube }\end{array}$ \\
\hline $\begin{array}{l}\text { Reactor outer } \\
\text { diameter }\end{array}$ & $40 \mathrm{~mm}$ & $\begin{array}{l}\text { It is a sensible diameter size, not too big nor too } \\
\text { small. Also, a furnace for this diameter size is } \\
\text { available in the market. }\end{array}$ \\
\hline $\begin{array}{l}\text { Reactor inner } \\
\text { diameter }\end{array}$ & $30 \mathrm{~mm}$ & $\begin{array}{l}\text { It is a sensible diameter size, not too big nor too } \\
\text { small. This size is also because the quartz tube is } \\
\text { thick, with a thickness of } \sim 5 \mathrm{~mm} \text {. }\end{array}$ \\
\hline $\begin{array}{l}\text { Windbox } \\
\text { height }\end{array}$ & $300 \mathrm{~mm}$ & $\begin{array}{l}\text { The total length of the heating zone of the furnace } \\
\text { is } 500 \mathrm{~mm} \text {. The quartz frit was placed } 200 \mathrm{~mm} \\
\text { from the bottom of the heating of the furnace. This } \\
\text { size meets the minimum windbox height } \\
\text { calculated from equation }(2.20)(72 \mathrm{~mm}) \text {. }\end{array}$ \\
\hline $\begin{array}{l}\text { Freeboard } \\
\text { height within } \\
\text { the hot zone } \\
\text { (Figure 3.8) }\end{array}$ & $300 \mathrm{~mm}$ & $\begin{array}{l}\text { The highest freeboard height from the cold test is } \\
\sim 250 \mathrm{~mm} \text {. The additional } 50 \mathrm{~mm} \text { is to make sure } \\
\text { that fluidised particles are within the hot zone }\end{array}$ \\
\hline Gas distributor & Quartz frit & $\begin{array}{l}\text { It is the same material as the reactor. A } \\
\text { glassblower can easily fit it to the quartz tube. }\end{array}$ \\
\hline Frits porosity & $40-90 \mu \mathrm{m}$ & $\begin{array}{l}\text { Mostly use ironsand with a particle size fraction of } \\
\text { 106-125 } \mu \mathrm{m} \text {. Smaller porosity sizes could result a } \\
\text { much higher pressure drop. }\end{array}$ \\
\hline $\begin{array}{l}\text { Sampling tube } \\
\text { material }\end{array}$ & Inconel $625 \circledR$ & $\begin{array}{l}\text { It contains only about } 5 \text { wt.\% iron. This is to } \\
\text { minimise the iron-iron sticking to ironsand } \\
\text { particles during the reduction process. Also, it is } \\
\text { rated for temperatures up to } 1100^{\circ} \mathrm{C}\end{array}$ \\
\hline $\begin{array}{l}\text { Sampling tube } \\
\text { size }\end{array}$ & 1/4" size tubing & $\begin{array}{l}\text { From the results of initial tests in Section 4.5.1, } \\
\text { ironsand particles flow smoothly through the tube }\end{array}$ \\
\hline $\begin{array}{l}\text { Thermocouple } \\
\text { sheath material }\end{array}$ & Pyrosil $®$ & Pyrosil is a NiCrSi alloy. It does not contain iron. \\
\hline
\end{tabular}


The FB reactor was designed in AutoCAD and then the various constituent parts were procured. After that, the reactor was carefully assembled and tested for safety. The hightemperature reactor was designed and assembled alongside with an engineer from Callaghan Innovation (Diego del Puerto). Some complicated custom parts were machined by an external workshop. The LabVIEW software used the reactor was originally made by a scientist from Callaghan Innovation (Robert Holt), and then all necessary modification was carried out by an engineer from Robinson Research Institute (Joseph Bailey).

\subsection{General set-up of the high-temperature FB reactor}

Figure 4.7 presents a photograph and a schematic design of the fully assembled high temperature FB reactor and sampling system. The reactor tube is located in a vertical tube furnace. The hot zone of the reactor is the distance from the frit to the top of the heating zone of the furnace. The total length of the heating zone inside the furnace is $500 \mathrm{~mm}$. The quartz frit was placed $200 \mathrm{~mm}$ above the bottom of the heating zone. This gave a freeboard height within the hot zone of $300 \mathrm{~mm}$ (refer to Figure 3.8). The top part of the reactor, is wrapped with alumina fibre, and the top flange is wrapped with a band heater that maintain a temperature of $\sim 120^{\circ} \mathrm{C}$ at the reactor oulet, and hence prevent water condensation at the this point. Within the reactor tube, one end of the sampling tube is located $20 \mathrm{~mm}$ above the quartz frit and the other end is connected to the cyclone-type sampler. Thermocouples are located at the top and bottom of the reactor with the tip of each thermocouple close to the quartz ditributor. Pressure transducers are connected at the inlet and outlet of the gas line to record the pressure drop of the bed during fluidisation. Additionally, a sampling system (see Section 4.5) is installed for the reactor to extract samples during the reduction process. Electronically-controlled solenoid valves are installed on the sampling system line for quick and accurate automatic timing of the open-close cycle for sampling small quantities of the bed during an experimental run. 


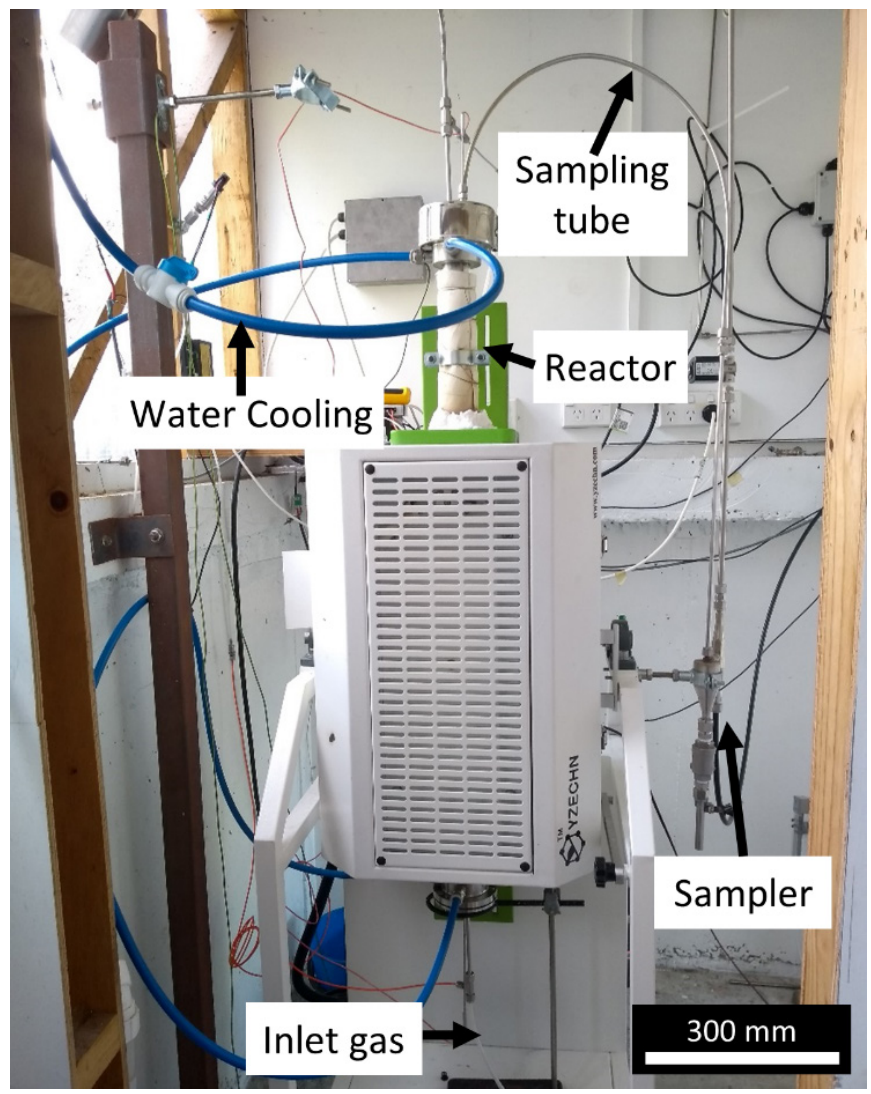

(a)

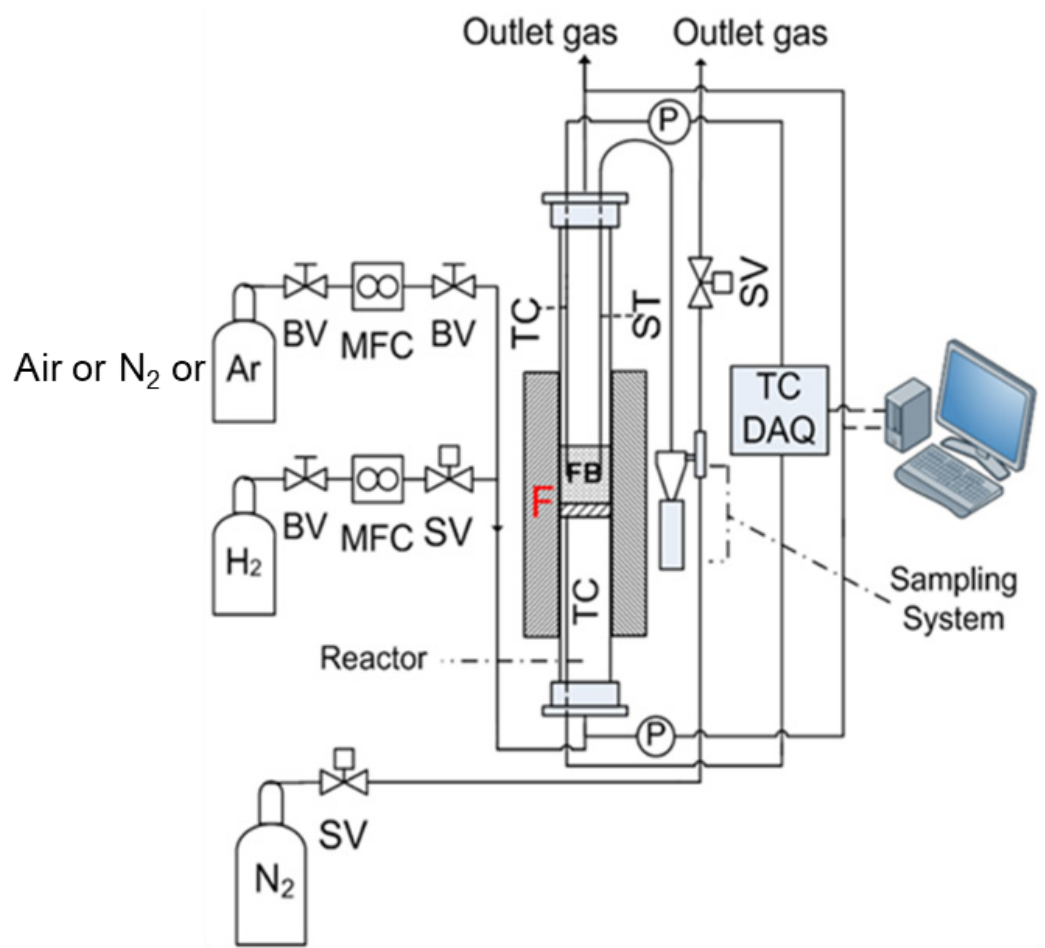

BV: Ball valve

SV: Solenoid valve

MFC: Mass flow controller
FB: Fluidized bed TC: Thermocouple

F: Furnace ST: Sampling tube

P: Pressure sensor TC DAQ: TC data acquisition

(b)

Figure 4.7 A photograph (a) and schematic diagram (b) of the FB reactor 


\subsection{Sampling system}

The key feature of the high-temperature FB reactor shown in Figure 4.7 is its sampling system that is capable to extract samples during the reduction process. This system was designed to be independent from the reactor so there would be no need to stop the experimental operation while sampling. This would allow the collection of multiple samples at different times during each reduction experiment. More importantly, these samples can be used to analyse the extent of the reduction process and microstructural evolution of ironsand particles during the process. The design of the sampling system was according to the following criteria:

1. The sampling system should be able to collect samples of the bed material at various times during the reaction, with minimum interruption of the ongoing reaction process.

2. The sample amount that withdrawn should be less than $5 \mathrm{~g}$. This amount is sufficient to perform XRD and SEM analysis, without significantly reducing the overall mass of the bed.

3. The system should be able to quench the sample to retain the microstructure and phases contained in the sample at a certain reaction time.

4. The system should be simple and safe to be operated under $\mathrm{H}_{2}$ gas atmospheres.

A venturi suction system was chosen for the sampling system. The main reason for this is because it enables the use of inert gas with the opportunity to heavily dilute any hot flammable gas emitted when sampling. Additionally, this system does not require complicated mechanical parts, hence operation is relatively simple.

The principle of the venturi system is to introduce a high flow rate to the motive inlet of a venturi ejector. This provides a significant gas velocity change at the venturi nozzle, producing a pressure drop, which drives the suction of sample particles from the bed.

\subsubsection{Initial tests in a laboratory set-up at room temperature}

Before installing the venturi to the reactor, initial tests were carried out at room temperature to test the effectiveness of the venturi system to suck ironsand samples during fluidisation. Cold tests of the venturi suction system were performed using ironsand with a size fraction of 106-125 $\mu \mathrm{m}$. A custom venturi ejector was fabricated for this purpose. The experimental set-up for these tests at room temperature is illustrated in Figure 4.8. Three 
different outer diameters of stainless-steel tube were used (1/8", 3/16", and 1/4") to test the optimum size of sampling tube. A flow meter was installed in the gas line between the $\mathrm{N}_{2}$ gas bottle and the venturi ejector to measure the minimum flow rate of $\mathrm{N}_{2}$ gas that was required to suck samples out from the FB tube.

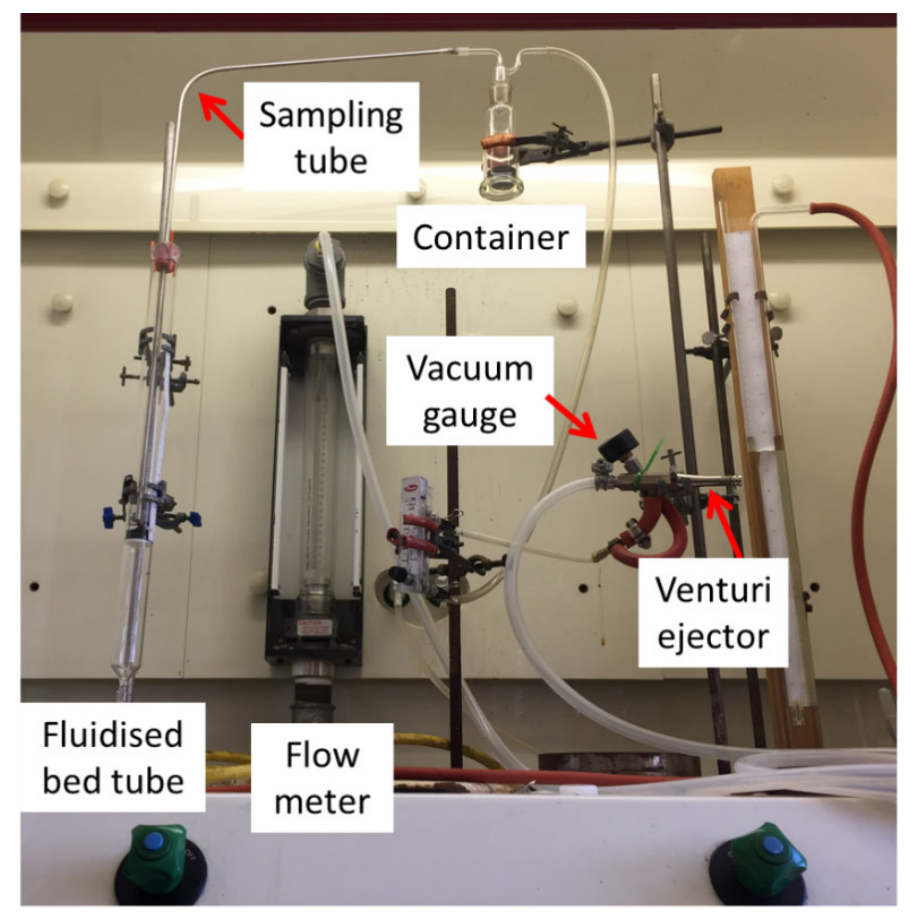

(a)

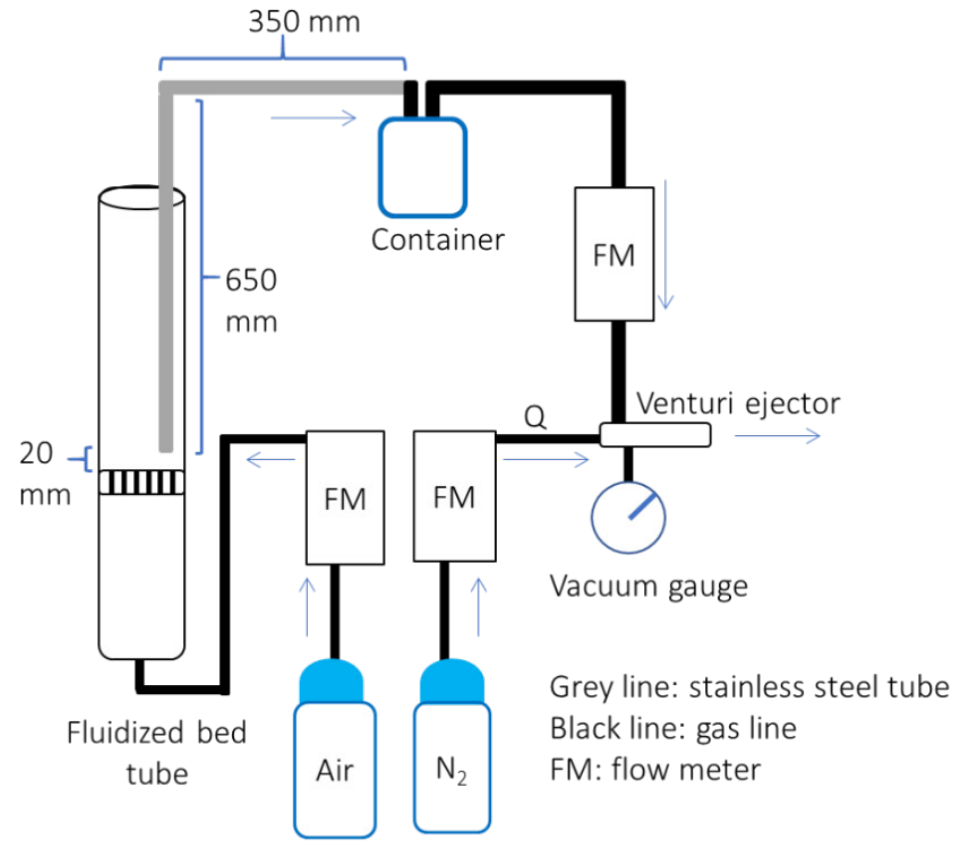

(b)

Figure 4.8 A photograph (a) and schematic diagram for sampling system tests a laboratory set-up at room temperature. 
From these tests, it was found that the venturi system was able to suck out samples from the FB tube configured in Figure 4.8. Table 4.3 presents the minimum flow rate of $\mathrm{N}_{2}$ gas required to blow the venturi (Q), for all tube sizes tested. During the tests, some stuck particles were stuck at the connection and curve section points when using 1/8" and 3/16" diameter tubes. Accordingly, the 1/4" size tube was chosen as most suitable for the experimental sampling system.

Table 4.3 Comparison of the minimum flow rate and vacuum needed for different tube sizes.

\begin{tabular}{|c|c|c|c|}
\hline $\begin{array}{c}\text { Tube size } \\
\text { (inch) }\end{array}$ & $\begin{array}{c}\text { Tube inner } \\
\text { diameter } \\
(\mathrm{mm})\end{array}$ & $\begin{array}{c}\text { Vacuum } \\
(\mathrm{cm} \mathrm{Hg})\end{array}$ & $\begin{array}{c}\mathrm{Q} \\
(\mathrm{L} / \mathrm{min})\end{array}$ \\
\hline $1 / 8$ & $\sim 1.8$ & -35 & 100 \\
\hline $3 / 16$ & $\sim 2.9$ & -30 & 100 \\
\hline $1 / 4$ & $\sim 3.9$ & -20 & 90 \\
\hline
\end{tabular}

\subsubsection{Sampling tests using the high-temperature FB reactor set-up}

The next step was to install the venturi system to the high-temperature FB reactor setup in Figure 4.7. Figure 4.9 presents a photograph and a schematic design of the venturi sampling system installed to the reactor. This consists of a venturi ejector, a cyclone sampler, and a sample container. A ball valve is installed between the cyclone sampler and the sample container, which enables the reactor atmosphere to be isolated when the sample container is changed. The sampling tube is located below the top of the cyclone, allowing solid particles to fall straight into the container, see Figure 4.9(b).

The particle collection system can extract the entire bed if suction is performed for a prolonged time, making it convenient for sample exchange. To obtain small aliquots, the suction needs to be applied for only a short period. Solenoid valves, acting as an open-close system, are installed at the inlet and the outlet of the ejector. The length of time for which these valves are open controls the amount of sample collected. 


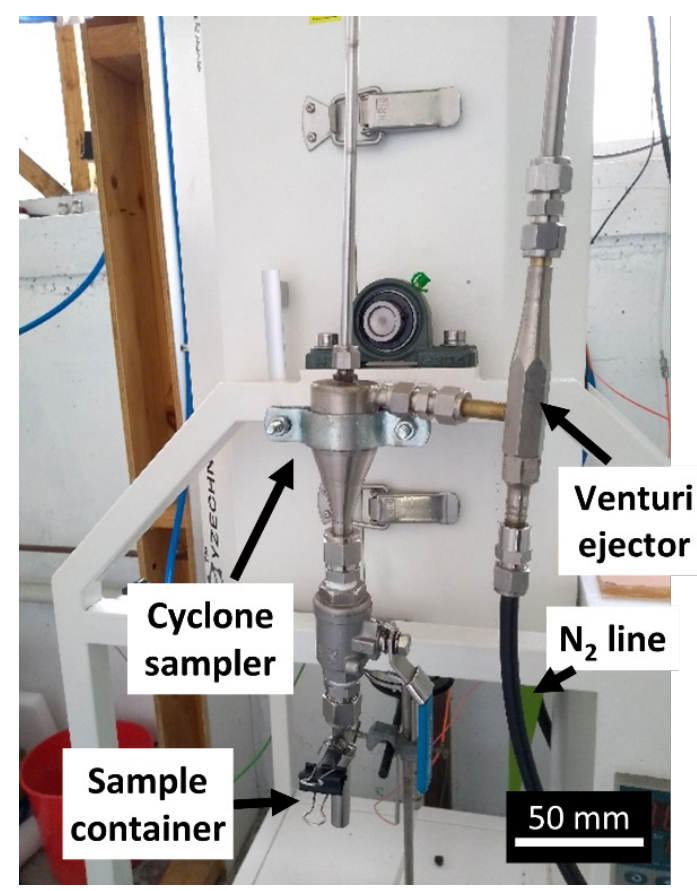

(a)

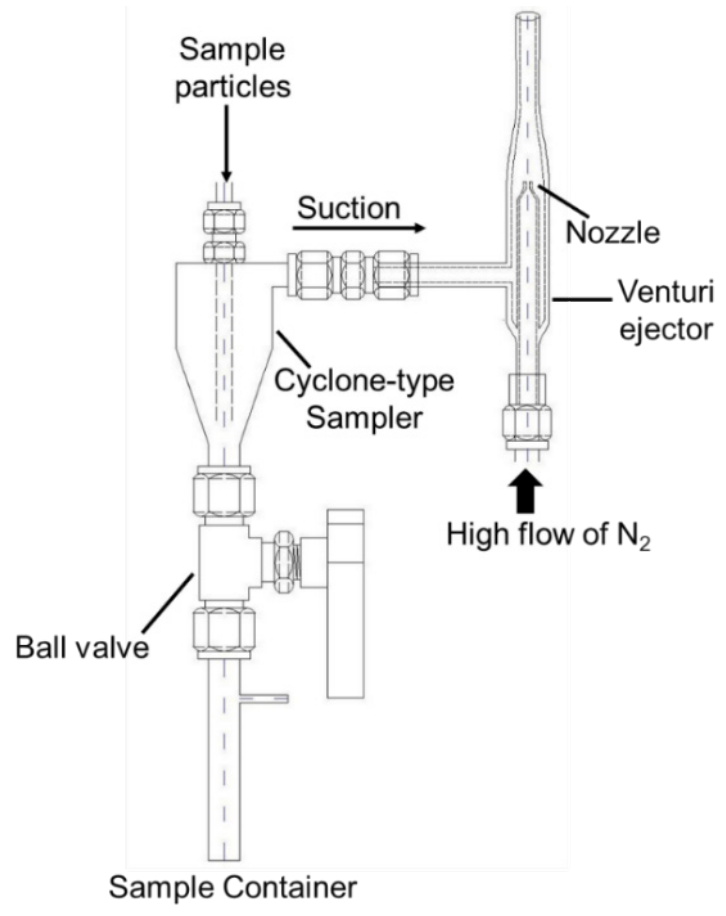

(b)

Figure 4.9 A photograph (a) and a schematic diagram (b) of the sampling system installed to the high-temperature FB reactor.

Initial tests of sampling using the reactor set-up in Figure 4.7 were conducted to test the possibility for obtaining small aliquots of less than $5 \mathrm{~g}$. These tests were conducted during fluidisation of ironsand with 106-125 $\mu \mathrm{m}$ size fraction in $\mathrm{N}_{2}$ gas, at both room temperature (cold) and $1000^{\circ} \mathrm{C}$ (hot). Figure 4.10 (a) shows the amount of ironsand 
collected as a function of 'valve-open' time for both cold and hot sampling. Figure 4.10(b) shows the repeated sampling of four sample sets, each collected for 'valve-open' times of $1.5 \mathrm{~s}$ under hot fluidisation conditions. Under these conditions, the sample mass collected varied between one and four grams. This variability in total mass sample is not a problem if the total mass sampled over $\mathrm{N}=5$ samples is not more than $\sim 10 \%$ of total initial bed mass.

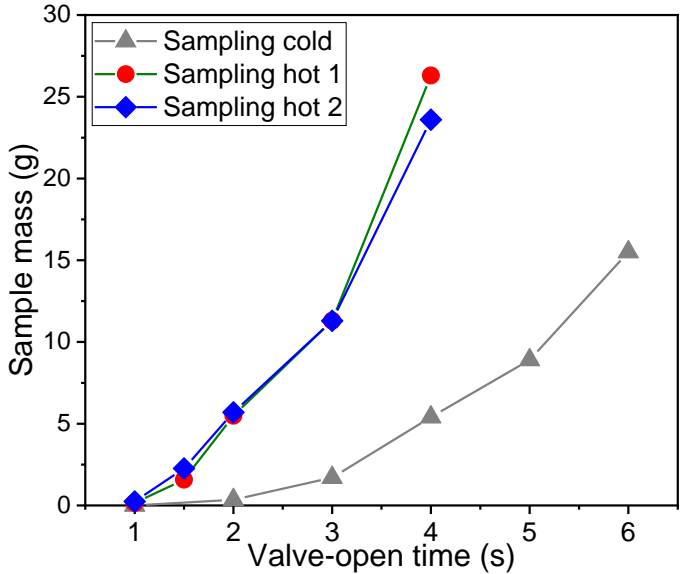

(a)

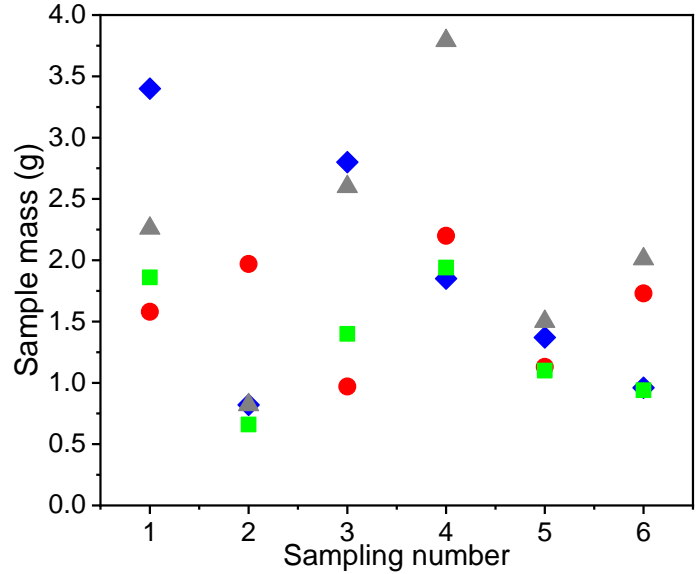

(b)

Figure 4.10 Sampling collection at different "valve-open" times (a) and at six repetitions for every $1.5 \mathrm{~s}$ of "valve open" at $1000^{\circ} \mathrm{C}$ (b).

Another concern is to ensure that the sample collected by this system is representative of the particle population in the bed. Figure 4.11 shows that this is the case, as PSD of the sampled material is reproducible over multiple samples, and closely matches the original PSD of the bed. This is true even when the bed comprises the non-sieved raw ironsand concentrate with a broad particle size distribution (Figure 3.2 in Chapter 3).

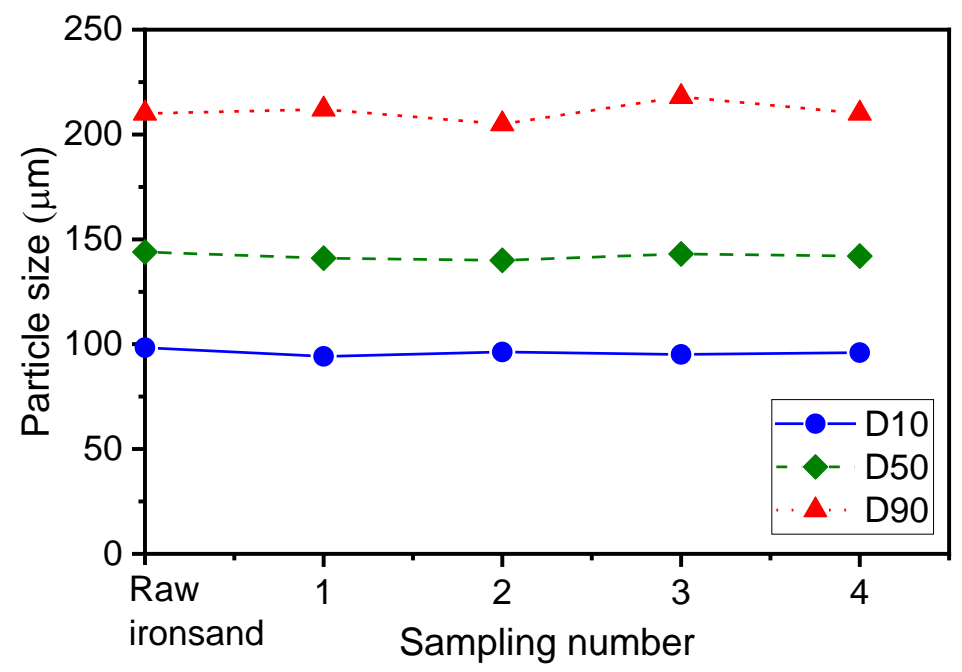

Figure 4.11 PSD analysis of raw ironsand concentrate and raw ironsand samples collected by the sampling system 


\subsection{Commissioning of the high-temperature FB reactor}

\subsubsection{Initial commissioning of the reactor system using an inert gas $\left(\mathrm{N}_{2}\right)$ at $1000^{\circ} \mathrm{C}$}

Initial tests of the hot fluidisation of ironsand were conducted at $1000^{\circ} \mathrm{C}$ using ironsand with a particle size of 106-125 $\mu \mathrm{m}$ and nitrogen as the fluidising gas (to enable comparison to the cold model fluidisation results). The $\Delta P$ profile obtained during hot fluidisation is shown in Figure 4.12. Overall, these results show a similar behaviour to the cold fluidisation data in Figure 4.5(a). Comparison with the data shown in Table 4.1 confirms that the hot fluidisation parameters are close to the cold fluidisation conditions using the 63-90 $\mu \mathrm{m}$ ironsand size fraction and helium gas. In Figure 4.12, an approximately constant $\Delta P$ is observed for the fluidisation state (i.e. between $1 \mathrm{kPa}$ and $1.2 \mathrm{kPa}$ ), which is equal to the $\frac{W_{b}}{A_{b}}$ value. Particles started to be entrained and leave the reactor when the flow rate is $65 \mathrm{~cm} / \mathrm{s}$. This implies that the $U_{t}$ value is between 55 and $65 \mathrm{~cm} / \mathrm{s}$.

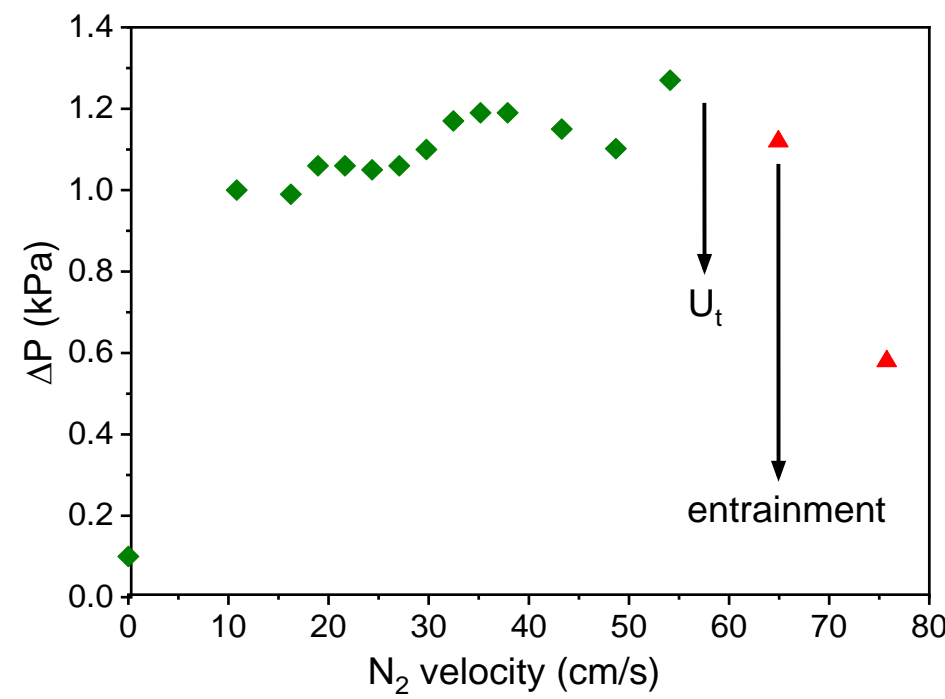

Figure 4.12 Measured Pressure drop across the $\mathrm{FB}$ at $1000^{\circ} \mathrm{C}$ at different $\mathrm{N}_{2}$ gas velocities.

The $U_{m f}$ value during hot fluidisation was not measured, as it occurs at a gas flow below $1 \mathrm{~L} / \mathrm{min}$. This is less than the minimum flow available from the mass flow controller.

During the heating step before performing these measurements, $3 \mathrm{l} / \mathrm{min}$ of $\mathrm{N}_{2}$ gas was purged to keep the ironsand particles fluidised. As a result, a pressure drop was measured across the frit and bed throughout the heating step. The $\mathrm{N}_{2}$ gas was then stopped to record the $\Delta P$ at zero $\mathrm{N}_{2}$ gas velocity. The non-zero $\Delta P$ observed at zero $\mathrm{N}_{2}$ gas velocity in Figure 
4.12 is the residual pressure across the frit read at this time. Note that it is not the digital offset of the pressure sensor reading, which was measured to be much smaller ( $0.02 \mathrm{Kpa})$.

\subsubsection{Commissioning of the reactor system using air at $1000^{\circ} \mathrm{C}$}

The next step in commissioning the reactor set-up was to test reproducibility of experimental data for materials sampled over the course of a reaction. For this purpose, initial oxidation tests of ironsand were performed at different temperatures. These oxidation experiments were carried out before the reduction tests, as it enabled further safety checks of the full operating system. Air is not explosive but still provides a reactive atmosphere for ironsand during fluidisation (oxidation). These tests were also to check for possible errors in the installation of the reactor.

The oxidation tests were performed using 106-125 $\mu \mathrm{m}$ ironsand as the bed material. A series of experiments was performed at different oxidation temperatures between $800^{\circ} \mathrm{C}$ and $1000^{\circ} \mathrm{C}$ in $50^{\circ} \mathrm{C}$ intervals. Two experimental runs were performed for each temperature. For each experimental run, a fresh $100 \mathrm{~g}$ sample of ironsand powder was oxidized in air with a flow rate of $3 \mathrm{~L} / \mathrm{min}$.

The q-XRD analysis was used to obtain the wt.\% of each crystalline phase in each sample. Figure 4.13 shows the time evolution of each crystalline phase for each temperature. Again, the experiments show excellent reproducibility of phase evolution data for each temperature.

The q-XRD data shown in Figure 4.13 can be used to calculate oxidation degree by equation (4.5),

$$
\text { Oxidation degree }=\frac{m T T M_{0}-m T T M_{t}}{m T T M_{0}} \times 100 \%
$$

where $m T T M_{0}$ is wt.\% of TTM phase in the raw ironsand and $m T T M_{t}$ is wt.\% of TTM phase after $t$ time oxidation. Figure 4.14 shows plots of oxidation degree as a function of time for all temperatures. As can be seen, these experiments showed excellent reproducibility of oxidation degree for each temperature. 


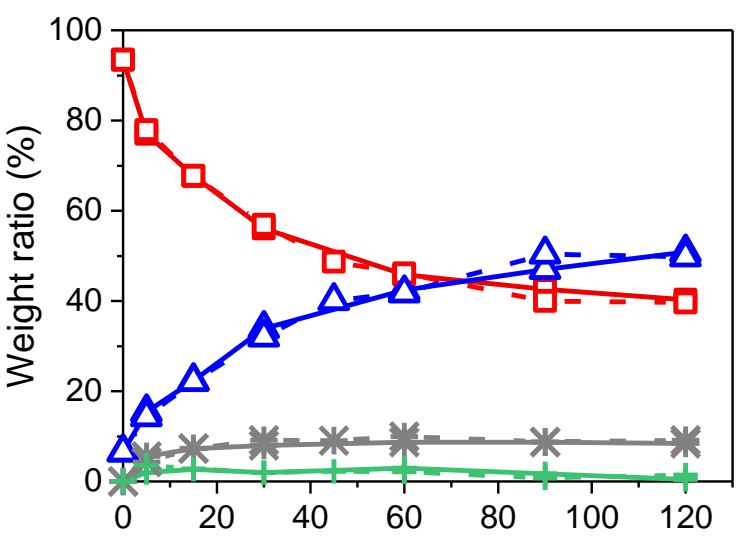

(a)

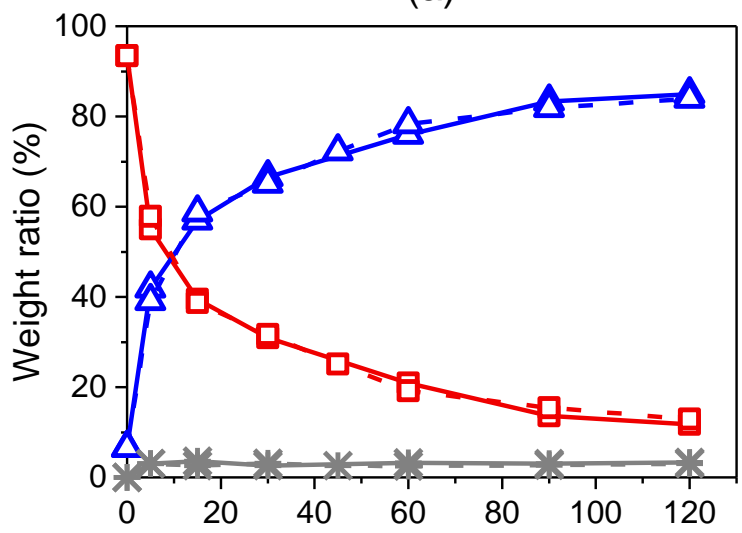

(c)

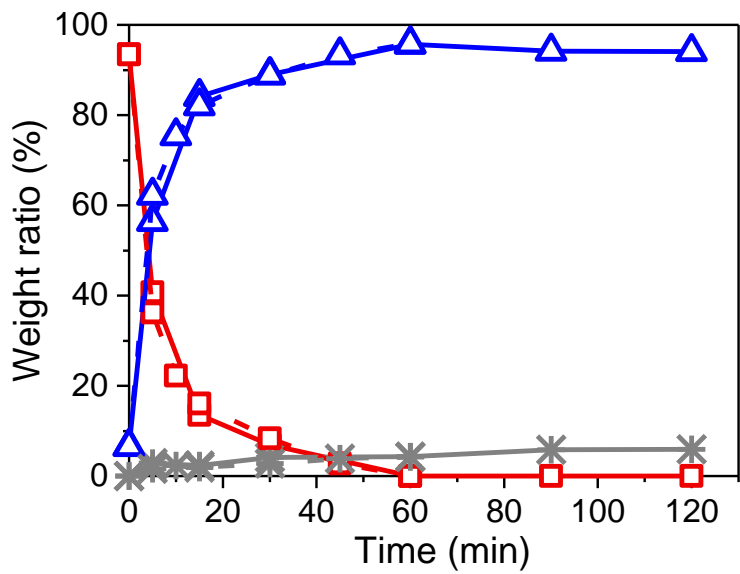

(e)

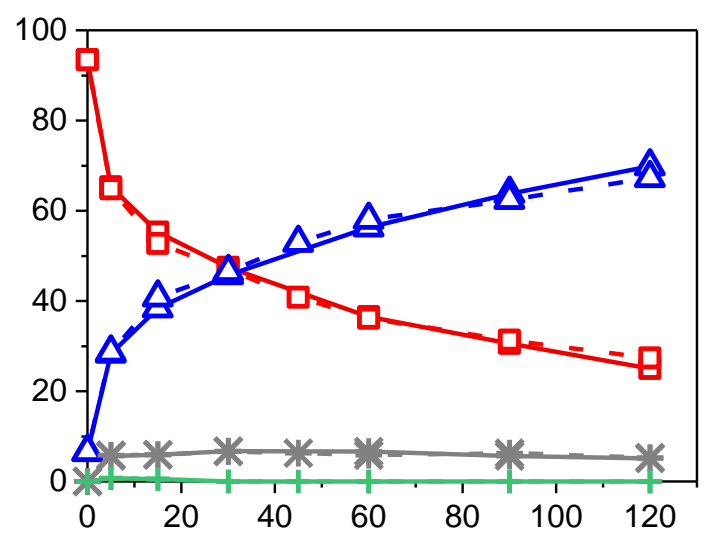

(b)

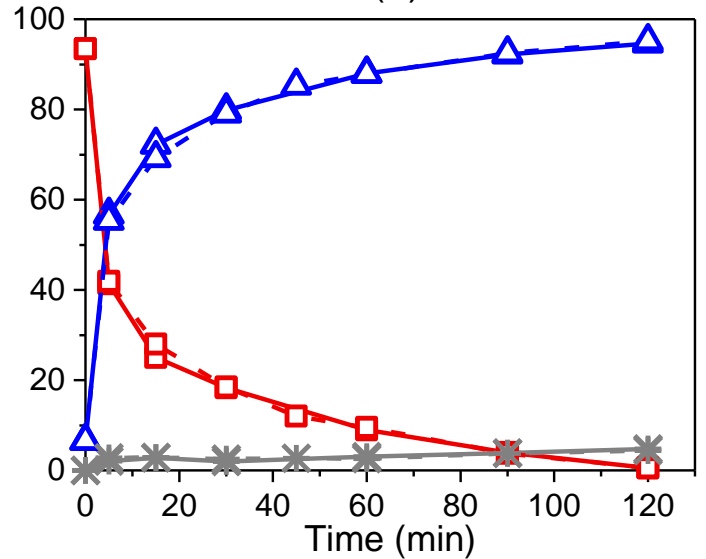

(d)

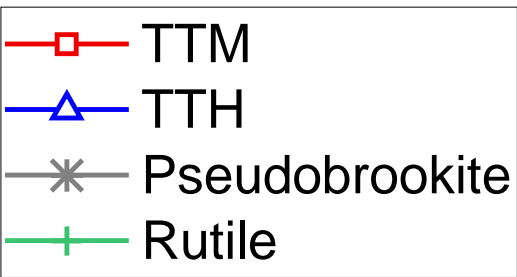

Figure 4.13 The evolution of the crystalline phases as a function of time during the FB oxidation of ironsand in air at various temperatures. Temperatures are (a) $800^{\circ} \mathrm{C}$, (b) $850^{\circ} \mathrm{C}$, (c) $900^{\circ} \mathrm{C},(\mathrm{d}) 950^{\circ} \mathrm{C}$, and $(e), 1000^{\circ} \mathrm{C}$. Solid lines indicate the first trial and dashed lines indicate the second trial for each temperature. 


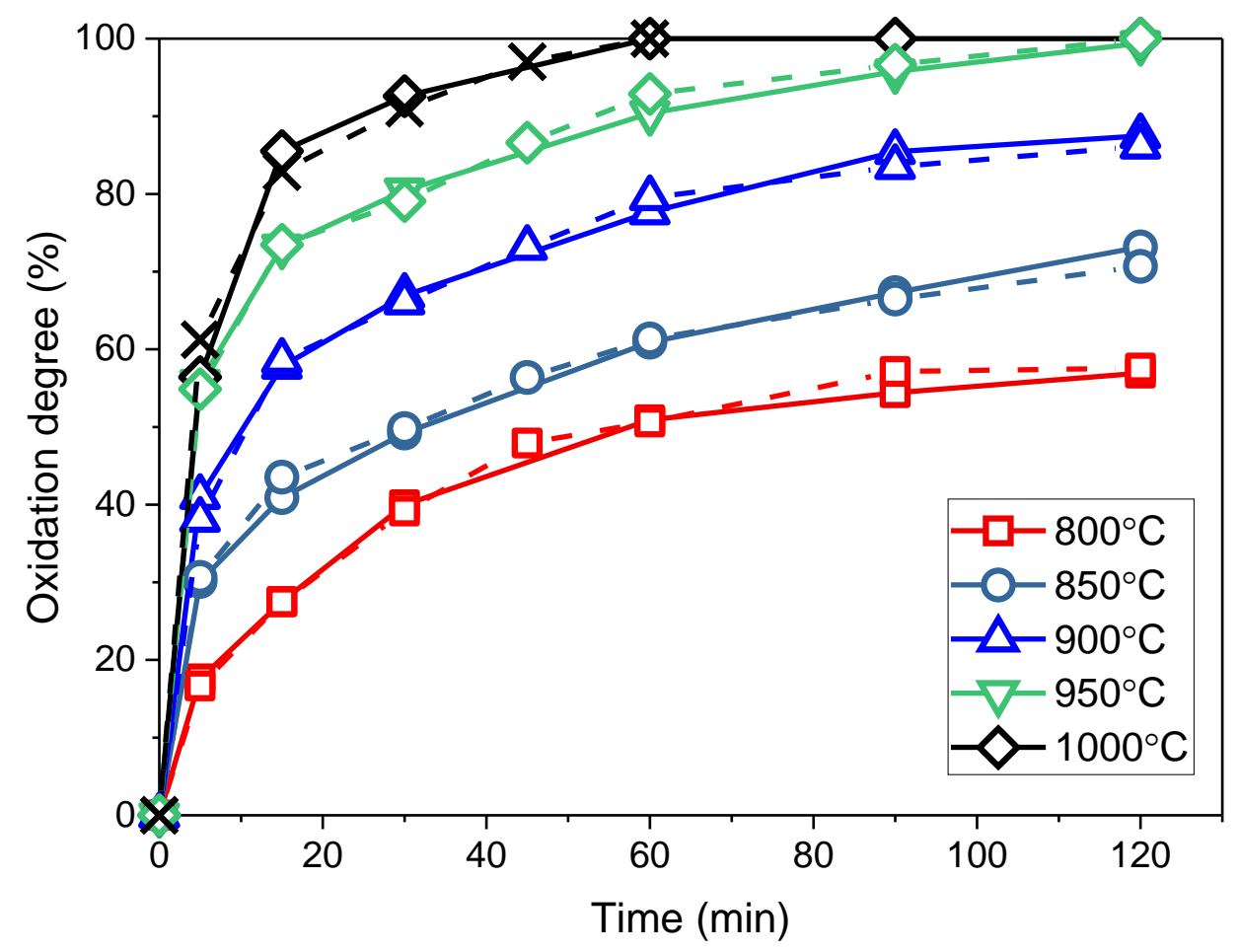

Figure 4.14 Oxidation degree of TTM ironsand oxidised in air at various temperatures.

Solid lines indicate the first trial and dashed lines indicate the second trial for each temperature.

\subsection{Summary}

A lab-scale experimental FB reactor has been designed and commissioned for the high temperature hydrogen reduction of TTM ironsand. The fluidisation parameters of NZ ironsand in this system have been determined from both theoretical calculations and actual experiments.

A sampling system employing a venturi ejector was designed to be able to collect samples directly during a fluidisation process in a flammable gas atmosphere. This system can controllably collect samples of less than $5 \mathrm{~g}$ by timed switching of a solenoid valve. The particle size distribution of samples collected is consistent with the initial bed samples, indicating that samples collected are representative of the whole bed within the reactor. 


\section{Chapter 5}

\section{Sticking in the Reduction of Magnetite by $\mathrm{H}_{2}$ Gas at $950^{\circ} \mathrm{C}$}

\subsection{Outline}

This chapter discusses the reduction of Hoganas magnetite ore at $950^{\circ} \mathrm{C}$. This temperature is known to be higher than the reported sticking temperatures for conventional hematite and magnetite ore (Gransden and Sheasby, 1974; Komatina and Gudenau, 2004; Guo et al., 2015). The purpose of this experiment is to confirm that sticking occurs during the high temperature hydrogen reduction of pure magnetite in our experimental FB reactor.

The onset of sticking during an FB reduction process can be detected from a sudden sharp fall of the pressure drop across the bed (Bartels et al., 2008; Zhang et al., 2012; Zhang, Lei and Zhu, 2014). As particles stick each other, the bed will de-fluidise and become a porous sintered mass. This condition will rapidly decrease the pressure drop.

The bed material used for this study was commercially-supplied Hoganas 'Magnetite 60', from which a size-sieved fraction between 106 and $150 \mu \mathrm{m}$ was screened. The chemical composition (measured by XRF) and the XRD pattern of the sample are presented in Table 3.2 and Figure 5.1, respectively. The reducing gas used was $100 \% \mathrm{H}_{2}$ with a flow rate of $5 \mathrm{~L} / \mathrm{min}$.

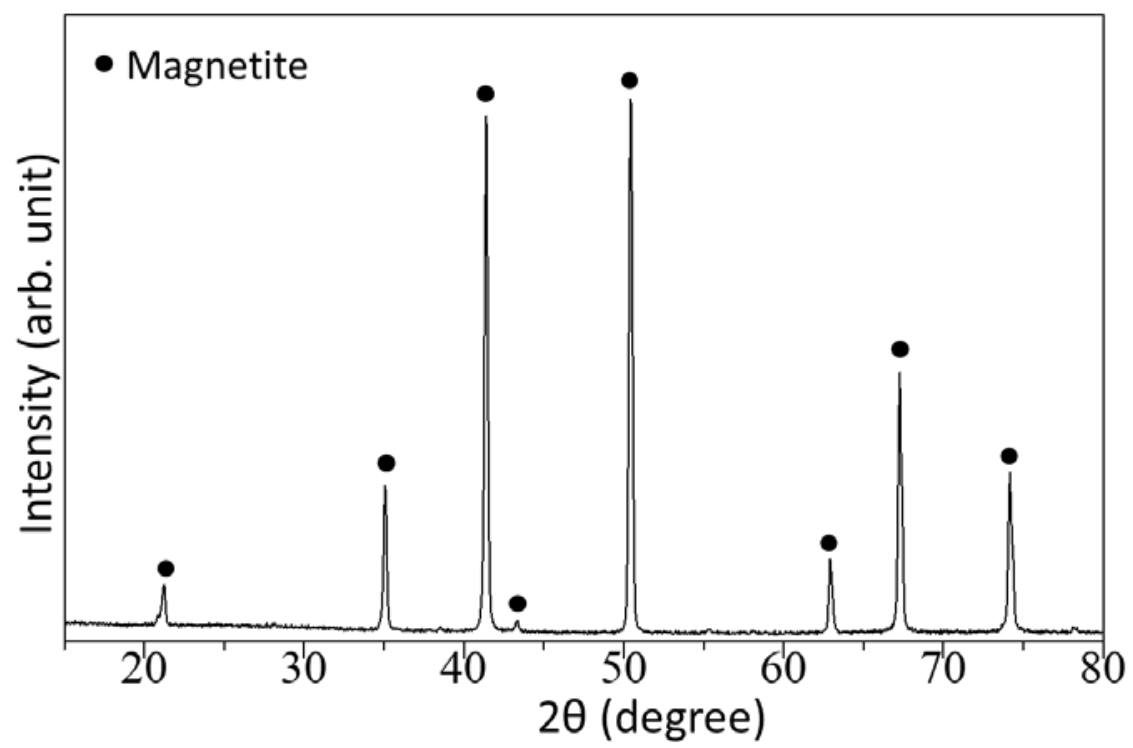

Figure 5.1 XRD pattern of the commercially-sourced Hoganas Magnetite material (106$150 \mu \mathrm{m}$ size fraction) used in the experiments reported in this chapter. 


\subsection{Observation of sticking}

Figure 5.2 shows measured time profiles for the gas flow rate, bed temperature, and $\Delta P$ during the reduction of magnetite at $950^{\circ} \mathrm{C}$. In the Figure, the reduction period is when the $5 \mathrm{~L} / \mathrm{min} \mathrm{H}_{2}$ gas is flowed to the reactor (Figure 5.2(a)). In the beginning of the reduction, the bed temperature decreases slightly and rises again quickly (Figure 5.2(b)). This is because the reduction process is endothermic, hence absorbs heat from the furnace. Shortly before about four minutes of reduction, a sharp fall in $\Delta P$ was observed, as shown in Figure 5.2(c). A slight fall of the bed temperature is also observed at this point (Figure 5.2(b)). This could be due to the change in the heat transfer from the reactor to the bed when the bed is defluidised. As the bed is defluidised (in a static condition), the thermocouple may read the colder section of the sintered bed (centre of the bed). It can be seen in the Figure that the bed temperature increases again. This is because the furnace controller gives more heating power to ramp up the bed temperature again. In this condition, the wall temperature might become higher than the bed temperature read by the thermocouple. After this time, the $\Delta P$ of the bed remains low. The reduction run was then stopped after about six minutes by switching the $\mathrm{H}_{2}$ gas to Ar gas (Figure 5.2(c)). Bed samples could not be extracted from the reactor by the venturi sampling system, even after switching to Ar gas. Taken together, these observations indicated de-fluidisation due to sticking of the bed. Bed samples were taken out from the reactor after the furnace had cooled to room temperature. 

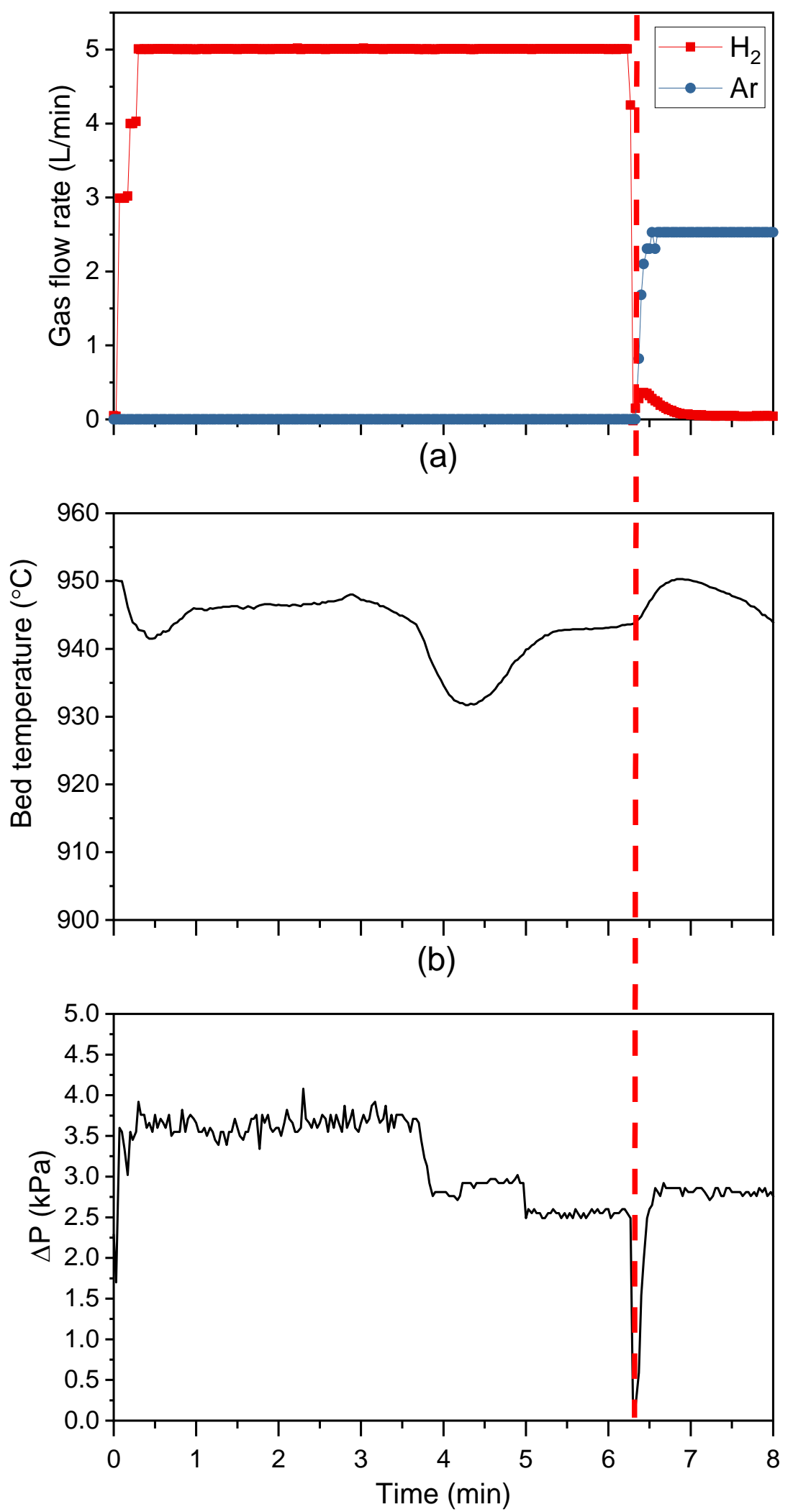

(c)

Figure 5.2 Profiles of gas flow rate (a), temperature (b), and $\triangle P(c)$ during the reduction of magnetite by $100 \% \mathrm{H}_{2}$ gas at $950^{\circ} \mathrm{C}$. Red dotted line indicates the reduction period. Reduction period is the period when the hydrogen gas flow rate is $5 \mathrm{~L} / \mathrm{min}$. 
A photograph of the bed sample after the reduction experiment had prematurely ended is shown in Figure 5.3. A combination of sintered and loose powder is observed. The sintered parts (Figure 5.3(a)) are brittle, indicating that the sintering bond is weak. Some loose powder is also observed in Figure 5.3(b), which might be from disintegration of the sintered part. Disintegration of the sintered part may have occurred due to material handling during sample removal from the reactor. It should be noted that these images show the state of the bed at room temperature, after cooling under $\mathrm{Ar}$ gas from $950^{\circ} \mathrm{C}$. It is possible that the bonding of the sinter is stronger at high temperature, which would explain why fluidisation stopped.

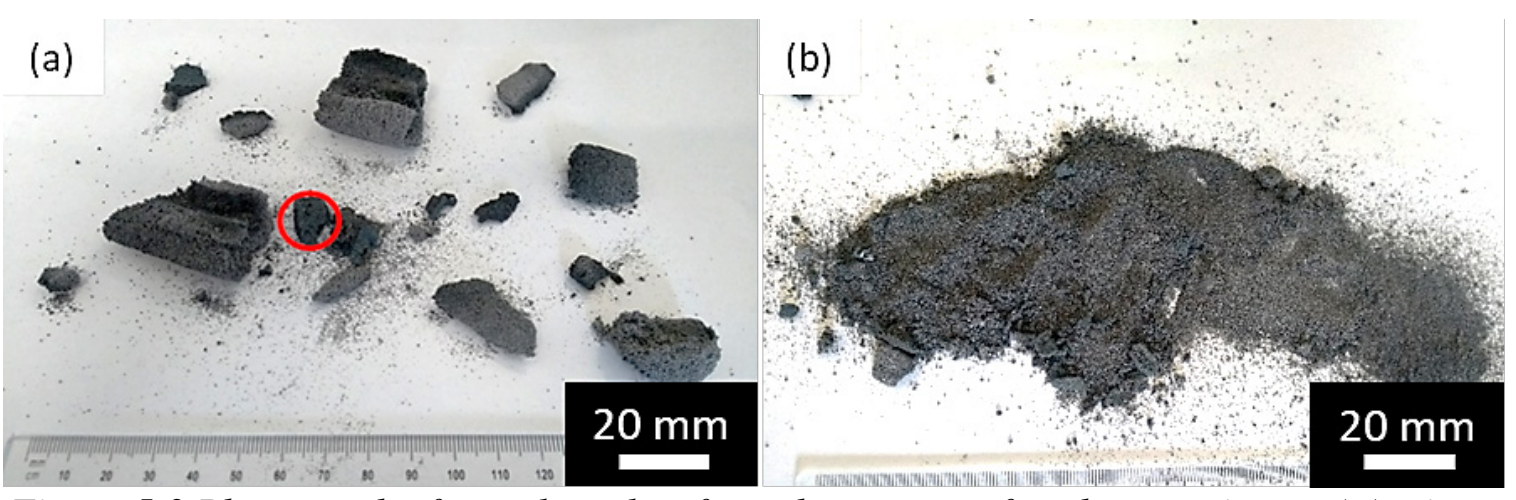

Figure 5.3 Photograph of samples taken from the reactor after the experiment. (a): sinter part; (b): loose powder part.

Figure 5.4 shows the XRD patterns of the sintered part (red circle) and loose powder part shown in Figure 5.3. The two XRD patterns are almost identical, implying that the powder part most likely comes from the disintegration of the sinter part. Compared to Figure 5.1, the dominant XRD peak in both samples is wüstite, implying that both samples have been partially reduced. Small metallic iron XRD peaks are also observed in both samples. This indicates that the onset of sticking occurred as wüstite started to be reduced to metallic iron. This result is consistent with several previous studies which have reported that sticking occurs during FB reduction of iron ores by $\mathrm{H}_{2}$ gas (Gransden and Sheasby, 1974; Nicolle and Rist, 1979; Komatina and Gudenau, 2004; Shao, Guo and Tang, 2013), at the point when metallic iron is started to be formed from wüstite. 


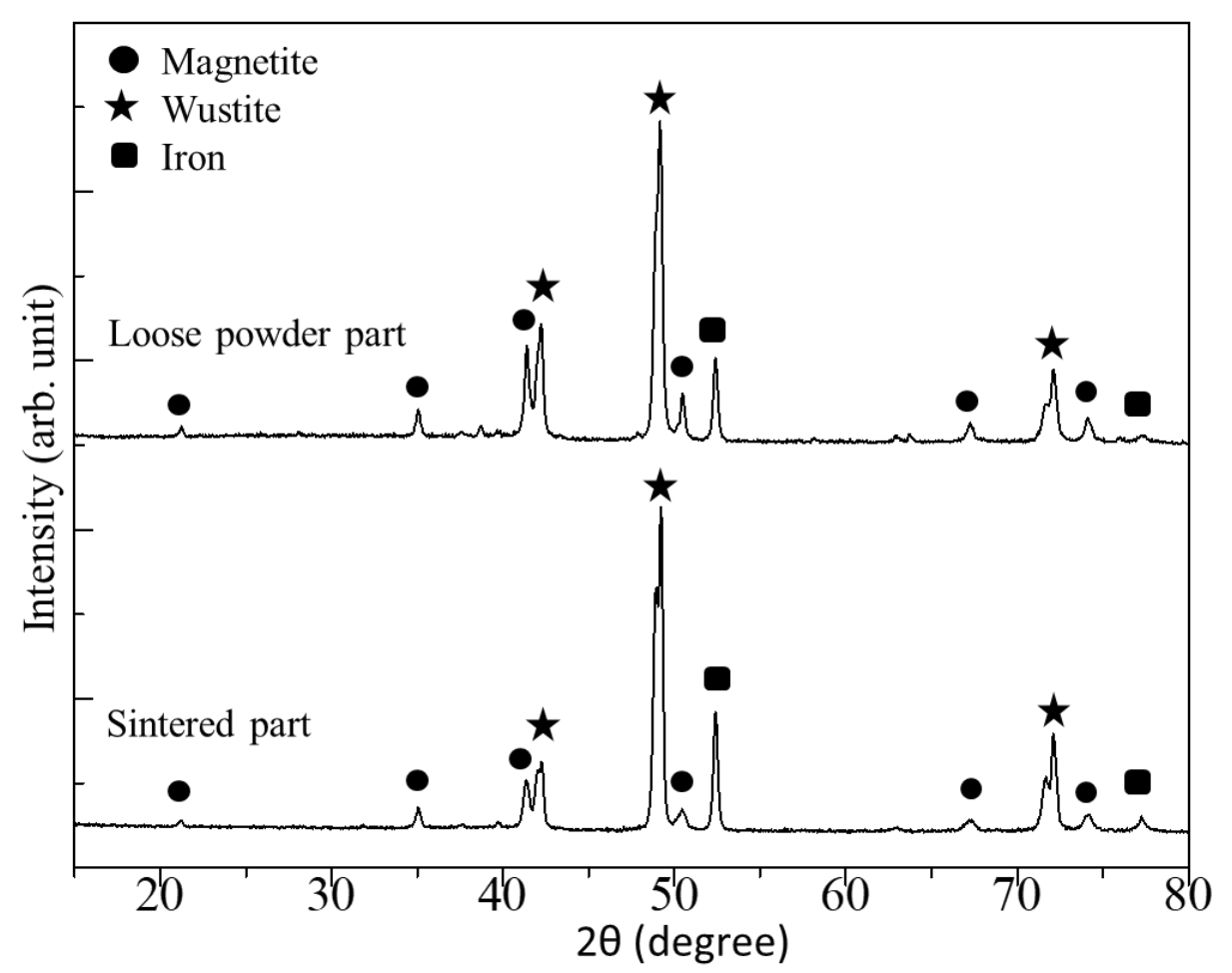

Figure 5.4 XRD patterns of the sintered part and powder part of the sample.

\subsection{Microstructure of the bed material after sticking}

SEM analysis was carried out on both sinter and loose powder parts to further evaluate the origin and cause of sticking in this case. Images were obtained of both the material surface and in cross-section.

\subsubsection{Sintered part}

A photograph of a sample of the sintered material (red circle in Figure 5.3) is shown in Figure 5.5(a). A higher magnification SEM image (65x magnification) of this is shown in Figure 5.5(b). The sintered sample appears to be highly porous, as can be seen from the many voids (black regions) in between the individual stuck-together particles. The shape of individual particles is maintained, which is consistent with this being a weak sinter. 

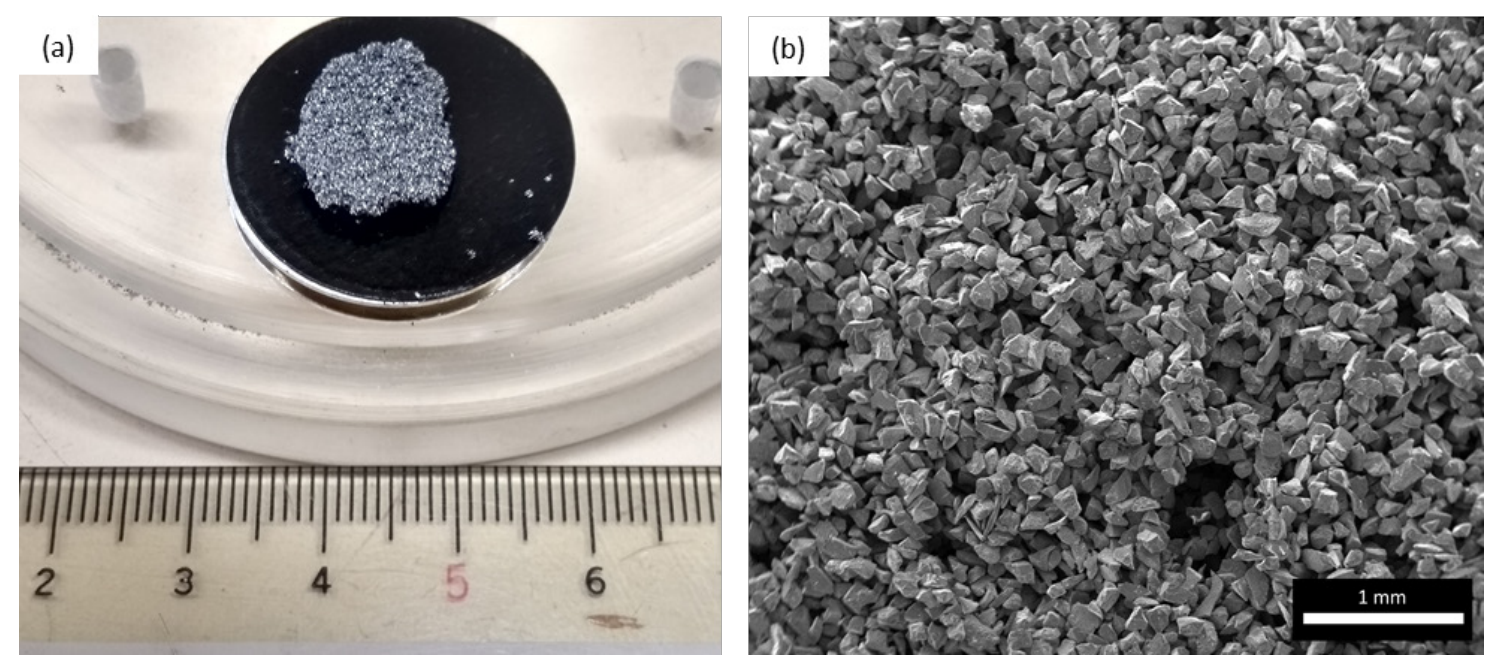

Figure 5.5 Photograph (a), and SEM image (65x magnification) (b), of a sample of sintered bed material.

Figure 5.6 shows BSE images of the points at which two adjoining particles are 'stuck' together. Images shown in Figure 5.6 (a-d) are taken at four different sticking locations in the sintered sample shown in Figure 5.5. The different contrast of the BSE image show that some areas of each particles surface is covered by a thin bright light grey phase (black arrow).

Figure 5.6(e, f, g, h) show higher magnification images of the respective images of Figure 5.6(a, b, c, d). In each case a small sintered "bridge" (red arrow) can be seen connecting two adjacent particles. The BSE contrast in Figure 5.6(e, f, g, h) shows that this sintered bridge is a part of the bright light grey phase. Apart from these small bridging points, it is apparent that the two particles are not fully sintered on the surface. Instead, the sticking between adjacent particles appears to be solely due to these point-to-point connections. This microstructure likely explains the weak bonding between particles in the sinter.

EDS point analysis for each of the numbered spots shown in Figure 5.6 is presented in Table 5.1. Analyses taken on the bright light grey areas (points 1, 2, 5, 6, 8, 9, 11) correspond to a much higher Fe content than those taken on the grey areas (points 3, 4, 7, $10,12)$. This implies that the bright light grey phase is metallic iron. Since the grey area contains much higher oxygen, this area is most likely the wüstite phase detected by XRD in Figure 5.4. Taken together, this data suggests that the onset of sticking in this FB experiment was caused by iron-iron contact on the surface of two colliding particles. The 
small oxygen signals obtained from the metallic iron regions are likely to be a measurement artefact because the sample is not flat.
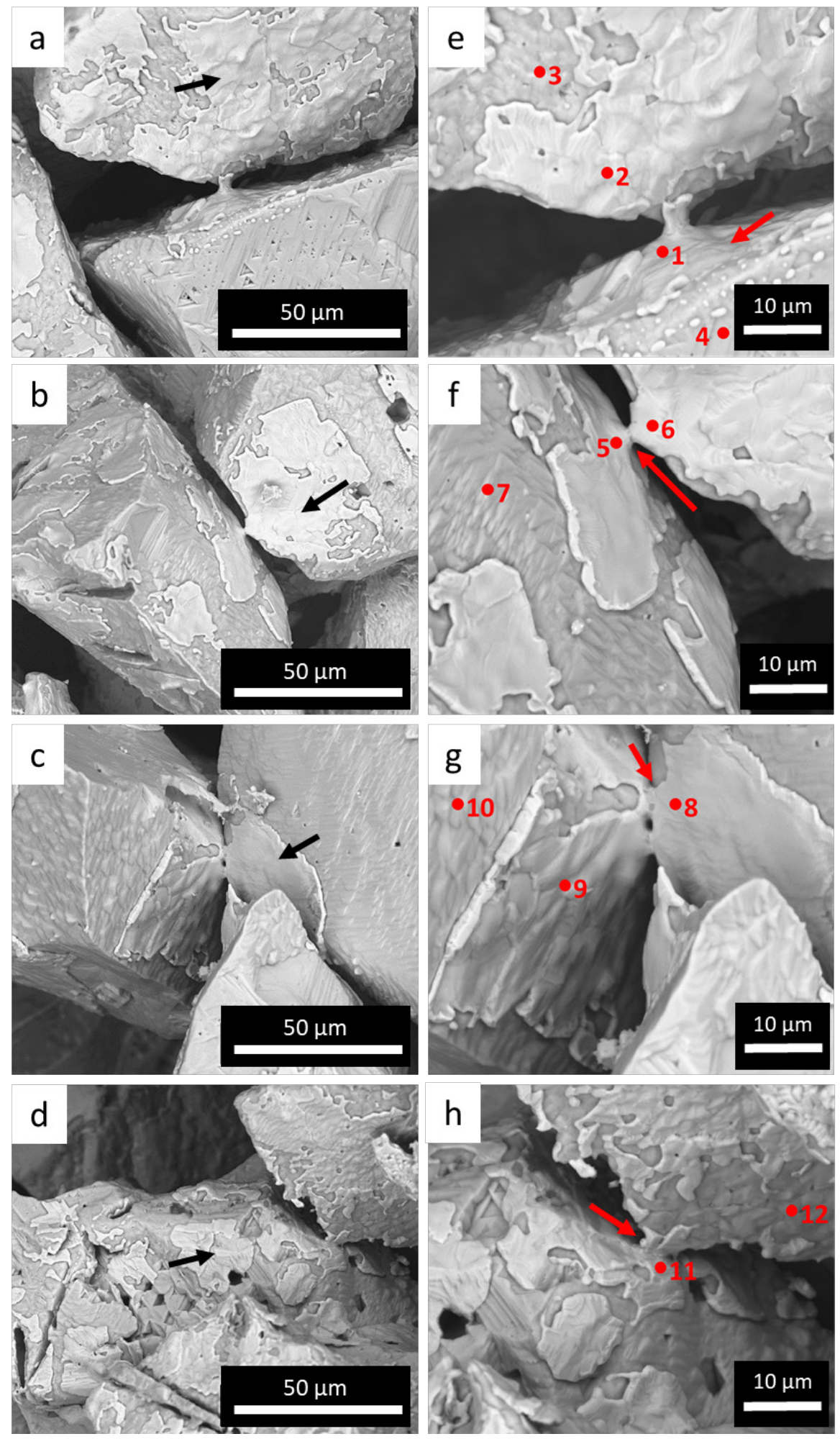

Figure 5.6 Surface BSE-SEM images of the sticking between two particles in the sinter sample from the reduction of Hoganas magnetite by $5 \mathrm{~L} / \mathrm{min}$ at $950^{\circ} \mathrm{C}$. Red arrows indicate sticking contact locations. Black arrows indicate metallic iron. Images on the right side (e-h) are the high magnification images of the respective left images $(a-d)$. 
Table 5.1 Elemental spot EDS analysis of points shown in Figure 5.6. Red coloured fonts are for the bright light grey phase.

\begin{tabular}{ccccccccccccc}
\hline \multirow{2}{*}{ Element } & \multicolumn{10}{c}{ Point (At. \%) } \\
\cline { 2 - 12 } & 1 & 2 & 3 & 4 & 5 & 6 & 7 & 8 & 9 & 10 & 11 & 12 \\
\hline $\mathrm{O}$ & 10.6 & - & 48.1 & 53.9 & - & - & 58.2 & 4.7 & - & 59.3 & 5.4 & 39.1 \\
$\mathrm{Fe}$ & 89.4 & 100 & 51.9 & 46.1 & 100 & 100 & 41.8 & 95.3 & 100 & 40.7 & 94.6 & 60.9 \\
$\mathrm{Fe} / \mathrm{O}$ & 8.4 & - & 1.1 & 0.9 & - & - & 0.7 & 20.3 & - & 0.7 & 17.5 & 1.6 \\
\hline
\end{tabular}

The hyphen sign in the table means no signal for the respective element.

Figure 5.7 shows EDS element maps of the sticking contact points between two particles at two different locations in the sample. Figure 5.7(b) and (e) confirm that the sintered "bridge" that connects between particles is metallic iron.
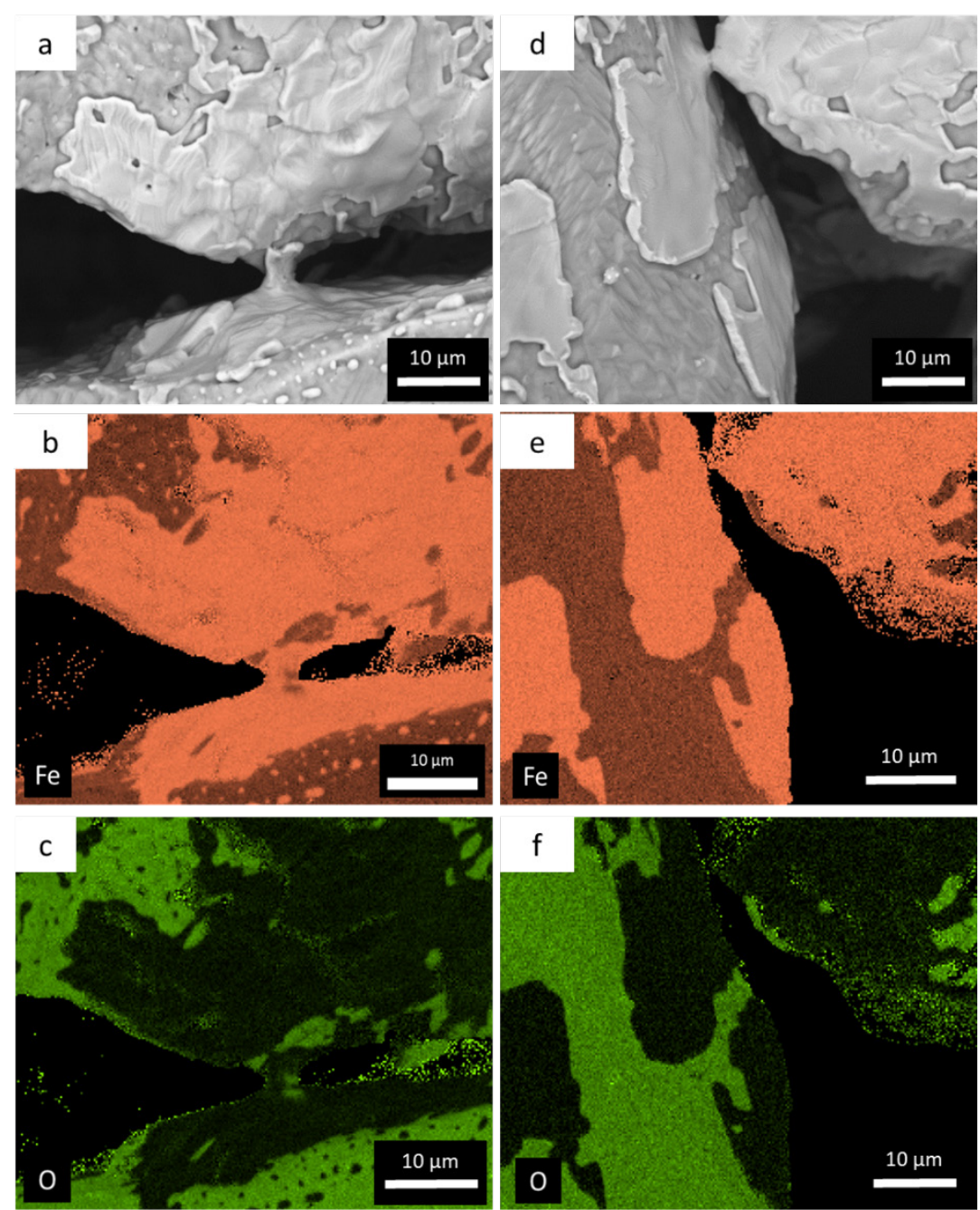

Figure 5.7 Elemental EDS map of two sticking locations. (b and (c) are the element map of BSE image (a). (e) and ( $f$ ) are the element map of BSE image (d). (b), (c), (e), (f) refer to the element noted in each image. 
A photograph of a polished cross-section of the sintered sample is presented in Figure 5.8(a). A higher magnification SEM image of the sinter is presented in Figure 5.8(b). In the Figure, most particles appear separated because the low density of the sinter. This means that any plane cut through its volume largely intersects a void.
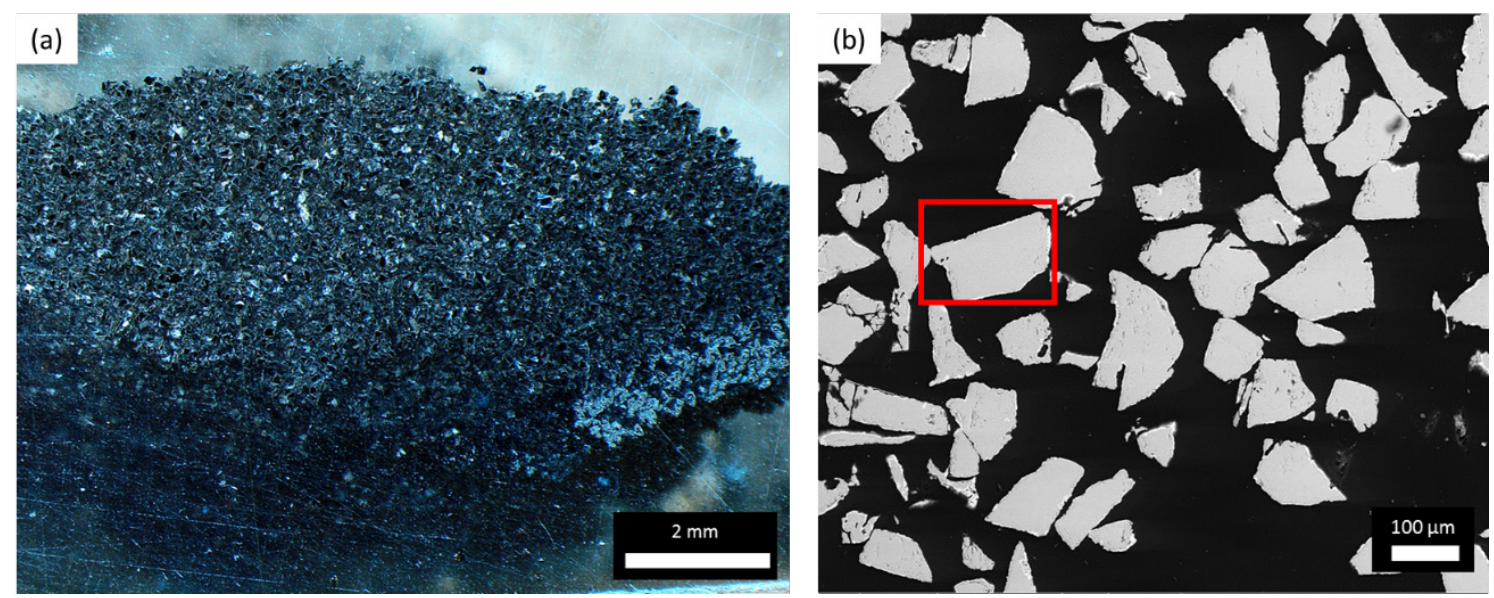

Figure 5.8 Photograph (a) and SEM image (300x magnification) (b) of the sintered sample.

Figure 5.9 shows a typical cross-section image of a particle within the sintered part. The EDS point analysis of each point in Figure 5.9 is listed in Table 5.2. It is clearly seen that the particle is surrounded by the bright phase. EDS confirms that this bright phase on the particle surface is metallic iron [see points 2 and 3 in Figure 5.9(b)]. This is consistent with the observations of surface morphology in Figures 5.6 and 5.7.

The Fe/O ratio of the grey area at points 13 and 18 is 1.1 , which is comparable to the $\mathrm{Fe} / \mathrm{O}$ ratio of wüstite (=1). It is noticeable that there is no significant difference in the EDS data obtained from the darker grey (points 16 and 17) and the slightly lighter grey areas (points 13 and 18) in Figure 5.9(b), which infers that the dark grey area is not a different phase. The darker grey area could be due to stress-relief from the polishing preparation of the specimen. This result is consistent with the phase assignment from the XRD result in Figure 5.4 which shows that the sticking occurs during the early stage of the reduction of wüstite to metallic iron. According to this data, we can infer that the sticking occurs once the metallic iron started to form on the particle surface. This result is consistent with previous literature in which it was reported that the iron-iron contact on the particle surface leads to particle sticking (Gransden and Sheasby, 1974; Hayashi and Iguchi, 1992; Komatina and Gudenau, 2004; Shao, Guo and Tang, 2013). 


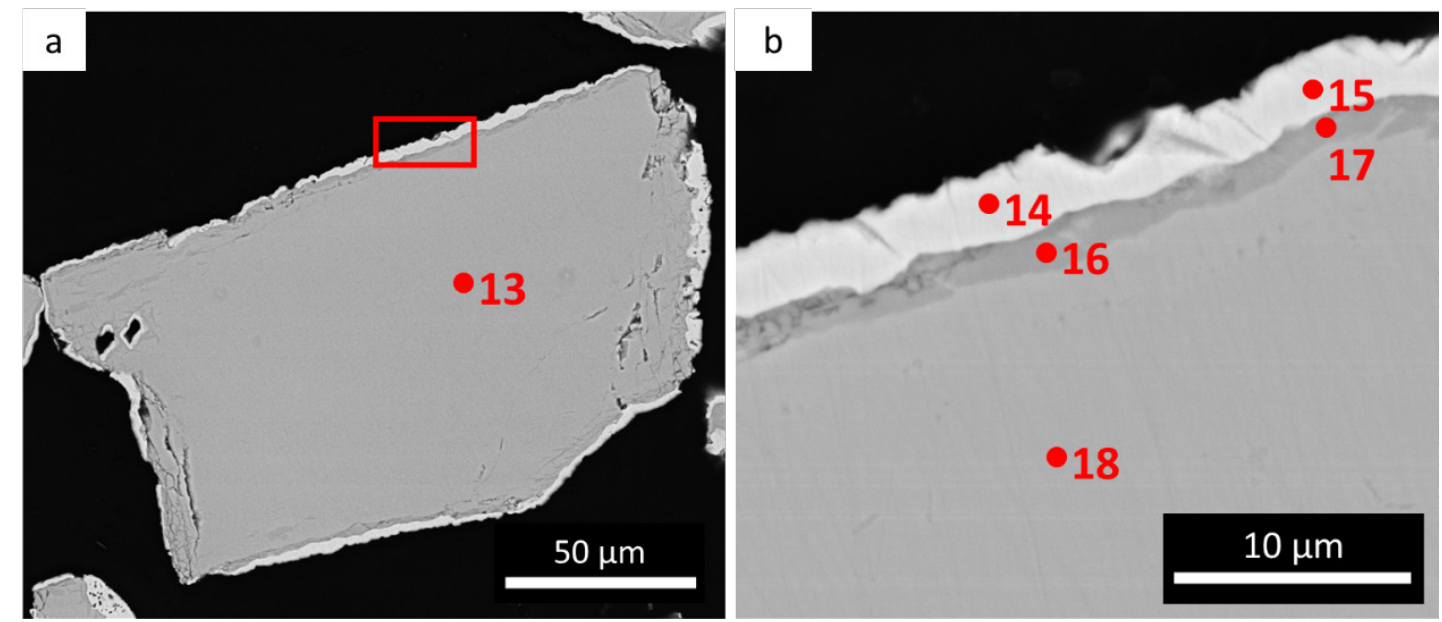

Figure 5.9 Cross-section BSE SEM images of a particle in the sinter part from the reduction of Hoganas magnetite by $5 \mathrm{~L} / \mathrm{min}$ at $950^{\circ} \mathrm{C}$. Image (b) is the higher magnification image of (a). Red marker indicates the location of magnified image.

Table 5.2 Elemental spot EDS analysis of points shown in Figure 5.9. Red coloured fonts are for the bright phase.

\begin{tabular}{ccccccc}
\hline \multirow{2}{*}{ Element } & \multicolumn{7}{c}{ Point (At. \%) } \\
\cline { 2 - 7 } & 13 & 14 & 15 & 16 & 17 & 18 \\
\hline $\mathrm{O}$ & 47.1 & - & - & 49.6 & 50.8 & 48.3 \\
$\mathrm{Fe}$ & 52.9 & 100 & 100 & 50.4 & 49.2 & 51.7 \\
$\mathrm{Fe} / \mathrm{O}$ & 1.1 & - & - & 1.0 & 0.9 & 1.1 \\
\hline
\end{tabular}

The hyphen sign in the table means no signal for the respective element.

\subsubsection{Loose powder part}

The sinter part has a weak sinter bond and the XRD results showed that the loose powder exhibited a similar pattern to the sinter part. It can thus be expected that particles in the loose powder are likely to have a similar microstructure to those in the sintered part. Figure 5.10 shows the typical surface morphology of particles in the loose powder part. It is clear that the metallic iron is also present on the particle surface (bright light grey region), which is similar to what was observed for the particle in the sinter. EDS point analysis on point 20 and 22 is shown in Table 5.3, and this again confirms that the bright region is metallic iron. 

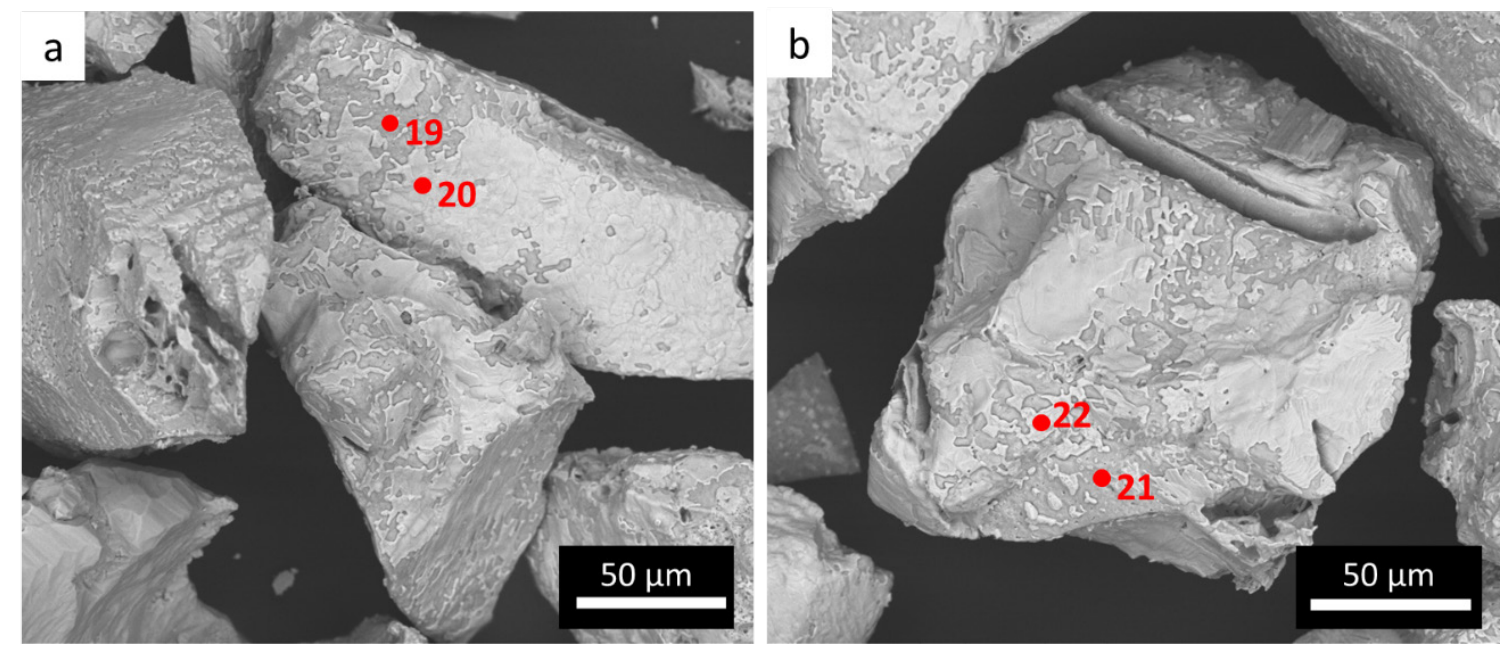

Figure 5.10 Surface BSE-SEM images of particles in the loose powder part from the reduction of Hoganas magnetite by $5 \mathrm{~L} / \mathrm{min}$ at $950^{\circ} \mathrm{C}$. Images (a) and (b) are two different observation locations.

Table 5.3 Elemental spot EDS analysis of points shown in Figure 5.10. Red coloured fonts are for the bright phase.

\begin{tabular}{ccccc}
\hline \multirow{2}{*}{ Element } & \multicolumn{5}{c}{ Point (At. \%) } \\
\cline { 2 - 5 } & 19 & 20 & 21 & 22 \\
\hline O & 48.4 & - & 44.5 & 20.6 \\
Fe & 51.6 & 100 & 55.5 & 79.4 \\
Fe/O & 1.1 & - & 1.2 & 3.9 \\
\hline
\end{tabular}

The hyphen sign in the table means no signal for the respective element.

Figure 5.11 shows a typical cross-section image of a particle from the loose powder part. Again, it is apparent that the particle is surrounded by the bright phase, which EDS point analysis (Table 5.4) confirms to be metallic iron. As both the surface and crosssectional microstructure of these particles appear the same as to that of particles in the sintered part, this supports the argument that the powder part has arisen from disintegration of the weak sintered part. 


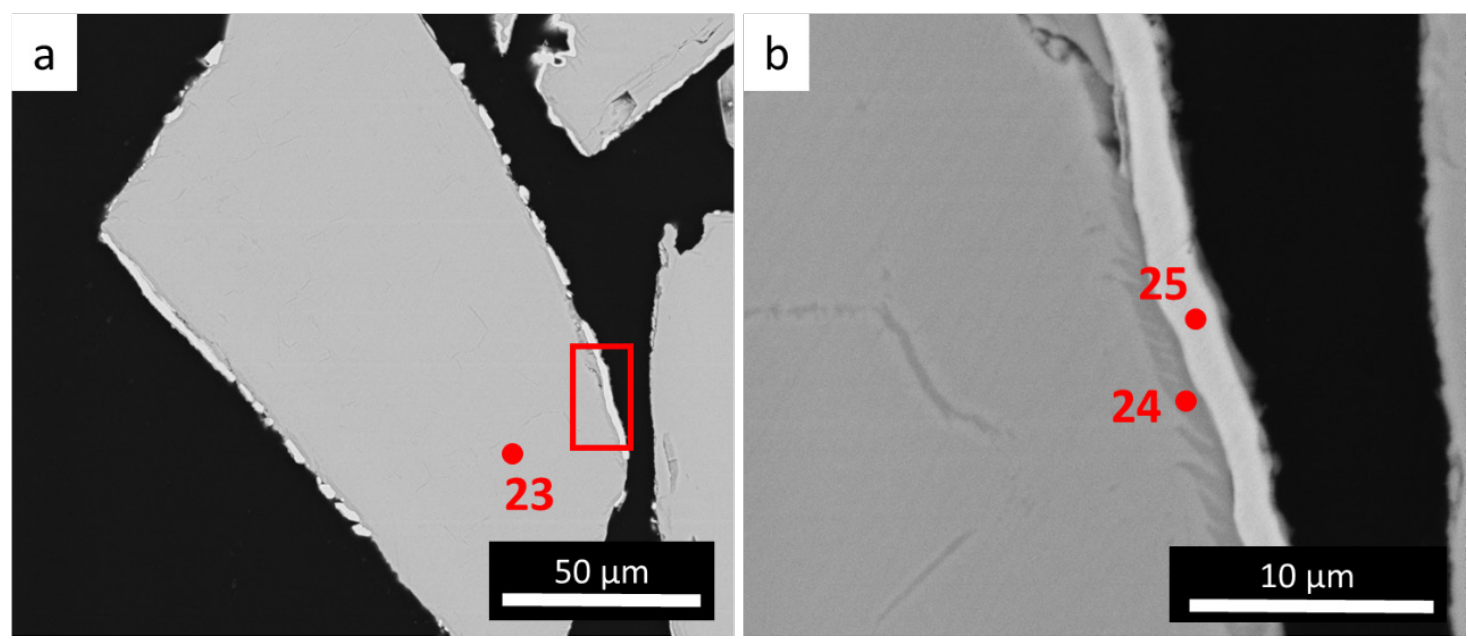

Figure 5.11 Cross-section BSE SEM images of a particle in the loose powder part from the reduction of Hoganas magnetite by $5 \mathrm{~L} / \mathrm{min}$ at $950^{\circ} \mathrm{C}$. (b) is the higher magnification image of (a). The red marker indicates the location of the magnified image.

Table 5.4 Elemental spot EDS analysis of points shown in Figure 5.11. Red coloured fonts are for the bright phase.

\begin{tabular}{cccc}
\hline \multirow{2}{*}{ Element } & \multicolumn{3}{c}{ Point (At. \%) } \\
\cline { 2 - 4 } & 23 & 24 & 25 \\
\hline $\mathrm{O}$ & 49.1 & 51 & - \\
$\mathrm{Fe}$ & 50.9 & 48.9 & 100 \\
$\mathrm{Fe} / \mathrm{O}$ & 1.04 & 0.96 & -
\end{tabular}

The hyphen sign in the table means no signal for the respective element.

\subsection{Summary}

This chapter investigated the reduction of commercially-sourced titanium-free Hoganas magnetite in a $\mathrm{FB}$ by $100 \% \mathrm{H}_{2}$ gas at a temperature higher than the reported sticking temperature $\left(950^{\circ} \mathrm{C}\right)$. The sticking of particles was observed to start within only four minutes of reduction. After cooling, the 'stuck' bed consisted of some sinters and loose powder. The XRD patterns and the microstructure of the particle in powder and sinters are similar. This result suggests that the whole bed sintered during the reduction experiment, with the loose powder being formed due to subsequent partial disintegration of the weak sinter bond during and after cooling. 
The SEM data indicates that the main cause of the sticking in this reaction was the iron-iron contact on the surface of the partially-reduced particles. The sticking appears to initiate during the initial reduction stage from wüstite to metallic iron. At this stage, metallic iron starts to form on the particle surface. When two iron-coated particles contact each other the iron surfaces can sinter and join, sticking the particles together. Overall, the results of this experiment confirm literature reports that particle sticking does occur during the FB reduction of titanium-free magnetite at a temperature of $950^{\circ} \mathrm{C}$. 


\section{Chapter 6}

\section{Reduction of NZ TTM Ironsand by Ar- $\mathrm{H}_{2}$ Gas Mixture at $950^{\circ} \mathrm{C}$}

\subsection{Outline}

This chapter reports a series of experiments investigating the FB reduction of TTM ironsand by $\mathrm{H}_{2}$ gas at $950^{\circ} \mathrm{C}$. This temperature is well above the onset of sticking for conventional Ti-free hematite and magnetite ores (in Chapter 5). The purpose of this experimental series is to investigate the sticking phenomena during the hydrogen reduction of NZ TTM ironsand. Some of the results in this chapter have been published in Prabowo et al. (2019a). Figures 6.12 to 6.21 and Tables 6.1 to 6.2 were also taken directly from the paper. All of these are reproduced with permission of Springer Nature through Copyright Clearance Centre.

\subsubsection{Description of experimental procedure}

In this chapter, the influence of several parameters on the FB reduction of TTM ironsand are investigated to determine the optimum reduction conditions at $950^{\circ} \mathrm{C}$. Parameters studied in this chapter are $\mathrm{H}_{2}$ gas concentration, $\mathrm{H}_{2}$ gas flowrate, the mass of the ironsand bed, and the particle size fraction of ironsand. In each case, the reduction experiment was conducted at $950^{\circ} \mathrm{C}$.

\subsubsection{Variation of $\mathrm{H}_{2}$ gas concentration}

In the first set of experiments, the effect of $\mathrm{H}_{2}$ gas concentration on the FB reduction of TTM ironsand was studied using a range of $\mathrm{H}_{2}$-Ar gas mixtures. The $\mathrm{H}_{2}$ gas composition was varied between 50 and 100 vol.\% with a total flow rate of $5 \mathrm{~L} / \mathrm{min}$. This total flow rate corresponded to the bubbling fluidisation regime within the reactor, from equations (2.14), (2.17), (2.18) and the results in Chapter 4 (Figure 4.5). For each experiment, the particle size fraction of ironsand sample was 106-125 $\mu \mathrm{m}$ and the initial mass of ironsand in the bed was $100 \mathrm{~g}$.

\subsubsection{Variation of $\mathrm{H}_{2}$ gas flow rate}

In the second set of experiments, the effect of $\mathrm{H}_{2}$ gas flow rate on the FB reduction of TTM ironsand was studied in $100 \% \mathrm{H}_{2}$ gas. The gas flow rate was varied between 1 and 
$5 \mathrm{~L} / \mathrm{min}$. Again, these flow rate regimes are within the bubbling FB regime for the reactor. For each experiment, the particle size fraction of ironsand sample was 106-125 $\mu \mathrm{m}$ and the mass of the sample of ironsand is $100 \mathrm{~g}$.

\subsubsection{Variation of the initial bed masses}

In the third set of experiments, the effect of the initial mass of ironsand in the bed was studied, in the range from $50 \mathrm{~g}$ to $250 \mathrm{~g}$. For each of these experiments, ironsand with a particle size fraction of 106-125 $\mu$ m was reduced in $100 \% \mathrm{H}_{2}$ at a flow rate of $4 \mathrm{~L} / \mathrm{min}$. This flow rate corresponded to a fluidisation velocity of $\sim 35 \mathrm{~cm} / \mathrm{s}$, which ensured that the freeboard height of the bed with $250 \mathrm{~g}$ ironsand remained within the hot zone of the reactor. This was estimated based on the cold fluidisation tests in Figure 4.6(a), and for a bed containing $250 \mathrm{~g}$ of ironsand, which had a static bed height of $\sim 13 \mathrm{~cm}$. The freeboard height at $4 \mathrm{~L} / \mathrm{min}$ was therefore estimated to be $\sim 22 \mathrm{~cm}$, which does not exceed the total length of the freeboard height within the hot zone (30 cm in Figure 3.8). However, this is only an estimation from the cold test, but the additional $8 \mathrm{~cm}$ provide a margin for error.

\subsubsection{Variation of particle size fractions}

In the fourth set of experiments, reduction studies were performed on fluidised beds containing ironsand samples with different particle sizes. The various particle sizes used were 60-93 $\mu \mathrm{m}, 106-25 \mu \mathrm{m}, 125-150 \mu \mathrm{m}, 150-180 \mu \mathrm{m}$, and the non-sieved (as-received) particle distribution of the raw ironsand. These particle size fractions correspond to the PSDs shown in Figure 3.3 (in Chapter 3). Only small amounts of ironsand were obtained by sieving for other particle size fractions outside those used here, and hence they were not used for this study. For each experiment, the ironsand sample of $100 \mathrm{~g}$ was reduced by $100 \% \mathrm{H}_{2}$ with a flow rate of $3 \mathrm{~L} / \mathrm{min}$. This flow rate ensured that there would be no entrainment for a particle size of about $50 \mu \mathrm{m}$. For the non-sieved raw ironsand, the wt.\% of iron sand particles $<50 \mu \mathrm{m}$ is less than $5 \mathrm{wt} . \%$ (Figure 3.2). Therefore, the entrainment of particles from this sample was assumed to be minimal.

\subsection{Reproducibility of the FB reactor system}

Initial tests were performed to confirm the reproducibility of the experimental FB reactor, sampling system and experimental methodology. Five experimental runs were performed under identical conditions. In each case a fresh $100 \mathrm{~g}$ sample of ironsand 
particles was reduced in a gas composition of 80 vol. $\% \mathrm{H}_{2}-20$ vol. $\%$ Ar at $950^{\circ} \mathrm{C}$. Figure 6.1 shows plots of \%met as a function of time for each of the five reduction runs. It is clear that these experiments show excellent reproducibility, and in each case the reaction reached a \%met of $\sim 93 \%$ after 40 minutes. These \%met curves was calculated using q-XRD data which will be shown later in Section 6.4

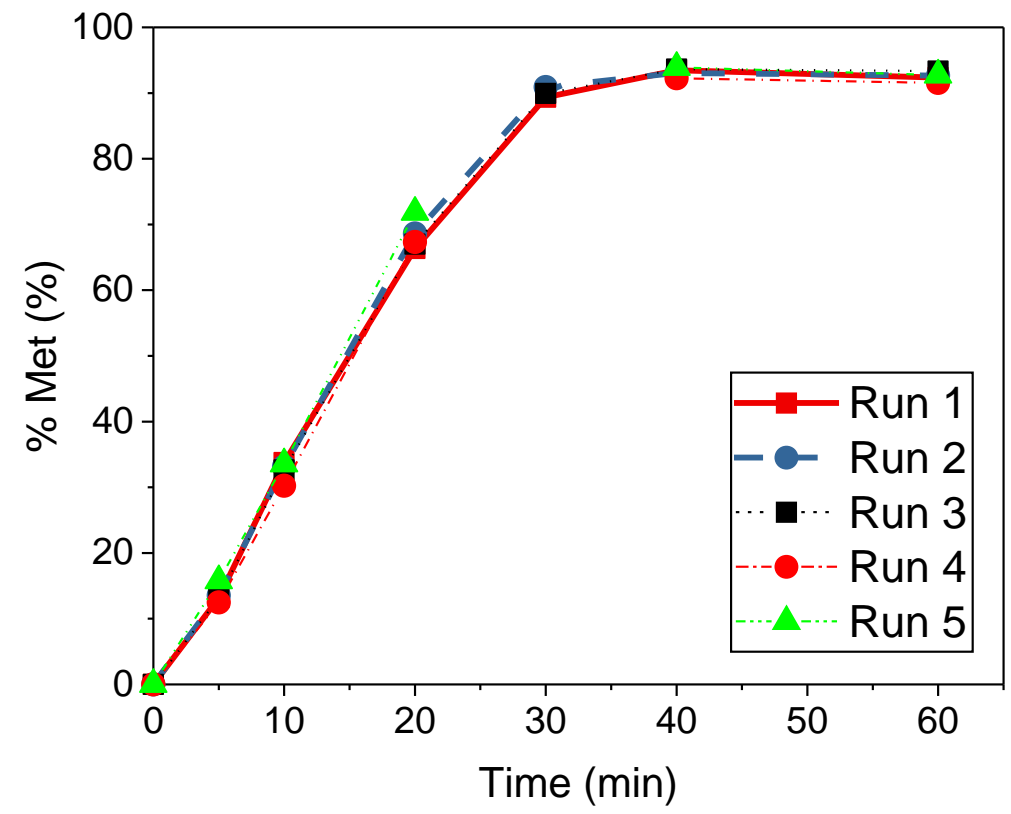

Figure $6.1 \%$ met curves for the five reduction runs of TTM ironsand in $80 \mathrm{vol} . \% \mathrm{H}_{2}-20$ vol.\% Ar gas mixture at $950^{\circ} \mathrm{C}$.

Importantly, despite the relatively high temperature employed $\left(950^{\circ} \mathrm{C}\right)$, no sticking was observed throughout any of these initial reduction runs. This is in direct contrast to previous reports on the FB hydrogen reduction of hematite ores, where sticking starts to occur at $\sim 800^{\circ} \mathrm{C}$ (Neuschütz, 1991; Komatina and Gudenau, 2004). In addition, subsequent XRD measurements of the reduced ironsand samples indicated that the samples appeared to be stable even after three weeks of exposure to air. In Section 6.6 both these properties are discussed. They are likely a result of the formation of a protective Ti-enriched oxide shell around each particle.

\subsection{Effect of various parameters on the reduction rate of TTM ironsand}

Figure 6.2 shows the plots of \%met as a function of time for each parameter studied ( $\mathrm{H}_{2}$ concentration, $\mathrm{H}_{2}$ flow rate, sample mass, and particle size). In Figure 6.2(a) and (b), the reduction rate increased with increasing $\mathrm{H}_{2}$ gas content and flow rate, respectively. A 
maximum \%met $\sim 93 \%$ was achieved after 30 minutes in $100 \% \mathrm{H}_{2}$ gas with a flow rate of $5 \mathrm{~L} / \mathrm{min}$.

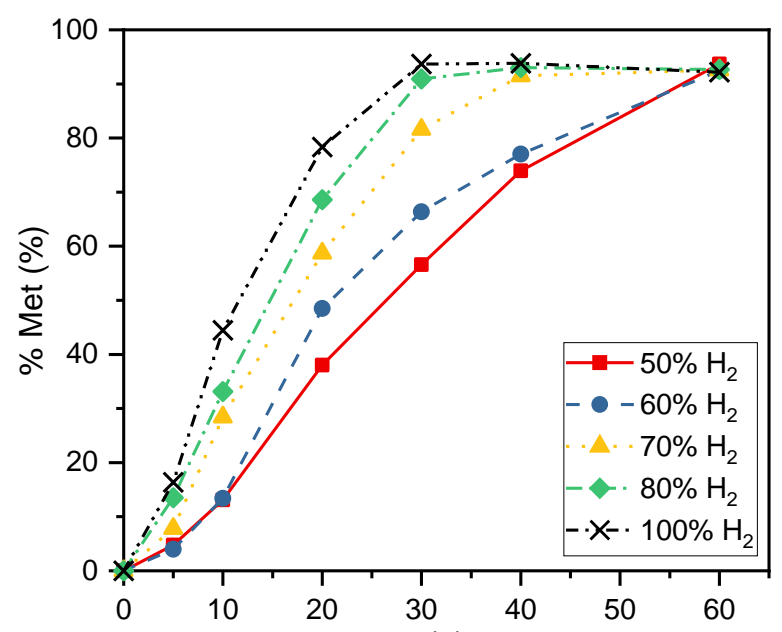

(a)

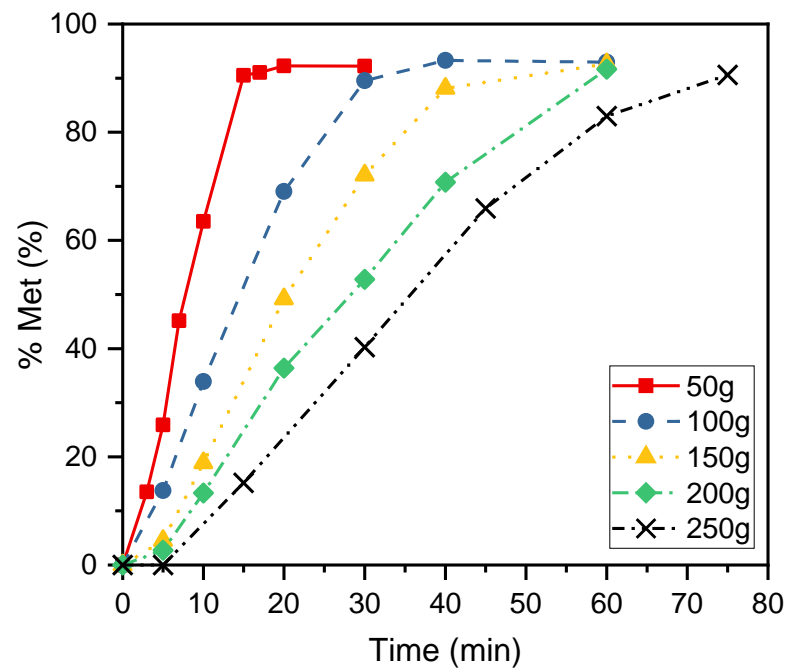

(c)

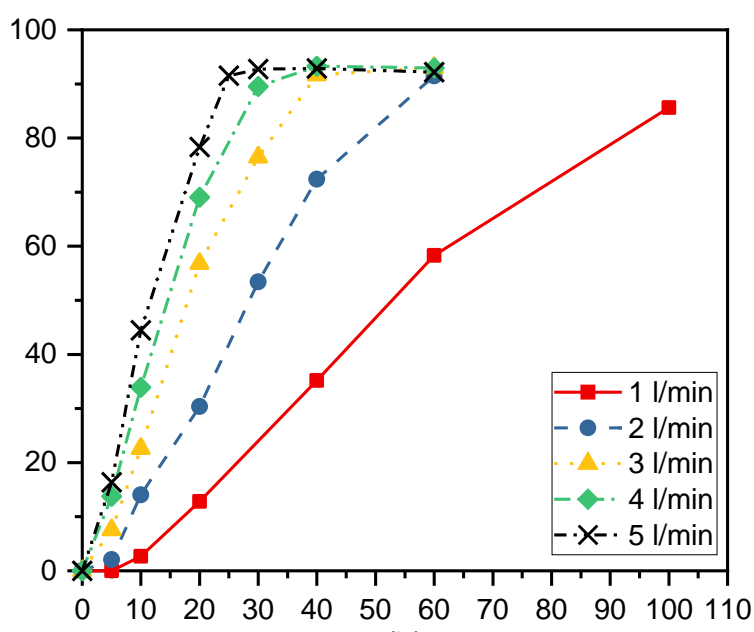

(b)

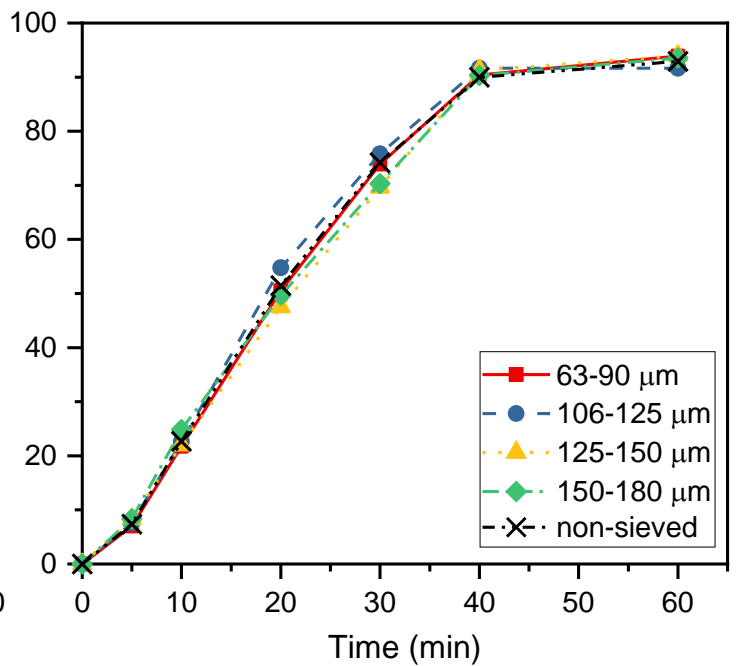

(d)

Figure $6.2 \%$ met as a function of time for the reduction of $N Z$ ironsand in various conditions at a constant temperature of $950^{\circ} \mathrm{C}$. (a): various $\mathrm{H}_{2}$ gas compositions; (b): various $\mathrm{H}_{2}$ gas flow rates; (c) various initial bed mass; (d): various particle size fractions.

Figure 6.2(c) shows the effect of the initial bed mass on the reduction rate of TTM ironsand. From the figure, it is clear that reduction rate decreased significantly with increasing sample mass. The reduction rate becomes five times slower when the sample mass increased from $50 \mathrm{~g}$ to $250 \mathrm{~g}$. It needs approximately 15 minutes to fully reduce $50 \mathrm{~g}$ ironsand by $4 \mathrm{~L} / \mathrm{min} \mathrm{H}_{2}$ gas at $950^{\circ} \mathrm{C}$. At the same condition, it needs approximately 75 minutes to fully reduce $250 \mathrm{~g}$ ironsand. 
Figure 6.2(d) shows the \%met as a function of time for the various particle size fractions studied. Note that there are no significant differences in the chemical composition and oxide phases in each particle size fraction (see Chapter 3). In contrast to the other parameters investigated, it is apparent that particle size of ironsand had no significant effect on the reduction rate. This may be because the particle size distribution of the raw ironsand concentrate is narrow.

The variables studied in the experiments were aimed at understanding the optimum condition for the reduction of NZ ironsand. Figure 6.3 reveals that for each parameter case, the reduction rate follows a similar relationship with the total volume of $\mathrm{H}_{2}$ gas delivered to the reactor. The figure shows that it needs about $150 \mathrm{~L}$ of $\mathrm{H}_{2}$ gas to fully reduce $100 \mathrm{~g}$ ironsand regardless of the experimental conditions. This suggests that the reduction reaction is limited by $\mathrm{H}_{2}$ gas supply, which means that all experimental conditions were under the condition of $\mathrm{H}_{2}$ gas 'starvation'.

These experimental results were obtained from a bubbling bed reactor, are fundamentally limited by the maximum gas flow rate that can be achieved in the bubbling bed regime. If the flow rate were increased beyond the levels studied, this would have resulted in a gas velocity higher than the terminal velocity $\left(U_{t}\right)$ for a bubbling FB. This would 'blow' hot particles out of the reactor before they could react. It is important to note that the entrainment velocity is a function only of particle and gas properties, and is independent of the size of the reactor. This means that if the reactor were scaled to a bigger diameter, it would still be subject to the same limit. The mass of the bed and the mass flow rate of $\mathrm{H}_{2}$ gas at $U_{\mathrm{t}}$, both scale linearly with the cross sectional area of the reactor tube, so increasing the tube size will not increase the ratio of hydrogen flow to ironsand mass in the reactor. This means that reactions performed in an atmospheric pressure bubbling bed reactor of any size will always take place in the $\mathrm{H}_{2}$ gas starvation regime. If there is a future desire to investigate higher $\mathrm{H}_{2}$ flow (mass) rates, then this would need to be conducted at elevated pressures in order to maintain the gas velocity below $U_{\mathrm{t}}$. However, high pressure conditions are not achievable using the reactor reported in this thesis. 


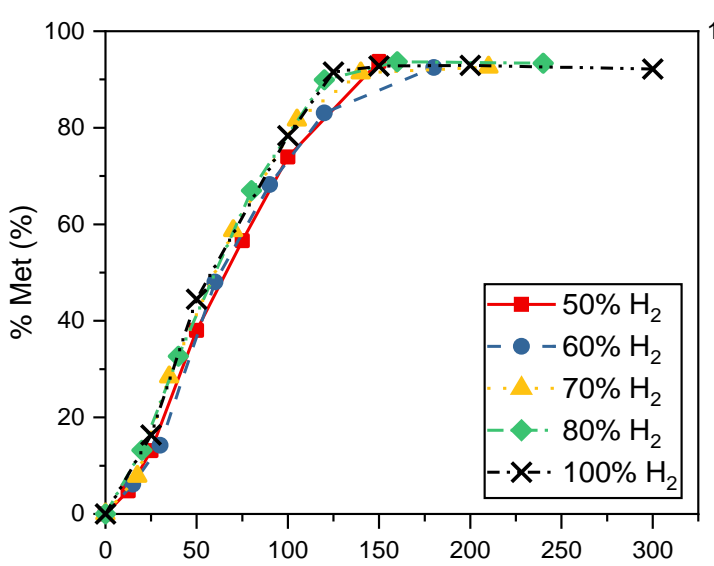

(a)

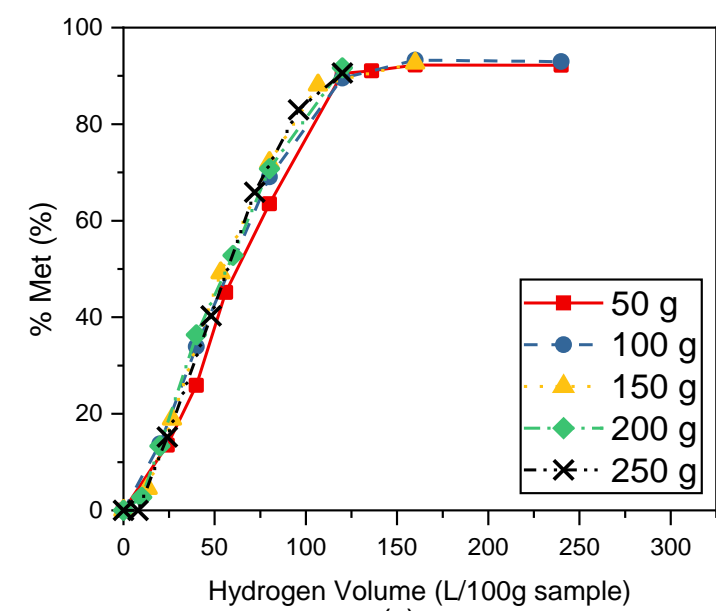

(c)

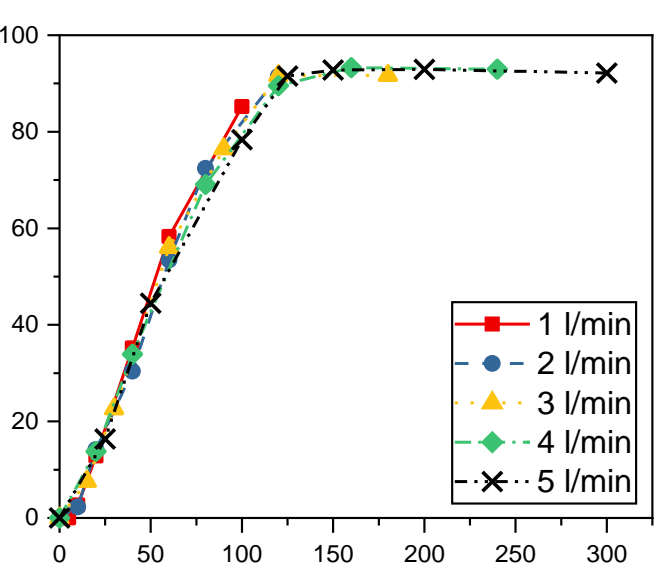

(b)

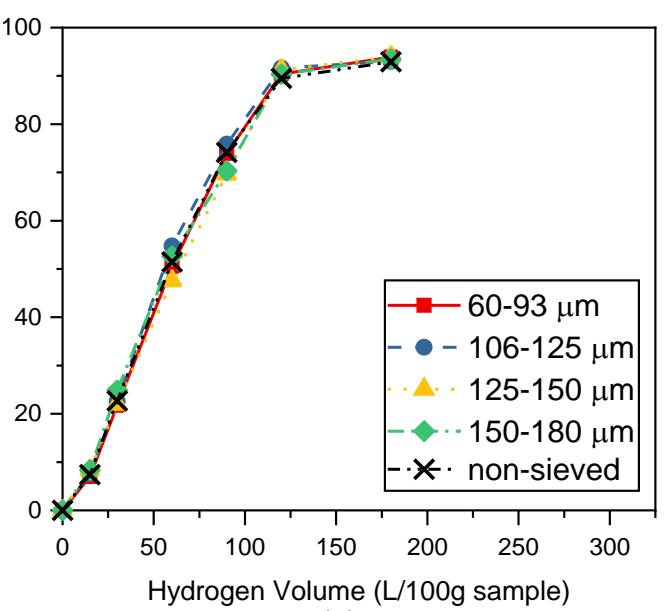

(d)

Figure $6.3 \%$ met as a function of total delivered $\mathrm{H}_{2}$ volume for the reduction of TTM ironsand in various conditions at a constant temperature of $950^{\circ} \mathrm{C}$. (a): various $\mathrm{H}_{2}$ gas compositions; (b): various $\mathrm{H}_{2}$ gas flow rates; (c) various initial bed mass; (d): various particle size fractions.

\subsection{Phase evolution within TTM ironsand during hydrogen reduction at $950^{\circ} \mathrm{C}$}

Figure 6.4 shows an example of XRD patterns obtained from samples extracted at various times during reduction in 80 vol.\% $\mathrm{H}_{2}-20$ vol.\% Ar at $950^{\circ} \mathrm{C}$. After 5 minutes reduction (corresponding to a \%met of $\sim 13 \%$ ), the initial TTH in ironsand has been completely reduced to TTM, whilst the metallic iron and wüstite peaks are already prominent. After 30 minutes, the wüstite peak has completely disappeared, and minority Ti-containing phases such as ilmenite and rutile start to appear. The formation of ilmenite and rutile in the final stage of the reaction is consistent with previous reports (Sun et al., 2013; Park and Ostrovski, 2004b). After 40 minutes, the reduction has reached its maximum \%met, and pseudobrookite peaks start to appear. Further reduction to 60 minutes 
does not completely reduce TTM to iron as indicated by the remaining small TTM peaks in the final product. However rutile is no longer observed at 60 minutes (Figure 6.4(b)), indicating that reactions involving minority Ti-containing phases continue beyond the apparent endpoint of the metallisation process.

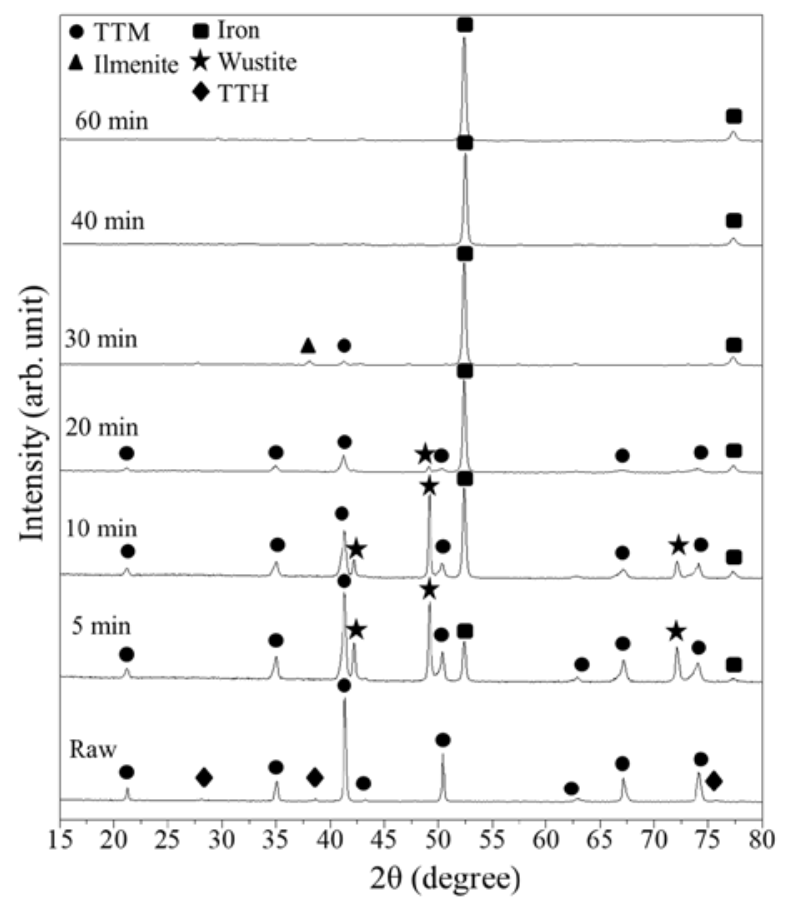

(a)

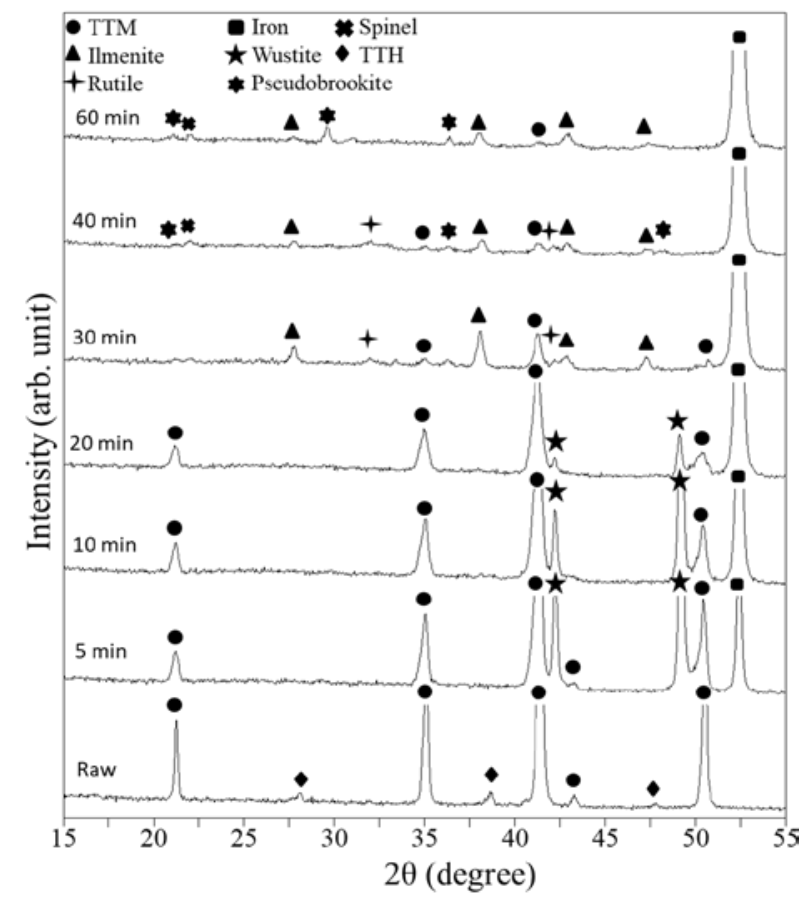

(b)

Figure 6.4 XRD patterns of reduced irosands showing the progression of reduction reaction by 80:20 vol.\% $\mathrm{H}_{2}$ :Ar gas mixture at $950^{\circ} \mathrm{C}$. (a) Full XRD pattern. (b) Magnified $X R D$ pattern showing detail of smaller peaks from minority oxide phases. 
Quantitative XRD analysis has been used to obtain the wt.\% of each crystalline phase from each of the XRD patterns as shown in Figure 6.4. Figures 6.5 to 6.8 show the time evolution of each crystalline phase for each reduction parameter studied. From these figures, it appears that the reduction of ironsand proceeds in a series of stages. The duration of each reduction stage for each condition is indicated by the numbered spans at the top of each plot in each figure.

Consistent with the results presented in Section 6.3, it is again clear that the $\mathrm{H}_{2}$ gas concentration, $\mathrm{H}_{2}$ gas flow rate, and sample mass significantly affect the reaction rate of each stage of reduction. The particle size does not appear to affect the reaction rate. It should be noted that these results only relevant for the experimentally accessible gas flows in the bubbling FB reactor studied here. 


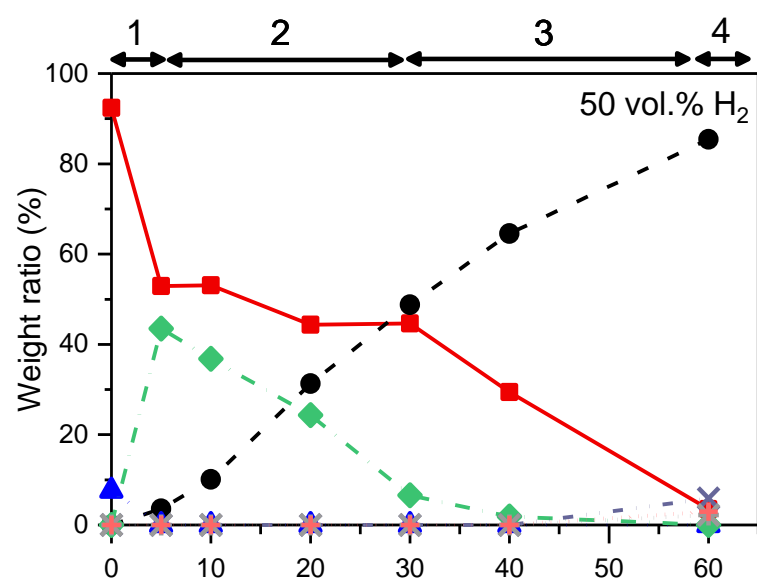

(a)

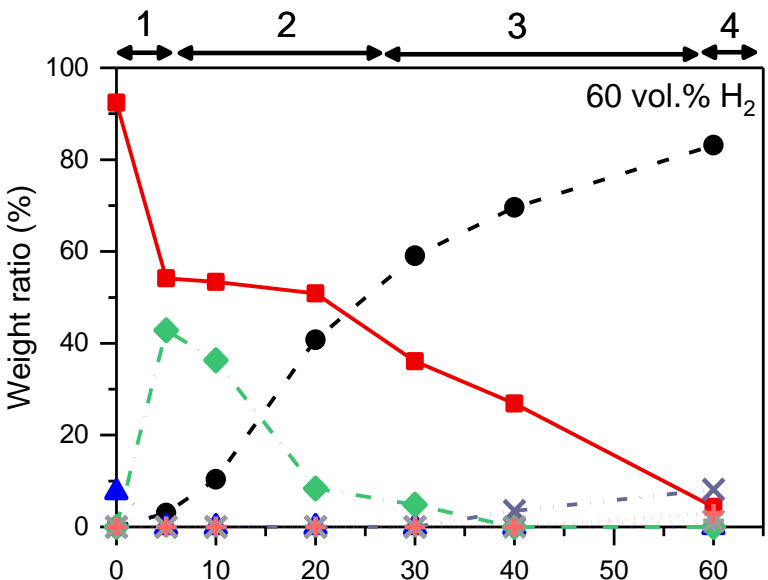

(b)

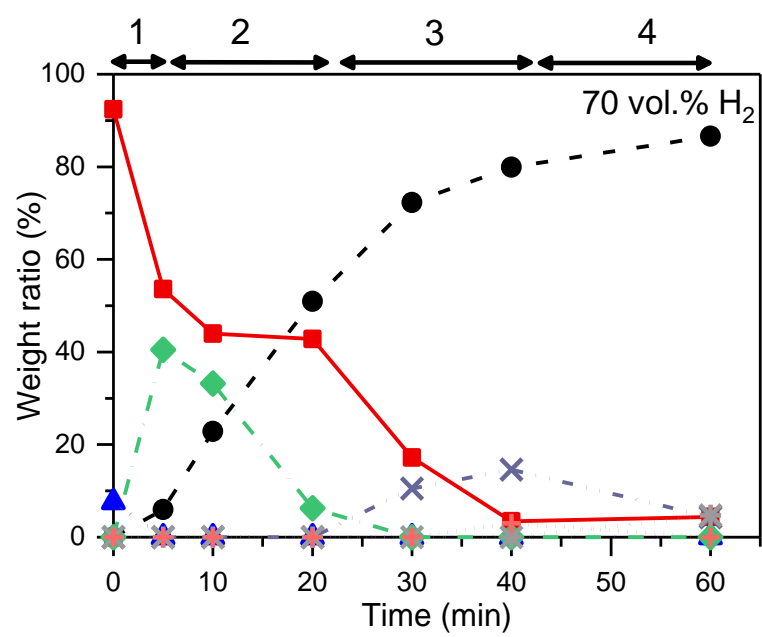

(c)

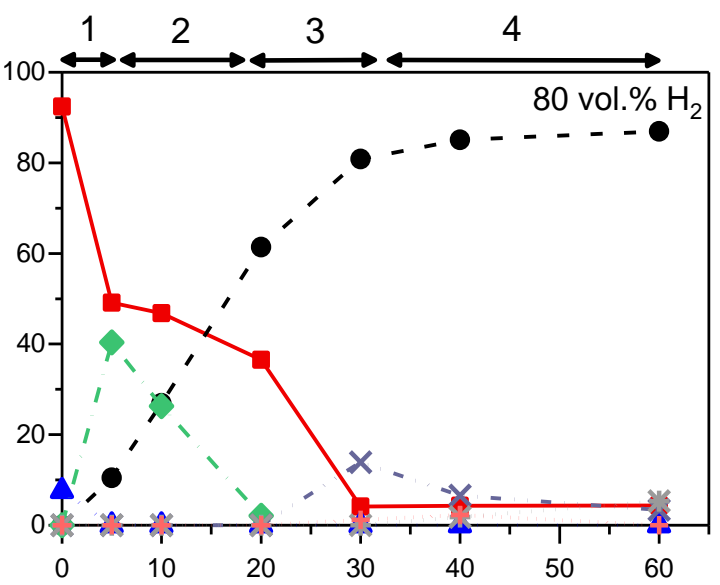

(d)

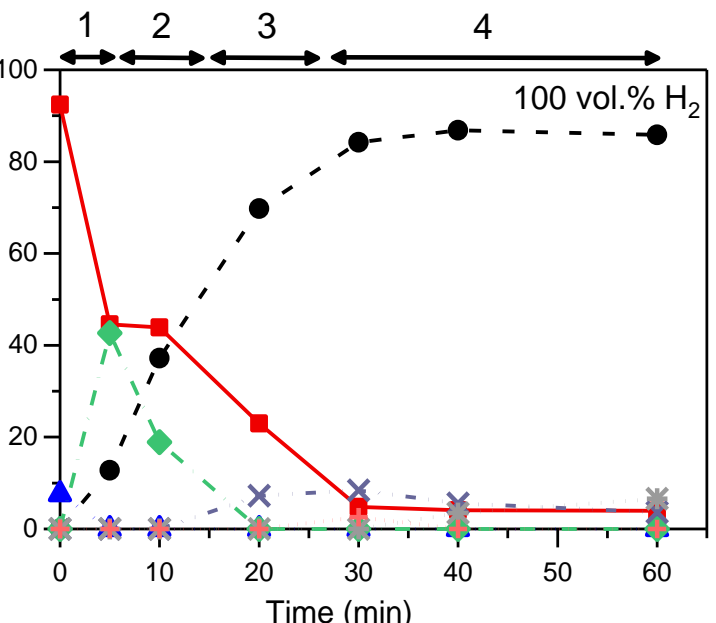

(e)

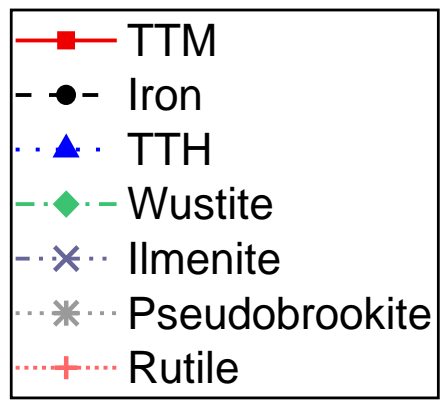

Figure 6.5 The evolution of crystalline phases as a function of time during the reduction of ironsand at $950^{\circ} \mathrm{C}$ in various $\mathrm{H}_{2}$ gas compositions. Numbered spans at the top of each plot indicate the duration of each reduction stage, as described in the body text. 


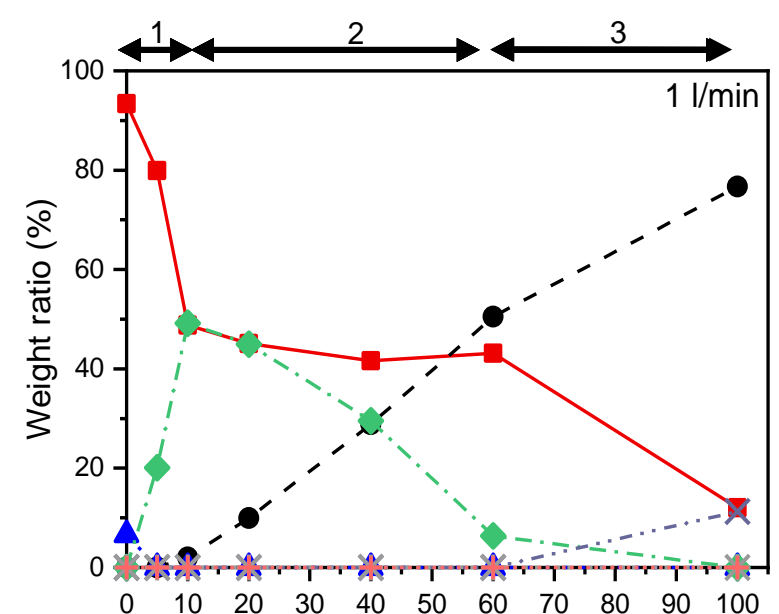

(a)

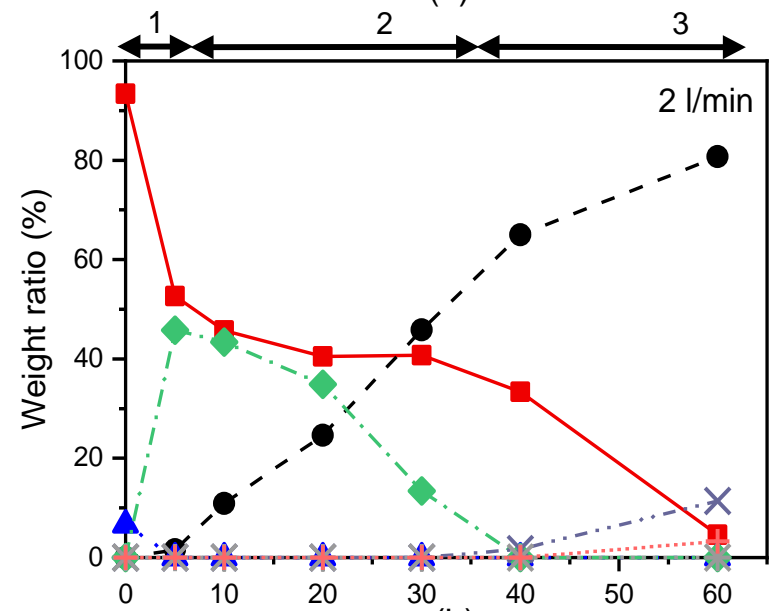

(b)

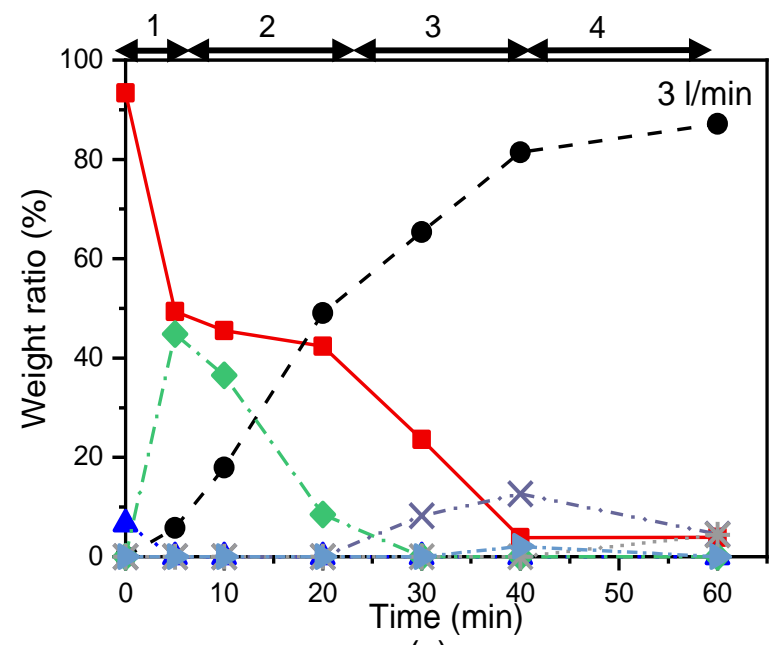

(c)

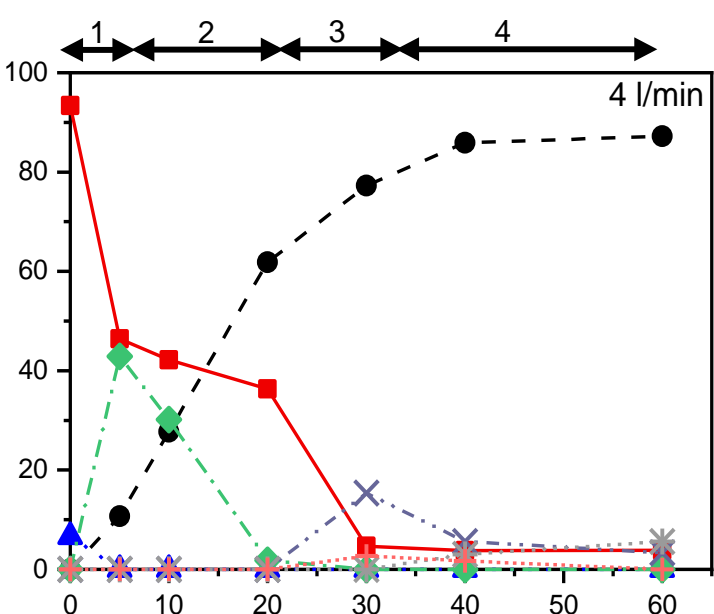

(d)

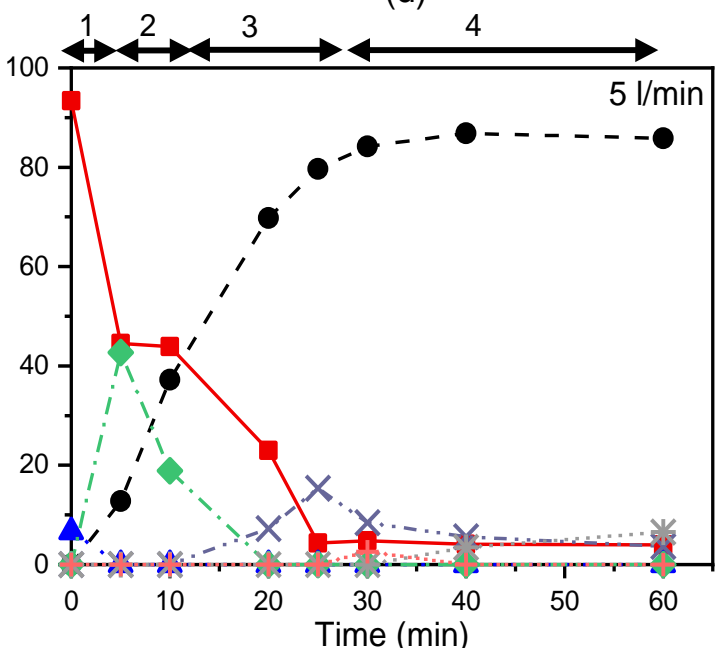

(e)

paFigure 6.6 The evolution of crystalline phases as a function of time during the reduction of ironsand by different $\mathrm{H}_{2}$ gas flow rates at $950^{\circ} \mathrm{C}$. Numbered spans at the top of each plot indicate the duration of each reduction stage. 

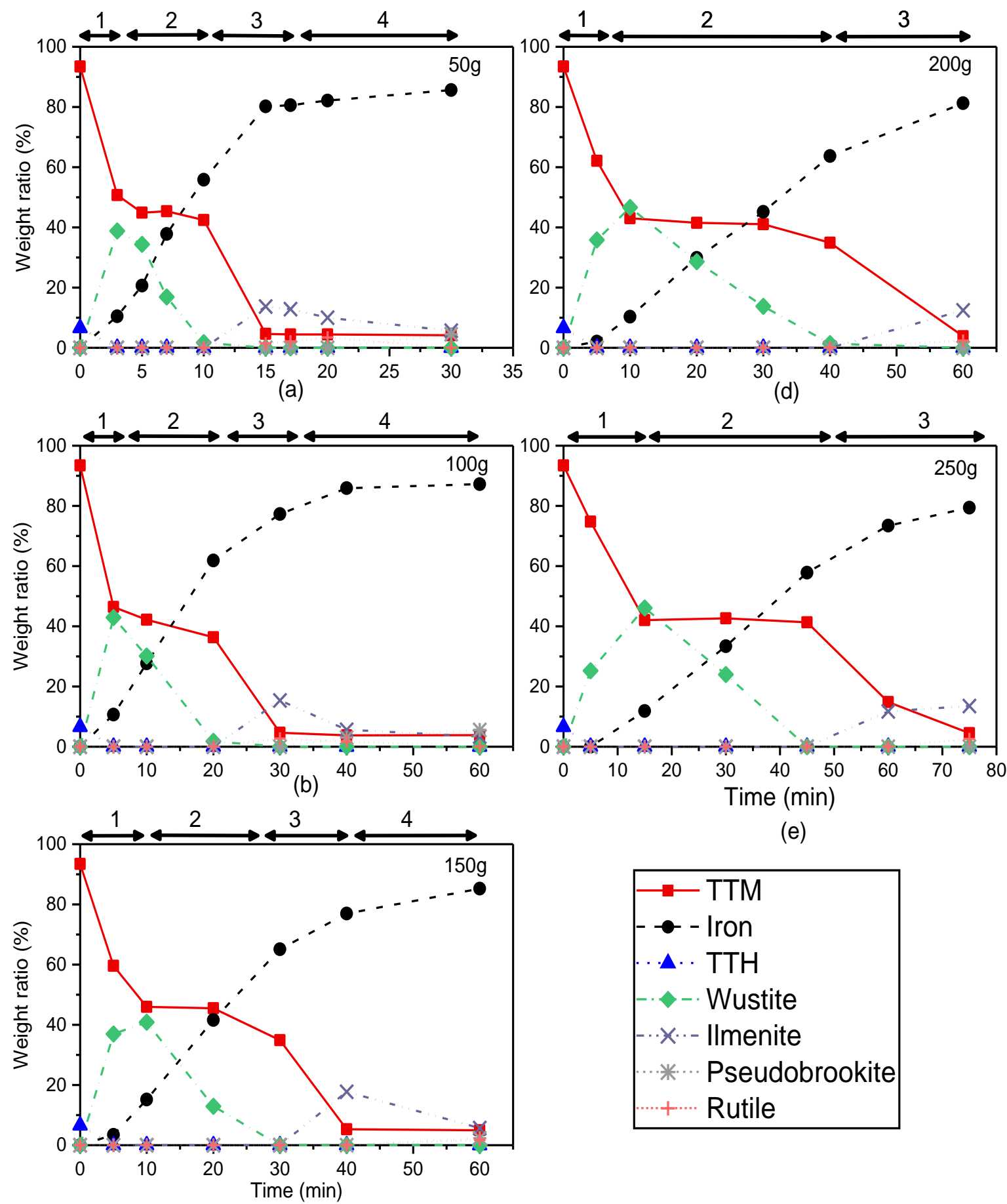

(e)

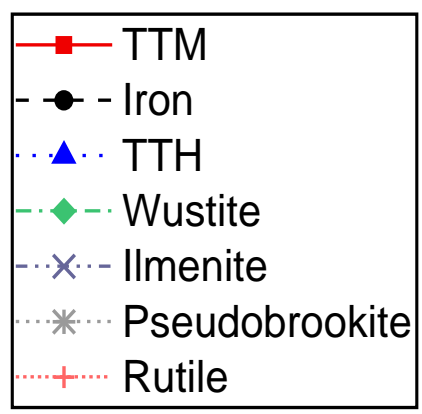

(c)

Figure 6.7 The evolution of crystalline phases as a function of time during the reduction of ironsand by $4 \mathrm{~L} / \mathrm{min} \mathrm{H}_{2}$ at $950^{\circ} \mathrm{C}$ for different sample masses. Numbered spans at the top of each plot indicate the duration of each reduction stage. 

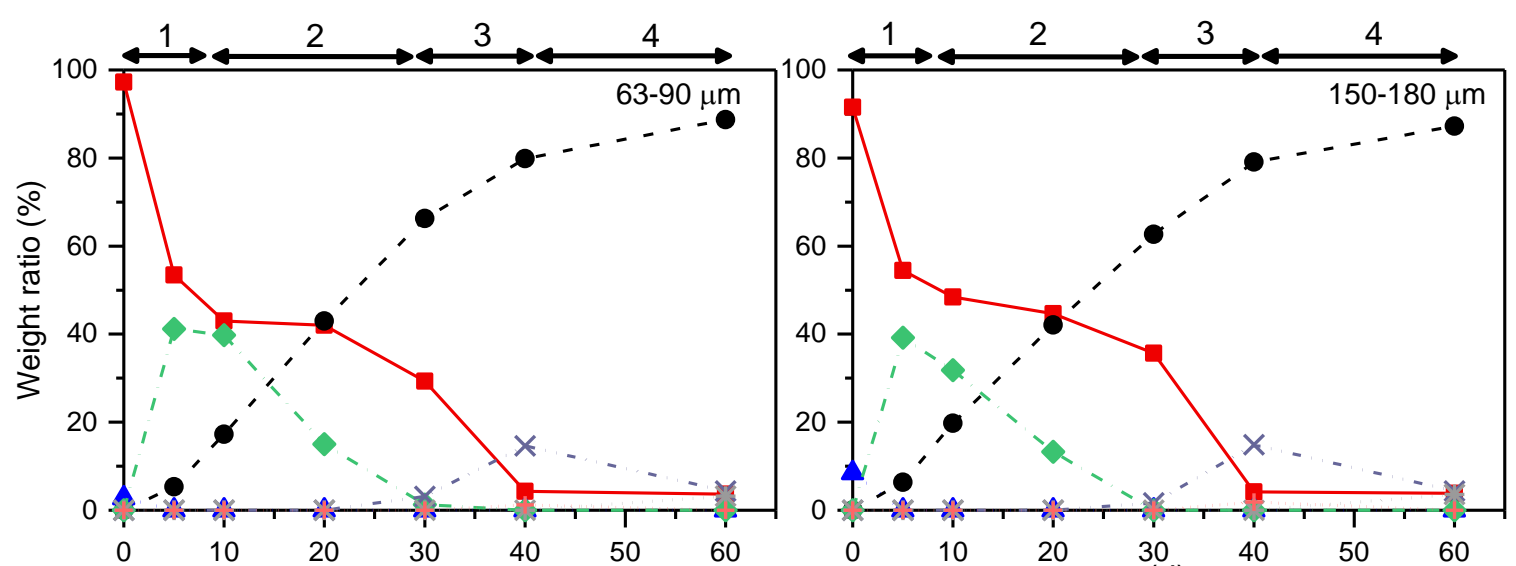

(a)

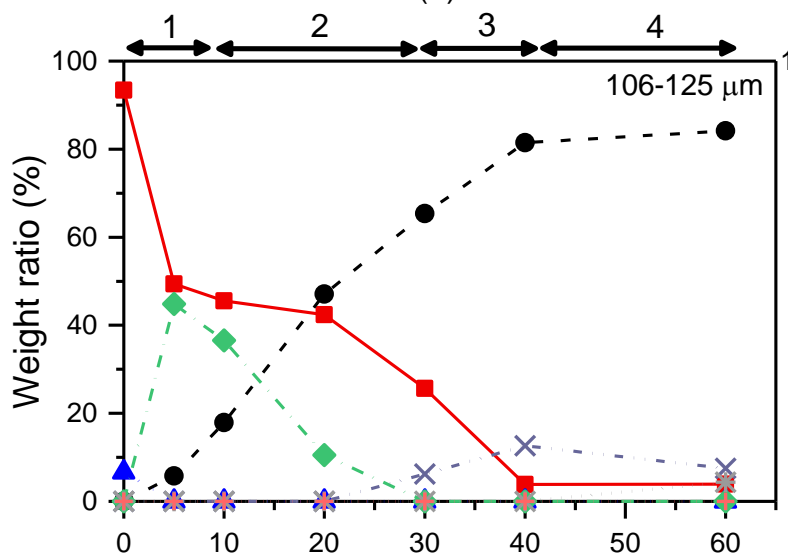

(b)
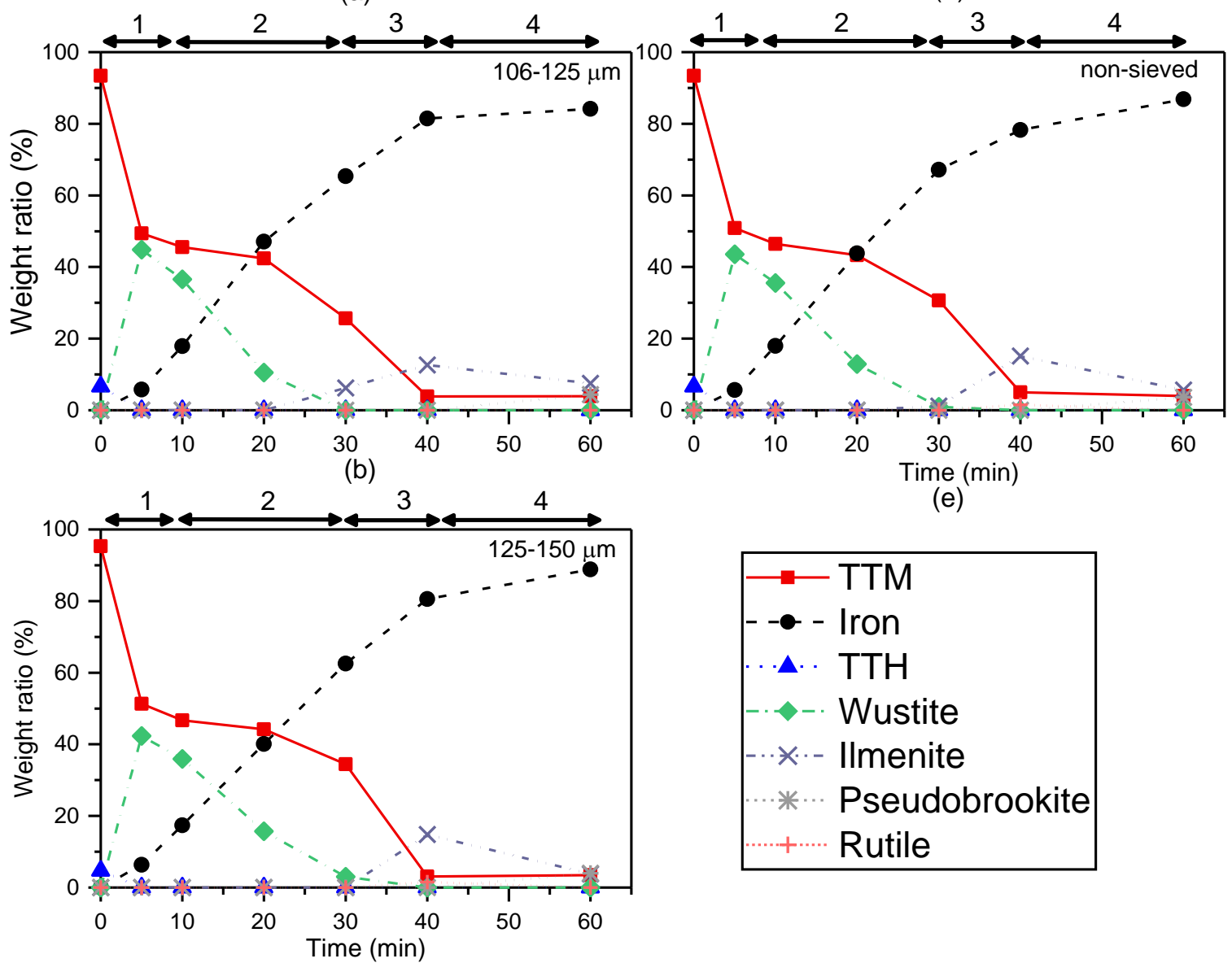

(e)

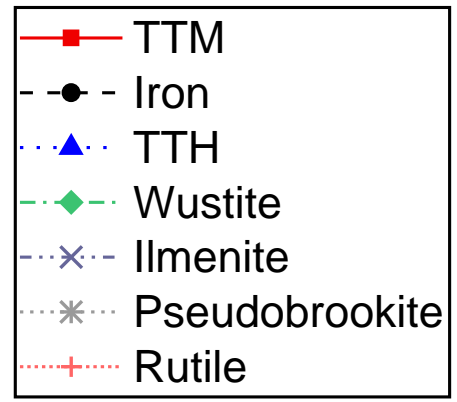

(c)

Figure 6.8 The evolution of crystalline phases as a function of time during the reduction of ironsand by $3 \mathrm{~L} / \mathrm{min} \mathrm{H}_{2}$ at $950^{\circ} \mathrm{C}$ for different particle size fractions. Numbered spans at the top of each plot indicate the duration of each reduction stage.

For every experimental parameter studied, the reduction appears to proceed in four stages. These are labelled stages 1 to 4 in the figures above, with their approximate duration marked at the top of each plot. It should be noted that this was observed for batch experiment and under the condition of $\mathrm{H}_{2}$ gas starvation. 
In stage 1, the small amount of TTH present in the raw ironsand ( 8 wt.\%) is fully reduced to TTM. This always occurs rapidly, within the first few minutes of starting the reaction. During this same stage, approximately $50 \%$ of the TTM phase is also reduced to wüstite. As an example, during the reduction of the $200 \mathrm{~g}$ and $250 \mathrm{~g}$ beds (by $4 \mathrm{~L} / \mathrm{min}_{2}$ ), this conversion of TTM to wüstite occurred within 10 and 15 minutes, respectively (Figure 6.7(d) and (e)).

In stage 2, wüstite is reduced to metallic iron, such that the wüstite composition decreases to zero in each case (from a maximum composition of $~ 40 \mathrm{wt} . \%$ ). At the same time, the reduction rate of the TTM phase slows significantly as can be seen by the plateau of the TTM curve during this stage. The duration of this plateau matches the period of the conversion of wüstite to metallic iron. This indicates that during this stage $\mathrm{H}_{2}$ gas is primarily being consumed by the wüstite reduction.

The observation of the wüstite phase during the reduction stages 1 and 2 is consistent with previous works (Sun et al., 2013; Wang, Zhang, Ma, et al., 2017), which also reported that wüstite occurred as a transitional phase during the early reduction of titanomagnetite. However, a different result was reported in a previous study of packed beds of NZ ironsand reduced by $\mathrm{H}_{2}$ gas at $900^{\circ} \mathrm{C}$ (Park and Ostrovski, 2004b). In that study the authors did not observe significant levels of wüstite and concluded that the reduction of TTM to wüstite is much slower than the subsequent reduction of wüstite to metallic iron. By contrast, the results shown in Figures 6.5 to 6.8 indicate that the initial reduction of TTM to wüstite (in stage 1) occurred rapidly and faster than the subsequent reduction of wüstite to metallic iron in stage 2. This difference could be because the experiment reported in (Park and Ostrovski, 2004b) was in a packed static bed at $900^{\circ} \mathrm{C}$, compared to the $\mathrm{FB}$ system at $950^{\circ} \mathrm{C}$ reported in this section.

The reduction stage 3 occurs once all wüstite has been consumed. At this point the reduction rate of the remaining TTM accelerates, and metallic iron is formed directly i.e. without forming wüstite as an intermediate phase. At the same time, ilmenite is also observed within the sample for the first time. The direct conversion of TTM to iron observed in stage 3 represents a significant change in the reaction pathway from the stepwise reduction via wüstite that was observed in stages 1 and 2 . This behavior differs significantly from that reported for conventional magnetite ore (Weiss et al., 2011; Pichler et al., 2016), which is always reduced via wüstite at these temperatures. This change in favored pathway implies that the thermodynamic potential of the TTM phase has itself 
changed over the course of the reaction. This could occur due to gradual Ti-enrichment of the TTM phase during the first two reaction stages, as described by reactions (6.1) and (6.2) below.

Stage 1: $\quad(x+\delta) \cdot \mathrm{Fe}_{(3-x)} \mathrm{Ti}_{x} \mathrm{O}_{4}+\delta \mathrm{H}_{2} \rightarrow 3 \delta \cdot \mathrm{FeO}+x \cdot \mathrm{Fe}_{3-(x+\delta)} \mathrm{Ti}_{(x+\delta)} \mathrm{O}_{4}+\delta \cdot \mathrm{H}_{2} \mathrm{O}$

Stage 2: $\quad \mathrm{FeO}+\mathrm{H}_{2} \rightarrow \mathrm{Fe}+\mathrm{H}_{2} \mathrm{O}$

Reaction (6.1) implies that the TTM phase becomes increasingly enriched with Ti during stage 1, which eventually appears to stabilise it thus limiting further reduction. Ultimately, the Ti-enriched TTM reaches a point at which it is less reducible than the coexisting wüstite. This represents the transition to stage 2 and the reaction pathway switches to prefer reduction of the wüstite phase, whilst the reduction rate of the remaining TTM slows significantly. From Figures 6.5 to 6.8 , it can be seen that this transition occurs at the approximate point when the original TTM has dropped to 50\% of its initial value. If it is assumed that equation (6.1) fully describes the fate of Ti during stage 1, then this implies that the transition to stage 2 occurs once the TTM composition reaches approximately $\mathrm{Fe}_{(3-}$ ${ }_{4)} \mathrm{Ti}_{\Delta} \mathrm{O}_{4}$. The $\Delta$ here refers to the stoichiometric composition of $\mathrm{Ti}$ at the endpoint of stage $1(\Delta=(\mathrm{x}+\delta))$. For NZ ironsand, the initial value of $x$ is 0.27 , hence $\Delta \approx 0.5$.

Once wüstite has been fully consumed, the reduction moves into the third stage of the reaction, whereby further reduction can proceed according to reaction (6.3).

Stage 3: $\quad \mathrm{Fe}_{(3-4)} \mathrm{Ti}_{\Delta} \mathrm{O}_{4}+(4-3 \Delta) \mathrm{H}_{2} \rightarrow$ A. $\mathrm{FeTiO}_{3}+(3-2 \Delta) \cdot \mathrm{Fe}+(4-3 \Delta) \cdot \mathrm{H}_{2} \mathrm{O}$

The reduction stage 4 is observed in Figure 6.5 to Figure 6.8 once the conversion to metallic iron nears completion. During this fourth stage, reactions between the residual Tibearing minority phases continue, with ilmenite being converted first into rutile and then pseudobrookite. Figure 6.9 shows an example of magnified plots of the phase evolution of these three phases during the reduction process at different $\mathrm{H}_{2}$ concentrations. Ilmenite is the first Ti-containing phase observed, as it is formed via reaction (6.3) in stage 3. Ilmenite is then itself reduced to metallic iron and rutile according to reaction (6.4). Prolonged exposure to high temperature reducing conditions, then results in the rutile combining with residual ilmenite to form pseudobrookite, according to reaction (6.5) (which reaches a maximum of $\sim 6$ wt. $\%$ of the final product after 60 mins reduction with $100 \% \mathrm{H}_{2}$ ). The 
pseudobrookite is a solid solution which its stoichiometric composition is between $\mathrm{Fe}_{2} \mathrm{TiO}_{5}$ and $\mathrm{FeTi}_{2} \mathrm{O}_{5}$ (see Section 2.3 in Chapter 2). As the reaction here is the reduction reaction, it is more likely that the pseudobrookite here has a stoichiometric composition close to $\mathrm{FeTi}_{2} \mathrm{O}_{5}$, as in reaction (6.5).

$$
\begin{array}{ll}
\text { Stage 4: } \quad \mathrm{FeTiO}_{3(\mathrm{~s})}+\mathrm{H}_{2(\mathrm{~g})} \rightarrow \mathrm{Fe}_{(\mathrm{s})}+\mathrm{TiO}_{2(\mathrm{~s})}+\mathrm{H}_{2} \mathrm{O}_{(\mathrm{g})} \\
\mathrm{FeTiO}_{3(\mathrm{~s})}+\mathrm{TiO}_{2(\mathrm{~g})} \rightarrow \mathrm{FeTi}_{2} \mathrm{O}_{5(\mathrm{~s})}
\end{array}
$$

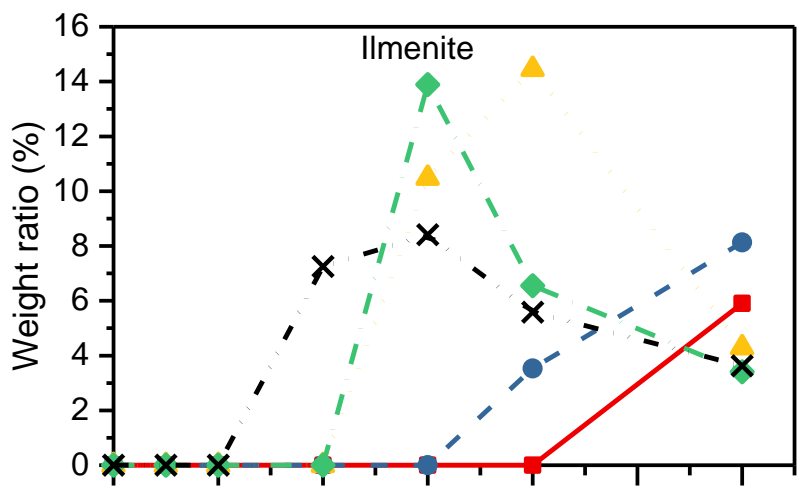

(a)

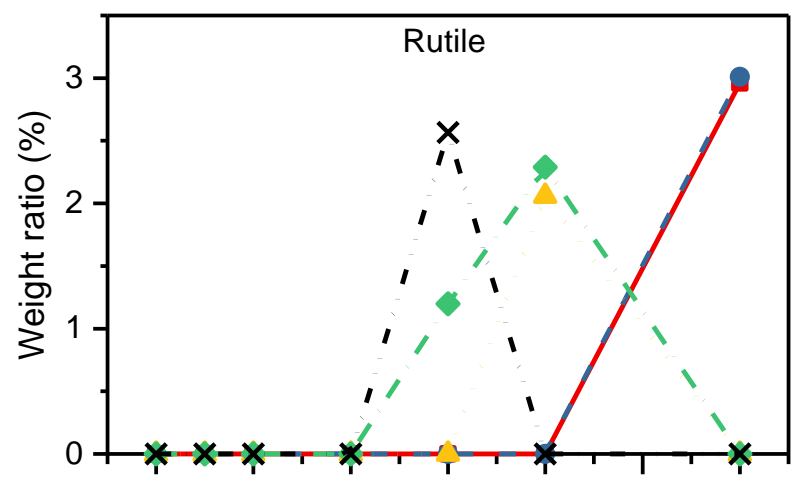

(b)

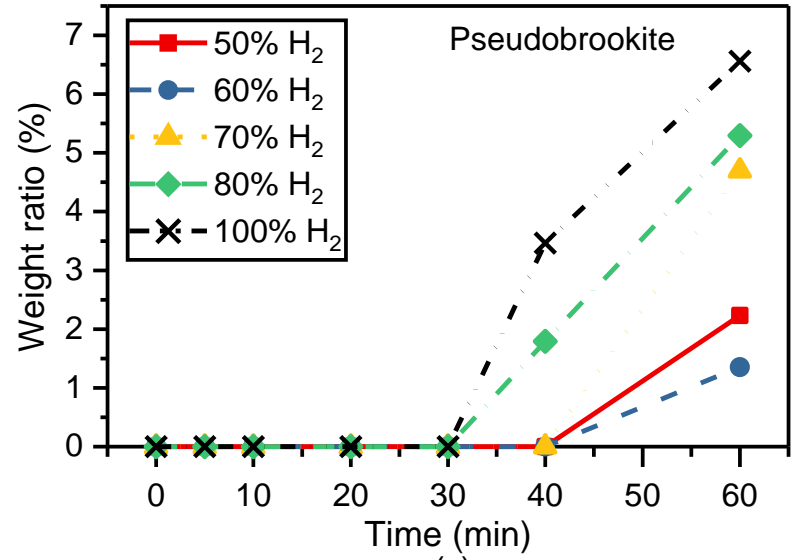

(c)

Figure 6.9 The proportions of the minority Ti-containing phases (ilmenite (a), rutile (b), and pseudobrookite (c)) as a function of time during the reduction of ironsand by various $\mathrm{H}_{2}$ gas compositions. 


\subsection{The effect of experimental parameters on the water vapour emitted during the reduction reaction}

The hydrogen reduction process of iron oxides produces water vapour as the gaseous product (equations 2.1 to 2.3, in Chapter 2). The concentration of $\mathrm{H}_{2} \mathrm{O}$ in the reactor should be expected to affect the thermodynamics during the reaction (Ross, 1980; Skorianz, 2012). However, the reduction sequence appears to be same for all parameters studied, suggesting that the thermodynamic conditions may not significantly change for all cases.

The concentration of $\mathrm{H}_{2} \mathrm{O}$ in the reactor can be calculated based on the expectation that for every mole of oxygen $(\mathrm{O})$ removed from the iron oxides in the sample there is one mole of $\mathrm{H}_{2} \mathrm{O}$ formed by the reduction process, according to reaction (6.6).

$$
\mathrm{H}_{2(\mathrm{~g})}+\mathrm{O}_{\text {(from iron oxides) }} \rightarrow \mathrm{H}_{2} \mathrm{O}_{(\mathrm{g})}
$$

The number of moles of oxygen removed from the bed during each time-step can then be calculated from the change of oxygen atom wt.\% in the iron oxide phases (including Ticontained phases) at each time-step (which is obtained from the q-XRD data). As the number of moles of $\mathrm{H}_{2} \mathrm{O}$ is the same the number of moles of oxygen, the $\mathrm{H}_{2} \mathrm{O} /\left(\mathrm{H}_{2} \mathrm{O}+\mathrm{H}_{2}\right)$ composition can be calculated according to equation (6.7):

$$
\mathrm{H}_{2} \mathrm{O} /\left(\mathrm{H}_{2} \mathrm{O}+\mathrm{H}_{2}\right)(\text { mole ratio })=n_{\mathrm{H} 2 \mathrm{O}} /\left(n_{\mathrm{H} 2 \mathrm{r}}+n_{\mathrm{H} 2 \mathrm{O}}\right)
$$

with,

$$
n_{H 2 r}=n_{H 2 i}-n_{H 2 c}
$$

where $n_{H 2 O}$ is the average $\mathrm{H}_{2} \mathrm{O}$ moles each time-step (mole/min), $n_{H 2 r}$ is the number of moles of $\mathrm{H}_{2}$ remaining after the reaction per minute, $n_{H 2 i}$ is the number of moles of $\mathrm{H}_{2}$ delivered per minute in the inlet, and $n_{H 2 c}$ is the number of moles of $\mathrm{H}_{2}$ consumed during the reaction per minute.

Figure 6.10 shows the resulting calculated $\mathrm{H}_{2} \mathrm{O} /\left(\mathrm{H}_{2} \mathrm{O}+\mathrm{H}_{2}\right)$ composition at the outlet from the reactor, as a function of the total $\mathrm{H}_{2}$ gas volume delivered to the reactor. For each parameter varied, the $\mathrm{H}_{2} \mathrm{O} /\left(\mathrm{H}_{2} \mathrm{O}+\mathrm{H}_{2}\right)$ ratio in the reactor can be seen to follow a similar relationship. This implies that the utilization of $\mathrm{H}_{2}$ gas is broadly the same for all experimental conditions studied. 
Specifically, it appears that (for the experimental parameters studied here) the $\mathrm{H}_{2} \mathrm{O}$ composition observed at the reactor outlet follows the same profile against total input $\mathrm{H}_{2}$ gas, regardless of $\mathrm{H}_{2}$ gas concentration, $\mathrm{H}_{2}$ gas flow rate, sample mass, or particle size. This suggests that the $\mathrm{H}_{2} \mathrm{O}$ concentrations in the reactor limit the reduction rate.
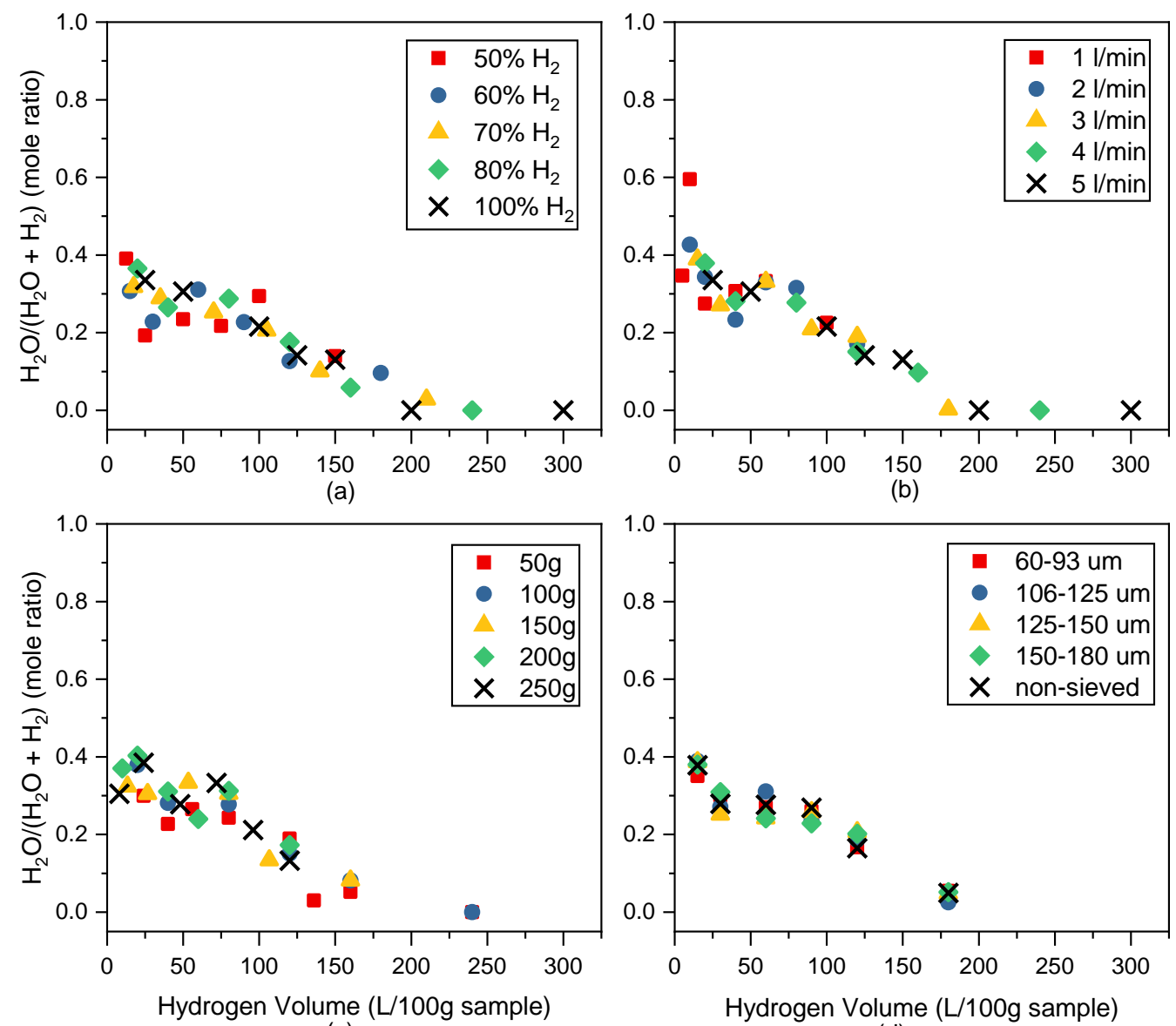

(c)

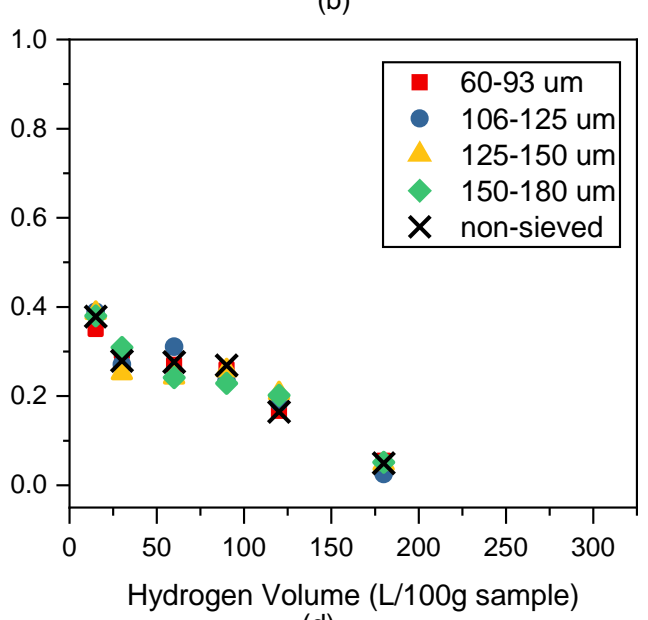

(d)

Figure 6.10 Calculated $\mathrm{H}_{2} \mathrm{O} / \mathrm{H}_{2}+\mathrm{H}_{2} \mathrm{O}$ ratio as a function of total delivered $\mathrm{H}_{2}$ volume during the reduction process at $950^{\circ} \mathrm{C}$ for different $\mathrm{H}_{2}$ gas concentration (a), $\mathrm{H}_{2}$ gas flow rate (b), initial bed mass (c), and particle size (d).

From Figure 6.3, we also know that the \%met also exhibits similarly uniform behaviour versus total $\mathrm{H}_{2}$ gas input volume, for every experimental parameter studied at $950^{\circ} \mathrm{C}$. Figure 6.11 shows a different perspective of looking at $\mathrm{H}_{2} \mathrm{O} /\left(\mathrm{H}_{2} \mathrm{O}+\mathrm{H}_{2}\right)$ ratio at different \%met for each reduction stage.

By pairing the \%met curves (in Section 6.3) with the phase evolution curve (in Section 6.4) for each parameter, information on the output $\mathrm{H}_{2} \mathrm{O} /\left(\mathrm{H}_{2} \mathrm{O}+\mathrm{H}_{2}\right)$ ratio for each reduction stage identified in Figures 6.5 to 6.8 can be obtained. Each stage of the reduction process is shown as a numbered span at the top of each plot in Figure 6.11. From 0 to 
$\sim 10$ \%met, the $\mathrm{H}_{2} \mathrm{O}$ composition decreases from $\sim 40 \%$ to $\sim 30 \%$. This condition corresponds to reduction stage 1, where TTM is partially reduced to wüstite. From 10\% to $\sim 70 \%$ met, the $\mathrm{H}_{2} \mathrm{O}$ composition appears to plateau at $\sim 30 \%$. This region corresponds to reduction stage 2 , where the reaction is favoured to reduce wüstite over TTM phase. From $\sim 70 \%$ to $\sim 90 \%$ met, the $\mathrm{H}_{2} \mathrm{O}$ composition decreases to $\sim 10 \%$. This region corresponds to reduction stage 3, where the reduction of the remaining Ti-enriched TTM to metallic iron continues. For \%met $>90 \%$, where the reaction involves mainly Ti-bearing phases (corresponding to stage 4), the $\mathrm{H}_{2} \mathrm{O}$ composition decreases close to 0 .

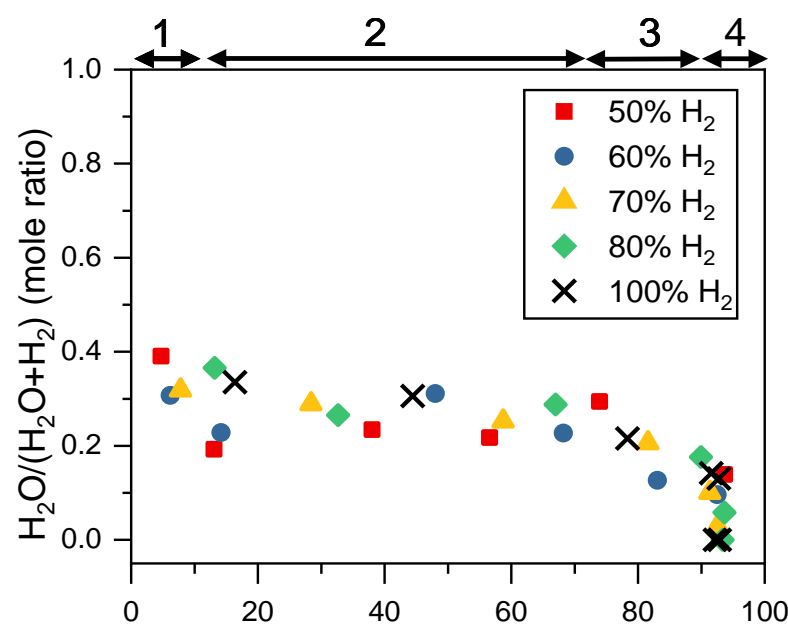

(a)

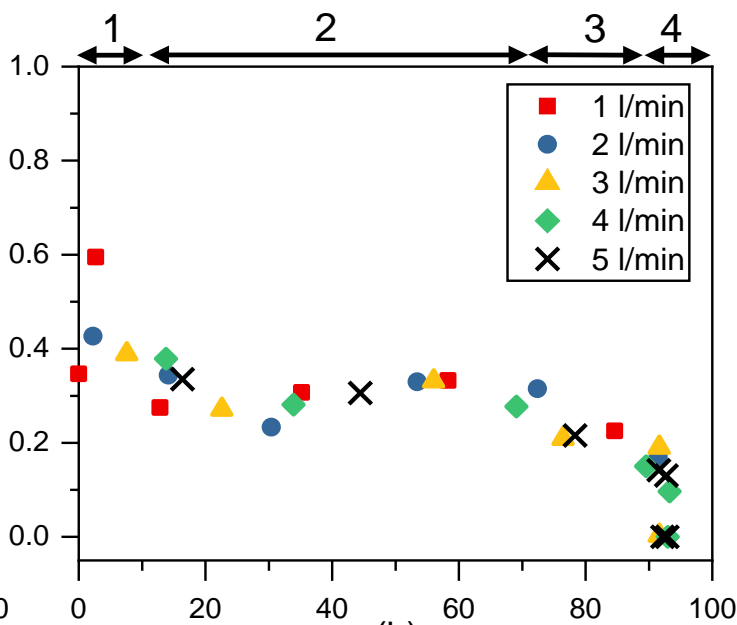

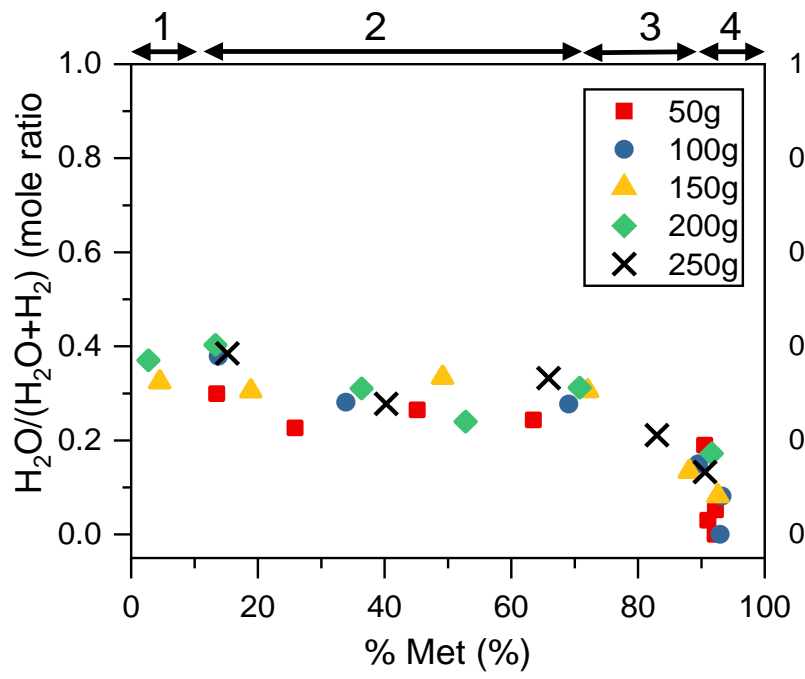

(c)

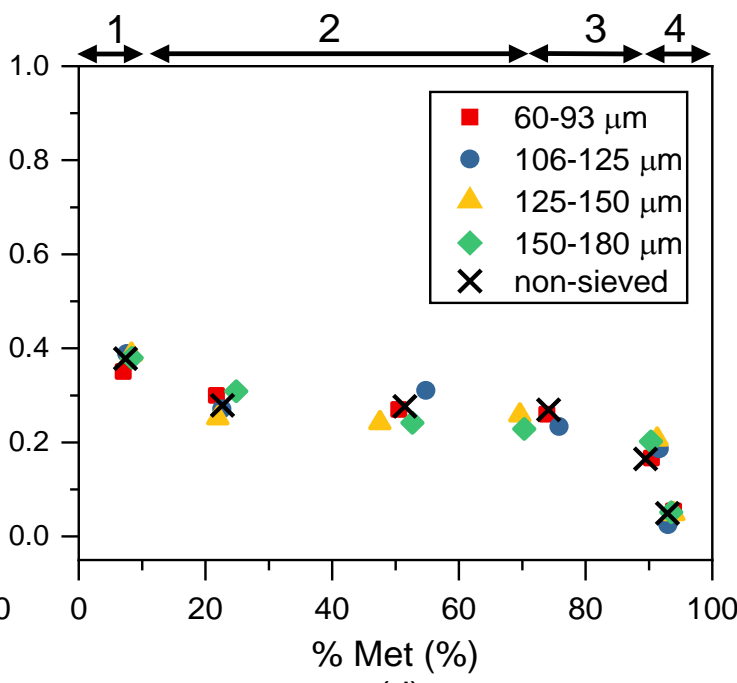

(d)

Figure 6.11 Calculated $\mathrm{H}_{2} \mathrm{O} /\left(\mathrm{H}_{2}+\mathrm{H}_{2} \mathrm{O}\right)$ ratio as a function of \%met during the reduction process at $950^{\circ} \mathrm{C}$ for different $\mathrm{H}_{2}$ gas concentration (a), $\mathrm{H}_{2}$ gas flow rate (b), initial bed mass (c), and particle size (d). Numbered spans at the top of each plot indicate the \%met corresponding to each reduction stage. 
Figure 6.11 shows there is a plateau for the gas composition during reduction stage 2 (reaction (6.2)). This indicates that the gas composition is fixed for all conditions. This is most likely because the reaction is near the thermodynamic limit between two phase region wüstite and iron. Once wüstite is reduced, the $\mathrm{H}_{2} \mathrm{O}$ composition is then decreased, during reduction stage 3 in Figure 6.11. The relation of the $\mathrm{H}_{2} \mathrm{O}$ composition to the relevant "BaurGlaessner” diagram for Fe-O-H system is further discussed in Chapter 7.

\subsection{Microstructural evolution of ironsand particles during the FB reduction}

The fact that ironsand particles were not observed to stick during any of the FB reductions at $950^{\circ} \mathrm{C}$ is a surprising and positive result, which differs from previous reports of FB reduction of iron ore fines at this temperature (Neuschütz, 1991; Hayashi and Iguchi, 1992; Komatina and Gudenau, 2004). In order to investigate the underlying cause of this behaviour, SEM microstructural analysis was performed on the samples reduced by 5 $\mathrm{L} / \mathrm{min} \mathrm{H}_{2}$ gas. Since the phase evolution during the reduction follows the same sequence of stages for all parameters studied, it is assumed there is no difference in the microstructural features for particles reduced at all conditions. To confirm this, samples taken during the reduction by 30 vol.\% $\mathrm{Ar}-70 \mathrm{vol} . \% \mathrm{H}_{2}$ were also studied in detail and found to show similar microstructures at each stage of reduction to those reduced in $100 \% \mathrm{H}_{2}$ gas. SEM images for the particles reduced in 30 vol.\% $\mathrm{Ar}-70$ vol.\% $\mathrm{H}_{2}$ are presented in Appendix B.

Figure 6.12 shows BSE images of both the unreduced ironsand and the final product after reduction for 60 minutes in $100 \% \mathrm{H}_{2}$. It is clear that the reduced particles retain a similar size distribution to the unreduced material and are individually separated, showing no evidence of agglomeration (see Figure 6.12(a) and (b)). There are also no fibres or whiskers of iron visible on the surface of the reduced particles as shown in Figures 6.12(b) and (d) (As discussed in Chapter 2, these are common features of reduced iron ore particles that do exhibit sticking).

As mentioned in Chapter 2, there are significant differences observed between the microstructural evolution of the two different types of particles found in the original unreduced ironsand, namely: the uniform homogeneous TTM particles; and the nonuniform particles containing TTH lamellae. It is useful to discuss each type of particle separately. These are discussed in turn below, starting with the uniform homogenous TTM 
particles. These uniform particles form by far the majority of the sample ( $\approx 90 \%)$ and hence determine to a large degree the bulk reduction behavior measured in the XRD.
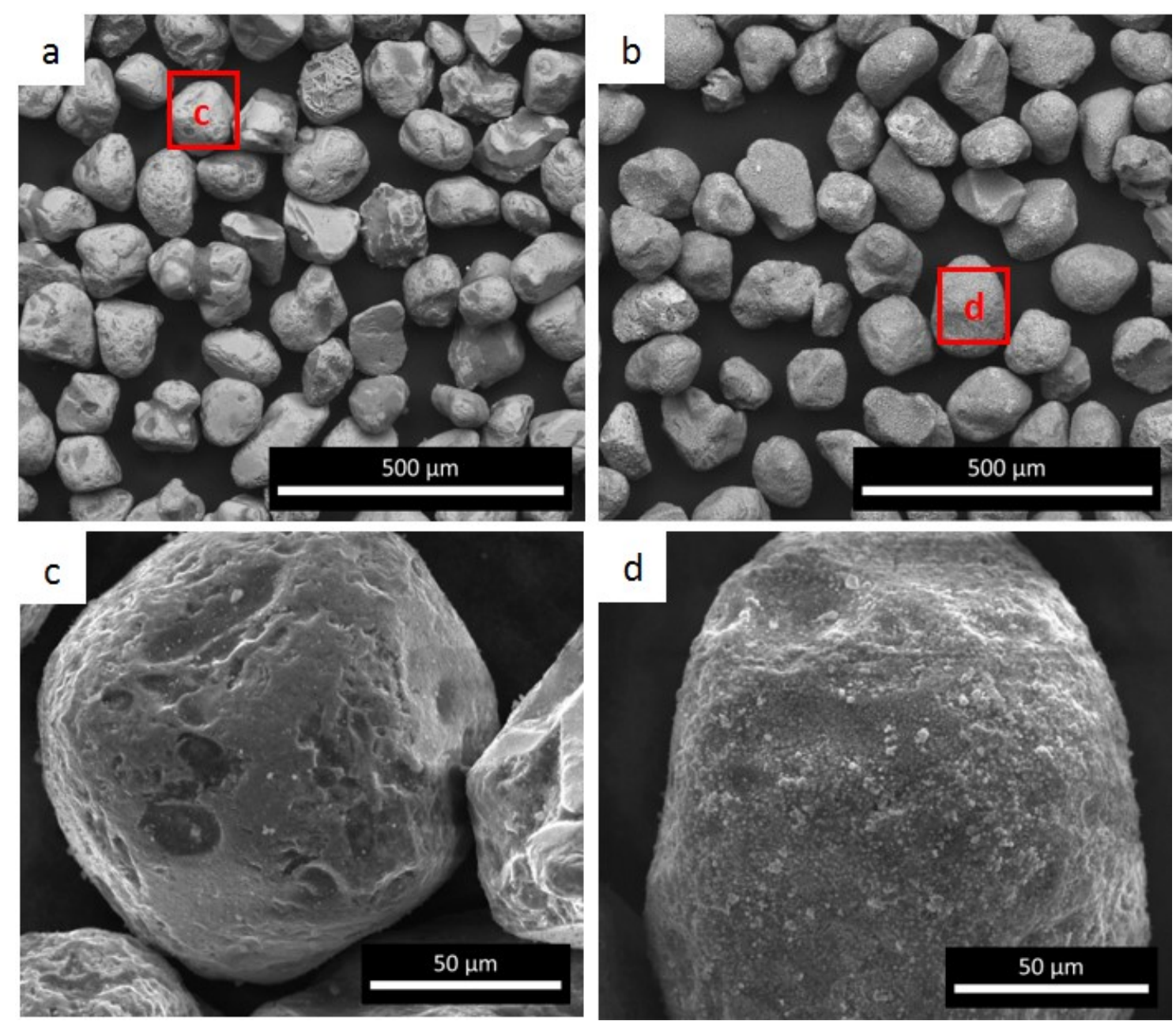

Figure 6.12 SEM micrographs for unreduced ironsand particles $(a, c)$ and ironsand particles reduced in $5 \mathrm{~L} / \mathrm{min} \mathrm{H}_{2}$ at $950^{\circ} \mathrm{C}$ for 60 minutes $(b, d)$. Red markers indicate the location of magnified image.

\subsubsection{Microstructural evolution of uniform TTM particles}

Figure 6.13 shows a typical cross-section of the BSE images formed by reduction of homogenous TTM particles. Images are shown for a representative particle from the bulk samples extracted at each sampling time during reduction in $100 \% \mathrm{H}_{2}$ gas. Low magnification images which show the bulk samples for each sampling time are presented in Appendix B. 

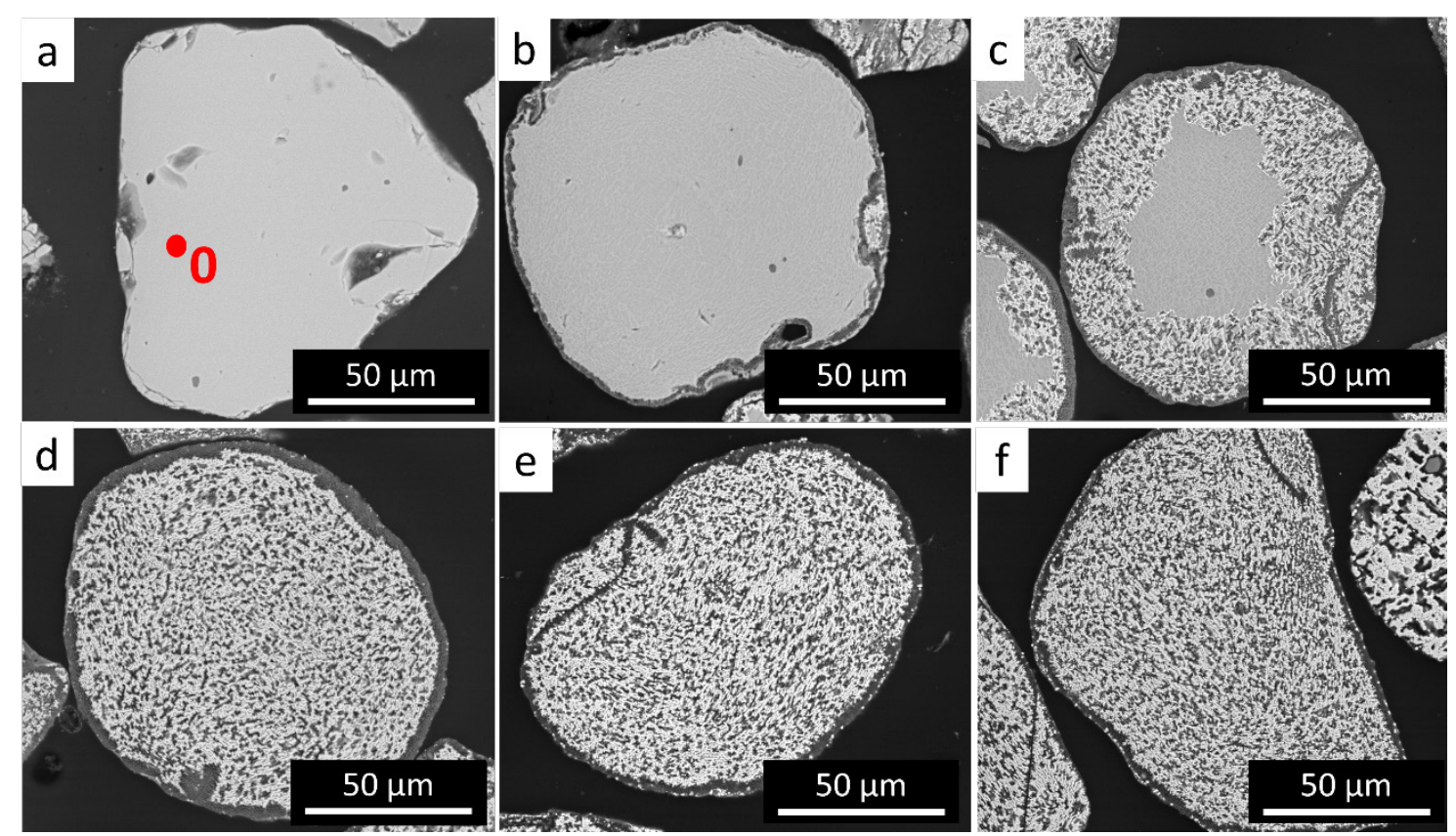

Figure 6.13 The microstructural evolution of the uniform grain during the reduction by 5 $\mathrm{L} / \mathrm{min} \mathrm{H}_{2}$ at $950^{\circ} \mathrm{C}$ : (a) raw ironsand, (b) 5 minutes (stage 1), (c) 10 minutes (stage 2), (d) 20 minutes (stage 3), (e) 40 minutes (stage 4), (f) 60 minutes (stage 4)

Several features are immediately apparent. The fully reduced samples (Figures 6.13(e) and (f)) show a filigree-like structure of metallic iron (bright phase) throughout the inner region of the particle, which is surrounded by a grey shell. This outer oxide shell is also apparent in all other images (except for the original unreduced ironsand) and is likely the key reason that these particles do not exhibit sticking during the FB reduction process. More importantly, formation of the shell layer does not prevent further reduction from occurring, as the reduction continues to progress steadily until a \%met of $>90 \%$ is achieved after 30 mins (Figure 6.2(a)). This implies that gas can readily diffuse through the shell layer.

In the sample taken after 10 mins (Figure 6.13(c)), a shrinking-core type boundary is observed for the conversion to metallic iron. However, the later stages of metallisation (Figure 6.13(d)) do not show a core-like structure, and there is no evidence of a topochemical boundary between wüstite and TTM phases, consistent with the XRD result in reduction stage 3 (see Figure 6.5(e)).

Higher magnification images of the same particles are shown in Figure 6.14. Figure 6.14(a) shows a region of the particle in which no metallic iron has yet been formed after 5 minutes reduction. Here, it can be seen that the inner region of the particle has been 
partially converted to form light grey channels (white arrow) which penetrate throughout the darker grey TTM matrix (black arrow). The increased contrast indicates higher $\mathrm{Fe} / \mathrm{O}$ ratios in the light-grey areas, indicating that they comprise the wüstite phase observed in XRD (see Figure 6.5(e)). This phase assignment is consistent with the EDS maps shown in Figure 6.15. These EDS maps also show that the iron-rich wüstite regions do not contain significant levels of $\mathrm{Al}$ or $\mathrm{Ti}$, and that the $\mathrm{Al}$ and $\mathrm{Ti}$ remain within the darker grey TTM regions. This is consistent with reaction (6.1).

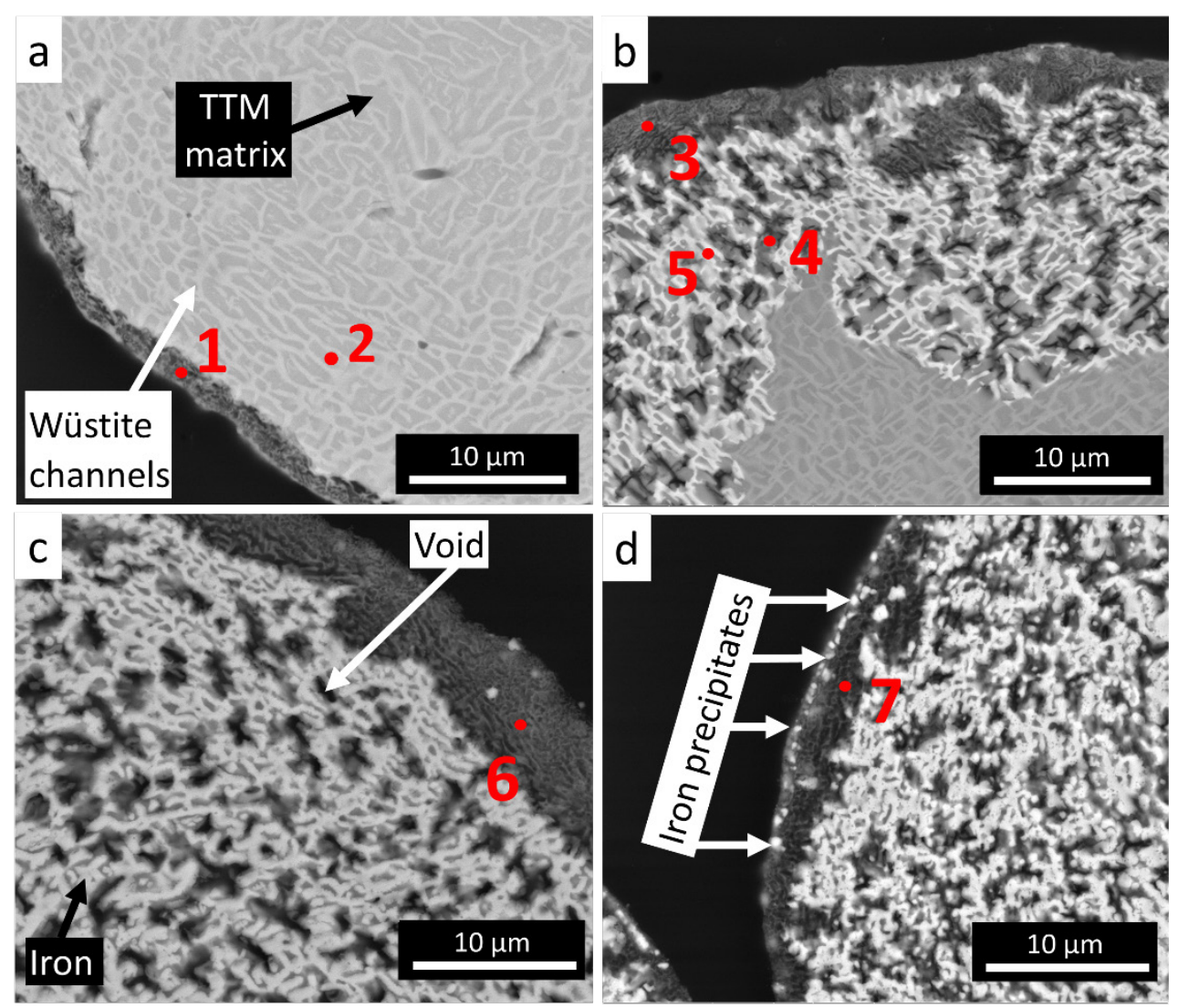

Figure 6.14 High magnification back scatter SEM images of cross-sectioned uniform particles after reduction by $5 \mathrm{~L} / \mathrm{min} \mathrm{H}_{2}$ at $950^{\circ} \mathrm{C}$. Images shown for reduction after: (a) 5 minutes (stage 1), (b) 10 minutes (stage 2), (c) 20 minutes (stage 3), and (d) 60 minutes (stage 4). The magnification is $8,000 X$.

The interlaced wüstite-TTM microstructure in Figures 6.14(a) and 6.15 also provides evidence of the mechanism by which $\mathrm{Ti}$ and $\mathrm{Al}$ migration affects the reduction process. The low solubility of $\mathrm{Al}$ and $\mathrm{Ti}$ in wüstite (McAdam, 1974; Longbottom, Ostrovski and Park, 2006; Longbottom et al., 2018), means that these species must be exsolved from all wüstite as it is formed (as described in reaction (6.1)). This is because $\mathrm{Ti}^{4+}$ and $\mathrm{Al}^{3+}$ ions can substitute onto octahedral $\mathrm{Fe}^{3+}$ sites in the TTM crystal structure (Richards et al., 1973; 
Wechsler, Lindsley and Charles T. Prewitt, 1984; Pearce et al., 2012), but are not readily incorporated into the (solely) $\mathrm{Fe}^{2+}$ sites within the wüstite lattice. By contrast, $\mathrm{Mg}^{2+}$ can substitute onto $\mathrm{Fe}^{2+}$ sites in both TTM and wüstite crystal lattices implying that $\mathrm{Mg}^{2+}$ is not exsolved as wüstite is formed. This is confirmed in Figure 6.15(e) where the distribution of $\mathrm{Mg}$ within the particle remains homogenous. Locally, this leads to the formation of the wüstite channels surrounded by Ti-enriched TTM as shown in Figure 6.15. This process continues until all the surrounding Ti-enriched TTM becomes less reducible than the wüstite channels. At this point, wüstite is then preferentially reduced to metallic iron, marking the transition point between stage 1 and stage 2 of the reduction process.

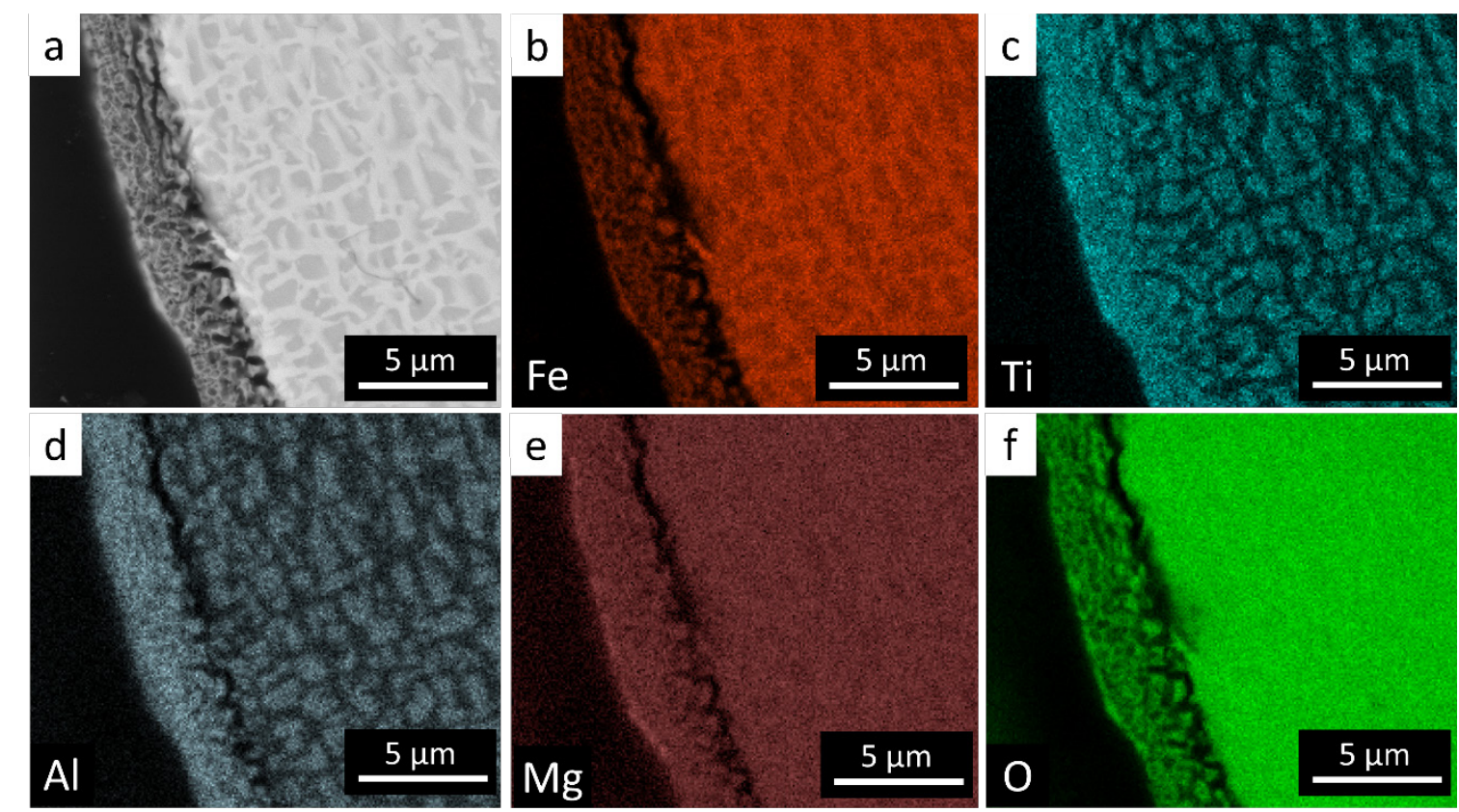

Figure 6.15 Elemental EDS map of a TTM ironsand uniform grain reduced by $5 \mathrm{~L} / \mathrm{min} \mathrm{H}_{2}$ at $950^{\circ} \mathrm{C}$ for 5 minutes. (a) is the BSE image, (b) to (f) refer to the element noted in each image.

Similar bright-channel microstructures have also been observed during the early reduction of the TTM ironsand in a fixed bed reactor by (Wang, Zhang, Ma, et al., 2017; Wang et al., 2018), although the phase was neither identified nor explained. This microstructure is different from that reported for conventional (i.e. titanium-free) magnetite and hematite ores. In those ores, the conversion of TTM to wüstite typically proceeds topochemically such that a wüstite ring develops from the particle surface, and this spatially separates the interface between any subsequently formed metallic iron and unreacted magnetite (Weiss et al., 2010, 2011; Pichler et al., 2016). 
Figure 6.14(b) shows the phase evolution during stage 2 (equation (6.2)) of the reaction when wüstite is being converted to metallic iron. The inner region of the particle shows a similar interlaced structure of wüstite and TTM as observed in Figure 6.14(a). However, outside of this region bright channels of iron are observed. These channels follow the same pattern as wüstite through the surrounding TTM matrix. This is consistent with the conversion of wüstite to iron, whilst the surrounding Ti-stabilised TTM remains unreduced, as described in reaction (6.2). Figure 6.14(c) shows the situation after 20 minutes of reduction, during stage 3 (equation (6.3)) of the reduction. At this point, all of the wüstite has been reduced and metallisation proceeds via the direct conversion of the remaining Ti-enriched TTM regions which are interspersed between the channels of metallic iron (black arrow). As a result, the fine channels of iron become thicker, and some voids (white arrow) appear due to the volume change as oxygen is removed from the TTM lattice. These voids will slightly reduce the apparent density of the particles within the FB, which could affect the fluidisation behavior. However, the gas flow rate has been chosen to lie well inside the bubbling bed regime, to ensure that such changes in particle density will not affect the operating mode of the bed.

Figure 6.14(d) shows the end point of the reduction after 60 mins, at which point 93\% metallisation has been achieved. The interior region is now fully occupied by porous metallic iron and small regions of grey slag oxides. Interestingly, Figure 6.14(d) is the first image in which metal precipitation is observed in the outer shell of the particle. This suggests that the small iron precipitates (white arrow) observed on the surface of the final particles (Figure 6.14(d)), are formed at a very late stage in the process and are a result of the final reduction of the Ti-rich phases in stage 4 ((equation (6.4)) of the reaction.

\subsubsection{Development of the protective outer oxide shell}

The outer oxide shell of each particle forms within the first 5 minutes of the reduction and is maintained throughout the reduction process (Figure 6.14(b-f)). Although only a few microns thick, this shell is likely providing the protective barrier which prevents metallic iron-to-iron contact between particles during fluidisation. It is likely that the formation of this shell around the uniform grains is the key reason that the TTM ironsand investigated in this study did not stick during FB reduction at $950^{\circ} \mathrm{C}$. 
An important point to note is that formation of the protective shell is not simply caused by heating under inert conditions. Samples taken following fluidisation of ironsand in $\mathrm{Ar}$ gas at $950^{\circ} \mathrm{C}$ for 30 minutes showed no evidence of the shell on the outer part of particles, as shown in Figures 6.16 and 6.17.
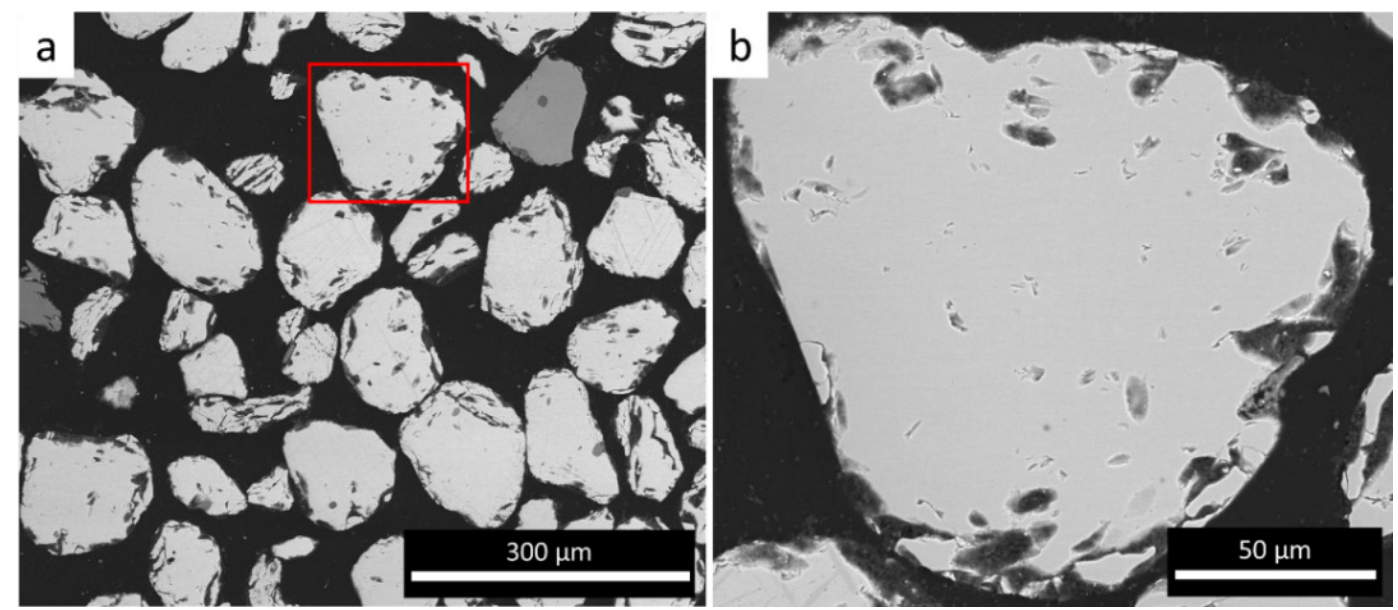

Figure 6.16 SEM cross-section micrographs of unreduced ironsand particles sample

taken after fluidisation in Ar gas at $950^{\circ} \mathrm{C}$ for 30 mins. (a) Bulk sample at $400 x$ magnification. Red marker indicates the location of magnified image shown in image (b).

(b) 1700x magnification image of uniform homogeneous particle. Dark features observed upon particles are polishing artefacts only.
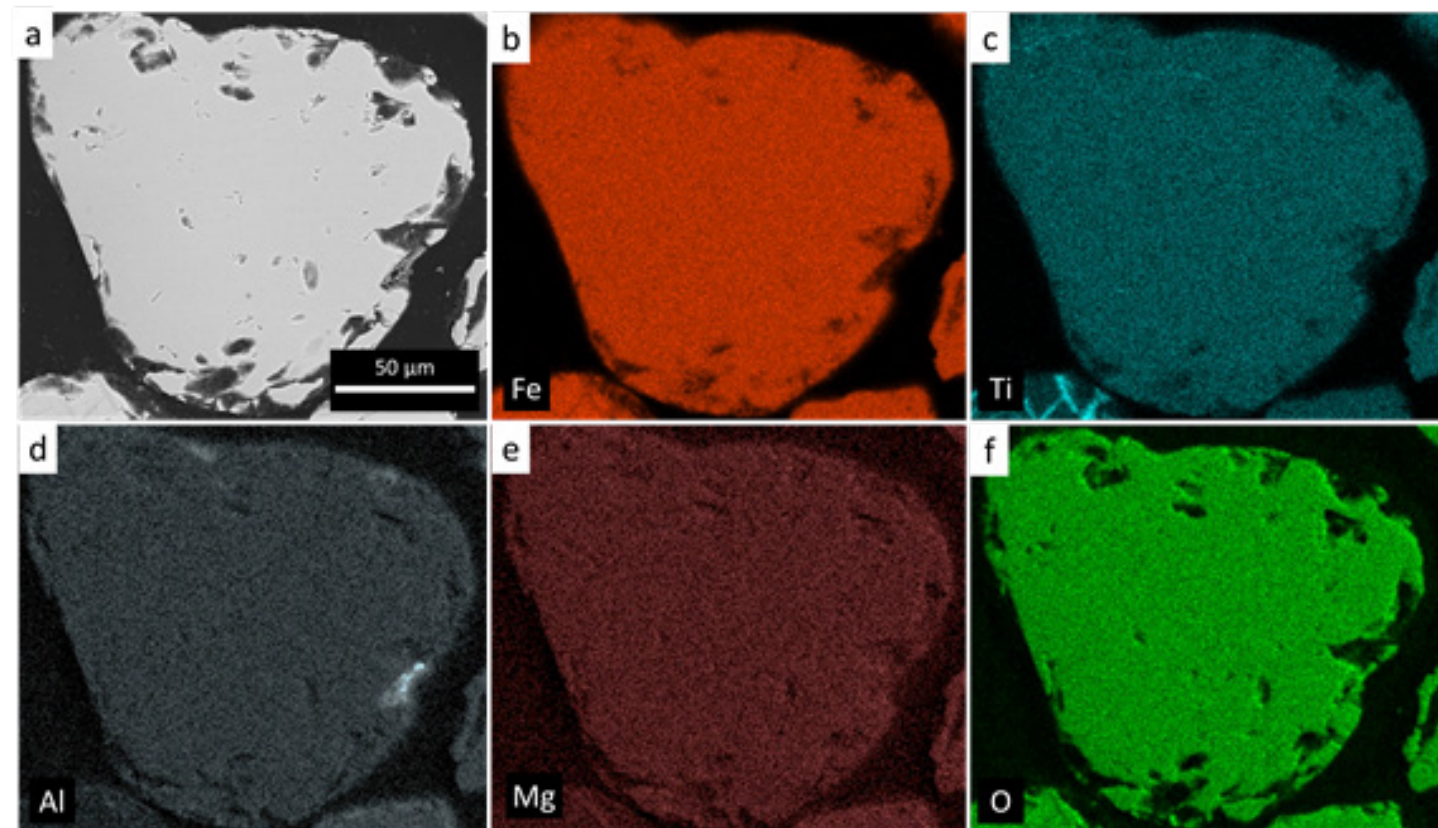

Figure 6.17 Elemental EDS map of the TTM ironsand uniform grain in Figure 6.16(b) from fluidisation in Ar gas at $950^{\circ} \mathrm{C}$ for 30 mins. 
The approximate elemental composition of the shell at each stage of the reduction was determined by EDS point analysis for each of the numbered spots shown in Figures 6.13 and 6.14. This EDS data is shown in Table 6.1.

Table 6.1 Elemental spot EDS analysis of points shown in Figure 6.13 and 6.14. Red coloured fonts indicate points in the shell.

\begin{tabular}{ccccccccc}
\hline \multirow{2}{*}{ Element } & \multicolumn{7}{c}{ Point (Atomic \%) } \\
\cline { 2 - 9 } & 0 & 1 & 2 & 3 & 4 & 5 & 6 & 7 \\
\hline $\mathrm{O}$ & 59.3 & 47.3 & 58.5 & 65.7 & 44.0 & 27.9 & 55.5 & 60.3 \\
$\mathrm{Mg}$ & 1.9 & 0.7 & 2.0 & 3.0 & 2.7 & 3.2 & 3.8 & 5.4 \\
$\mathrm{Al}$ & 1.5 & 2.0 & 1.9 & 6.3 & 3.2 & 3.2 & 8.8 & 7.3 \\
$\mathrm{Ti}$ & 2.5 & 8.6 & 3.5 & 5.1 & 6.7 & 2.3 & 9.0 & 12.7 \\
$\mathrm{Mn}$ & 0.5 & - & 0.5 & 0.3 & 0.7 & - & 0.0 & 1.2 \\
$\mathrm{Si}$ & - & - & - & 0.2 & - & - & 0.6 & 0.0 \\
$\mathrm{Fe}$ & 34.2 & 41.4 & 33.5 & 20.0 & 42.6 & 63.4 & 23.0 & 14.5 \\
$\mathrm{Fe} / \mathrm{Ti}$ & 13.5 & 4.8 & 16.5 & 4.0 & 6.3 & 27.8 & 2.6 & 1.2 \\
\hline
\end{tabular}

The hyphen sign in the table means no signal for the respective element.

In the early stage of reduction (Figure 6.14(a)), the shell is typically rich in titanium and aluminum (points 1, 3, 6, and 7) compared to the inner particle (points 2, 4, and 5). The inital development of the shell likely occurs via a process similar to that which causes the segregation of wüstite and Ti-enriched TTM within the interior of the particle. During the initial reduction stages of the particle, oxygen is removed from the outer layer of TTM. The remaining species combine to form a Ti (and Al) enriched TTM, but no wüstite is found at the outer surface of the particle. Instead the excess iron species seem to migrate inwards, and only form wüstite within the interior of the particle. It is speculated that this might be due to the higher relative concentration of $\left[\mathrm{H}_{2}\right] /\left[\mathrm{H}_{2} \mathrm{O}\right]$ at the particle surface, compared to its interior. This appears to prevent wüstite from forming at the outer surface, such that the surface oxide is quickly depleted in Fe and correspondingly enriched in $\mathrm{Ti}$ and $\mathrm{Al}$. As the reaction proceeds, further wüstite is formed within the particle and additional $\mathrm{Al}$ and $\mathrm{Ti}$ ions migrate to the outer shell. As a result, the outer shell becomes thicker as the reduction proceeds (Figures 6.14(a) and (c)), and the Fe/Ti ratio in the shell becomes progressively smaller over time (see points 1, 3, 6, and 7 in Table 6.1). 
Figure 6.18 plots the change in the $\mathrm{Fe}, \mathrm{Ti}, \mathrm{Al}$, and $\mathrm{Mg}$ content in the protective shell as the reduction process proceeds. The value shown for each element in Figure 6.18 is taken from an average of the EDS spot analysis from eight locations in each sample (from four particles), with the error bar denoting the standard error. The $\mathrm{M}$, the relative atomic fraction, value plotted on the y-axis is defined in equation (6.9),

$$
\mathrm{M}={ }^{M_{i}} /(\% F e+\% T i+\% A l+\% M g)
$$

where $\mathrm{M}_{\mathrm{i}}$ denotes the measured atomic \% of the element of interest (i.e. Fe, $\mathrm{Ti}, \mathrm{Al}$, or $\mathrm{Mg}$ ). All values are in atomic \%. By plotting this $\mathrm{M}$ value, the relative ratio of the key metallic species within the shell oxide over time can be followed. From this figure it can be seen that there is a marked decrease of iron content in the shell as the reduction progresses, whilst the Ti content increases substantially. The relative concentration of $\mathrm{Al}$ and $\mathrm{Mg}$ also increase over time. It was found that the average Fe/Ti ratio in the shell in after 60 mins is $0.97 \pm 0.20$, which is comparable to the $\mathrm{Fe} / \mathrm{Ti}$ ratio expected for Ilmenite $(=1.00)$. As discussed previously, ilmenite and small amount of TTM phases are reduced to metallic iron, rutile, and pseudobrookite in stage 4 of reduction. Figure 6.14(d) shows that small metallic iron precipitates have started to form in the shell after 60 mins. This implies that the oxide shell is also being reduced in the final stage of the reaction.

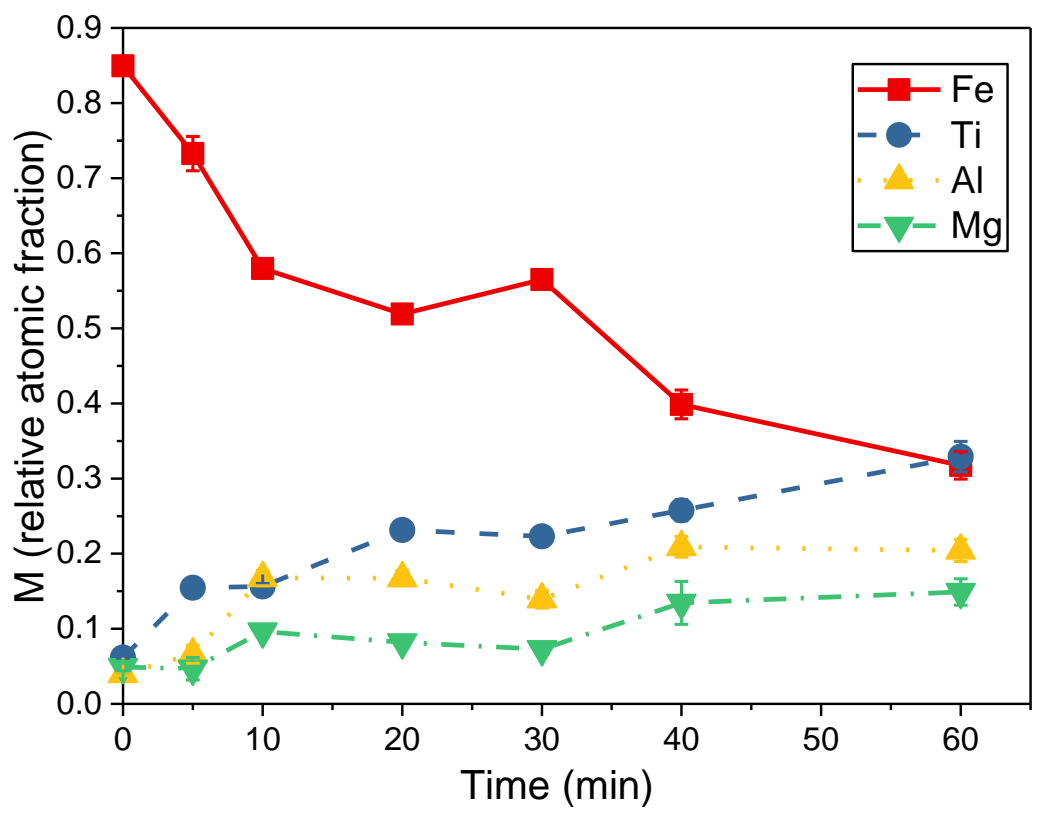

Figure 6.18 Plot showing relative change in ratios of key metallic elements within the shell, as a function of time during the reduction by 100 vol. $\% \mathrm{H}_{2}$ at $950^{\circ} \mathrm{C}$. The value $\mathrm{M}$ plotted on the $y$-axis is defined in equation (6.9). 
Figure 6.19 shows an EDS map of a particle reduced for 60 mins, again emphasising that the iron content of the shell matrix is greatly depleted compared to the inner region of the particle. The shell is rich in $\mathrm{Ti}, \mathrm{Al}$, and $\mathrm{Mg}$, as indicated by point 7 in Table 6.1. Besides in the shell, though difficult to see, small (sub-micron) exsolved regions of ( $\mathrm{Ti}, \mathrm{Al}, \mathrm{Mg}$ ) oxides are also found interspersed within the metallic iron.
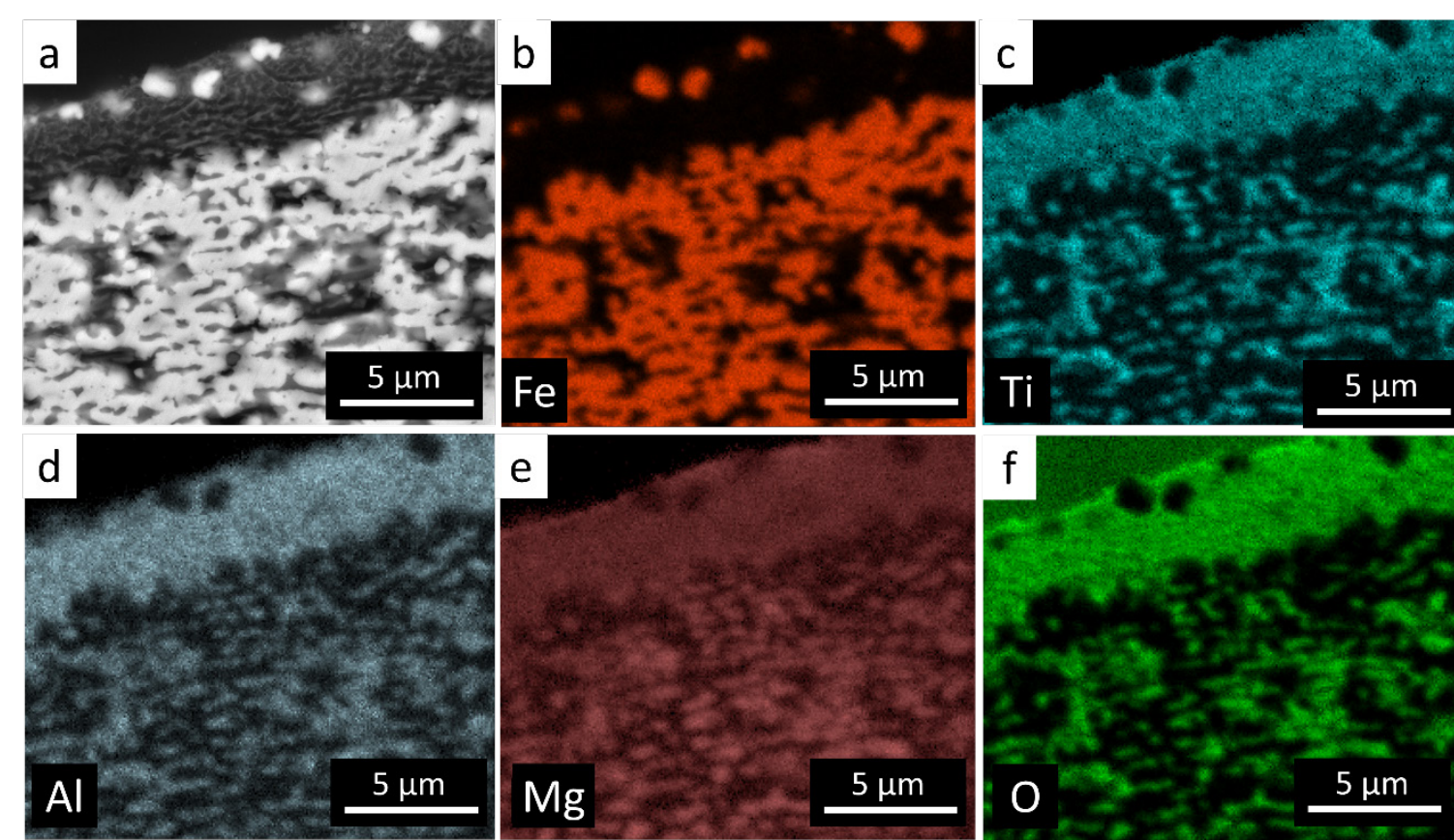

Figure 6.19 Elemental EDS map of the TTM ironsand uniform grain reduced by $5 \mathrm{~L} / \mathrm{min}$ $\mathrm{H}_{2}$ at $950^{\circ} \mathrm{C}$ for 60 minutes. (a) is the BSE image, (b) to (f) refer to the element noted in each image.

\subsubsection{Microstructural evolution of non-uniform lamella TTH/TTM particles}

A small proportion $(<10 \%)$ of the initial ironsand particles contain lamellae of TTH within the TTM matrix. Although these particles do not dominate the observed bulk reduction behavior, they are the main source of TTH in the initial unreduced sample. It is noteworthy that the reduction process in these lamellar particles initially proceeds quite differently from that of the uniform TTM particles. Figures 6.20 and 6.21 show SEM images of non-uniform lamellar particles at each stage of the reduction process, at low and high magnification respectively. It is apparent that reduction initiates along each lamella, and metallisation then subsequently encroaches into each of the surrounding TTM regions. 

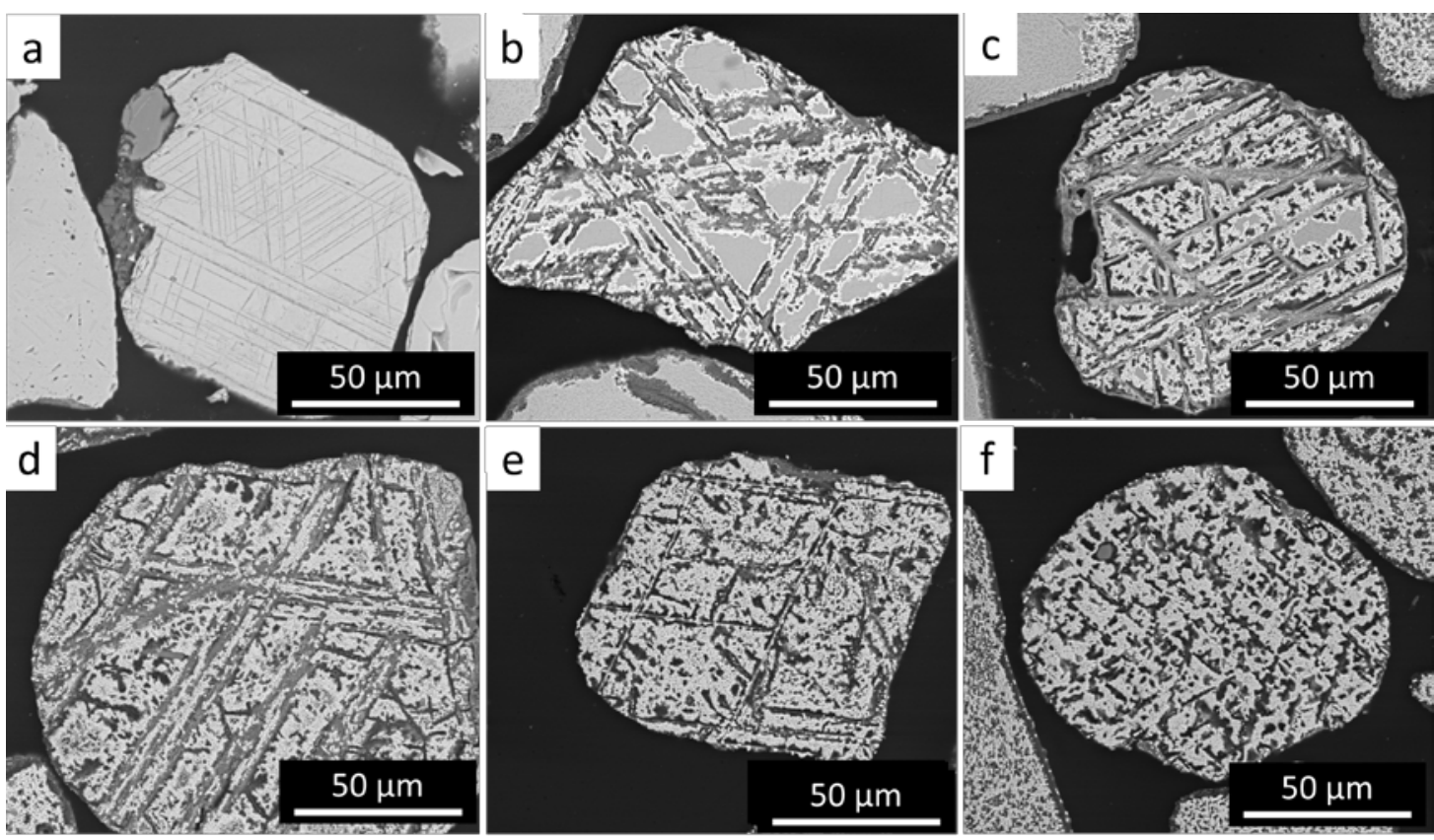

Figure 6.20 The microstructural evolution of non-uniform lamella particles during the reduction by $5 \mathrm{~L} / \mathrm{min} \mathrm{H}_{2}$ at $950^{\circ} \mathrm{C}$ : (a) original ironsand prior to reduction process; (b) after 5 minutes reduction; (c) after 10 minutes reduction; (d) after 20 minutes reduction; (e) after 40 minutes reduction; ( $f$ ) after 60 minutes reduction.

Figures 6.20(b) and 6.21(a) shows that the reduction of the TTH lamellae occurs in the first 5 minutes, which is consistent with the disappearance of TTH from the XRD traces within this timescale (Figure 6.5(e)). At this point, voids (white arrow in Figure 6.21(d)) have already formed within the lamella, and these may enable rapid gas diffusion along these channels during the latter stages of the reaction. As a result, the metallisation front within each enclosed region of TTM appears to start at the surrounding lamella boundary and progress inwards from there (as shown for example in Figures 6.21(b) and (c)). 

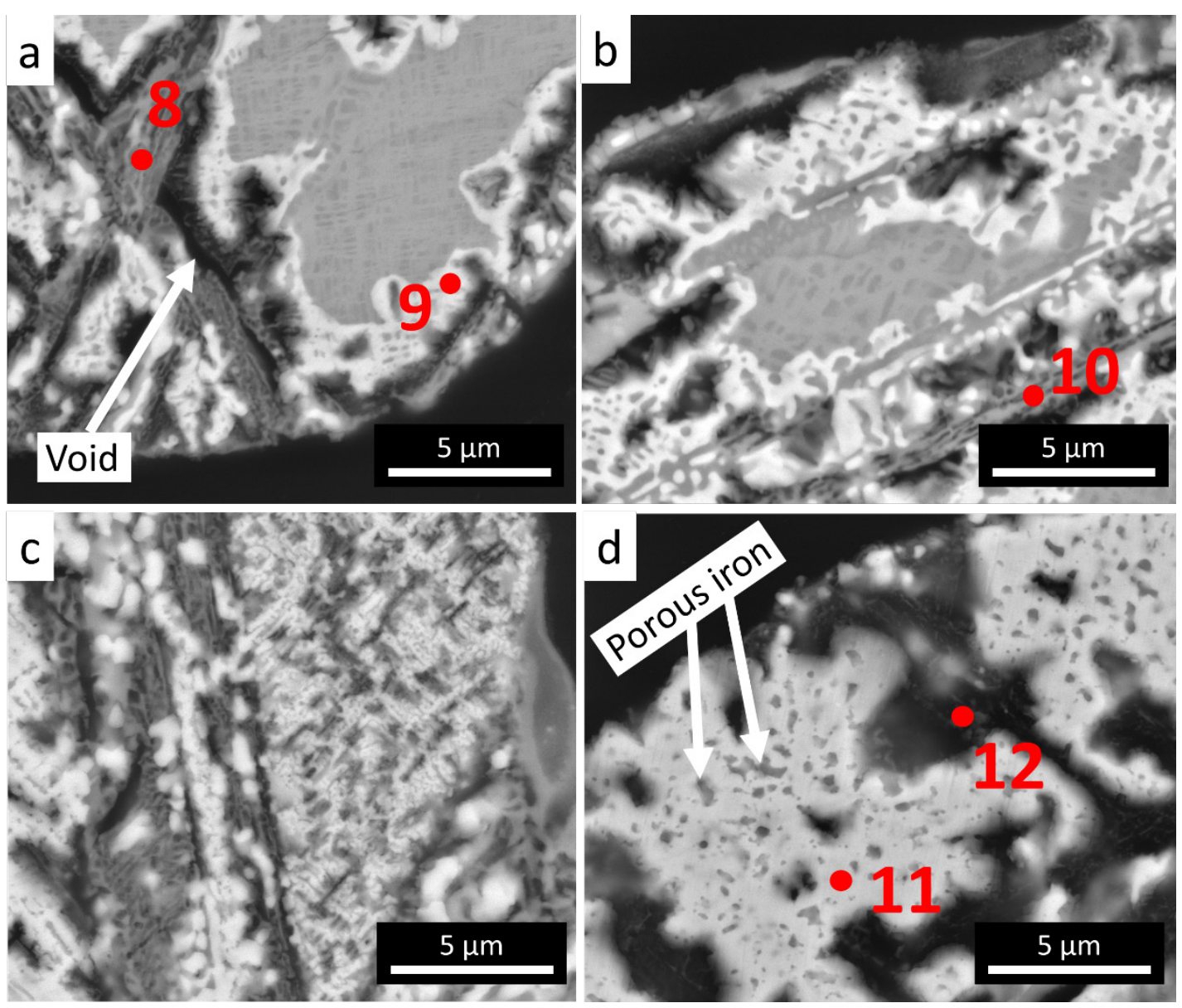

Figure 6.21 High magnification image (16,000X) of non-uniform lamella particles during the reduction by $5 \mathrm{~L} / \mathrm{min} \mathrm{H}_{2}$ at $950^{\circ} \mathrm{C}$ : (a) after 5 minutes reduction; (b) after 10 minutes reduction; (c) after 20 minutes reduction; (d) after 60 minutes reduction.

Table 6.2 shows data from EDS point analysis of selected points in Figure 6.21. Point 8 (in Figure 6.21(a)) shows that after 5 mins reduction the lamellar region exhibits a Fe/Ti ratio similar to that observed in the outer shell of the uniform particles at the same time. This implies that a similar migration of Fe elemental has occurred out of the lamellar regions. Evidence for this are the bright iron layers which lie on either side of the lamella.

In the top right region of Figure 6.21(a), a region of intermixed wüstite and TTM can be observed. Similar to the uniform grains after the same reduction time, bright grey channels of wüstite are found to interlace throughout the TTM matrix (stage 1). As a result, after 5 minutes each lamella-particle comprises multiple regions of wüstite-TTM which are each bounded by thin lamina of porous Ti-stabilised oxide. During the subsequent stages of reduction, the Ti-enriched lamellae then play a similar role to that played by the oxide protective shell in the uniform particles, and reduction proceeds through the same basic 
stages. Figure 6.21(b) shows that metallisation during stage 2 follows the wüstite channels. Figure 6.21(c) then shows the transition to stage 3 of the reduction process in which direct metallisation of the residual Ti-enriched TTM occurs. Figure 6.21(d) shows the final state after 60 minutes of reduction (stage 4), with regions of porous metallic iron (white arrows) surrounded by the oxide lamella.

Table 6.2 Elemental spot EDS analysis of points shown in Figure 6.21

\begin{tabular}{cccccc}
\hline \multirow{2}{*}{ Element } & \multicolumn{5}{c}{ Point (Atomic \%) } \\
\cline { 2 - 6 } & 8 & 9 & 10 & 11 & 12 \\
\hline $\mathrm{O}$ & 56.1 & 19.4 & 49.3 & - & 28.0 \\
$\mathrm{Mg}$ & 2.2 & 2.4 & 1.8 & - & 1.3 \\
$\mathrm{Al}$ & 1.6 & 1.0 & 1.0 & - & 4.9 \\
$\mathrm{Ti}$ & 7.8 & 3.2 & 11.2 & 1.5 & 10.4 \\
$\mathrm{Mn}$ & 0.7 & - & 1.0 & - & 2.9 \\
$\mathrm{Fe}$ & 32.0 & 77.2 & 35.7 & 98.5 & 52.9 \\
$\mathrm{Fe} / \mathrm{Ti}$ & 4.1 & 24.4 & 3.2 & 65.1 & 5.2 \\
\hline
\end{tabular}

\subsection{Summary}

The FB reduction of TTM ironsand by $\mathrm{H}_{2}$ gas at $950^{\circ} \mathrm{C}$ has been demonstrated and the effect of varying several key process parameters has been investigated, namely: $\mathrm{H}_{2}$ gas concentration, $\mathrm{H}_{2}$ gas flow rate, initial bed mass, and particle size. There were no occurrences of sticking between particles within the FB at any point during the experimental series. Sticking appears to be inhibited by the formation of a protective outer oxide shell on the majority of particles, which prevents iron-iron contact at the surface of each particle. This outer shell forms in the initial stage of the reduction as iron species migrate inwards, leaving a Ti-rich oxide layer around the exterior of the particle.

For all conditions studied, the reduction rate of TTM ironsand appears to be solely controlled by the $\mathrm{H}_{2}$ gas supply. The fastest reduction process was attained in the reduction at $5 \mathrm{~L} / \mathrm{min}$ of $\mathrm{H}_{2}$, which achieved a maximum \%met of 93\% after 30 minutes. For each parameter case studied, the phase evolution follows the same sequence of stages, and the $\mathrm{H}_{2} \mathrm{O}$ composition in the outlet is the same for each reduction stage. 
The reduction process is observed to proceed in four distinct stages. In stage 1, TTH lamellae are reduced, while at the same time, approximately half of the amount of TTM in the original sample is reduced to wüstite. In stage 2, wüstite is reduced to iron metal whilst the remaining TTM is not reduced any further. The reduction rate of TTM is decreased significantly during this stage, which may be due to titanium enrichment caused by the migration of species exsolved from the wüstite regions. In stage 3, the remaining Tienriched TTM is reduced to iron and ilmenite. In stage 4, ilmenite is partially converted to rutile and then to pseudobrookite. A limitation of this study is that the interpretation of the experimental result is relevant for batch operation and gas flows accessible in the bubbling FB reactor studied here. There is a possibility that some of the reactions in the sequence may take place simultaneously in excess $\mathrm{H}_{2}$ gas.

The titanium content in ironsand plays a highly significant role in the progress of this reduction, as it is primarily responsible for the formation of the protective outer oxide shell. In addition, the low solubility of Ti in wüstite also prevents the total conversion of TTM to wüstite in the second reduction stage. Instead channels of wüstite are formed which interlace the Ti-enriched TTM matrix. These channels are then preferentially reduced to iron metal, prior to reduction of the surrounding Ti-enriched TTM.

A minority ( $10 \%$ ) of particles in the original NZ ironsand contained multiple TTH lamellae running through the TTM matrix. In these non-uniform particles, the initial reduction proceeded along each lamella to form porous Ti-rich oxides similar to that observed in the shell formed around the uniform TTM particles. Subsequent reduction then proceeded through the same stages as observed in the majority uniform particles.

In conclusion, these findings show that titanium bearing ironsand can be reduced at $950^{\circ} \mathrm{C}$ without incurring the usual severe problems associated with iron particle sticking in the FB system. These findings suggest new opportunities for a further study in the application of FB technology for direct reduction of NZ ironsand. Further, the key process parameter of temperature on the FB hydrogen reduction of NZ ironsand is examined in Chapter 7. 


\section{Chapter 7}

\section{Reduction of NZ TTM Ironsand by $\mathrm{H}_{2}$ Gas at Different Bed Temperatures}

\subsection{Outline}

This chapter reports a series of experiments on the FB reduction of NZ TTM ironsand by $\mathrm{H}_{2}$ gas at temperatures ranging from $750^{\circ} \mathrm{C}$ to $1050^{\circ} \mathrm{C}$, in steps of $50^{\circ} \mathrm{C}$. For each experiment, a fresh 100 g sample of ironsand was reduced by $100 \% \mathrm{H}_{2}$ gas with a flow rate of $5 \mathrm{~L} / \mathrm{min}$. The particle size fraction was $106-125 \mu \mathrm{m}$.

The first aim of this experimental series is to investigate the phase and microstructural evolution of TTM ironsand during the FB reduction at different temperatures. This also includes investigating whether an onset sticking temperature can be determined. Characterisation of samples obtained has used both XRD and SEM-EDS analysis.

The second aim is to investigate the influence of temperature on the reaction progress and exhaust gas composition. As far as the author is aware, there is little existing data on the reaction pathway for the reduction of NZ TTM ironsand. The exhaust gas analysis uses both 'time-step' calculations from the q-XRD data, and real-time measurement of the $\mathrm{H}_{2} \mathrm{O}$ in the outlet gas by a humidity sensor.

\subsection{The effect of temperature on metallisation rate}

Figure 7.1 shows the resulting \%met as a function of time at different temperatures. The figure reveals that the reduction rate increases significantly with increasing temperature. The fastest reduction reaction is attained by reduction at $1000^{\circ} \mathrm{C}$, where a maximum \%met of approximately 93\% is reached within 25 minutes. No sticking was observed for any of the experiments shown in Figure 7.1. However, particle sticking was encountered during reduction at $1050^{\circ} \mathrm{C}$. This sticking event is discussed later in Section 7.7. The discussion in this Sections 7.3 to 7.6 is limited to temperatures at which sticking is not observed - that is, for reduction at temperatures ranging from $750^{\circ} \mathrm{C}$ to $1000^{\circ} \mathrm{C}$. 


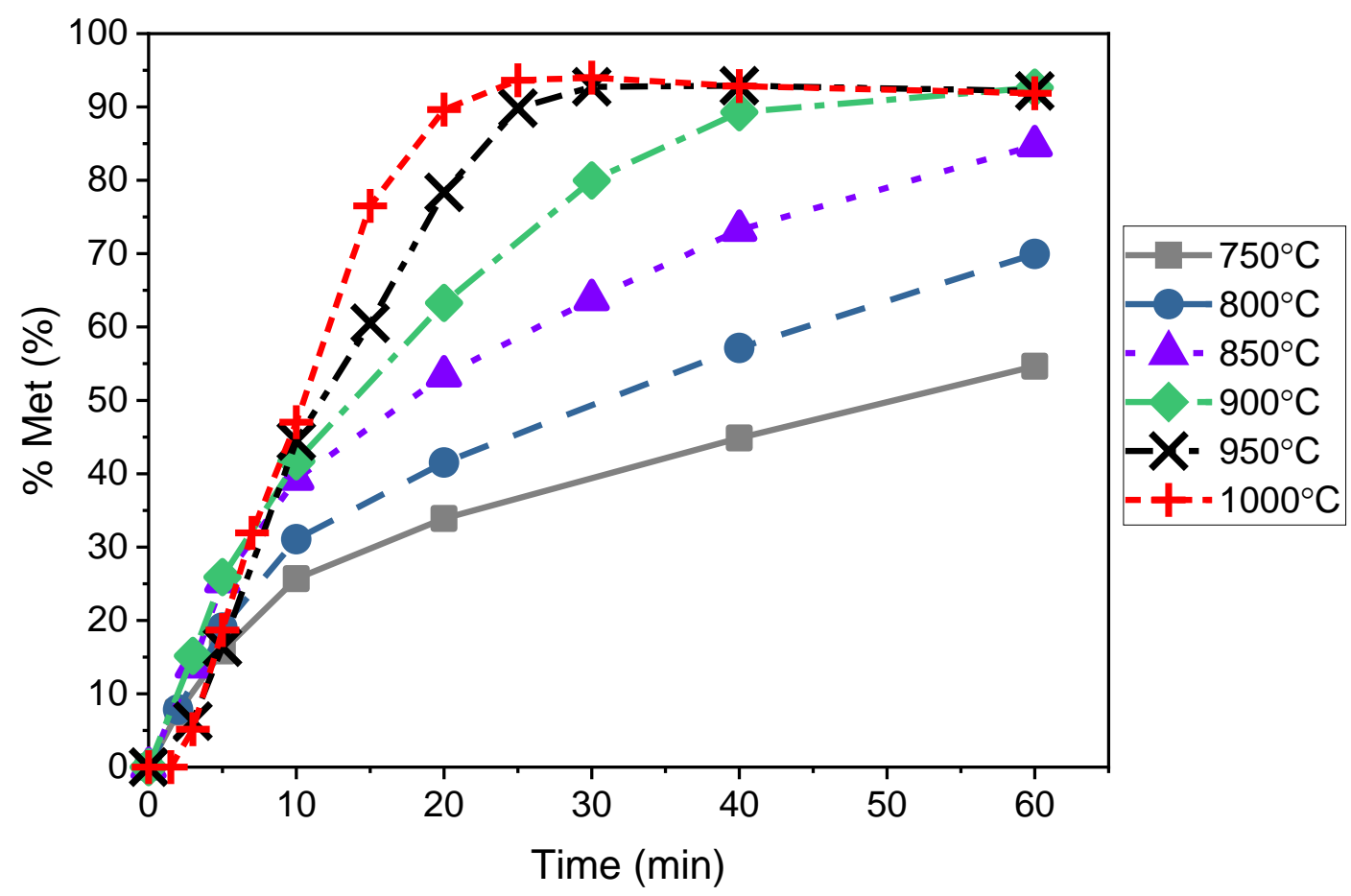

Figure $7.1 \%$ met as a function of time for the reduction of TTM ironsand by $5 \mathrm{~L} / \mathrm{min} \mathrm{H}_{2}$ at different temperatures.

\subsection{Effect of temperature on phase transition of TTM ironsand during the reduction reaction}

Figure 7.2 shows the composition changes throughout the reduction period of the three key Fe-containing crystalline oxide phases (TTM, wüstite, and ilmenite) determined from XRD. The amount of metallic iron is directly proportional to the \%met curves in Figure 7.1, so is not given in Figure 7.2. 

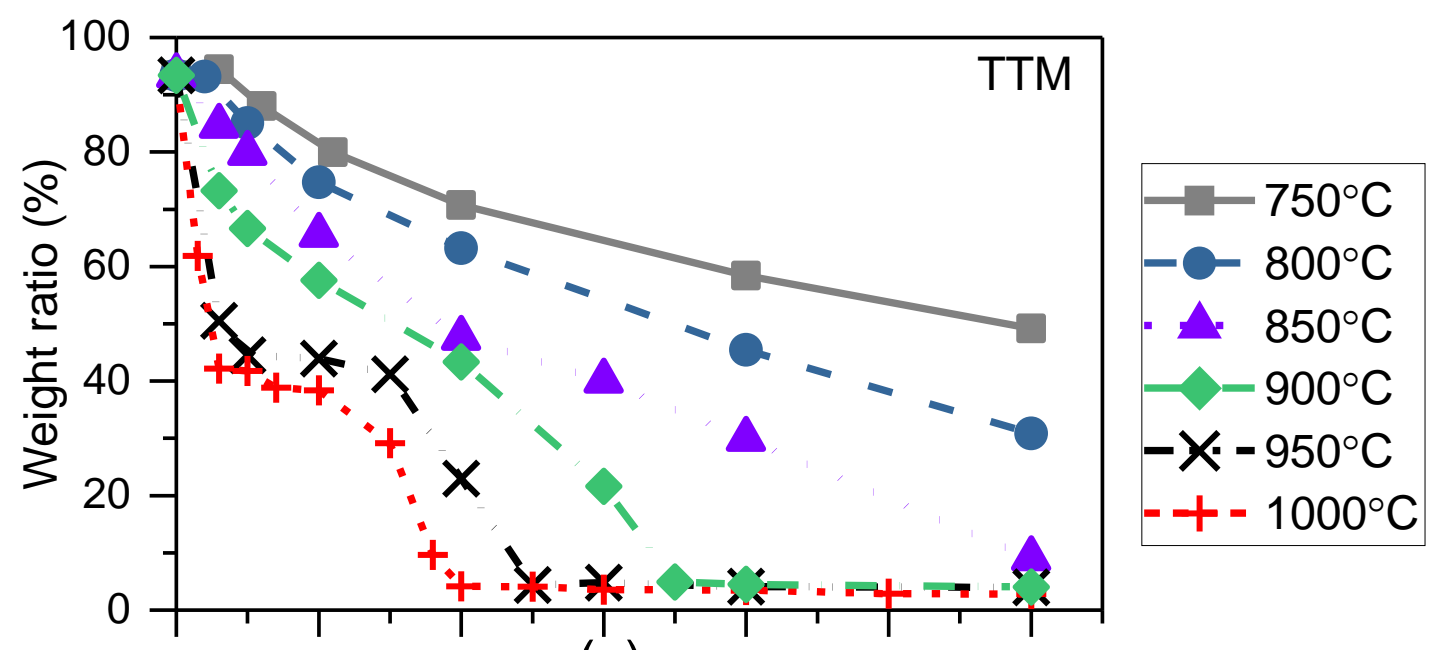

(a)
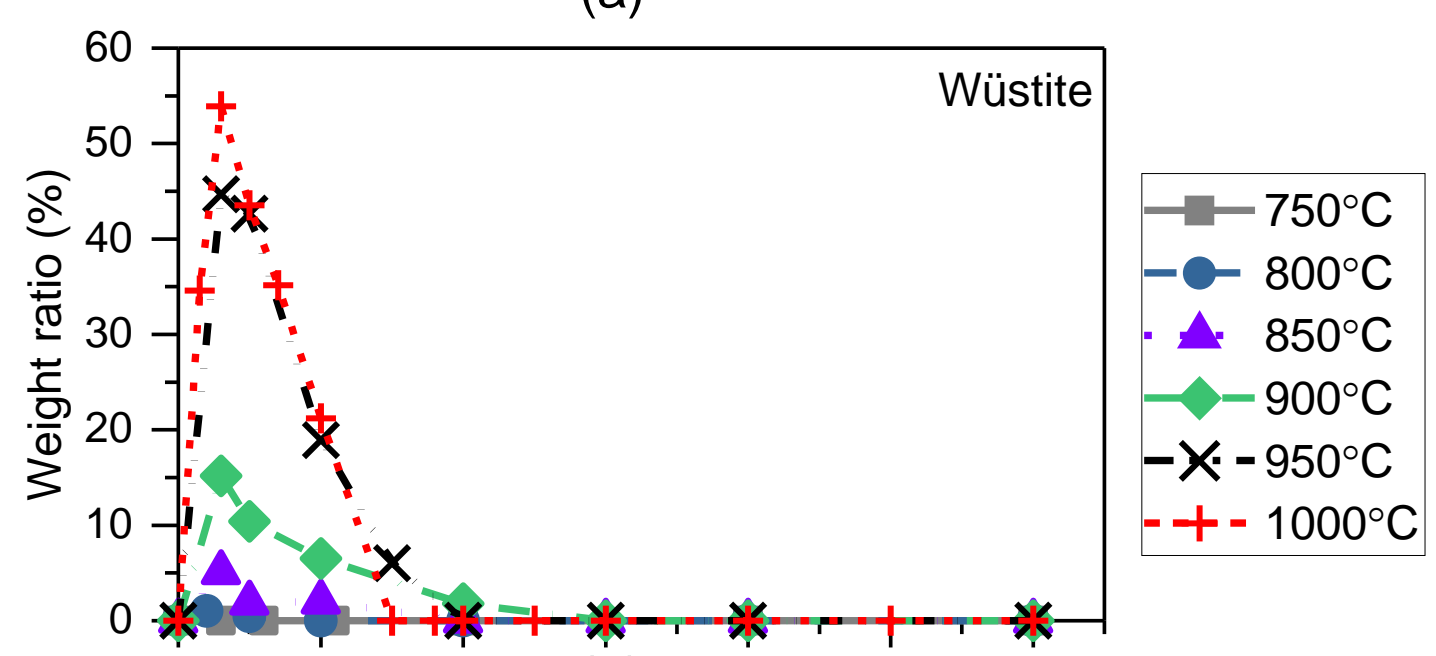

(b)

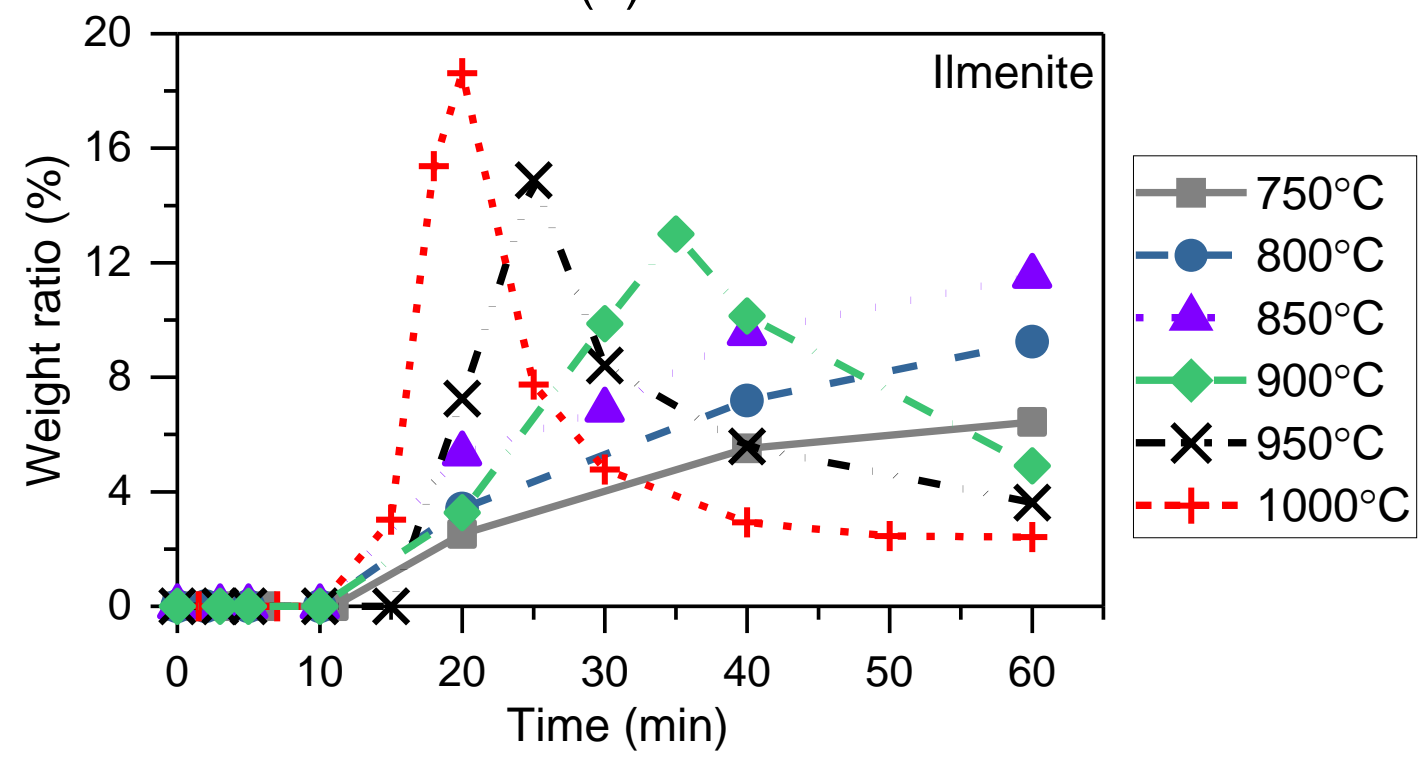

(c)

Figure 7.2 The change in wt.\% for the amount of (a) TTM, (b) wüstite, and (c) ilmenite as a function of time during the reduction by $5 \mathrm{~L} / \mathrm{min} \mathrm{H}_{2}$ at different temperatures. 
The results in Figure 7.2(a) indicate that the reduction temperature significantly affects the phase evolution of TTM phase during the reduction. The reduction stages at $950^{\circ} \mathrm{C}$ have already been identified in Chapter 6. It appears that the reduction stages at $1000^{\circ} \mathrm{C}$ are similar to those at $950^{\circ} \mathrm{C}$. However, as the temperature decreases, the reduction stages are not clearly defined.

For temperatures $\geq 950^{\circ} \mathrm{C}$, an interesting aspect is that the reduction curve of TTM plateaus at about 40-50 wt.\% (Figure 7.2(a)). During this time, the reaction seems to prefer to reduce wüstite (Figure 7.2(b)). Once wüstite is fully reduced, TTM is then reduced again, reaching a final level of about 3 wt.\% (Figure 7.2(a)). By contrast, during reductions in the temperature range $750^{\circ} \mathrm{C}$ to $900^{\circ} \mathrm{C}$, the amount of TTM phase decreases continuously over time without a plateau region (see Figure 7.2(a)). It appears that the data for $900^{\circ} \mathrm{C}$ represents a transition between these two patterns.

At $750^{\circ} \mathrm{C}$ and $800^{\circ} \mathrm{C}$ (Figure 7.2(b)), there is no wüstite detected by XRD throughout the reduction. At these temperatures TTM appears to reduce directly to metallic iron without the intermediate wüstite phase. For temperatures of $850^{\circ} \mathrm{C}$ and $900^{\circ} \mathrm{C}$, a small amount of wüstite phase is observed after three minutes of reduction with the composition of $\sim 5 \mathrm{wt} \%$ and $\sim 15 \%$, respectively (Figure $7.2(\mathrm{~b})$ ), which is consistent with the result in Park and Ostrovski, 2004b. Although wüstite is formed at these temperatures, the TTM reduction curve does not plateau during this period of the reaction. As the temperature goes higher to $\geq 950^{\circ} \mathrm{C}$, the reduction of TTM to wüstite accelerates; hence we see much more wüstite ( $\sim 50 \mathrm{wt} . \%$ ) at temperatures $\geq 950^{\circ} \mathrm{C}$ Figure $7.2(\mathrm{~b})$. At the same time, a plateau is observed in the reduction of TTM at these temperatures. This plateau is related to the Ti enrichment in the TTM crystal.

The above results are broadly consistent with the study in Chapter 6 which linked the wüstite formation with the enrichment of Ti to TTM phase. The argument presented there stated that Ti became concentrated in TTM phase as it was not soluble in the wüstite phase by reaction (6.1). Reaction (6.1) is reproduced below to assist the discussion in this chapter.

$$
(x+\delta) \cdot \mathrm{Fe}_{(3-x)} \mathrm{Ti}_{x} \mathrm{O}_{4(\mathrm{~s})}+\delta \mathrm{H}_{2(\mathrm{~g})} \rightarrow 3 \delta \cdot \mathrm{FeO}_{(\mathrm{s})}+x \cdot \mathrm{Fe}_{3-(x+\delta)} \mathrm{Ti}_{(x+\delta)} \mathrm{O}_{4(\mathrm{~s})}+\delta \cdot \mathrm{H}_{2} \mathrm{O}_{(\mathrm{g})}
$$

According to reaction (6.1), TTM phase becomes increasingly enriched with $\mathrm{Ti}$ as the formation of the intermediate wüstite phase. As Ti is enriched in TTM phase, it will progressively stabilise the TTM spinel, as shown from the plateau in Figure 7.2(a) and as 
discussed in Section 6.6. This ultimately reaches a point where the reaction will then prefer to reduce wüstite over TTM phase according to reaction (6.2). Reaction (6.2) is reproduced below to assist the discussion in both this section, as well as the discussion in Section 7.6.2.

$$
\mathrm{FeO}_{(\mathrm{s})}+\mathrm{H}_{2(\mathrm{~g})} \rightarrow \mathrm{Fe}_{(\mathrm{s})}+\mathrm{H}_{2} \mathrm{O}_{(\mathrm{g})}
$$

The point at which reduction of wüstite becomes preferred over reduction of TTM occurs approximately when the peak wt.\% of wüstite (in Figure 7.2(b)) is reached. The stoichiometric level of Ti in TTM at this point can be expressed as $\mathrm{Fe}_{(3-4)} \mathrm{Ti}_{\Delta} \mathrm{O}_{4}$, (where $\Delta=$ $x+\delta$ at this time from equation (6.1)). The value $\Delta$ can be estimated by equation (7.1),

$$
\Delta=0.27 x^{m_{t} / m_{i}} x^{M_{T T M x} / M_{T T M \Delta}}
$$

where $m_{t}$ refers to the wt.\% of TTM at the point where wüstite reaches its maximum composition, $m_{i}$ refers to the wt\% of TTM in the raw ironsand, $M_{T T M x}$ refers to the molar mass of the raw TTM ironsand and $M_{\text {TTM }}$ refers to the molar mass of TTM at $\Delta$. The maximum possible $\Delta$ value is 1 , which corresponds to the stoichiometric composition of ulvöspinel $\left(\mathrm{Fe}_{2} \mathrm{TiO}_{4}\right)$. The molar mass difference between ulvöspinel and TTM is small ( 2.5\%), hence $M_{T T M x} /_{M_{T T M \Delta}} \approx 1$. Equation (7.1) assumes that there are no other Ticontaining phases during this period of the reduction (see Figure 7.2).

Figure 7.3 presents the $\Delta$ value at the wüstite peak calculated from equation (7.1) for each reduction temperature. It is clear that the Ti-enrichment levels at $950^{\circ} \mathrm{C}$ and $1000^{\circ} \mathrm{C}$ are much higher than those occurring in the $750^{\circ} \mathrm{C}$ to $900^{\circ} \mathrm{C}$ range. As wüstite is not observed at $750^{\circ} \mathrm{C}$ and $800^{\circ} \mathrm{C}$, this implies that either wüstite is not formed or wüstite is reduced faster than TTM at all subsequent times. Therefore, the $\Delta$ value must occur at time $t=$ zero. Therefore, at these temperatures $\Delta$ is assumed to be the same as in the initial ironsand (i.e. $\Delta=x=0.27$ ). For $850^{\circ} \mathrm{C}$ and $900^{\circ} \mathrm{C}$, the TTM wt. $\%$ decreases only slightly before the wüstite peak is reached. This means that the $\Delta$ values correspondingly only increase slightly to $\sim 0.3$, and hence the enrichment of Ti in TTM phase seems to be minimal at these temperatures. As a result, the stability of TTM does not change greatly during the reduction at lower temperatures, and hence the TTM reduction follows a smooth continuous curve regardless of the formation of wüstite. 


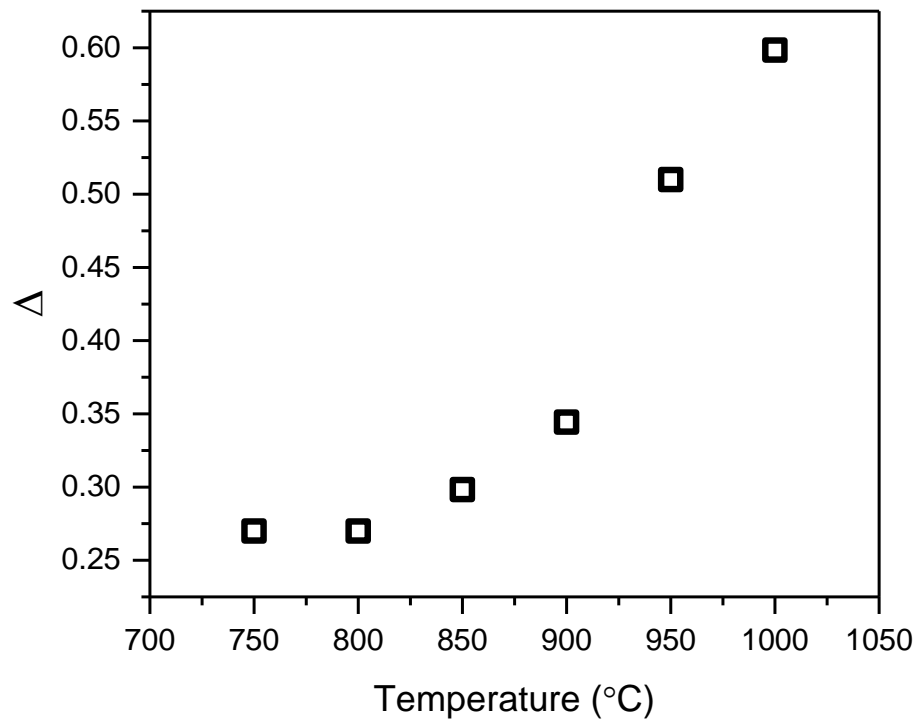

Figure 7.3 Plot showing the estimated $\Delta$ value at the peak wüstite composition (in Figure 7.2) for different temperatures. $\Delta$ value for $750^{\circ} \mathrm{C}$ and $800^{\circ} \mathrm{C}$ remain $\approx 0.27$ as there is no wüstite detected by the $X R D$.

Once wüstite has been reduced, the formation of ilmenite follows reaction (6.3). This reaction is reproduced below to assist the discussion here.

$$
\mathrm{Fe}_{(3-4)} \mathrm{Ti}_{\Delta} \mathrm{O}_{4(\mathrm{~s})}+(4-3 \Delta) \mathrm{H}_{2(\mathrm{~g})} \rightarrow \Delta \cdot \mathrm{FeTiO}_{3(\mathrm{~s})}+(3-2 \Delta) \cdot \mathrm{Fe}_{(\mathrm{s})}+(4-3 \Delta) \cdot \mathrm{H}_{2} \mathrm{O}_{(\mathrm{g})}
$$

According to reaction (6.3), the generation of ilmenite is dependent on the $\Delta$ value. As the $\Delta$ value is expected to increase with the increasing amount of wüstite formed, the generation rate of ilmenite produced should be expected to increase in a corresponding manner. This is consistent with the results shown in Figures 7.2(b) and (c), which indicate that high levels of ilmenite are observed at those temperatures where high levels of wüstite were also formed during the reduction. In the figures, the production of ilmenite also appears to be faster at high temperatures, which may also contribute to the maximum peak wt.\% of ilmenite being higher at these temperatures.

\subsection{Evolution of TTM lattice parameter during reduction at different temperature.}

Figure 7.4 presents magnified plots of the XRD $<220>$ peak for TTM in samples reduced at each different temperature. The figure clearly shows that the TTM peak shifts 
to lower angles over the course of the reduction reaction at $950^{\circ} \mathrm{C}$ and $1000^{\circ} \mathrm{C}$. The shift of TTM peak indicates an enrichment of Ti in the TTM crystal lattice during the reduction of TTM at high temperatures. By contrast, at temperatures of $750^{\circ} \mathrm{C}$ to $900^{\circ} \mathrm{C}$, the TTM peak position remains constant (Figures 7.4(a-d)).

It can also be seen that there is also a broadening effect of TTM peaks for temperatures $850^{\circ} \mathrm{C}$ to $1000^{\circ} \mathrm{C}$ (Figures $7.4(\mathrm{c}-\mathrm{f})$ ), which makes them asymmetric. This broadening effect is likely caused by a non-uniform distribution of Ti content at different points in the TTM lattice within the sample. This can be seen from the fact that the peaks skew to the lower angle side (higher lattice parameter).

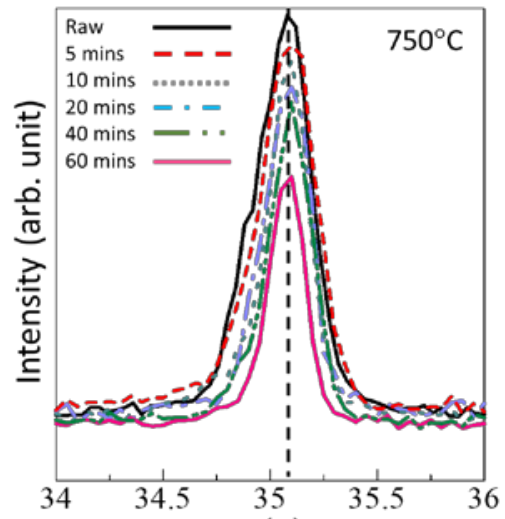

(a)

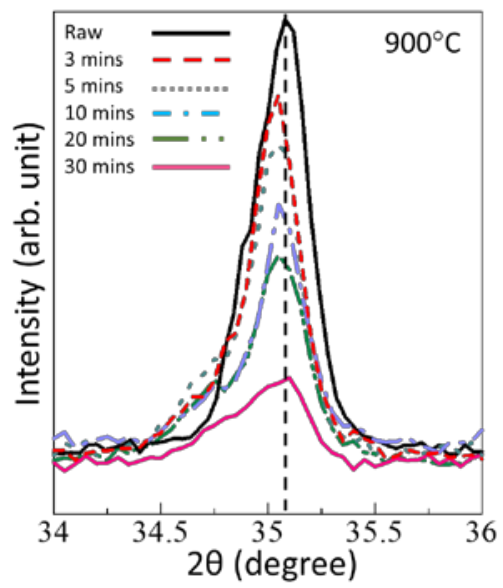

(d)

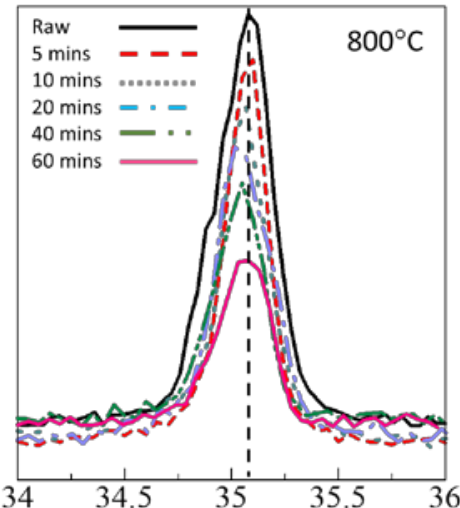

(b)

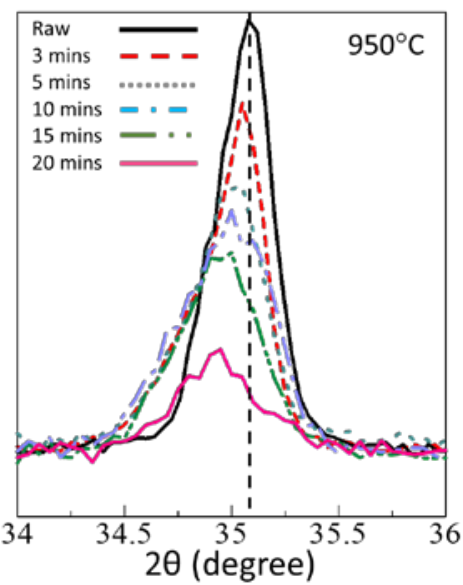

(e)

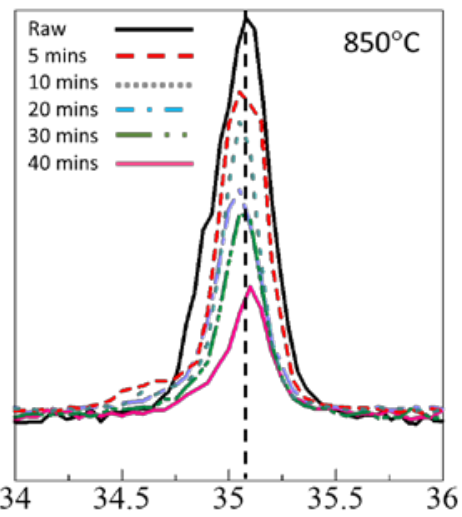

(c)

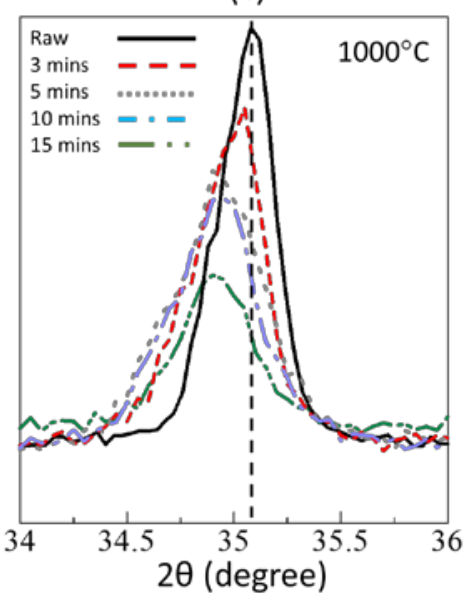

(f)

Figure 7.4 Close up of a TTM XRD peak obtained from the sample reduced at $750^{\circ} \mathrm{C}(\mathrm{a})$, $800^{\circ} \mathrm{C}(\mathrm{b}), 850^{\circ} \mathrm{C}(\mathrm{c}), 900^{\circ} \mathrm{C}(\mathrm{d}), 950^{\circ} \mathrm{C}(\mathrm{e})$, and $1000^{\circ} \mathrm{C}(\mathrm{f})$. Dashed line in the middle of each figure indicates the TTM peak position of the raw concentrate.

It is known that the TTM lattice parameter, $a$, increases with increasing Ti content (Tanaka and Kono, 1987; Bosi, Hålenius and Skogby, 2009; Pearce et al., 2012). The general rule is that two $\mathrm{Fe}^{3+}$ cations are replaced by one $\mathrm{Ti}^{4+}$ and one $\mathrm{Fe}^{2+}$ cation. $\mathrm{As} \mathrm{Ti}^{4+}$ 
prefers to substitute onto octahedral $\mathrm{Fe}^{3+}$ sites, more $\mathrm{Fe}^{2+}$ must be found on the tetrahedral sites in order to maintain charge neutrality (see the position of these sites in Figure 2.4). This causes a distortion of the cubic structure, stretching the Fe-O bonding at tetrahedral sites (Tanaka and Kono, 1987; Bosi, Hålenius and Skogby, 2009). Figure 7.5 shows the calculated $a$ value of TTM phase, fitted from the XRD peaks in Figure 7.4. The error bars in the figure are the error fitting from the Topas software. The $a$ values presented in the Figure correspond to all times at which TTM comprises $>5$ wt.\% of the total mass (see Figure 7.2(a)). Below 5 wt.\%, TTM XRD peaks become too small to fit with confidence.

In Figure 7.5, there is a clear trend of increasing $a$ value for samples reduced at high temperatures $\left(950^{\circ} \mathrm{C}\right.$ and $\left.1000^{\circ} \mathrm{C}\right)$. At these temperatures, the $a$ value increases by about $0.05 \AA$, corresponding to $\sim 0.6 \%$ increase in the initial lattice constant value compared to the unreduced concentrate. This increase in $a$ is comparable with the TTM lattice parameter values reported in (Tanaka and Kono, 1987; Bosi, Hålenius and Skogby, 2009) for initial and final stoichiometric Ti compositions of $x=0.27$ and $\Delta=0.6$ (see Figure 7.6). As such, this result provides further evidence to support the argument that Ti is enriched in TTM phase during the early stages of reduction at $950^{\circ} \mathrm{C}$ and above.

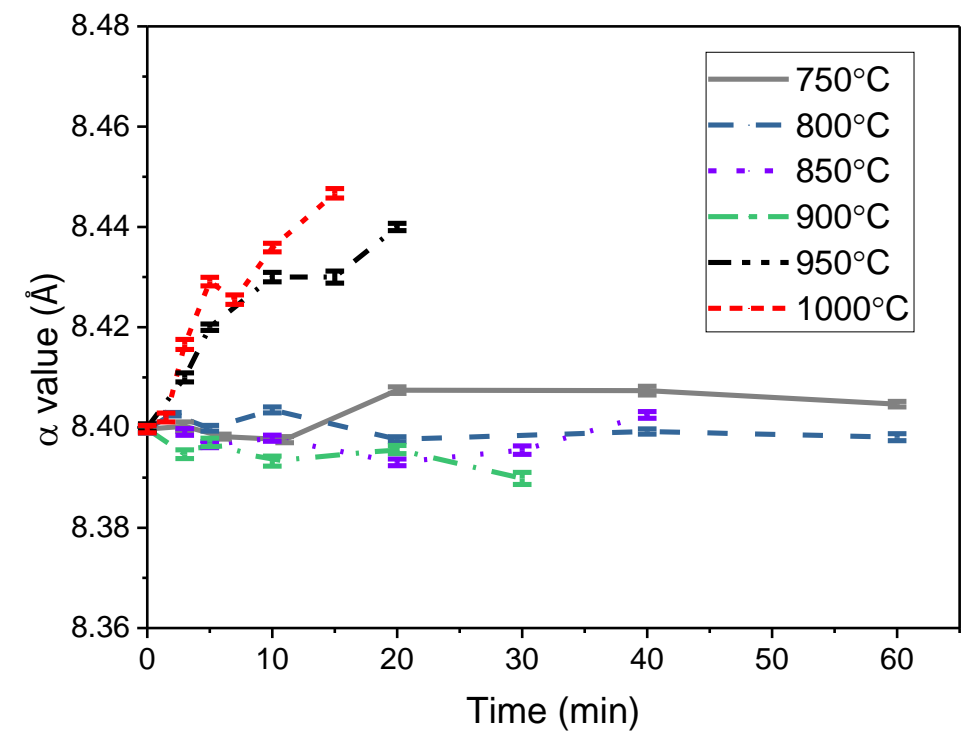

Figure 7.5 Fitted lattice parameter of TTM phase as a function of time during the reduction by $5 \mathrm{~L} / \mathrm{min} \mathrm{H}_{2}$ at different temperatures. The error bars in the Figure is the error fitting from the Topas software 


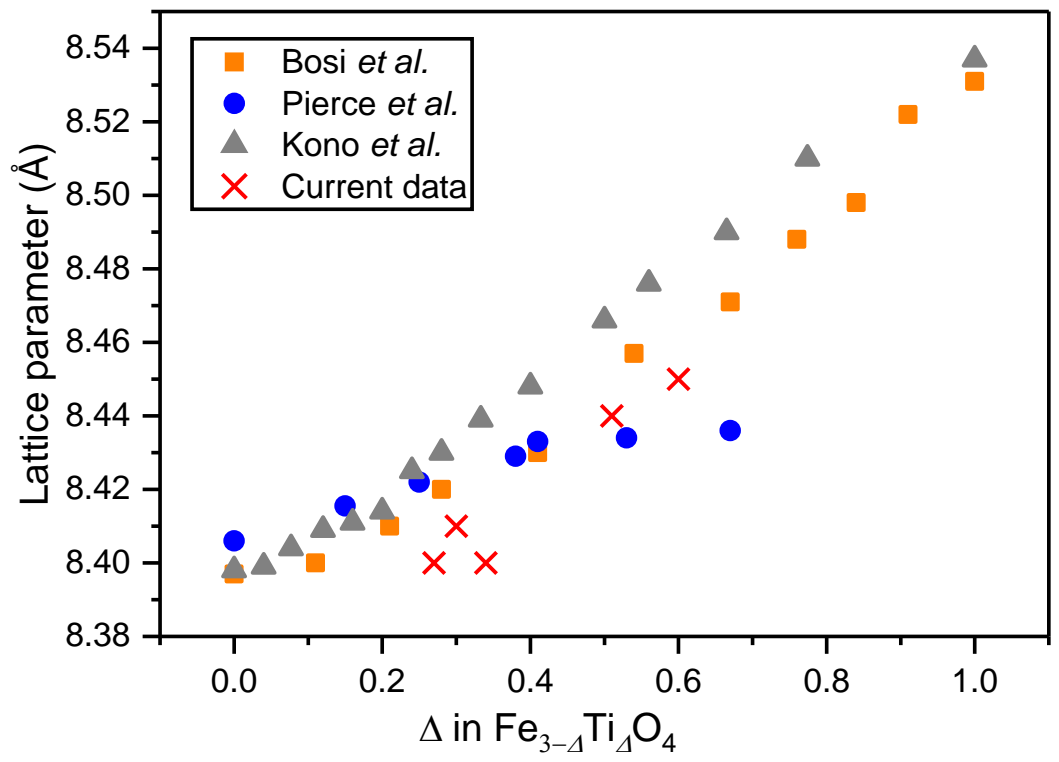

Figure 7.6 Measured lattice parameter values for TTM at different $\Delta$ values taken from literature.

\subsection{Overall reduction mechanism of TTM ironsand at different temperatures}

The results in Section 7.3 and 7.4 indicate that the reduction mechanism of TTM ironsand is strongly affected by the reduction temperature. In the 'high temperature regime' $\left(950^{\circ} \mathrm{C}-1000^{\circ} \mathrm{C}\right)$, the reduction of TTM is observed to proceed through the intermediate wüstite phase. However, in the 'low temperature regime' $\left(750^{\circ} \mathrm{C}-800^{\circ} \mathrm{C}\right)$, no wüstite is observed, and TTM phase appears to be directly reduced to metallic iron.

This section addresses each temperature regime in turn, in order to analyse the crystal phase evolution and microstructural transformations observed in each case. An 'intermediate temperature regime' $\left(850^{\circ} \mathrm{C}-900^{\circ} \mathrm{C}\right)$ is also identified, in which mixed behaviour is observed with low levels of short-lived wüstite being observed within the particles

\subsubsection{Key Information - a reminder.}

Figure 7.7 shows the BSE-image of an ironsand particle reduced by $5 \mathrm{~L} / \mathrm{min}$ at $950^{\circ} \mathrm{C}$ for 10 minutes. This figure is presented here to assist in the interpretation of the phasecontrast in BSE-SEM images of partially reduced particles shown later in this section. In 
the figure, the bright phase (A) is metallic iron, the grey matrix (B) is TTM, the light grey channel (C) is wüstite, and the dark grey phase at the outer particle (D) is the Ti-rich shell.

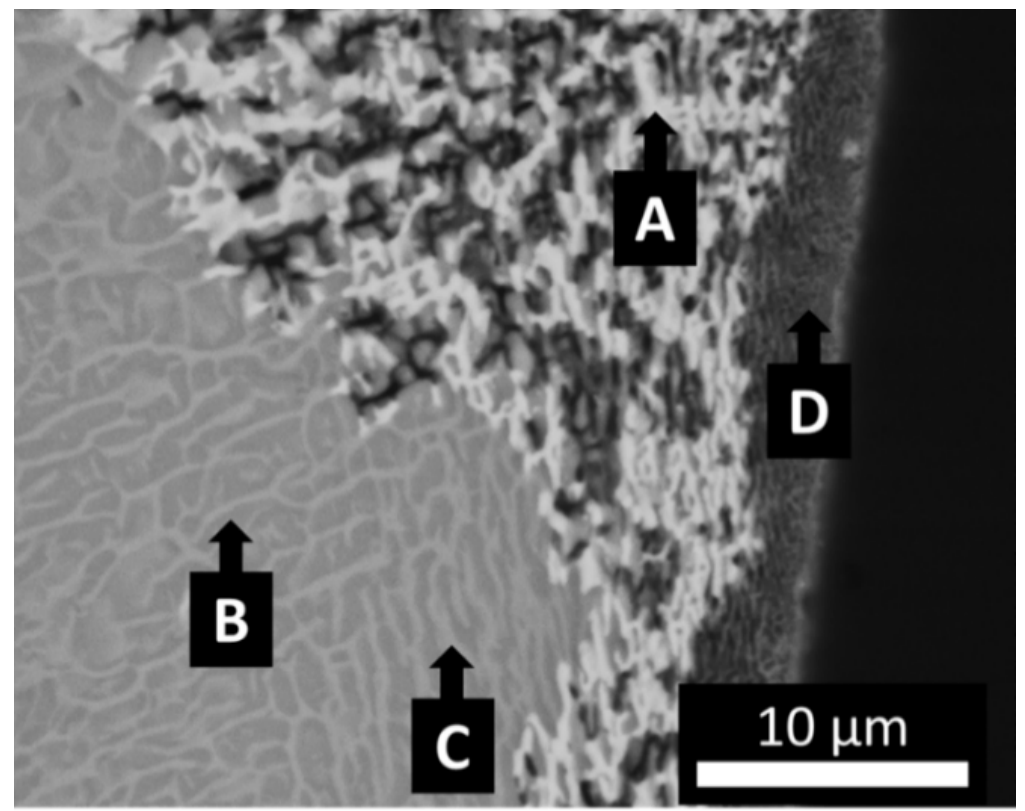
A. Metallic iron
C. Wüstite iron
B. TTM matrix
D. Ti-rich shell

Figure 7.7 BSE-SEM image of the ironsand particle reduced by $5 \mathrm{~L} / \mathrm{min} \mathrm{H}_{2}$ gas at $950^{\circ} \mathrm{C}$ for 10 minutes.

\subsubsection{Reduction at high temperature regime $\left(950^{\circ} \mathrm{C}-1000^{\circ} \mathrm{C}\right)$}

Figure 7.8 shows the evolution of phases during the reduction at $950^{\circ} \mathrm{C}$ and $1000^{\circ} \mathrm{C}$. The figure generally shows the same four reduction stages as that already discussed in Chapter 6. The numbered regions at the top of each plot in Figure 7.8 indicate the approximate duration of each reduction stage. It should be noted that this was observed under batch operation and the experimentally accessible gas flows in the bubbling FB reactor studied here. 


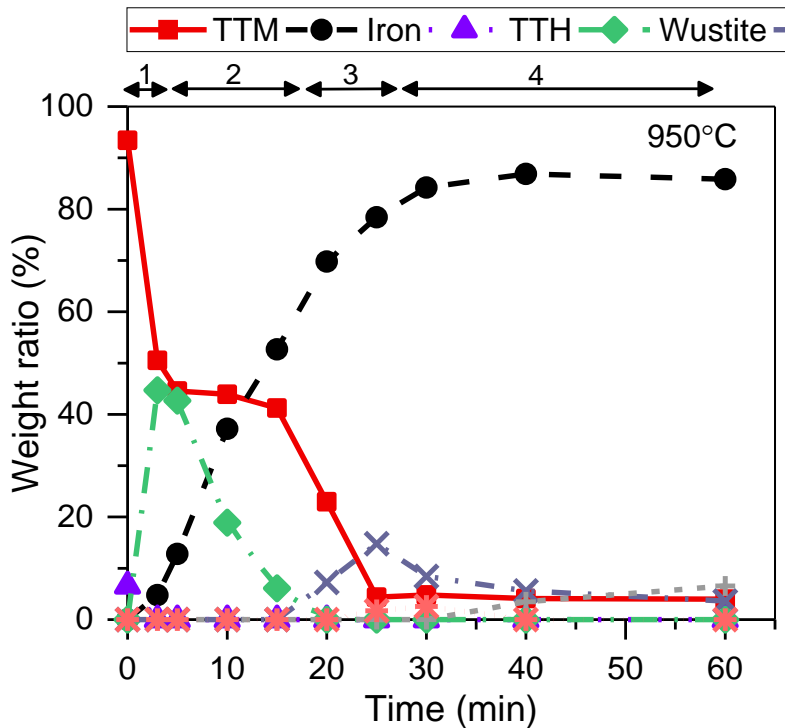

(a)

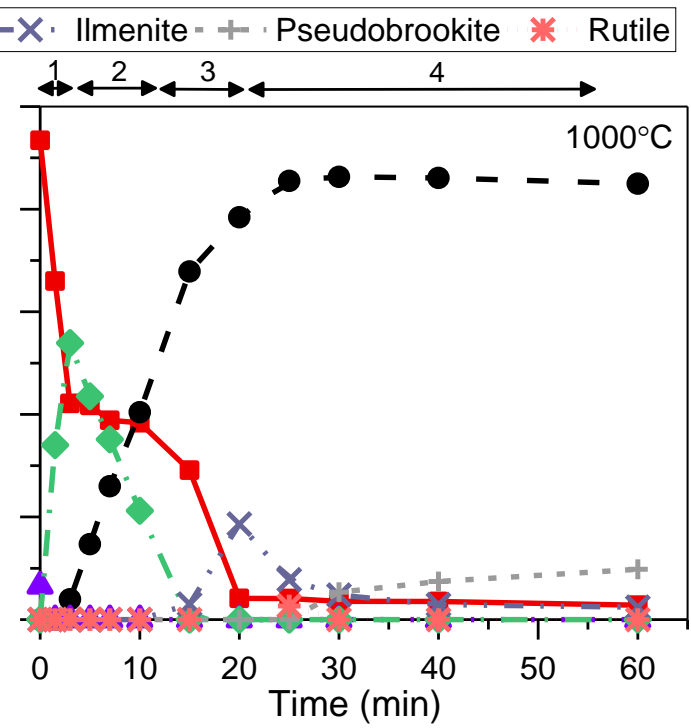

(b)

Figure 7.8 Phase evolution as a function of time during the reduction of ironsand in 5 $\mathrm{L} / \mathrm{min} \mathrm{H}_{2}$ at (a) $950^{\circ} \mathrm{C}$ and (b) $1000^{\circ} \mathrm{C}$.

At both these temperatures, about 50 wt.\% of TTM phase is initially converted to wüstite (stage 1). During the conversion of wüstite phase to metallic iron, the reduction of TTM slows down (stage 2). Once wüstite has totally reduced, the reduction of TTM recontinues and now forms metallic iron and ilmenite (stage 3). After that, further reactions between Ti-bearing phases continue, which involves the conversion of ilmenite to rutile and then to pseudobrookite (stage 4).

In general, the microstructures of particles reduced at $1000^{\circ} \mathrm{C}$ show similar features to the particle reduced at $950^{\circ} \mathrm{C}$, which has already been discussed in Chapter 6. Figure 7.9 shows BSE-SEM images of homogenous particles at various times during reduction at $1000^{\circ} \mathrm{C}$. Here it can be seen that a dark grey shell is apparent on the outer layer of the particle throughout the reduction process (see Figures 7.9(a-e)). This shell is similar to that found on the particle reduced at $950^{\circ} \mathrm{C}$, as discussed in Chapter 6. EDS analysis of the shell is presented in Table 7.1, revealing that the shell is an oxide enriched with Ti. As no sticking was observed, it appears that the shell also inhibits particle sticking at $1000^{\circ} \mathrm{C}$. 

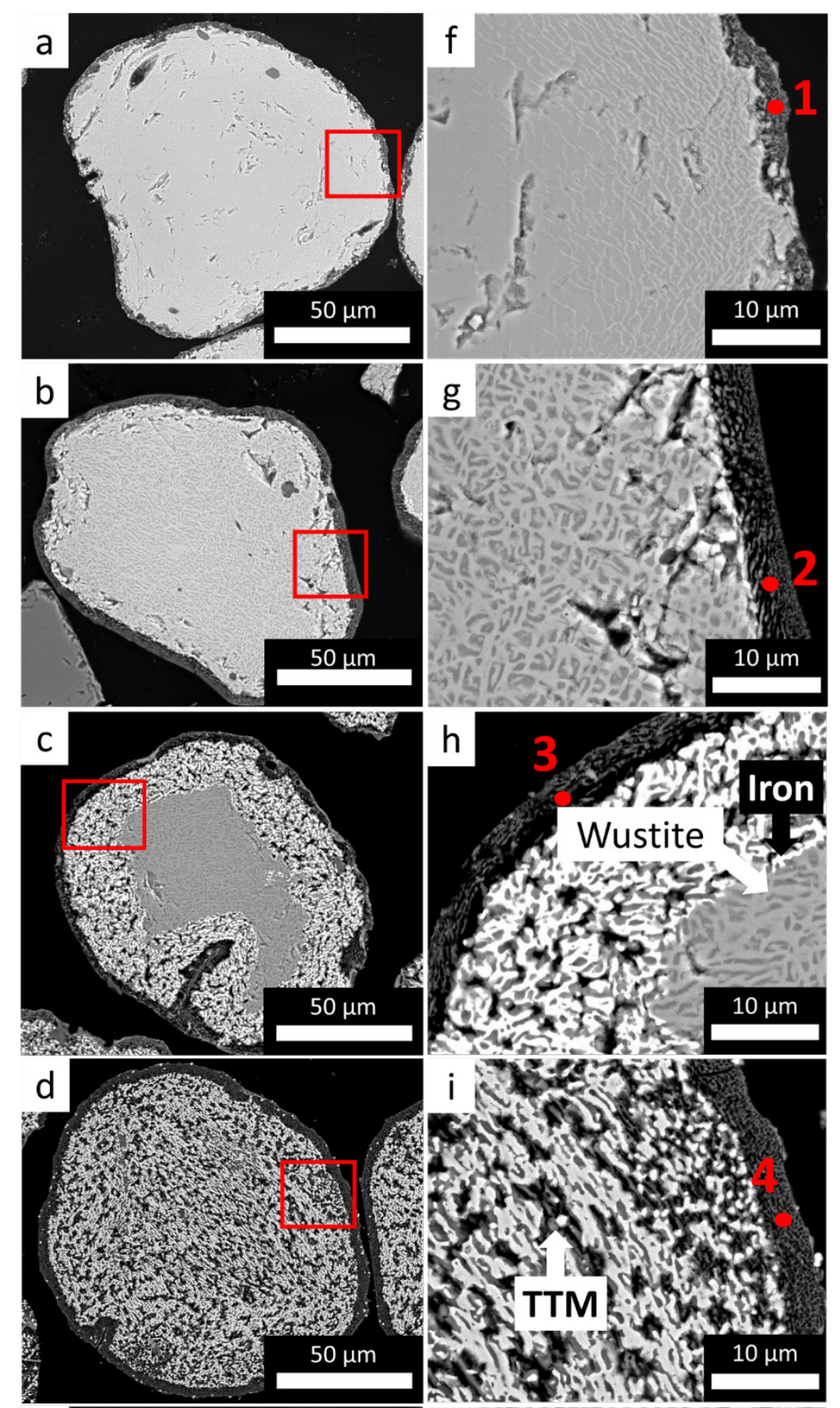

i (Not) 3 .

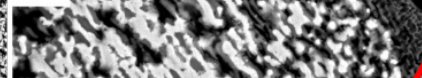

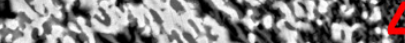

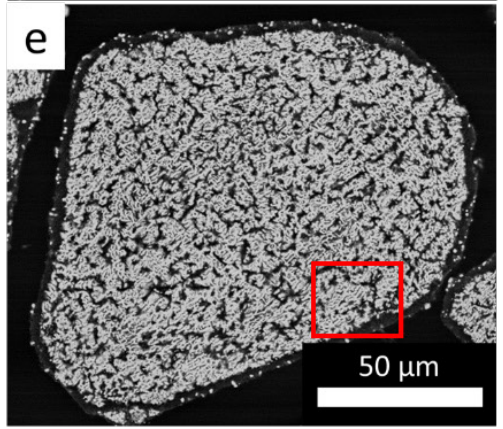

that
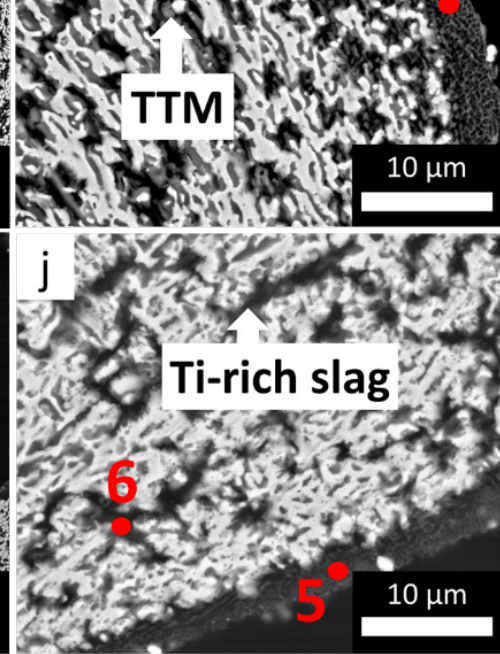

Figure 7.9 BSE-SEM images of a typical TTM ironsand particle during reduction by 5 L/min $\mathrm{H}_{2}$ at $1000^{\circ} \mathrm{C}$ : (a) 1.5 minutes, (b) 5 minutes, (c) 10 minutes, (d) 15 minutes, and (e) 60 minutes. Images ( $f-j)$ on the right side are high magnification of the images of the respective marked red areas. 

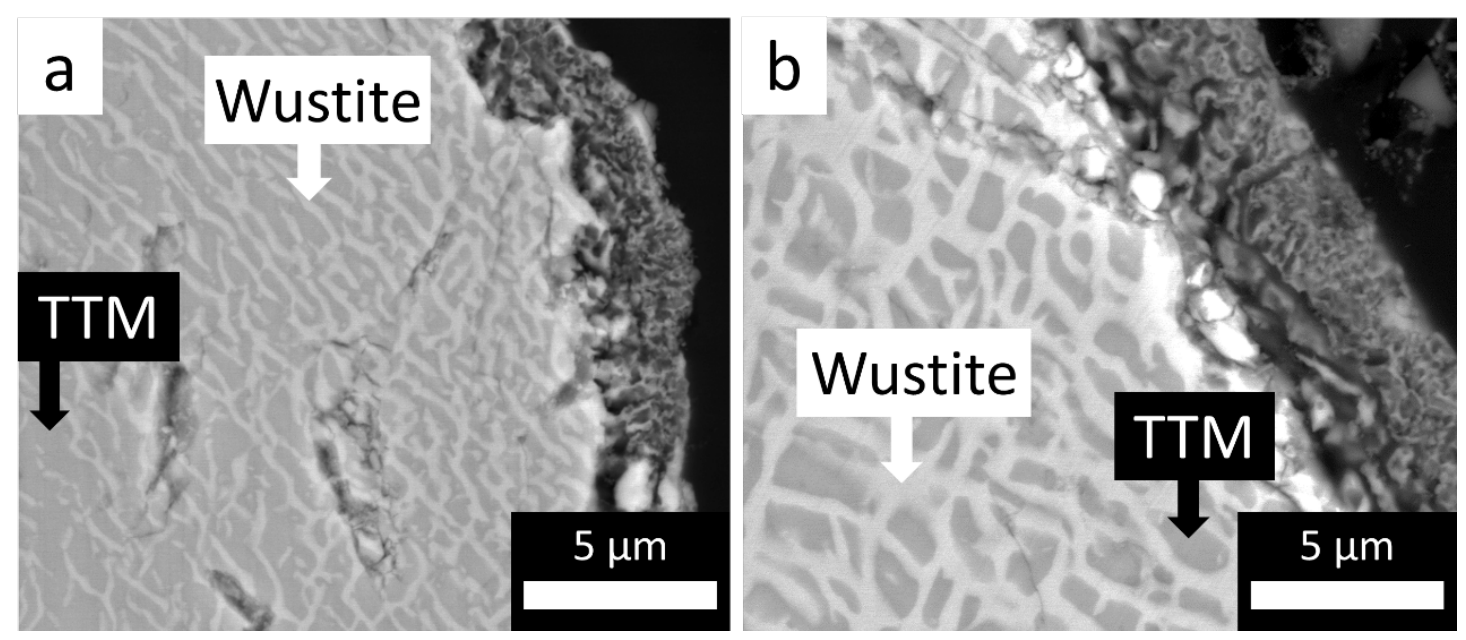

Figure 7.10 High magnification BSE SEM images of the TTM ironsand particle reduced by $5 \mathrm{~L} / \mathrm{min}_{2}$ at $1000^{\circ} \mathrm{C}$ for 1.5 minutes (a) and 5 minutes (b). The magnification is $16000 x$.

Table 7.1 Elemental spot EDS analysis of points shown in Figure 7.9

\begin{tabular}{ccccccc}
\hline \multirow{2}{*}{ Element } & \multicolumn{7}{c}{ Point (At. \%) } \\
\cline { 2 - 7 } & 1 & 2 & 3 & 4 & 5 & 6 \\
\hline $\mathrm{O}$ & 44.6 & 32.4 & 49.2 & 42.7 & 36.5 & 12.7 \\
$\mathrm{Mg}$ & 6 & 6.3 & 4.5 & 7.5 & 10 & 1.6 \\
$\mathrm{Al}$ & 8.7 & 11.2 & 8.8 & 10.4 & 16 & 2.9 \\
$\mathrm{Ti}$ & 9.5 & 11.5 & 8.2 & 11.3 & 13.6 & 11.3 \\
$\mathrm{Mn}$ & - & 0.5 & 0.6 & 0.6 & 1.3 & 1.8 \\
$\mathrm{Fe}$ & 31.1 & 38.7 & 28.8 & 27.5 & 22.6 & 69.6 \\
$\mathrm{Fe} / \mathrm{Ti}$ & 3.3 & 3.4 & 3.5 & 2.4 & 1.7 & 6.2 \\
\hline
\end{tabular}

The hyphen sign in the table means no signal for the respective element.

Figures 7.9(f-j) show magnified images of the microstructure at the different reduction stages observed in Figure 7.8(b).

Figures 7.9(f) and (g) represent microstructures during stage 1 (equation (6.1)): the reduction of TTM to wüstite. Figure 7.9(f) shows a shrinking-core type boundary between light grey channels (white arrow in Figure 7.10) and darker grey unreacted TTM phases (black arrow in Figure 7.10). In Figure 7.9(g), the wüstite channels become thicker, and this represents the endpoint of stage one. In comparison to Figure 7.7, the wüstite channels formed at $1000^{\circ} \mathrm{C}$ appears to be thicker than what was found at $950^{\circ} \mathrm{C}$. This could be because the wt. $\%$ level of wüstite formed at $1000^{\circ} \mathrm{C}$ is higher than that at $950^{\circ} \mathrm{C}$.

Figure 7.9(h) represents the microstructure during stage 2 (equation (6.2)): the reduction of wüstite to metallic iron. In the figure, the shrinking-core type boundary is also 
observed for the conversion of wüstite to metallic iron. Bright metallic iron (black arrow in Figure 7.9(h)) appears to penetrate to the inner particle following the light grey wüstite channels (white arrow in Figure 7.9(h)). The dark grey region represents the Ti-enriched TTM which remains unreduced during this stage (see Figure 7.8(b)).

Figures 7.9(i) and (j) represent the microstructure during stage 3 (equation (6.3)) and stage 4 (equations (6.4) and (6.5)) of the reduction, respectively. In Figure 7.9(i), wüstite has been fully converted to metallic iron, and this represents the beginning of stage 3 . After reduction for 60 minutes, the dark grey region in Figure 7.9(j) appears to be less than in Figure 7.9(i). This may be because the remaining TTM (white arrow in Figure 7.9(i)) is converted to metallic iron, (Figure 7.2). In the fully reduced particle (Figure 7.9(j)) the metallic iron exhibits a filigree-like structure which is interspersed along with the dark grey slag oxides (white arrow). The EDS analysis at point 6 shows that the slag oxide is rich in Ti. This indicates that the reaction between minority Ti-rich phases (ilmenite, rutile, and pseudobrookite) could occur in this region.

The outer shell appears to become thicker with the progression of the reduction process (Figure 7.9). Figure 7.11 presents measurements of the approximate shell thickness from images of samples extracted during the reduction at $950^{\circ} \mathrm{C}$ and $1000^{\circ} \mathrm{C}$. At both temperatures the shell thickness increases from $\sim 2 \mu \mathrm{m}$ (at \%met of $\sim 10 \%$ ) to $\sim 4 \mu \mathrm{m}$ (at \%met of $\gtrsim 75 \%$ ). The \%met of $75 \%$ corresponds to the point at which wüstite has been fully reduced (from Figure 7.8). The shell thickness then appears to be constant. This observation suggests that the shell develops during the formation of wüstite, which is consistent with the hypothesis in Chapter 6 (Section 6.6.2). 


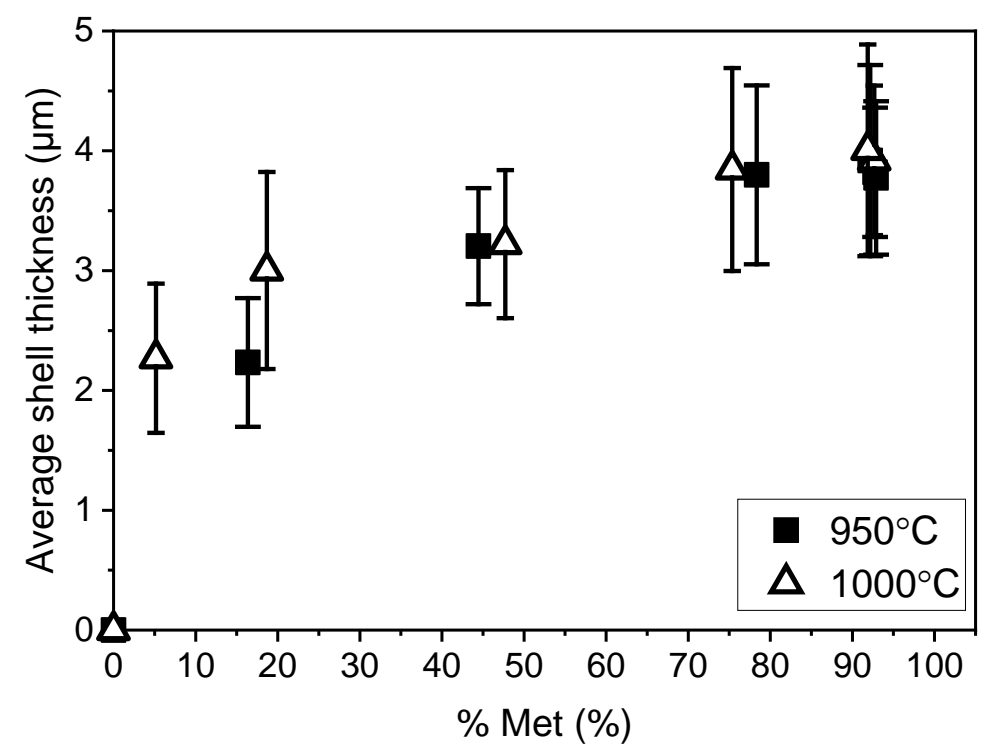

Figure 7.11 Plot showing the average shell thickness as a function of time during the reduction by $5 \mathrm{~L} / \mathrm{min} \mathrm{H}_{2}$ at $950^{\circ} \mathrm{C}$ and $1000^{\circ} \mathrm{C}$. The shell thickness value shown for each time period, is an average value measured from 20 particles. The error bars in the figure correspond to one standard deviation.

\subsubsection{Reduction at low temperature regime $\left(750^{\circ} \mathrm{C}-800^{\circ} \mathrm{C}\right)$}

Figure 7.12 shows the evolution of observed crystalline phases with time during the reduction at $750^{\circ} \mathrm{C}$ and $800^{\circ} \mathrm{C}$. As mentioned in Section 7.3 , there is no wüstite phase observed during the reduction at these temperatures, with TTM phase seeming to be reduced directly to metallic iron.

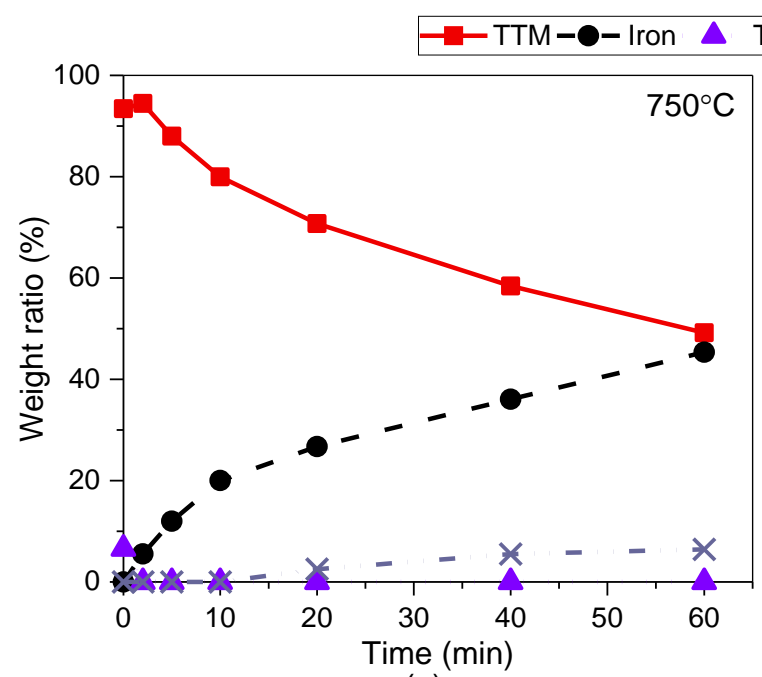

(a)

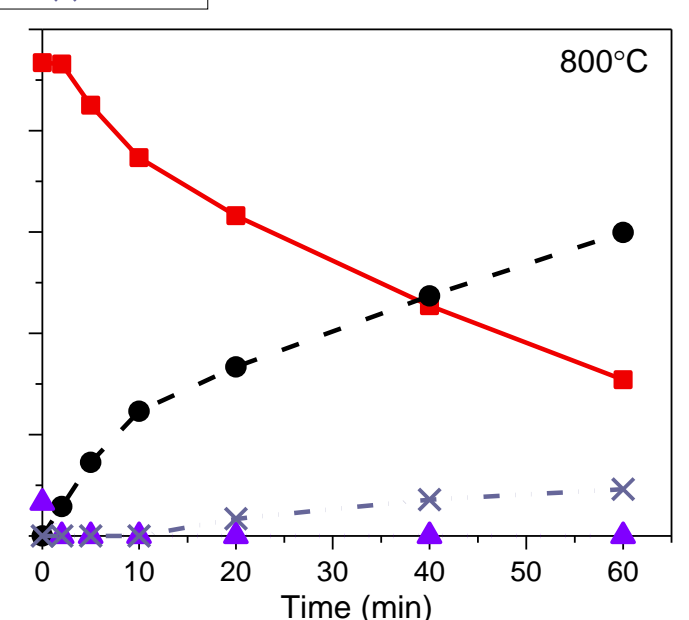

(b)

Figure 7.12 Phase evolution as a function of time during the reduction of ironsand in 5 $\mathrm{L} / \mathrm{min} \mathrm{H}_{2}$ at (a) $750^{\circ} \mathrm{C}$ and (b) $800^{\circ} \mathrm{C}$. 
Figure 7.13 shows a typical cross-section of the BSE-SEM images of the particle reduced at $750^{\circ} \mathrm{C}$. Samples reduced at $800^{\circ} \mathrm{C}$ also display similar microstructural features to the sample reduced at $750^{\circ} \mathrm{C}$. The SEM images for the particle reduced at $800^{\circ} \mathrm{C}$ are presented in Appendix C.
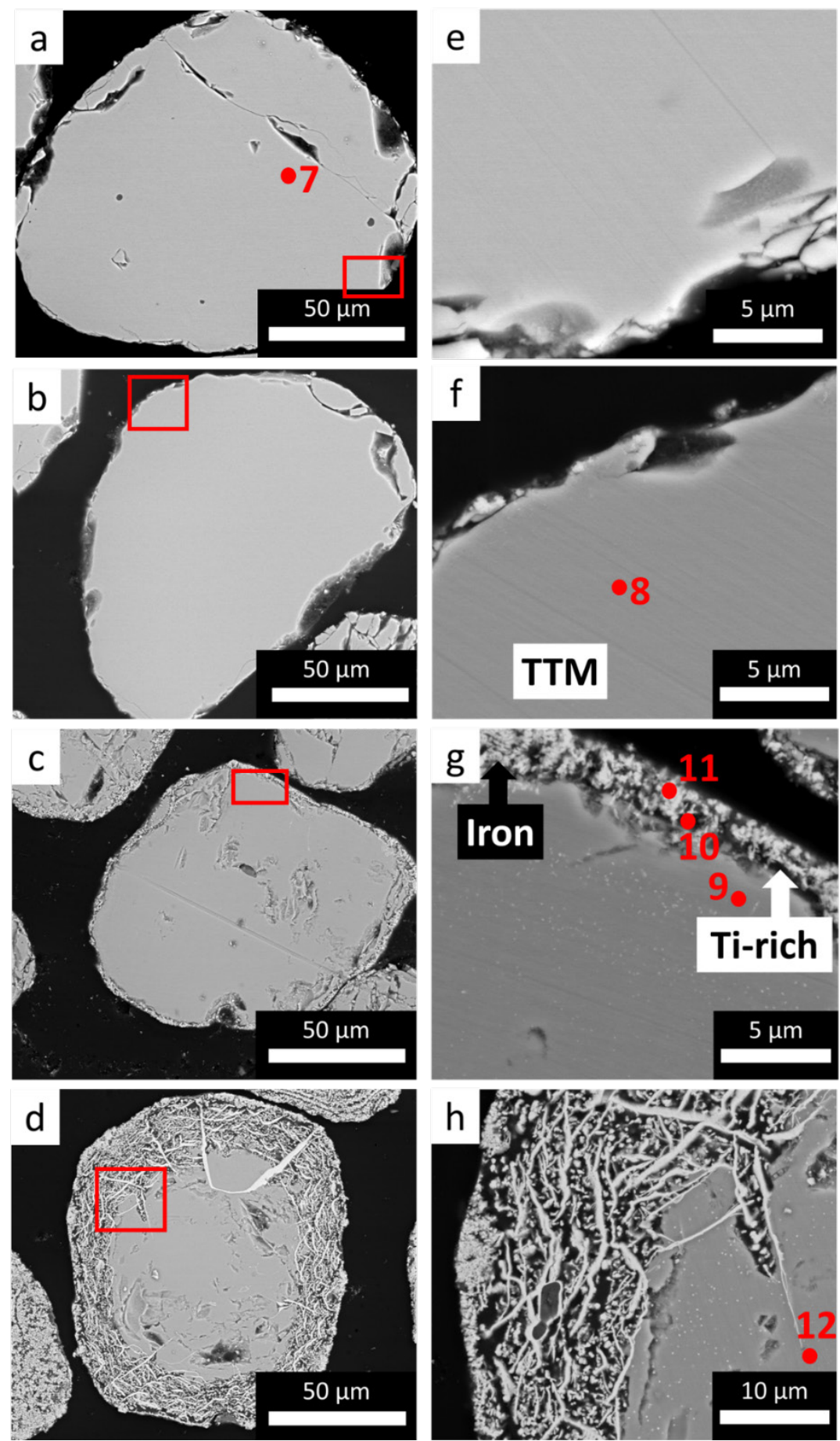

Figure 7.13 BSE-SEM images of the TTM ironsand particle from samples taken during the reduction by $5 \mathrm{~L} / \mathrm{min} \mathrm{H}_{2}$ at $750^{\circ} \mathrm{C}$ : (a) raw ironsand, (b) 5 minutes, (c) 20 minutes, (d) 60 minutes. Images $(e-h)$ are the right side are respective high magnification images of the red markers. 
On the surface of the particle reduced for 20 minutes (Figures 7.13(c) and (g)), a bright phase is observed, which is assumed to be metallic iron. This phase further develops and penetrates to the inner TTM region after 60 minutes of reduction (Figures 7.13(d) and (h)). The EDS analysis (Table 7.2) confirms that the Fe content in the bright phase (point 11 ) is much higher than the grey region (points 8, 9, and 12). This implies that the conversion of TTM to metallic iron proceeds topochemically.

It is noticeable that there is no difference in contrast between TTM phase (grey region) in the reduced particles (Figures 7.13(f, g, h)) and unreduced particle (Figure 7.13(a)). Closer inspection of the high magnification images in Figures 7.13(f, g, h) showed that none of the TTM regions display evidence of wüstite phase. This is consistent with the XRD results in Figure 7.2(b) and Figure 7.12(a), where there was no wüstite phase detected for these samples. From Table 7.2, the Fe/Ti ratio at points 8, 9, 12 are found to be broadly similar to point 7. This implies that there is no significant Ti enrichment to the TTM matrix (the grey region) during the reduction reaction. This is consistent with the results shown in Figures 7.4 and 7.5 .

Table 7.2 Elemental spot EDS analysis of points shown in Figure 7.13. Red coloured fonts indicate points in the grey region. Blue coloured fonts indicate points in the dark region. Black coloured fonts indicate points in the bright phase.

\begin{tabular}{ccccccc}
\hline \multirow{2}{*}{ Element } & \multicolumn{7}{c}{ Point (At. \%) } \\
\cline { 2 - 7 } & 7 & 8 & 9 & 10 & 11 & 12 \\
\hline $\mathrm{O}$ & 54.8 & 53.1 & 53.5 & 33.1 & 10.6 & 53.9 \\
$\mathrm{Mg}$ & 2.8 & 2.9 & 2.1 & 4.2 & 2.6 & 1.5 \\
$\mathrm{Al}$ & 2.2 & 2.7 & 1.8 & 4.9 & 2.7 & 1.4 \\
$\mathrm{Ti}$ & 2.7 & 3.0 & 2.7 & 7.7 & 0.9 & 2.9 \\
$\mathrm{Mn}$ & 0.5 & 0.5 & 0.5 & 1.7 & - & 0.7 \\
$\mathrm{~V}$ & 0.4 & - & - & - & - & - \\
$\mathrm{Fe}$ & 36.6 & 37.8 & 39.5 & 48.4 & 83.3 & 39.6 \\
$\mathrm{Fe} / \mathrm{Ti}$ & 13.4 & 12.7 & 14.6 & 6.3 & 95.7 & 13.7 \\
\hline
\end{tabular}

The hyphen sign in the table means no signal for the respective element.

In the particle reduced for 20 minutes (Figure 7.13(g)), a dark region (white arrow) is observed around the metallic iron. Table 7.2 shows that the Fe/Ti ratio in this dark region (point 10) is much lower than in the grey region (point 9). This indicates that the region is 
rich in Ti. This is also consistent with the EDS maps in Figure 7.14, which shows that Ti is concentrated in the dark region.

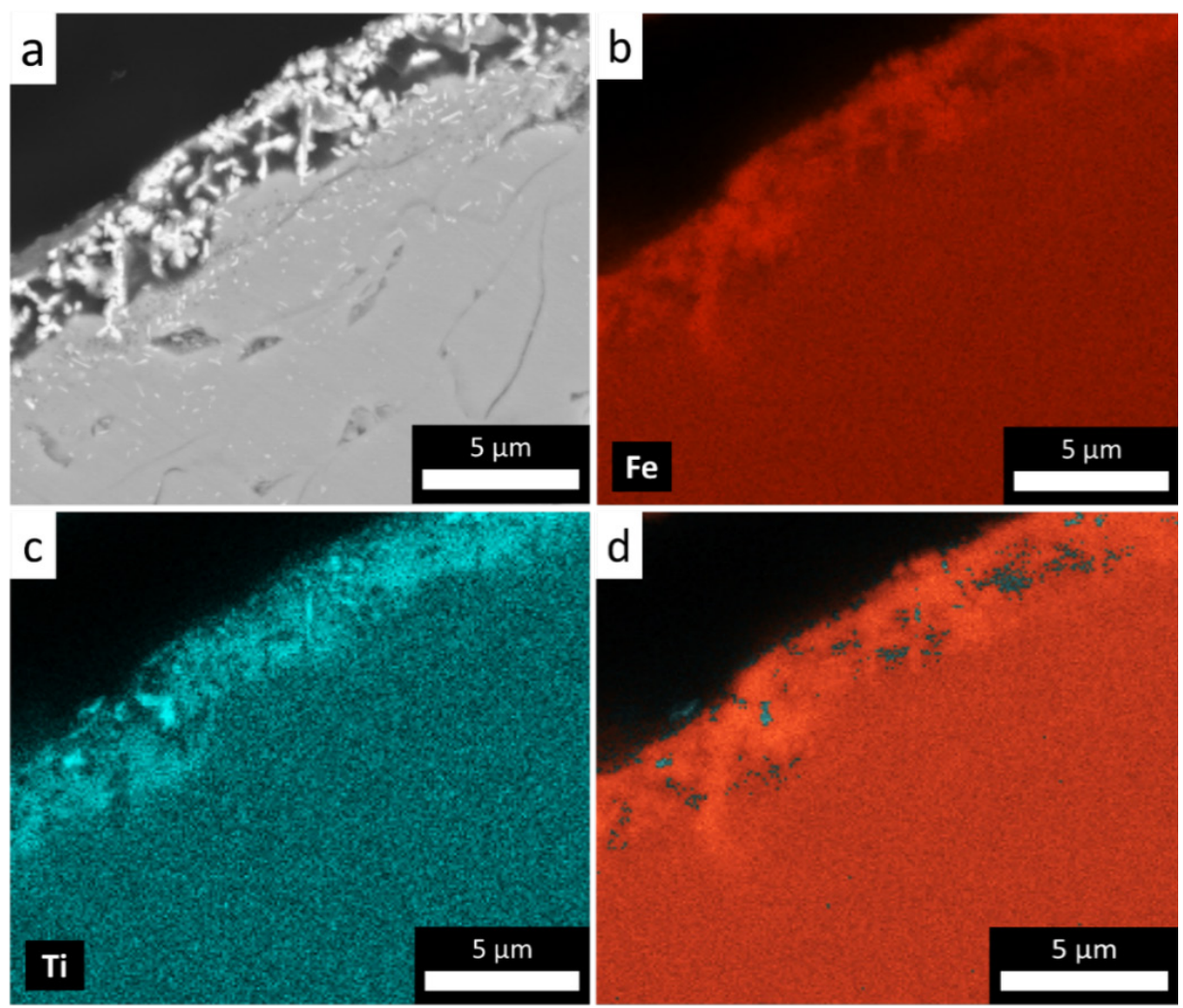

Figure 7.14 Elemental EDS map of a TTM ironsand particle reduced by $5 \mathrm{~L} / \mathrm{min} \mathrm{H}_{2}$ at $750^{\circ} \mathrm{C}$ for 20 minutes. (a) BSE image. (b) and (c) refer to the element noted in each image. (d) is the overlay image (a) to (c).

The EDS point analysis (Table 7.2) and maps (Figure 7.14) provide information on the migration of $\mathrm{Ti}$ species during the reduction at $750^{\circ} \mathrm{C}$. The formation of Ti metal is unfavoured here as the Gibbs energy for the reduction of $\mathrm{TiO}_{2}$ to $\mathrm{Ti}$ by $\mathrm{H}_{2}$ gas is highly positive at any temperature (Kubaschewski, Alcock and Spencer, 1993). Therefore, Ti is most likely exsolved as an oxide when metallic iron is formed. As the dark region is rich in $\mathrm{Ti}$ (point 10), it is most likely that the Ti is exsolved into this region. This can also be seen in Figures 7.14(c) and (d), where the Ti element is concentrated in the dark regions.

According to reaction (6.3), ilmenite should form along with metallic iron from the reduction of TTM. However, ilmenite phase is not detected in the first 10 minutes of reaction. There are two possible reasons for this. The first possibility is that ilmenite may have formed during this period but remains below the detection limits of the XRD. The second possibility might be that the Ti has formed an amorphous Ti-oxide instead of ilmenite, which is not readily detected by XRD. Nonetheless, after 20 minutes, ilmenite is 
detected by XRD with a composition of $~ 3$ wt.\% (in Figure 7.12(a)). According to the results in Figures 7.13 and 7.14, ilmenite phase is most likely in the dark region (in Figure $7.13(\mathrm{~g}))$.

In the sample reduced for 60 mins (Figures 7.13(d, h)), the particle exhibits acicular (needle-like) metallic iron structures. This microstructure is different from that reported for titanium-free magnetite and hematite ores. At $750^{\circ} \mathrm{C}$, the reduction of these ores is always through wüstite (Weiss et al., 2010, 2011; Pichler et al., 2016). The microstructure of these ores typically exhibits a dense metallic iron and wüstite ring, which surround the unreacted magnetite in the inner core. The reason for the formation of acicular metallic iron in TTM ironsand particles used in this work is not clear.

Unlike at the higher temperatures, a Ti-rich oxide shell is not observed around any of the imaged particles. This significant difference could again be due to the absence of a wüstite phase. At lower temperatures, TTM phase appears to be directly reduced to metallic iron, starting from the surface of the particle. As wüstite channels are not formed, there is no apparent segregation of Ti from Fe. This appears to result in a particle without the Tioxide shell. This interpretation is consistent with the argument in Section 7.5.2, which stated that the development of the shell is associated with the formation of wüstite.

\subsubsection{Reduction at the intermediate temperature regime $\left(850^{\circ} \mathrm{C}-900^{\circ} \mathrm{C}\right)$}

For the reductions conducted at the intermediate temperatures of $850^{\circ} \mathrm{C}$ and $900^{\circ} \mathrm{C}$, a small proportion of wüstite was detected during the initial reduction stage (see Figure 7.2(b)). Figure 7.15 shows high magnification images of particles reduced at $900^{\circ} \mathrm{C}$. Within particles reduced for 5 and 10 minutes (Figures 7.15(a, b)), the wüstite channels (white arrow) seem to be much thinner than those in the particle reduced at $1000^{\circ} \mathrm{C}$. This may be because the proportion of wüstite is only 15 wt.\% (in Figure 7.2(b)). The nucleation of metallic iron (black arrow) follows the wüstite channels, which is similar to what was observed at $1000^{\circ} \mathrm{C}$. However, the conversion to metallic iron seems to occur before the wüstite channels have been fully formed across the entire particle.

Figure 7.15 (c) shows the microstructure of a fully reduced particle at $900^{\circ} \mathrm{C}$. This particle now exhibits filigree-like metallic iron, along with dark grey oxide slag regions (Figure $7.15(d)$ ). This structure is similar to that seen in fully reduced particles at $1000^{\circ} \mathrm{C}$. 

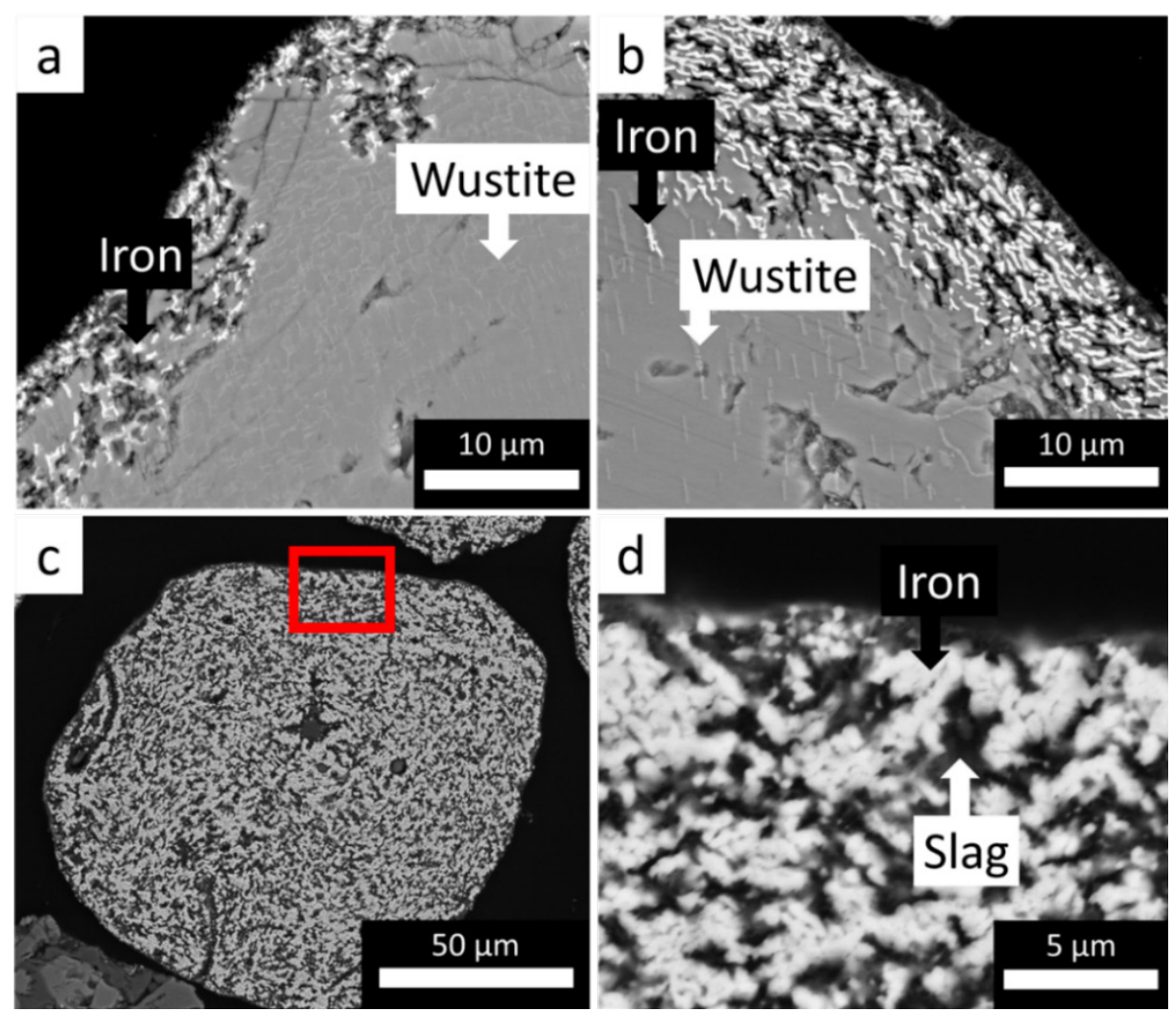

Figure 7.15 BSE SEM image of the ironsand particle during the reduction at $900^{\circ} \mathrm{C}$ : (a) 5 minutes, (b) 10 minutes, and (c \& d) 60 minutes. Image (d) is the high magnification of image (c). Red marker indicates the location of magnified image.

There is no obvious sign of an outer oxide shell during any stage of the reduction at $900^{\circ} \mathrm{C}$ (Figure 7.15). Despite this, there is also no sticking observed during the reduction at this temperature. Figure 7.16 shows an EDS map of the particle reduced for 60 minutes. The figure reveals that Ti species, as oxides, are present at the particle surface. It is possible that this very thin layer of Ti-oxides on the particle surface is just enough to inhibit particle sticking during the reduction process.
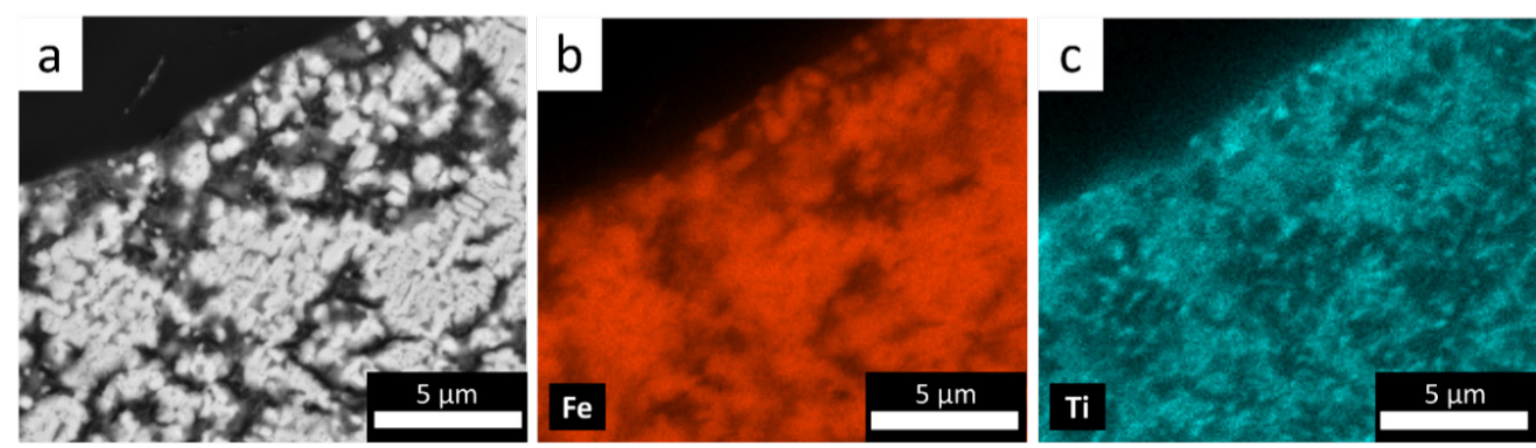

Figure 7.16 Elemental EDS map of a TTM ironsand particle reduced at $900^{\circ} \mathrm{C}$ for 60 minutes. (a) is the BSE image. (b) and (c) refer to the element noted in each image. 


\subsection{Thermodynamic analysis of the reduction of TTM ironsand at different temperatures.}

\subsubsection{Measurement of $\mathrm{H}_{2} \mathrm{O}$ (water vapour) emitted during the reduction reaction}

Previous sections have shown that the reduction pathway of TTM varies for different temperature ranges. To further investigate this effect, the concentration of $\mathrm{H}_{2} \mathrm{O}$ in the outlet gas was measured at each reduction temperature. This data is then plotted into the "Baur Glaessner” diagram which shows the thermodynamic equilibrium conditions for conventional (Ti-free) iron oxides in an $\mathrm{H}_{2} / \mathrm{H}_{2} \mathrm{O}$ atmosphere.

Real-time measurements were made using a humidity sensor which provides the actual data for the amount of $\mathrm{H}_{2} \mathrm{O}$ released from ironsand during the reduction process. The details of the humidity sensor set-up are described in Chapter 3, and the calibration process is described in Appendix A. In addition, the average quantity of $\mathrm{H}_{2} \mathrm{O}$ removed from ironsand during each time-step (between taking consecutive samples) was also calculated from the q-XRD data. The two independent sets of data are compared below.

\subsubsection{Reproducibility of the moisture data measured by the humidity sensor}

Initial tests were performed to confirm the reproducibility of the moisture data measured by the humidity sensor during the reduction process. Three experimental runs were performed under identical conditions. In each case, a fresh 100 g sample of ironsand was reduced in $5 \mathrm{~L} / \mathrm{min}$ at $950^{\circ} \mathrm{C}$. Figure 7.17 shows plots of partial pressure of $\mathrm{H}_{2} \mathrm{O}\left(P_{\mathrm{H}_{2} \mathrm{O}}\right)$ in the outlet gas as a function of time from each of the five reduction runs. The calculation for $P_{H 2 O}$ from $T_{d}$ data measured by the sensor is presented in equation (3.3), found in Chapter 3. These experiments clearly show excellent reproducibility. 


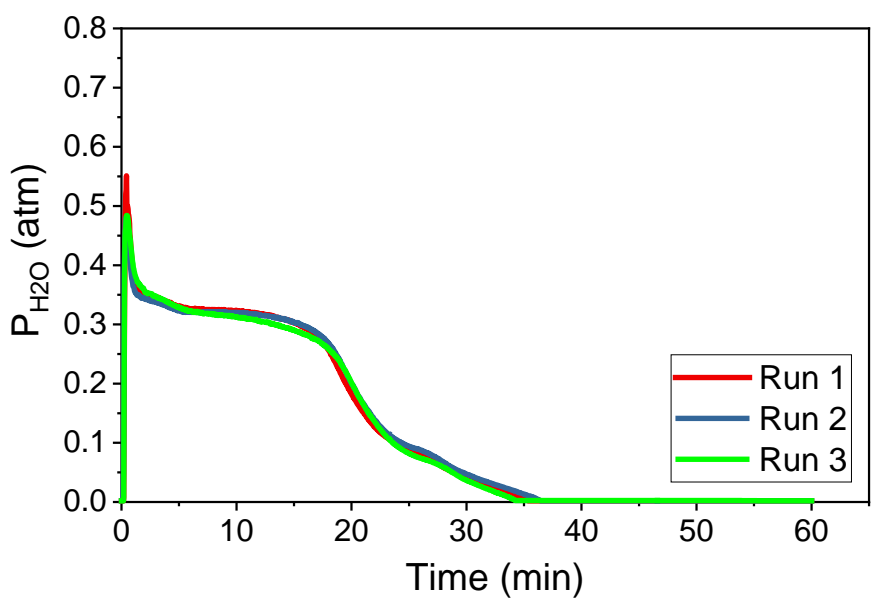

Figure 7.17 Plots of the measured $P_{H 2 O}$ in the outlet gas for the three reduction runs of TTM ironsand in $5 \mathrm{~L} / \mathrm{min}$ of $\mathrm{H}_{2}$ at $950^{\circ} \mathrm{C}$.

\subsubsection{Calculation of $\mathrm{H}_{2} \mathrm{O}$ compositions from $q-X R D$ data}

The average $P_{H 2 O}$ values during each time-step were also calculated from the q-XRD data were calculated in the same way as described in Section 6.5. In brief, the number of moles of oxygen $(\mathrm{O})$ removed from the bed during each time-step was calculated from the change in the crystalline iron oxide phases at each time-step (as obtained from the q-XRD data). According to reaction (6.6), the number of moles of $\mathrm{H}_{2} \mathrm{O}$ formed by the reduction reaction is the same as the number of moles $\mathrm{O}$ removed. At low pressures and high temperatures, such as the condition in the current reactor, steam approaches the ideal gas

condition. Therefore, the molar fraction of $\mathrm{H}_{2} \mathrm{O}\left(=n_{\mathrm{H} 2 \mathrm{O}} / n_{\mathrm{H} 2 \mathrm{O}}+n_{\mathrm{H} 2}\right)$ can be assumed to be the same as $P_{H 2 O}$. The molar fraction of $\mathrm{H}_{2} \mathrm{O}$ was calculated from equation (6.7).

\subsection{2 $\mathrm{H}_{2} \mathrm{O}$ emitted during the reduction and comparison with Baur-Glaessner diagram for iron oxides}

Figure 7.18 shows the $P_{H 2 O}$ as a function of time during the reduction reaction at different temperatures. Each plot contains both the $P_{\mathrm{H} 2 \mathrm{O}}$ values measured by the sensor (solid black line) and the values calculated from the q-XRD data (red squares). The error bars for the sensor data presented in blue pattern represent the standard deviation of the linear regression from calibration data (see Appendix A). The error bars of the q-XRD data represent the error of the fittings by the Topas software. The error bars are small, providing a high degree of confidence in the data. In general, the time-step averaged $P_{H 2 O}$ values 
calculated from the q-XRD data broadly agree with the data measured by the sensor for all temperatures.

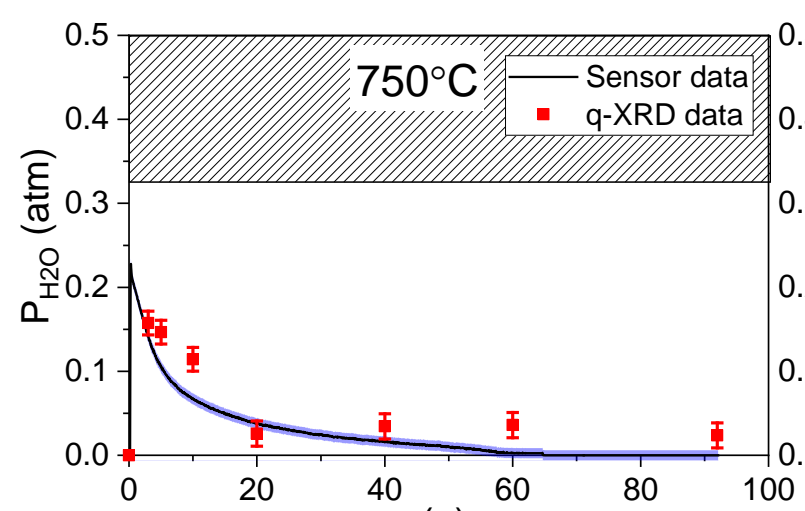

(a)

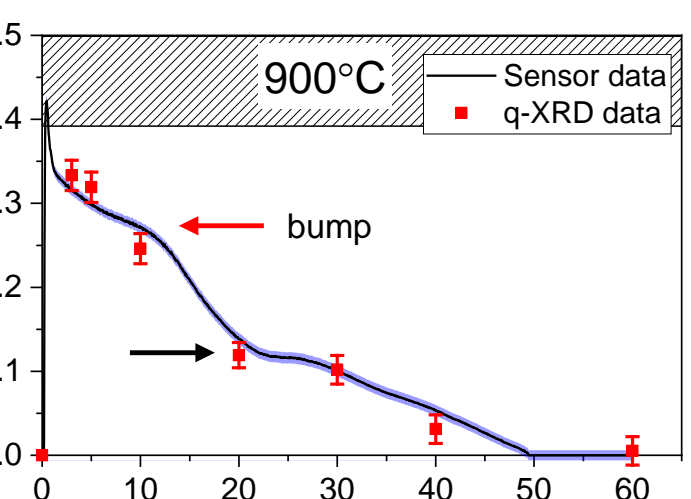

(d)

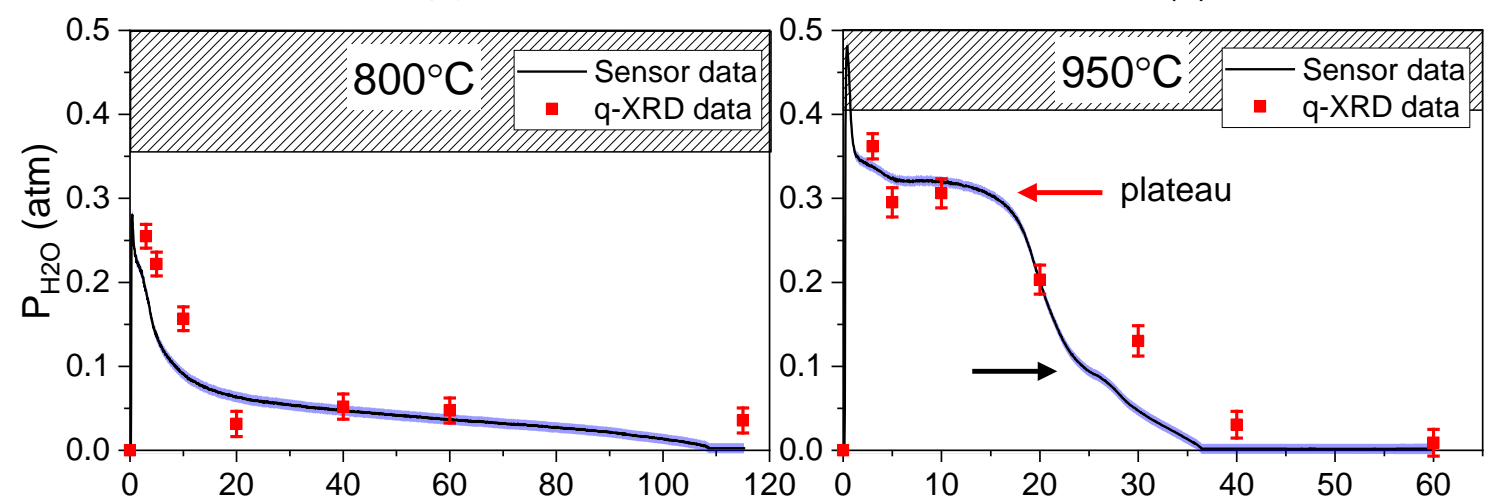

(b)

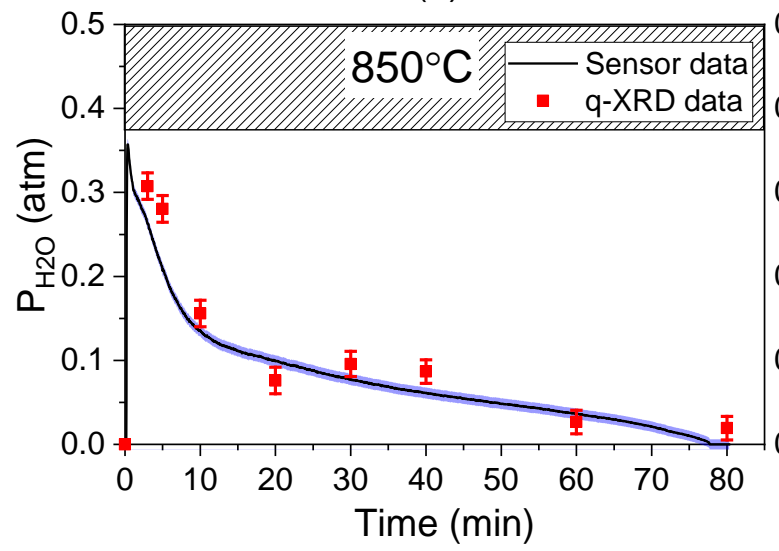

(c)

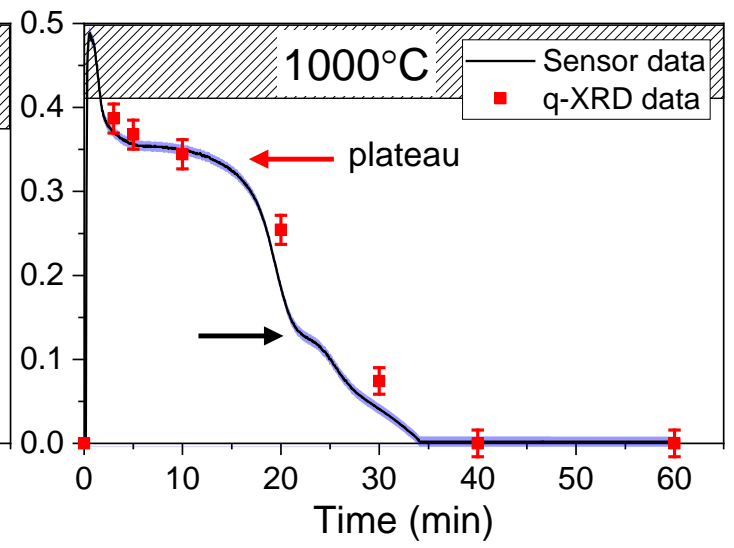

(f)

Figure 7.18 Plots of $P_{\mathrm{H} 2 \mathrm{O}}$ as a function of time for the reduction of TTM ironsand by 5 $\mathrm{L} / \mathrm{min}$ of $\mathrm{H}_{2}$ at different temperatures: (a) $750^{\circ} \mathrm{C}$, (b) $800^{\circ} \mathrm{C}$, (c) $850^{\circ} \mathrm{C}$, (d) $900^{\circ} \mathrm{C}$, (e) $950^{\circ} \mathrm{C}$, and $(f) 1000^{\circ} \mathrm{C}$. Solid line indicates the $P_{H 2 O}$ value measured by the humidity sensor. Red square indicates $P_{H 2 O}$ value calculated from q-XRD data. The shaded area corresponds to the wüstite-stability region shown in Figure 7.19. Blue patterns are the error bars for the sensor data, which correspond to the standard deviation of the linear regression from calibration data. The error bars of the $q-X R D$ data is the error fitting from the Topas software. 
Figure 7.19 shows the "Baur-Glaessner" diagram, which depicts the stability of iron species at different $\mathrm{H}_{2}-\mathrm{H}_{2} \mathrm{O}$ compositions and temperatures. In this figure, the $P_{\mathrm{H} 2 \mathrm{O}}$ values measured by the humidity sensor (from Figure 7.18) are also plotted for different temperatures and reduction times. This diagram does not include phases containing Ti.

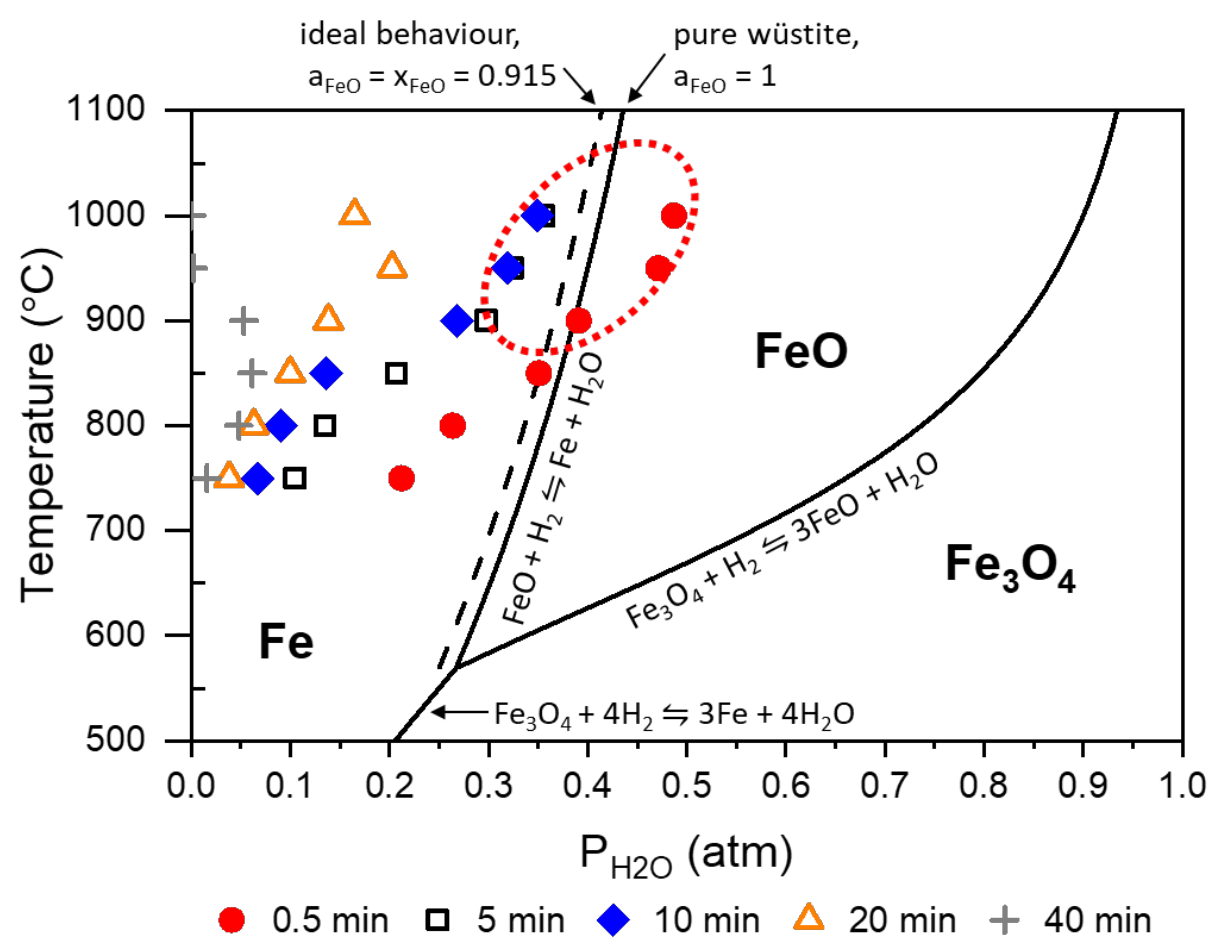

Figure 7.19 Equilibrium diagram for $\mathrm{H}_{2}-\mathrm{H}_{2} \mathrm{O}$ gas mixture for iron oxides system (plotted from thermodynamic data in Kubaschewski, Alcock and Spencer, 1993) containing estimated gas compositions at each temperature during the reduction. The dashed line indicates the equilibrium line for calculated behaviour of wüstite in an ideal solution with 8.1 wt.\% $\mathrm{TiO}_{2}$. Red dotted ellipse indicates the area where wüstite phase is found in the sample.

Both Figure 7.18 and Figure 7.19 provide supporting evidence for the reaction pathway of TTM at different temperatures that was discussed in Section 7.5. The shaded area in each plot in Figure 7.18 corresponds to the wüstite-stability region shown in Figure 7.19. For temperatures of $750^{\circ} \mathrm{C}$ and $850^{\circ} \mathrm{C}$, the $P_{H 2 O}$ values do not reach the wüstitestability region (Figures 7.18(a) and (b)), and are in the iron-stability region throughout the reduction process (Figure 7.19). It is thus suggested that wüstite is not stable in this region during the reduction at these temperatures, and is therefore wüstite not observed. This is consistent with the XRD and SEM data shown in Section 7.5. 
With increasing temperature, the measured $P_{\mathrm{H} 2 \mathrm{O}}$ values in the beginning of the reduction (within 0.5 minutes) move toward the wüstite-stability region, see Figures 7.18(cf) and 7.19. For temperatures of $850^{\circ} \mathrm{C}$ and $900^{\circ} \mathrm{C}$, the $P_{H 2 O}$ values within the first minute (Figure 7.18(c) and (d)) are near the Fe-FeO equilibrium line in Figure 7.19. This appears to result in smaller levels of wüstite formed at these temperatures, as shown in Figure 7.2(b). For temperatures of $950^{\circ} \mathrm{C}$ and $1000^{\circ} \mathrm{C}$, the $P_{H 2 O}$ values within first minute are in the wüstite-stability region, see Figure 7.18(e, f) and 7.19. This is consistent with the XRD and SEM data (Section 7.5) where high levels of wüstite are observed to form during the early stages reduction at these temperatures.

Another interesting feature in Figure 7.18 is the strong 'plateau' (red arrow) effect which is observed at high temperatures of $950^{\circ} \mathrm{C}$ and $1000^{\circ} \mathrm{C}$ (Figures $7.18(\mathrm{e})$ and (f)), but not at lower temperatures (Figures 7.18(a-d)). This plateau suggests that the reaction becomes thermodynamically limited during this stage of the reduction. This is consistent with the earlier observation in Section 6.3 , that the reaction at $950^{\circ} \mathrm{C}$ is always operating under $\mathrm{H}_{2}$ gas starvation regime (for all $\mathrm{H}_{2}$ gas flow rates below the entrainment regime of the bubbling bed FB).At the plateau in Figure 7.18(e) and (f), the $P_{H 2 O}$ value is respectively about $0.33 \mathrm{~atm}$ at $950^{\circ} \mathrm{C}$, and $0.35 \mathrm{~atm}$ at $1000^{\circ} \mathrm{C}$. These values lie close to the iron-wustite equilibrium boundary in Figure 7.19, implying that the $P_{H 2 O}$ plateau appears when the reaction shifts from the reduction of TTM to wüstite to the reduction of wüstite to metallic iron (stage 2). This is consistent with the behaviour observed in Figures 7.2 and 7.8.

With decreasing temperature, the plateau seems to disappear. For $900^{\circ} \mathrm{C}$ (Figure 7.18(d)), there is no obvious sign of the plateau region, although there is a little bump (red arrow) at about 10 minutes. At lower temperatures $\left(750^{\circ} \mathrm{C}\right.$ to $\left.850^{\circ} \mathrm{C}\right)$, there is neither plateau nor bump throughout the reduction process. The reaction at lower temperatures may be occurred under excess $\mathrm{H}_{2}$ gas, although more research using lower $\mathrm{H}_{2}$ gas flow rate is needed to elucidate this interpretation. However, the reduction at low temperatures is less preferable for industrial application.

The data in Figures 7.18 is also consistent with the previous data in Figures 6.10 and 6.11 (in Chapter 6), which also showed the $\mathrm{H}_{2} \mathrm{O}$ composition plateau during the reduction stage 2. It is important to remember that at the point in the reaction when the plateau occurs, approximately half of the Ti-enriched TTM remains in the bed. There is a possibility for simultaneous reduction of TTM to wüstite as well as of wüstite to iron if the reaction is in excess $\mathrm{H}_{2}$ gas, but this does not occur under the condition of $\mathrm{H}_{2}$ gas starvation (current 
experiments). Instead, the remaining TTM appears not to be further reduced whilst the plateau exists. As discussed in Sections 7.3 and 7.4, this is likely because the enrichment of Ti stabilises the TTM spinel, so that it requires a higher thermodynamic driving force for reduction and hence slowing or stopping its reduction rate.

With decreasing temperature, the plateau seems to disappear. For $900^{\circ} \mathrm{C}$ (Figure 7.18(d)), there is no obvious sign of the plateau region, although there is a little bump (red arrow) at about 10 minutes. This could be because the level of wüstite is lower than at higher temperatures. At lower temperatures $\left(750^{\circ} \mathrm{C}\right.$ to $\left.850^{\circ} \mathrm{C}\right)$, there is neither plateau nor bump throughout the reduction process. This could be expected as wüstite is not observed at lower temperatures (note that the wüstite level formed at $850^{\circ} \mathrm{C}$ is very low ( $\left.5 \mathrm{wt} . \%\right)$ ), see Figures 7.2 and 7.12. The data in Figure 7.18 shows that the reaction at lower temperature may be occurred under excess $\mathrm{H}_{2}$ gas. However, the reaction occurs more slowly at

A different set of small bumps in the $P_{H 2 O}$ plots are also observed in Figures 7.18(d, e, f) after about 20 minutes of reduction (black arrow in each plot). From Figure 7.2(c), it can be seen that this seems to correspond to the period during the reduction of ilmenite. This smaller feature may therefore be related to equilibrium between ilmenite and iron. However, this is not shown in Figure 7.19, as the diagram is only for iron oxides.

This data must be interpreted with caution because there is also a possibility that the actual equilibrium line between wüstite and iron may be different because of the Ti content. To test the possible effects of the titanium content in TTM ore on the reduction of wüstite, the equilibrium gas composition for equation (6.2) was re-calculated assuming all of the titanium content in the ore was in fact present in wüstite. Due to the lack of data for this system, the extreme case assuming ideal behaviour has been used (using the total Fe and $\mathrm{TiO}_{2}$ content of the original ore given in Table 3.1), with the calculated gas compositions given by the dashed line in Figure 7.19. It can be seen that the effect of ideal behaviour of titanium on the equilibrium for equation (6.2) is small. For the effect of titanium in wüstite to cause substantial differences between the expected equilibrium and measured experimental gas compositions, a substantial negative deviation (decrease in $\mathrm{a} F e \mathrm{O}$ ) away from ideal behaviour would be required. It should be noted that there are some issues with this simple analysis. Equation (6.2) only considers wüstite and iron as solid phases, ignoring the presence of other species. In reality, other impurity species are also present 
(e.g. Al, Mg, or V), and these may also affect the position of the equilibrium boundary, and hence the equilibrium gas composition at each temperature.

\subsection{Observations of particle sticking in specific non-optimal FB reduction conditions}

The previous sections have shown that there are a wide range of conditions under which $\mathrm{FB}$ reduction of ironsand by $\mathrm{H}_{2}$ gas can be conducted without sticking occurring. However, during this study, particle sticking was observed to occur under two specific sets of experimental conditions. These are: (a) reduction by $100 \% \mathrm{H}_{2}$ gas at $1050^{\circ} \mathrm{C}$; and (b) reduction by $7.5 \mathrm{~mol} . \% \mathrm{H}_{2} \mathrm{O}-92.5 \mathrm{~mol} . \% \mathrm{H}_{2}$ at $950^{\circ} \mathrm{C}$.

In both cases, sticking generally took place in the area near the surfaces of reactor wall (quartz furnace tube) and sampling tube, while most of the particles remained as loose powder. The loose powder part appeared to be fluidised in the middle section of the reactor, away from the wall, throughout the reduction process. The mechanism of the sticking is not clear, but it seems probable that both sticking cases were related to the use of a quartz furnace tube in this work. The next subsections will show selected materials characterisation (photographs and micrographs) undertaken in these experiments. More XRD and SEM data can be found in Appendix D.

\subsubsection{Case A: Particle sticking during the reduction at $1050^{\circ} \mathrm{C}$}

In this case, the reduction was carried out in $5 \mathrm{~L} / \mathrm{min} \mathrm{H}_{2}$ gas $\left(100 \% \mathrm{H}_{2}\right)$ at $1050^{\circ} \mathrm{C}$. The sticking started after approximately 17 minutes, and the reduction experiment was stopped shortly afterwards at 20 minutes. Figures 7.20(a) and (b) show photographs of the bed sample after the reduction experiment. Small curved pieces of sinters (points 1, and 4) were found to have adhered to the inner quartz wall of the reactor. It can be seen in Figure 7.20(c) that the quartz reactor wall has turned black due to these adhered particles. A large piece of sinter (point 2) was also found adhered to the Inconel sampling tube. Figure 7.20(d) reveals that during this experiment, the bottom section of the tube had deformed (red arrow). It seems likely that the sticking of the 'sampling tube sinter' can be attributed to the softening of the Inconel tube due to the exposure to a high temperature of $1050^{\circ} \mathrm{C}$.

Figure 7.21 shows BSE-SEM images for the particle in the loose powder (point 4) and a small piece of sinter stuck to the quartz wall (point 1) shown in Figure 7.20. Ti-oxide 
shell (white arrow) is apparent at the surface of the particle in the loose powder part (Figure 7.21(a)), similar to the particle reduced at $950^{\circ} \mathrm{C}$ and $1000^{\circ} \mathrm{C}$ (Figures 6.13 and 7.9). This might explain why these particles remained fluidised throughout the reaction. By contrast, the Ti-oxide shell is not apparent in the particles found in either sinter. The Ti-oxide shell seems to have been converted to a denser Fe-oxides (red arrow), as indicated by the lighter grey contrast in Figure 7.21(b) and (c) than in (a). More results for XRD and EDS maps of particles in both sinters are presented in Appendix D.

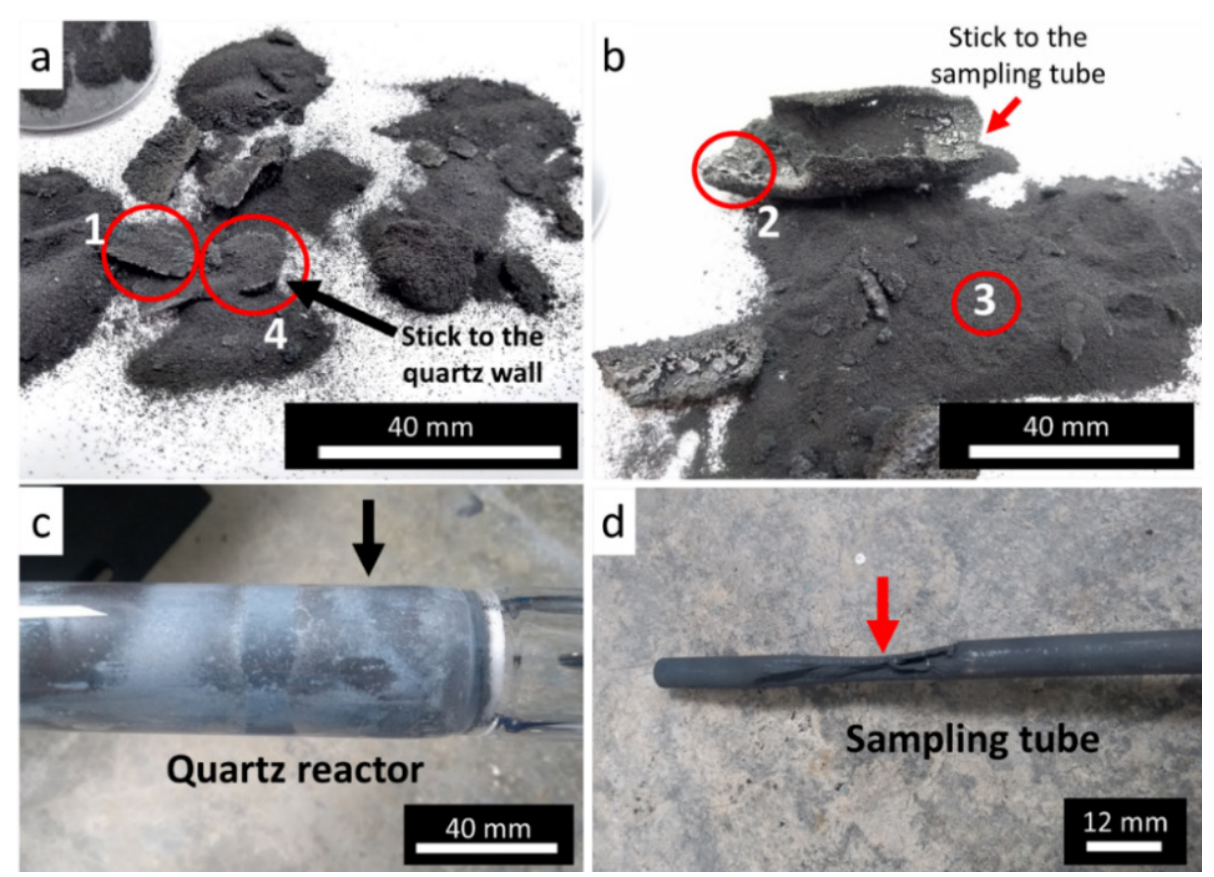

Figure 7.20 Photograph showing sintered part that was stuck to the wall (a), stuck to the sampling tube (b), and reduced ironsand powder. Images (c) and (d) show the condition of the quartz reactor and the sampling tube after the experimental run, respectively.

It should be noted that if the bed is defluidised, there may be a radial temperature gradient in the bed. The thermocouple reads the temperature in the centre of the bed. As the bed is defluidised, the bed temperature in the centre is colder than the bed sintered to the wall. As a result, the furnace controller gives more heating power to ramp up the bed temperature again (as discussed in Section 5.2). In this condition, the wall temperature might run away faster than the bed temperature. So, the bed section close to the wall may become higher than $1050^{\circ} \mathrm{C}$. This may cause an interaction between iron and silicate in the quartz reactor wall, thus nucleating the initial particle sticking. These stuck particles may then catch other particles nearby and then sintered together. Several studies have reported 
that $\mathrm{FeO}$ and $\mathrm{SiO}_{2}$ may form a low-melting point multi-component phase at high temperatures $\left(>900^{\circ} \mathrm{C}\right.$ ) (Wong et al., 1999; Komatina and Gudenau, 2004; Yi et al., 2014, Luo et al., 2016). It is recommended that a future study to explore the use of alternative ceramic materials for the reactor tube, for experiments at temperatures $\geq 1050^{\circ} \mathrm{C}$.
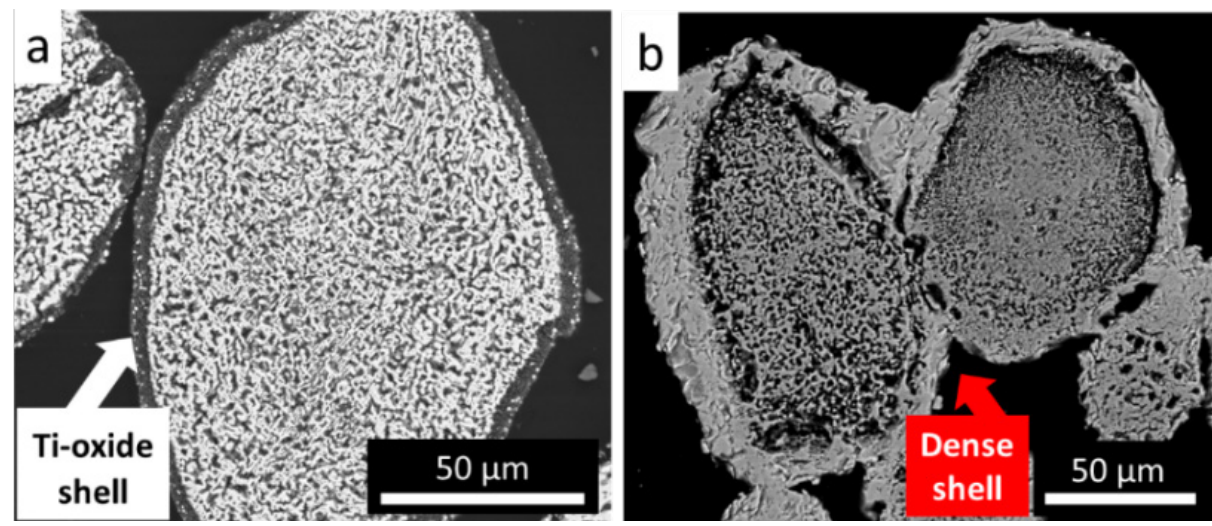

Figure 7.21 BSE-SEM cross-section images for the particle in the loose powder (a) and the sintered part that stuck to the wall (b) found in Figure 7.20, after the reduction experiment in $5 \mathrm{~L} / \mathrm{min} \mathrm{H}_{2}$ at $1050^{\circ} \mathrm{C}$ for 20 minutes

\subsubsection{Case B: Particle sticking during the reduction by $7.5 \mathrm{~mol} . \% \mathrm{H}_{2} \mathrm{O}$ at $950^{\circ} \mathrm{C}$}

Commercial FB technologies typically utilise multi-stage reactors with a countercurrent flow of raw iron ore and reducing gas (as mentioned in Chapter 2, Section 2.6). In the first reactor, the fresh iron ores meet reducing gas that contains $\mathrm{H}_{2} \mathrm{O}$ resulting from previous reactions of the $\mathrm{H}_{2}$ gas stream. Initially, a series of experiments were planned to investigate the effect on the reduction rate of TTM of changing the $\mathrm{H}_{2} \mathrm{O}$ concentration in the input reducing gas. However, particle sticking was observed to occur in the first experimental run.

In this case, the reduction was carried out in 7.5 mol.\% $\mathrm{H}_{2} \mathrm{O}-92.5 \mathrm{~mol} \% \mathrm{H}_{2}$, using a flow of $5 \mathrm{~L} / \mathrm{min} \mathrm{H}_{2}$ gas (with $0.3 \mathrm{ml} / \mathrm{min}$ water) at $950^{\circ} \mathrm{C}$. During the experiment, there was no sudden drop of $\Delta P$ observed, and therefore the reduction experiment was allowed to continue under reducing conditions until 70 minutes (see Appendix D). However, sampling was found to not be possible beyond 30 minutes of reduction. Figure 7.22 shows photographs of the final bed samples taken after cooling to room temperature. A sinter was found to have formed which was mainly stuck to the quartz reactor wall (Figure 7.22(a)). In this case, only a tiny amount of particles were found adhered to the sampling tube (see Appendix D), and there was no deformation observed in the tube, probably because this 
experimental temperature $\left(950^{\circ} \mathrm{C}\right)$ was lower than case A above $\left(1050^{\circ} \mathrm{C}\right)$. Again, despite the presence of the sinter, most particles remained as a loose powder in the centre of the bed (Figure 7.22(b)).

a

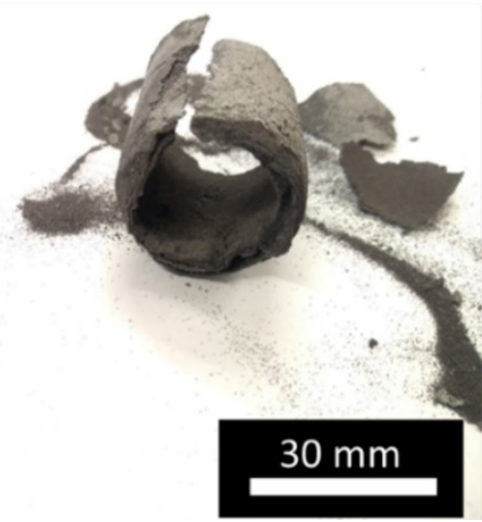

Figure 7.22 Photograph of the sintered sample (a). (b) is the loose powder. b

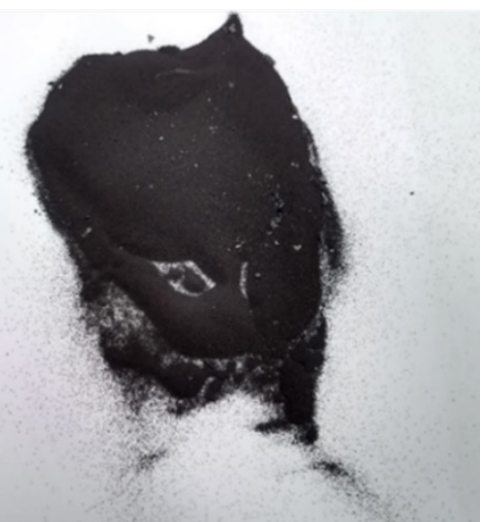

Figure 7.23 shows BSE-SEM images of the surface morphology of the sinter, which formed facing the reactor wall. More XRD and SEM data can be found in Appendix D. It can be seen that the particles are only loosely sintered at point contacts. In addition, several dark 'flakes' are observed to be sticking to particles. EDS point analysis (Table 7.3) shows that these flakes contain considerably elevated levels of Si (points 14, 15, 17, 18). It is possible that these flakes may have peeled off from the quartz reactor walls. This would indicate that some of the silicates from the quartz wall may have bonded with Fe elemental from particles. It should be noted that it is unlikely that a commercial reactor will use a quartz tube, so the observations of sticking reported in this section may only be a laboratory artefact. This may also be valid for case A. Future works are recommended to use a different inert reactor material, to remove the potential for quartz to affect the observed sticking behaviour. 

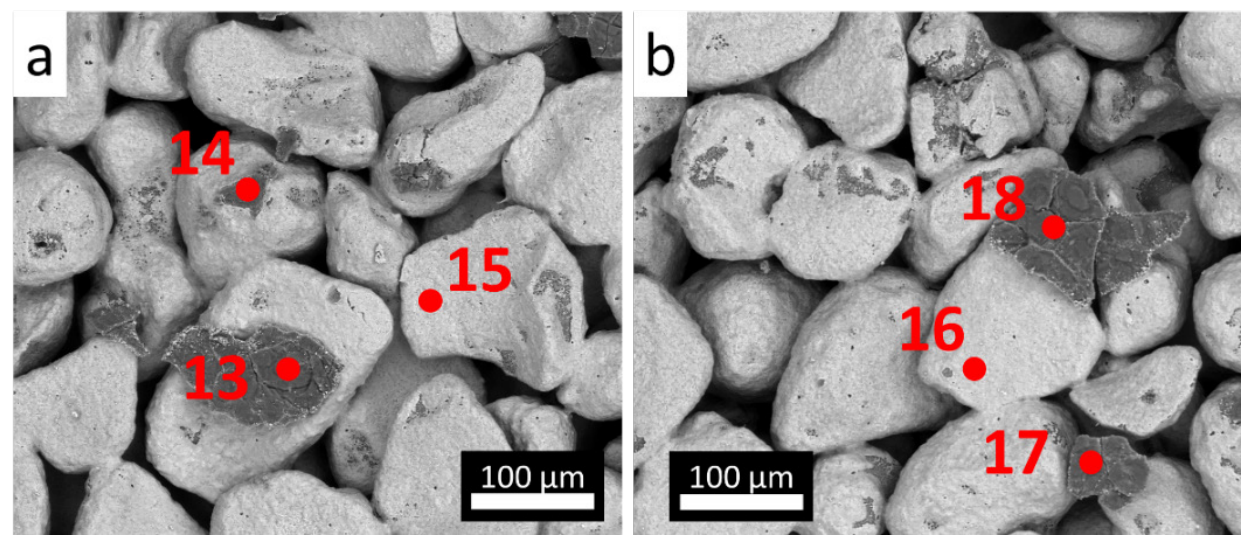

Figure 7.23 BSE-SEM micrographs for the surface morphology of particles in the sintered part (in Figure 7.22). The figure shows the sinter surface which is facing the wall. Images (a) and (b) are images taken at different locations in the sinter.

Table 7.3 Elemental spot EDS analysis of points shown in Figure 7.23. Red coloured fonts are for the dark flakes.

\begin{tabular}{ccccccc}
\hline \multirow{2}{*}{ Element } & \multicolumn{7}{c}{ Point (At. \%) } \\
\cline { 2 - 7 } & 13 & 14 & 15 & 16 & 17 & 18 \\
\hline $\mathrm{O}$ & 64.3 & 52.1 & - & - & 33.7 & 60.7 \\
$\mathrm{Mg}$ & 1.3 & 1.4 & - & - & 4.5 & - \\
$\mathrm{Al}$ & 1.3 & - & - & - & 1.6 & 0.7 \\
$\mathrm{Ti}$ & 1.4 & 0.9 & - & - & 2.5 & 1.1 \\
$\mathrm{Si}$ & 24.9 & 41.8 & - & - & 21.3 & 34.9 \\
$\mathrm{Fe}$ & 6.8 & 3.9 & 100 & 100 & 36.5 & 2.6 \\
\hline
\end{tabular}

The hyphen sign in the table means no signal for the respective element.

\subsection{Summary}

The FB reduction of NZ TTM ironsand by $100 \% \mathrm{H}_{2}$ gas at temperatures ranging from $750^{\circ} \mathrm{C}$ to $1050^{\circ} \mathrm{C}$ was demonstrated and investigated. No sticking was observed during reductions at temperatures up to $1000^{\circ} \mathrm{C}$ by using $100 \% \mathrm{H}_{2}$ gas.

The reduction rate increased with increasing temperature. The fastest reduction process was attained at $1000^{\circ} \mathrm{C}$, where a maximum \%met of $\sim 93 \%$ was achieved after 25 minutes in $5 \mathrm{~L} / \mathrm{min} \mathrm{H}_{2}$. More importantly, the data shows that the reduction reaction pathway of ironsand appears to be different at the higher and lower ends of the temperature range studied.

At high temperatures $\left(950^{\circ} \mathrm{C}\right.$ to $\left.1000^{\circ} \mathrm{C}\right)$, the early stages of the reduction reaction proceed through the initial formation of wüstite. The measured $P_{\mathrm{H} 2 \mathrm{O}}$ at the beginning of 
these reactions, is in the wüstite-stability region. In this initial stage, approximately half of the original TTM phase is converted to wüstite. Beyond this point, the reduction of TTM then stops and the reduction path switches to reducing wüstite. The XRD data shows that there is an increase of TTM lattice parameter $(\sim 0.05 \AA)$ during this initial period of wüstite generation. Together with the SEM data, this suggests that the change in reaction pathway is due to the enrichment of Ti to the TTM matrix, which acts to stabilise TTM so that wüstite reduction is preferred.

At intermediate temperatures $\left(850^{\circ} \mathrm{C}\right.$ to $\left.900^{\circ} \mathrm{C}\right)$, smaller levels of wüstite were found ( $\leq 15$ wt.\%) during the early reduction stage. This could be because the measured $P_{H 2 O}$ in the beginning of the reduction is near the Fe-FeO equilibrium line, so that the driving force to produce Fe metal increases. In this temperature range, the reduction of TTM does not stop at any point in the reduction, regardless of the formation of wüstite. The XRD data shows that the TTM lattice parameter remains approximately constant throughout the reduction process. This suggests that any Ti enrichment of the TTM matrix at these temperatures is a much smaller effect than that found at higher temperatures.

At the lowest temperatures studied $\left(750^{\circ} \mathrm{C}\right.$ to $\left.800^{\circ} \mathrm{C}\right)$, TTM appears to be reduced directly to metallic iron and ilmenite. XRD and SEM data showed no evidence of the wüstite phase throughout the reduction process. Moreover, the lattice parameter of TTM remains constant throughout the reduction process. This implies that there is no enrichment of Ti as no wüstite was formed. This is because wüstite is not stable at any point during the reduction at these temperatures. This is confirmed by the measured $P_{\mathrm{H} 2 \mathrm{O}}$ in the outlet gas, which shows that the $P_{H 2 O}$ lies below the wüstite-stability region throughout the reduction process.

The Ti-rich oxide shell is only apparent on particles reduced at high temperatures, in which wüstite is formed in the beginning of the reduction reaction. The development of this shell is likely related to the formation of wüstite during the initial reduction stage. The average thickness of the shell at the end of the reduction is found to be $\sim 4 \mu \mathrm{m}$. Interestingly, no sticking was observed during the reduction at $900^{\circ} \mathrm{C}$, even though the shell is not apparent on particles reduced at this temperature. A possible reason for this is might be that a very thin layer of Ti-oxide species is nonetheless present at the surface of the particle, and this is sufficient to prevent iron-iron contact. 
This chapter has shown that the FB reduction of ironsand by $\mathrm{H}_{2}$ gas can be conducted in $100 \% \mathrm{H}_{2}$ gas (or in an $\mathrm{Ar}-\mathrm{H}_{2}$ gas mixture) at temperatures up to $1000^{\circ} \mathrm{C}$ without sticking occurring. This appears to be an applicable regime for the reduction in the FB system. Throughout the entire experimental program for this thesis, particle sticking was observed to occur only under two specific non-optimal conditions. These were: reduction by $100 \%$ $\mathrm{H}_{2}$ gas at $1050^{\circ} \mathrm{C}$ (case A) and reduction by $7.5 \mathrm{~mol} \% \mathrm{H}_{2} \mathrm{O}-92.5 \mathrm{~mol} . \% \mathrm{H}_{2}$ at $950^{\circ} \mathrm{C}$ (case B). In both cases, sticking appeared to nucleate a sinter at the reactor wall surface, while most particles remained fluidised as loose powder. These sticking events were a significant problem for the experimental programme as they caused delays, due to the need to disassemble the reactor, remove the sintered material, and replace the reactor tube. 


\section{Chapter 8}

\section{Conclusions and Recommendations for Future Work}

\subsection{Conclusions}

The main goal of this thesis was to investigate the sticking behaviour of NZ ironsand particles during hydrogen reduction in a FB system. Unlike other conventional iron ore fines, no occurrences of the sticking phenomenon have been observed during the reduction reaction by $\mathrm{H}_{2}$ or $\mathrm{Ar}-\mathrm{H}_{2}$ gas at high temperatures of up to $1000^{\circ} \mathrm{C}$. This allows the reduction reaction to proceed rapidly to completion within 20 minutes. Particle sticking appears to be inhibited by the formation of a protective outer Ti-bearing oxide shell on each particle, which prevents iron-iron contact at the surface of each particle. This shell forms in the initial stage of the reduction and remained present throughout the reduction process.

The FB reduction experiments were carried out under various parameters: hydrogen gas concentrations, $\mathrm{H}_{2}$ gas flow rates, sample masses, particle size fractions, and temperatures. The results of experiments at a constant temperature of $950^{\circ} \mathrm{C}$ indicate that the reduction rate of TTM ironsand is controlled by the rate of $\mathrm{H}_{2}$ gas supply, which means that the reaction is under the condition of $\mathrm{H}_{2}$ gas starvation. The data in Chapter 6 shows that a minimum of 150 litres of hydrogen gas is needed to reduce $100 \mathrm{~g}$ of raw ironsand concentrate.

The results of the experiment at different temperatures show that the reduction reaction pathway is different at different temperature ranges. These results are relevant for batch operation and the experimentally accessible gas flows in the bubbling FB reactor studied here.

a. Low temperatures $\left(750^{\circ} \mathrm{C}\right.$ to $\left.800^{\circ} \mathrm{C}\right)$ :

TTM appears to be reduced directly to metallic iron and ilmenite. Wüstite is not detected at any time throughout the reduction process.

\section{b. Intermediate temperatures $\left(850^{\circ} \mathrm{C}\right.$ to $\left.900^{\circ} \mathrm{C}\right)$ :}

Some of the amount of TTM appears to be reduced to wüstite, and some is directly reduced to metallic iron. Low levels of wüstite were found ( $\leq 15 \mathrm{wt} . \%)$ in this temperature range. After that, ilmenite is formed in the final reduction stage. 


\section{c. High temperatures $\left(950^{\circ} \mathrm{C}\right.$ to $\left.1000^{\circ} \mathrm{C}\right)$ :}

High levels of wüstite are observed in this temperature range. The reduction of TTM proceeds in four distinct stages. Firstly, approximately half of the amount of TTM in the original sample is reduced to wüstite. Secondly, this wüstite is reduced to metallic iron whilst the reduction of the remaining TTM stops. Thirdly, the remaining Ti-enriched TTM is then reduced to iron and ilmenite. Finally, ilmenite is partially converted to rutile and then to pseudobrookite.

Chapter 6 and 7 have shown a wide range of operating conditions under which FB reduction of ironsand by $\mathrm{H}_{2}$ gas can be conducted without sticking occurring. However, particle sticking was observed to occur only under two non-optimal conditions. These were: reduction by $100 \% \mathrm{H}_{2}$ gas at $1050^{\circ} \mathrm{C}$ (case A) and reduction by $7.5 \mathrm{~mol} . \% \mathrm{H}_{2} \mathrm{O}-92.5 \mathrm{~mol} \%$ $\mathrm{H}_{2}$ at $950^{\circ} \mathrm{C}$ (case B). In both cases, sticking appeared to nucleate a sinter at surface of the quartz the reactor wall, while most particles remained fluidised as loose powder. The loose powder was observed to still have the Ti-oxide shells; hence these particles did not stick. The mechanism of the sticking is not clear, but it seems probable that silicate from the quartz reactor wall is reacting and bonding with Fe elemental from particles to nucleate the initial sinter.

This thesis has studied an experimental-scale FB reactor, which is necessarily much smaller than an industrial-scale reactor system. In spite of this, the study highlights that the maximum gas flow that can be delivered to any bubbling-bed reactor is limited by the entrainment velocity of ironsand in the $\mathrm{H}_{2}$ gas stream - and this is independent of the size of the reactor. This means that any bubbling-bed reactor operating at atmospheric pressure can only be operated in the 'gas starvation' regime, as trying to deliver higher gas flows will simply 'blow' the ironsand particles out of the reactor exhaust. Increasing the diameter of the reactor will proportionally increase both the achievable gas flow and bed mass by the same factor.

The experimental-scale reactor studied here also offers valuable insights into the nonsticky properties of NZ ironsand during the reduction in the FB system. However, the effect of scaling on other aspects at the industrial scale, such as heat transfer, will require further future research. 


\subsection{Recommendations for future work}

This thesis has demonstrated that the FB process works especially well to reduce NZ ironsand to a DRI powder product. However, several questions remain to be answered, including:

1. If the $\mathrm{FB}$ reduction experiment is conducted beyond the $\mathrm{H}_{2}$ gas starvation condition, what aspect of kinetics that plays an important role for the reduction reaction?

2. Why does sticking occur mainly in the area close to the reactor wall? What kind of interaction occurs at the surface between the quartz wall and ironsand particles?

3. If a different reactor wall material were used (e.g. an alternative ceramic oxide, such as alumina or silicon carbide), will it be possible to reduce ironsand particles without sticking at temperatures significantly above $1000^{\circ} \mathrm{C}$ ? What is the ultimate sticking onset temperature for ironsand particles if the wall material was completely inert?

From those questions, I would recommend future work in the following area:

1. Increasing hydrogen gas flow rate will result in entrainment of particles. Reducing the mass of ironsand would give a higher ratio of $\mathrm{H}_{2}$ gas over ironsand mass. To give enough bed height for fluidisation, ironsand can be mixed with inert material such as alumina or silicon carbide powder.

2. Experiments to examine the reaction/interaction between quartz and ironsand particle in pure hydrogen gas or in steam-hydrogen gas mixture would help answer question number 2 .

3. Design and construction of a reactor made from ceramic materials, such as alumina, silicon carbide, or boron nitride, is recommended for experiments at temperatures above $1000^{\circ} \mathrm{C}$. These experiments could help answer question number 3 .

4. This thesis has not investigated the migration of vanadium species during the reduction reaction. This is because $\alpha$ peak position of vanadium is the same with $\beta$ peak position of titanium in the EDS spectra, making it difficult to distinguish these two species. Although vanadium occurs at fairly low levels in TTM ( 0.6 wt.\% $\mathrm{V}_{2} \mathrm{O}_{5}$ equivalent), it is a high-value material ( 23 times mild steel price). It 
is recommended to carry out melting-quench experiments for reduced ironsand powder and subsequently analyse the iron melt and slag. These would confirm whether vanadium goes to the iron or slag phase (or maybe even to the crucible).

\subsection{Implications of the thesis}

Hydrogen reduction in a FB system to process ironsand makes it possible to produce DRI powder. The system studied in this thesis seems to be robust and stable at temperatures up to $1000^{\circ} \mathrm{C}$. The reaction is quite fast: about 20 minutes to reduce $100 \mathrm{~g}$ of raw ironsand concentrate. In this system, the reduction rate is controlled by the hydrogen supply rate, which means that it needs high flow rates of hydrogen gas. If new reactors designs can be produced that allow for very high hydrogen flow rates (for example as circulating beds, conical reactors, or pressurised reactors) then it may be possible to achieve even faster reaction times. This is important as it increases the total throughput of a commercial plant of fixed size.

A limitation of this thesis is that the thesis does not test multi reactors FB system. In spite of its limitation, there seems to be clear potential for the undesired 'sticking' problem to occur if water vapour is present in the incoming reducing gas, as normally operated in industrial multi-reactor cascade (counter-flow) system. More research is recommended using the condition of an industrial multi-reactor system to elucidate this.

Based on the results of this thesis, future work is now planned at the Robinson Research Institute to scale up to a bigger continuous FB reactor, aiming for a throughput of $10 \mathrm{~kg}$ ironsand per hour. 


\section{References}

Åhman, M., Nilsson, L. J. and Johansson, B. (2017) 'Global climate policy and deep decarbonization of energy-intensive industries’, Climate Policy. Taylor \& Francis, 17(5), pp. 634-649.

Anthony, J. W. et al. (2001) Handbook of Mineralogy, Mineralogical Society of America. Chantilly: Mineral Data Publishing. Available at: http://www.handbookofmineralogy.org/. Askerov, E. (2019) Economic impact of the global steel industry. Available at: https://www.worldsteel.org/media-centre/blog/2019/economic-impact-of-the-global-steelindustry.html (Accessed: 21 June 2020).

Bartels, M. et al. (2008) 'Agglomeration in fluidized beds at high temperatures: Mechanisms, detection and prevention', Progress in Energy and Combustion Science, 34(5), pp. 633-666.

Bjäreborn, O. et al. (2018) 'Phase development of titanomagnetite ironsand during oxidation conditions', in International Congress on Science and Technology in Ironmaking. Vienna, pp. 1-6.

Bosi, F., Hålenius, U. and Skogby, H. (2009) 'Crystal chemistry of the magnetiteulvöspinel series’, American Mineralogist, 94(1), pp. 181-189.

Brathwaite, R. L., Gazley, M. F. and Christie, A. B. (2017) 'Provenance of titanomagnetite in ironsands on the west coast of the North Island, New Zealand', Journal of Geochemical Exploration. Elsevier B.V., 178, pp. 23-34.

Buddington, A. F. and Lindsley, D. H. (1964) 'Iron-titanium oxide minerals and synthetic equivalents', Journal of Petrology, 5(2), pp. 310-357.

Chen, H. et al. (2017) 'Reduction of hematite $\left(\mathrm{Fe}_{2} \mathrm{O}_{3}\right)$ to metallic iron ( $\left.\mathrm{Fe}\right)$ by $\mathrm{CO}$ in a micro fluidized bed reaction analyzer: A multistep kinetics study', Powder Technology. Elsevier B.V., 316, pp. 410-420.

Climate Change Response (Zero Carbon) Amendment Act (2019). Wellington. Available at: http://www.legislation.govt.nz/act/public/2019/0061/latest/LMS183848.html (Accessed: 21 June 2020).

Dey, W. (1981) The volume and structural changes associated with the gaseous reduction of hematite. University of Surrey. 
Evans, N. (1986) 'Direct reduction at New Zealand's Glenbrook works.', Steel Times International, 10(4).

Feinman, J. (1999) 'Direct reduction and smelting processes', in Ironmaking Volume. Pittsburgh: The AISE Steel Foundation, pp. 742-780.

Geldart, D. (1973) ‘Types of gas fluidization’, Powder Technology, 7, pp. 285-292.

Glicksman, L. R. (1988) 'Scaling relationships for fluidized beds', Chemical Engineering Science, 43(6), pp. 1419-1421.

Glicksman, L. R., Hyre, M. and Woloshun, K. (1993) 'Simplified scaling relationships for fluidized beds', Powder Technology, 77(2), pp. 177-199.

Gong, X. et al. (2014) 'Insight of iron whisker sticking mechanism from iron atom diffusion and calculation of solid bridge radius', Metallurgical and Materials Transactions B, 45, pp. 2050-2056.

Gong, X. et al. (2016) 'Relationship between iron whisker growth and doping amount of oxide during $\mathrm{Fe}_{2} \mathrm{O}_{3}$ reduction', Metallurgical and Materials Transactions B. Springer US, 47(2), pp. 1137-1146.

Goodman, N. J. (2019) 'The HIsmelt technology: from Australia to China... and back again?', in Proceeding of the Iron Ore Conference 2019. The Australian Institute of Mining and Metallurgy, pp. 3-13.

Graham, D. J. and Midgley, N. G. (2000) 'Graphical representation of particle shape using triangular diagrams: an excel spreadsheet method', Earth Surface Processes and Landforms, 25, pp. 1473-1477.

Gransden, J. F. and Sheasby, J. S. (1974) 'The sticking of iron ore during reduction by hydrogen in a fluidized bed', Canadian Metallurgy Quarterly, 13(4), p. 649-657.

Grohse, E. W. (1955) ‘Analysis of gas-fluidized solid systems by x-ray absorption’, The American Institute of Chemical Engineers, 1(3), pp. 358-365.

Gudenau, H. W. et al. (1989) 'Fluidized bed reduction as the prestep of smelting reduction', Steel Research International, 60(314), pp. 138-144.

Guo, L. et al. (2015) 'Influence of different MgO Coating methods on preventing sticking during reduction of $\mathrm{Fe}_{2} \mathrm{O}_{3}$ particles in a fluidized bed', Materials Today: Proceedings. Elsevier Ltd., 2, pp. S332-S341. 
Guo, L. et al. (2016) 'Effect of coating $\mathrm{Mg}(\mathrm{OH})_{2}$ with heterogeneous deposition method on sticking during fluidized bed reduction of iron ore', ISIJ international, 56(5), pp. 736743.

Guo, L. et al. (2020) 'A review on prevention of sticking during fluidized bed reduction of fine iron ore', ISIJ International, doi: 10.2355/isijinternational.ISIJINT-2019-392.

Guo, W. Q. et al. (1999) 'Crystal structure and cation distributions in the $\mathrm{FeTi}_{2} \mathrm{O}_{5}-\mathrm{Fe}_{2} \mathrm{TiO}_{5}$ solid solution series', Journal of Physics Condensed Matter, 11(33), pp. 6337-6346.

Habermann, A. et al. (2000) 'An experimental study on the kinetics of fluidized bed iron ore reduction', ISIJ International, 40(10), pp. 935-942.

Hayashi, S. and Iguchi, Y. (1992) 'Factors affecting the sticking of fine iron ores during fluidized bed reduction.', ISIJ International, 32(9), pp. 962-971.

Hayashi, S., Sawai, S. and Iguchi, Y. (1993) 'Influence of coating oxide and bed reduction of Iron sulfur ores’, ISIJ International, 33(10), pp. 1078-1087.

Hayashi, S., Sayama, S. and Iguchi, Y. (1990) 'Relation between sulfur pressure and sticking of fine lron ores in fluidized bed reduction.', ISIJ International, 30(9), pp. 722730.

Hilman, P. M. et al. (2014) Pasir Besi di Indonesia. Ministry of Energy and Minreal Resources of Indonesia, Bandung. (in Bahasa Indonesia)

Hu, T. U. et al. (2013) 'Reduction behavior of panzhihua titanomagnetite concentrates with coal', Metallurgical and Materials Transactions B, 44, pp. 252-260.

Inoue, O., Itoh, S. and Azakami, T. (1998) 'Phase relations and equilibrium oxygen partial pressures in the iron-titanium-oxygen system at 1373 K', Materials Transactions, Journal of the Japan Institute of Metals, 39(3), pp. 391-398.

International Energy Agency (2020) Tracking Industry 2020. Paris. Available at: https://www.iea.org/reports/tracking-industry-2020 (Accessed: 21 June 2020).

International standard ISO 16878:2016, 'Iron ores - Determination of metallic iron content - Iron (III) chloride titrimetric method'.

International standard ISO 2597-1:2006, 'Iron ores - Determination of total iron content Part 1: Titrimetric method after tin(II) chloride reduction.

Kaushik, P. and Fruehan, R. J. (2006) 'Behavior of direct reduced iron and hot briquetted 
iron in the upper blast furnace shaft: Part I. Fundamentals of kinetics and mechanism of oxidation', Metallurgical and Materials Transactions B, 37(5), pp. 715-725.

Komatina, M. and Gudenau, H. (2004) 'The sticking problem during direct reduction of fine iron ore in the fluidized bed', Metalurgija, 10, pp. 310-328.

König, U., Gobbo, L. and Reiss, C. (2012) 'Quantitative XRD for ore, sinter, and slag characterization in the steel industry', in Proceeding of the 10th International Congress for Applied Mineralogy (ICAM), pp. 385-393.

Kubaschewski, O., Alcock, C. B. and Spencer, P. J. (1993) Materials Thermochemistry. 6th Editio. Oxford: Pergamon Press.

Kunii, D. and Levenspiel, O. (1977) Fluidization Engineering. New York: Robert E. Krieger Publishing Co. Inc., pp 1-103.

Lei, C. et al. (2014) 'Influence of content and microstructure of deposited carbon on fluidization behavior of iron powder at elevated temperatures', ISIJ International, 54(3), pp. 589-595.

Lei, C. et al. (2015) 'Optimization of carbon deposition process during the pre-reduction of fine iron ore in a fluidized bed', Powder Technology. Elsevier B.V., 296, pp. 79-86. d Litz, W. J. (1972) 'Design of gas distributors', Chemical Engineering, 13, pp. 162-166. Longbottom, R. J. et al. (2018) 'In situ neutron diffraction study of the reduction of New Zealand ironsands in dilute hydrogen mixtures', Mineral Processing and Extractive Metallurgy. Taylor \& Francis. doi: 10.1080/03719553.2017.1412877

Longbottom, R. J., Ostrovski, O. and Park, E. (2006) 'Formation of cementite from titanomagnetite ore', ISIJ International, 46(5), pp. 641-646.

McAdam, G. D. (1974) 'Instability of ironsands in reducing gases', Ironmaking and Steelmaking (Quarterly), 3, pp. 138-150.

McAdam, G. D., Dall, R. E. A. and Marshall, T. (1969) 'Direct reduction of new zealand ironsand concentrates', New Zealand Journal of Science, 12(4), pp. 649-668.

McCammon, C. A. (1992) 'Magnetic properties of $\mathrm{Fe}_{\mathrm{x}} \mathrm{O}(\mathrm{x}>0.95)$ : Variation of Néel temperature', Journal of Magnetism and Magnetic Materials, 104-107(Part 3), pp. 19371938.

Ministry for the Environment of New Zealand (2020) New Zealand's Greenhouse Gas 
Inventory.

Wellington.

Available

at:

https://www.mfe.govt.nz/sites/default/files/media/Climate\%20Change/new-zealandsgreenhouse-gas-inventory-1990-2018-vol-1.pdf (Accessed: 21 June 2020).

Miyagawa, K., Kamijo, T. and Deguchi, M. (1992) 'Sticking and its prevention in fluidized bed reduction of iron ores', Journal of The Iron and Steel Institute of Japan, 782(7), pp. 1258-1265. (in Japanese)

Momma, K. and Izumi, F. (2011) 'VESTA 3 for three-dimensional visualization of crystal, volumetric and morphology data', Journal of Applied Crystallography, 44(6), pp. 12721276.

Neuschütz, D. (1991) 'Sticking prevention during fine-ore metallization in two-stage smelting-reduction processes’, Steel Research International, 62(8), pp. 333-337.

New Zealand Steel. The History of Ironsand. Available at: https://www.nzsteel.co.nz/newzealand-steel/the-story-of-steel/the-history-of-ironsand/ (Accessed: 21 June 2020).

New Zealand Steel. The Ironmaking Process. Available at: https://www.nzsteel.co.nz/newzealand-steel/the-story-of-steel/the-science-of-steel/the-ironmaking-process/ (Accessed: 21 June 2020).

New Zealand Steel. The Mining Operation. Available at: https://www.nzsteel.co.nz/sustainability/the-mining-operation/ (Accessed: 21 June 2020). Nicolle, R. and Rist, A. (1979) 'The mechanism of whisker growth in the reduction of wüstite’, Metallurgical Transactions B, 10(3), pp. 429-438.

Nuber, D., Eichberger, H. and Rollinger, B. (2006) 'Circored fine ore direct reduction', Millenium steel 2006. Available at: http://millennium-steel.com/wpcontent/uploads/articles/pdf/2006/pp37-40 MS06.pdf.

Okamura, A. et al. (1995) 'Mössbauer study of the impurity effect of $\mathrm{In}^{3+}$ and $\mathrm{Cr}^{3+}$ in the high temperature phase of $\mathrm{Fe}_{3} \mathrm{O}_{4}$ ', Journal of the Physical Society of Japan, 64(9), pp. 3484-3495.

Okube, M. et al. (2018) 'Site occupancy of $\mathrm{Fe}^{2+}, \mathrm{Fe}^{3+}$ and $\mathrm{Ti}^{4+}$ in titanomagnetite determined by valence-difference contrast in synchrotron X-ray resonant scattering', Journal of Synchrotron Radiation, 25(6), pp. 1694-1702.

Park, E. (2002) Gaseous reduction of Titanomagnetite Ironsand. University of New South 
Wales.

Park, E. et al. (2004) 'Reduction of the mixture of titanomagnetite ironsand and hematite iron ore fines by carbon monoxide’, ISIJ International, 44(1), pp. 214-218.

Park, E. and Ostrovski, O. (2003) 'Reduction of titania-ferrous ore by carbon monoxide', ISIJ International, 44(9), pp. 1316-1325.

Park, E. and Ostrovski, O. (2004a) 'Effects of preoxidation of titania-ferrous ore on the ore structure and reduction behavior', 44(1), pp. 74-81.

Park, E. and Ostrovski, O. (2004b) 'Reduction of titania-ferrous ore by hydrogen’, ISIJ International, 44(6), pp. 999-1005.

Pearce, C. I. et al. (2012) 'Synthesis and properties of titanomagnetite $\left(\mathrm{Fe}_{3-\mathrm{x}} \mathrm{Ti}_{\mathrm{x}} \mathrm{O}_{4}\right)$ nanoparticles : A tunable solid-state Fe (II/III) redox system', Journal of Colloid And Interface Science. Elsevier Inc., 387(1), pp. 24-38.

Pichler, A. et al. (2016) 'Reduction behavior and structural evolution of iron ores in fluidized bed technologies - Part 2: characterization and evaluation of worldwide traded fine iron ore brands', Steel Research International, 87(5), pp. 642-652.

Plaul, F. J., Böhm, C. and Schenk, J. L. (2009) 'Fluidized-bed technology for the production of iron products for steelmaking', Journal of the Southern African Institute of Mining and Metallurgy, 109(2), pp. 121-128.

Prabowo, S. W. et al. (2019a) 'Sticking-free reduction of titanomagnetite ironsand in a fluidized bed reactor', Metallurgical and Materials Transactions B. Springer US, 50(4), pp. 1729-1744.

Prabowo, S. W. et al. (2019b) 'Development of an experimental fluidised bed reactor for the processing of New Zealand titanomagnetite ironsand', in Proceeding of the Iron Ore Conference 2019. The Australian Institute of Mining and Metallurgy, pp. 456-463.

Richards, J. C. W. et al. (1973) 'A magnetic study of titanomagnetite substituted by magnesium and aluminium', Physics of the Earth and Planetary Interiors, 7(4), pp. 437444.

Ross, H. U. (1980) 'Physical Chemistry', in Azar, R. K., Breid, S. K., and Stueber, C. M. (eds) Direct Reduced Iron-Technology and Economics of Production and Use. 1st Editio. Warrendale: The Iron and Steel Society of AIME, pp. 9-34. 
Schenk, J. L. (2011) 'Recent status of fluidized bed technologies for producing iron input materials for steelmaking', Particuology. Chinese Society of Particuology, 9(1), pp. 1423.

Shannon, W., Kitt, W. and Marshall, T. (1960) 'Experimental fluidized-bed reduction of new zealand ironsands', New Zealand Journal of Science, 3, pp. 74-90.

Shao, J., Guo, Z. and Tang, H. (2011) 'Influence of temperature on sticking behavior of iron powder in fluidized bed', ISIJ International, 51(8), pp. 1290-1295.

Shao, J., Guo, Z. and Tang, H. (2013) 'Effect of coating MgO on sticking behavior during reduction of iron ore concentrate fines in fluidized bed', Steel Research International, 84(2), pp. 111-118.

Skorianz, M. (2012) Classification of iron ores regarding their reduction behavior in fluidized bed technologies. Montanuniversitaet Leoben.

Spanlang, A., Wukovits, W. and Weiss, B. (2016) 'Development of a blast furnace model with thermodynamic process depiction by means of the Rist operating diagram', Chemical Engineering Transactions, 52(February 2018), pp. 973-978.

Spreitzer, D. and Schenk, J. (2019a) 'Iron ore reduction by hydrogen using a laboratory scale fluidized bed reactor: Kinetic investigation-experimental setup and method for determination', Metallurgical and Materials Transactions B. Springer US, 2. doi: 10.1007/s11663-019-01650-9.

Spreitzer, D. and Schenk, J. (2019b) 'Reduction of iron oxides with hydrogen—a review', Steel Research International. doi: 10.1002/srin.201900108.

SSAB, LKAB and Vattenfall HYBRIT - Towards fossil-free steel. Available at: http://www.hybritdevelopment.com/hybrit-toward-fossil-free-steel (Accessed: 21 June 2020).

Sun, H. et al. (2013) 'Reduction mechanism of titanomagnetite concentrate by hydrogen', International Journal of Mineral Processing. Elsevier B.V., 125, pp. 122-128.

Sun, H. et al. (2016) 'Direct reduction behaviors of titanomagnetite ore by carbon monoxide in fluidized bed', ISIJ International, 56(6), pp. 936-943.

Sun, H. et al. (2017) 'Effects of high-temperature pre-oxidation on the titanomagnetite ore structure and reduction behaviors in a fluidized bed', Metallurgical and Materials 
Transactions B. Springer US, 48(3), pp. 1898-1907.

Tanaka, H. and Kono, M. (1987) 'Mossbauer spectra of titanomagnetite: a reappraisal', Journal of geomagnetism and geoelectricity, 39, pp. 463-475.

Ünal, A. and Bradshaw, A. V. (1983) 'Rate processes and structural changes in gaseous reduction of hematite particles to magnetite', Metallurgical and Materials Transactions B. Springer US, 14, pp. 743-752.

Vogl, V., Åhman, M. and Nilsson, L. J. (2018) 'Assessment of hydrogen direct reduction for fossil-free steelmaking', Journal of Cleaner Production. Elsevier Ltd, 203, pp. 736745.

Wang, Z. et al. (2016) 'Behavior of new zealand ironsand during iron ore sintering', Metallurgical and Materials Transactions B. Springer US, 47(1), pp. 330-343.

Wang, Z., Zhang, J., Jiao, K., et al. (2017) 'Effect of pre-oxidation on the kinetics of reduction of ironsand', Journal of Alloys and Compounds. Elsevier B.V, 729, pp. 874-883. Wang, Z., Zhang, J., Ma, J., et al. (2017) 'Gaseous reduction of titania-ferrous solution ore by $\mathrm{H}_{2}$-Ar Mixture', ISIJ International, 57(3), pp. 443-452.

Wang, Z. et al. (2018) 'Formation of multiple microstructures during the reduction of ironsand', The Journal of The Minerals, Metals \& Materials Society (TMS). Springer US, 71(5), pp. 1776-1784.

Watanabe, R. et al. (1986) 'Gasification and reduction of iron ore coated with carbon by use of a batch type fluidized bed reactor', Journal of The Iron and Steel Institute of Japan, 3, pp. 1279-1286. (in Japanese)

Wechsler, B. A., Lindsley, D. H. and Charles T. Prewitt (1984) 'Crystal structure and cation distribution in titanomagnetites $\left(\mathrm{Fe}_{3-\mathrm{x}} \mathrm{Ti}_{\mathrm{x}} \mathrm{O}_{4}\right)^{\prime}$, American Mineralogist, 69, pp. 754-770.

Wechsler, B. A. and Prewitt, C. T. (1984) 'Crystal structure of ilmenite $\left(\mathrm{FeTiO}_{3}\right)$ at high temperature and high pressure', American Mineralogist, 69, pp. 176-185.

Weiss, B. et al. (2010) 'Experimental and morphological investigations of the reduction from coarse hematite to magnetite and wustite under fluidized bed conditions', Steel Research International, 81(2), pp. 93-99.

Weiss, B. et al. (2011) 'Structural and morphological changes during reduction of hematite to magnetite and wustite in hydrogen rich reduction gases under fluidised bed conditions', 
Ironmaking \& Steelmaking, 38(1), pp. 65-73.

Wen, C. Y. and Yu, Y. H. (1966) 'A generalized method for predicting the minimum fluidization velocity', AIChE Journal, 12(3), pp. 610-612.

Werther, J. and Hartge, E. U. (2003) 'Elutriation and entrainment', in Yang, W. C. (ed.) Handbook of Fluidization and Fluid-particle System. New York: Marcel Dekker, Inc., pp. 113-128.

Wong, P. L. M. et al. (1999) 'Sticking behaviour in direct reduction of iron ore', Ironmaking and Steelmaking, 26(1), pp. 53-57.

Worldsteel (2019) Fact sheet - steel and raw materials. Brussels. Available at: https://www.worldsteel.org/en/dam/jcr:16ad9bcd-dbf5-449f-b42c-

b220952767bf/fact_raw\%2520materials_2019.pdf (Accessed: 20 June 2020).

Worldsteel (2020) Global crude steel output increases by 3.4\% in 2019. Available at: https://www.worldsteel.org/media-centre/press-releases/2020/Global-crude-steel-outputincreases-by-3.4--in-2019.html (Accessed: 21 June 2020).

Wright, J. B. (1964) 'Iron-titanium oxides in some New Zealand ironsands', New Zealand Journal of Geology and Geophysics, 7(3), pp. 424-444.

Wright, J. B. and Lovering, J. F. (1965) 'Electron-probe microanalysis of iron-titanium oxides in some New Zealand ironsands’, Mineralogy Magazine, 35(272), pp. 604-621.

Yang, W. C. (2003) 'Bubbling fluidized beds', in in Yang, W. C. (ed.) Handbook of Fluidization and Fluid-particle System. 1st edn. New York: Marcel Dekker, Inc., pp. 53111.

Yi, L. Y. et al. (2014) 'Sticking of iron ore pellets in direct reduction with hydrogen and carbon monoxide: Behavior and prevention', Journal of Central South University, 21(2), pp. 506-510.

Yi, S.-H., Cho, M.-Y. and Yi, J.-G. (2018) 'Footprints for the future of commercial finex plants', in 8th International Congress on Science and Technology of Ironmaking-ICSTI 2018. Vienna, pp. 1-6 (paper 234).

Yong-qi, L., Han-jie, G. and Lin, L. (2015) 'Hydrogen reduction mechanism of indonesia ironsands oxidized pellet', Chinese Journal of Engineering, 37(2), pp. 157-162.

Zhang, A. et al. (2020) 'Reduction kinetics of oxidized New Zealand Ironsand pellets in 
$\mathrm{H}_{2}$ at temperatures up to 1443 K', Metallurgical and Materials Transactions B. Springer US, 51(2), pp. 492-504.

Zhang, B. et al. (2011) 'Relation between sticking and metallic iron precipitation on the surface of $\mathrm{Fe}_{2} \mathrm{O}_{3}$ particles reduced by $\mathrm{CO}$ in the fluidized bed', ISIJ International, 51(9), pp. 1403-1409.

Zhang, B. et al. (2012) 'A comparative study of influence of fluidized conditions on sticking time during reduction of $\mathrm{Fe}_{2} \mathrm{O}_{3}$ particles with CO', Powder Technology. Elsevier B.V., 225, pp. 1-6.

Zhang, B. et al. (2013) 'Characterization of precipitated carbon by XPS and its prevention mechanism of sticking during reduction of $\mathrm{Fe}_{2} \mathrm{O}_{3}$ particles in the fluidized bed', ISIJ International, 53(3), pp. 411-418.

Zhang, T., Lei, C. and Zhu, Q. (2014) 'Reduction of fine iron ore via a two-step fluidized bed direct reduction process', Powder Technology. Elsevier B.V., 254, pp. 1-11.

Zhong, Y.-W. et al. (2011) 'Sticking behavior caused by sintering in gas fluidisation reduction of haematite', Ironmaking \& Steelmaking, 39(1), pp. 38-44.

Zhong, Y. et al. (2013) 'Prevention of agglomeration/defluidization in fluidized bed reduction of $\mathrm{Fe}_{2} \mathrm{O}_{3}$ by CO: The role of magnesium and calcium oxide', Powder Technology. Elsevier B.V., 241, pp. 142-148. 


\section{Appendix A}

\section{In-situ Calibration of the Humidity Sensor}

The in-situ calibration of the humidity sensor was conducted using the experimental set-up in Figure 3.11. This calibration is to compare the measured $T_{d}$ values by the sensor to known $T_{d}$ values under a series of tests. For this purpose, predefined gas-water mixtures were introduced to the reactor with a composition between 5 to 50 mol.\% of water. At low pressures and high temperatures, such as the condition in the current reactor, steam is approaching the ideal gas condition. Therefore, the mol.\% of water can be assumed to be the same as the partial pressure of $\mathrm{H}_{2} \mathrm{O}\left(P_{H 2 O}\right)$. The known $T_{d}$ values were calculated from equation (3.3) from the predefined $P_{\mathrm{H} 2 \mathrm{O}}$.

To tests the reproducibility of the humidity reading, a series of calibration tests were carried out in different gases, flow rates, and mol.\% ratios of water. If the reading is reproducible, the $T_{d}$ value reading by the sensor should be nearly consistent for different gas or flow rate with the same mol.\% of water in the gas mixture.

The series of tests were carried out in two different gases: $\mathrm{N}_{2}-\mathrm{H}_{2} \mathrm{O}$ and $\mathrm{H}_{2}-\mathrm{H}_{2} \mathrm{O}$ gas mixtures. For each gas, three different flow rates $\left(\mathrm{N}_{2}\right.$ or $\left.\mathrm{H}_{2}\right)$ were delivered for one set of tests: 3 , 3.5, and $4 \mathrm{l} / \mathrm{min}$. In one set, the gas was delivered at a fixed flow rate, but water was delivered at different flow rates so that the mol.\% of water varied between 5 to 50 mol.\%. These ranges of gas flow rate and $\mathrm{H}_{2} \mathrm{O}$ mol.\% are expected to be the range for the reduction study of ironsand. Table A.1 presents the composition of $\mathrm{N}_{2}$-water and $\mathrm{H}_{2}$-water for all set of tests. For all tests, the temperature of the main reactor and Furnace 1 (the steam generator in Figure 3.11) were maintained at $700^{\circ} \mathrm{C}$ and $350^{\circ} \mathrm{C}$, respectively. In addition to these, all gas lines for steam were heated by heating tape to $\geq 120^{\circ} \mathrm{C}$. The temperature in the 'humidity chamber' measured for all tests were between $120^{\circ} \mathrm{C}$ to $135^{\circ} \mathrm{C}$. 
Table A. 1 composition of $\mathrm{N}_{2}$-water and $\mathrm{H}_{2}$-water delivered for different mol.\% water ratios. The water flow rates delivered for $\mathrm{N}_{2}$-water are the same for $\mathrm{H}_{2}$-water mixture with the same mol.\% of water.

\begin{tabular}{|c|c|c|c|c|}
\hline \multirow[b]{2}{*}{$\begin{array}{c}\text { mol.\% } \\
\text { water (\%) }\end{array}$} & \multicolumn{2}{|c|}{$\mathrm{N}_{2}$-water mixture } & \multicolumn{2}{|c|}{$\mathrm{H}_{2}$-water mixture } \\
\hline & $\begin{array}{c}\mathrm{N}_{2} \text { flow } \\
\text { rate (l/min) }\end{array}$ & $\begin{array}{l}\text { Water flow } \\
\text { rate }(\mathrm{ml} / \mathrm{min}\end{array}$ & $\begin{array}{c}\mathrm{H}_{2} \text { flow } \\
\text { rate }(\mathrm{l} / \mathrm{min})\end{array}$ & $\begin{array}{l}\text { Water flow } \\
\text { rate } \\
\text { (ml/min) }\end{array}$ \\
\hline 5 & 4 & 0.2 & 4 & 0.2 \\
\hline 10 & 4 & 0.3 & 4 & 0.3 \\
\hline 15 & 4 & 0.5 & 4 & 0.5 \\
\hline 20 & 4 & 0.7 & 4 & 0.7 \\
\hline 25 & 4 & 1.0 & 4 & 1.0 \\
\hline 30 & 4 & 1.3 & 4 & 1.3 \\
\hline 35 & 4 & 1.6 & 4 & 1.6 \\
\hline 40 & 4 & 2.0 & 4 & 2.0 \\
\hline 45 & 4 & 2.4 & 4 & 2.4 \\
\hline 50 & 4 & 3.0 & 4 & 3.0 \\
\hline 5 & 3.5 & 0.2 & 3.5 & 0.2 \\
\hline 10 & 3.5 & 0.3 & 3.5 & 0.3 \\
\hline 15 & 3.5 & 0.5 & 3.5 & 0.5 \\
\hline 20 & 3.5 & 0.7 & 3.5 & 0.7 \\
\hline 25 & 3.5 & 0.9 & 3.5 & 0.9 \\
\hline 30 & 3.5 & 1.1 & 3.5 & 1.1 \\
\hline 35 & 3.5 & 1.4 & 3.5 & 1.4 \\
\hline 40 & 3.5 & 1.7 & 3.5 & 1.7 \\
\hline 45 & 3.5 & 2.1 & 3.5 & 2.1 \\
\hline 50 & 3.5 & 2.6 & 3.5 & 2.6 \\
\hline 5 & 3 & 0.1 & 3 & 0.1 \\
\hline 10 & 3 & 0.3 & 3 & 0.3 \\
\hline 15 & 3 & 0.4 & 3 & 0.4 \\
\hline 20 & 3 & 0.6 & 3 & 0.6 \\
\hline 25 & 3 & 0.7 & 3 & 0.7 \\
\hline 30 & 3 & 0.9 & 3 & 0.9 \\
\hline 35 & 3 & 1.2 & 3 & 1.2 \\
\hline 40 & 3 & 1.5 & 3 & 1.5 \\
\hline 45 & 3 & 1.8 & 3 & 1.8 \\
\hline 50 & 3 & 2.2 & 3 & 2.2 \\
\hline
\end{tabular}


Figure A.1(a) and (c) show the profile of gas and water flow rate in $\mathrm{N}_{2}$-water mixture and $\mathrm{H}_{2}$-water mixture, respectively. Figure A-1(b) and (d) shows the resulted $T_{d}$ measured for different gas and water flow rate delivered in $\mathrm{N}_{2}$-water mixture and $\mathrm{H}_{2}$-water mixture, respectively. It can be seen from the figure that the $T_{d}$ values in both $\mathrm{N}_{2}$-water mixture and $\mathrm{H}_{2}$-water mixture are broadly consistent for all gas mixtures with the same mol.\% water ratio. Moreover, the $T_{d}$ quickly changes as the water flow rate changes as can be seen from the steps in Figure A-1(b) and (d). This indicates that the sensor response to moisture changes is relatively fast. The delay of the sensor response is observed to be within 15 seconds. At low water flow rates (about $0.2 \mathrm{ml} / \mathrm{min}$ ), a lot of noises appear for the $T_{d}$ reading. This was because discrete water drops were being vaporized, so the steam flow was not steady.

From Figure A.1, we know that the resulted $T_{d}$ values are broadly the same for $\mathrm{N}_{2}$ $\mathrm{H}_{2} \mathrm{O}$ mixture and $\mathrm{H}_{2}-\mathrm{H}_{2} \mathrm{O}$ mixture. Figure A.2 plots the comparison between true $T_{d}$ values versus $T_{d}$ measured by the sensor in $\mathrm{H}_{2}-\mathrm{H}_{2} \mathrm{O}$ mixtures. The figure shows the calibration plot for three different $\mathrm{H}_{2}$ flow rates. Here it can be seen that the $T_{d}$ measured by the sensor is linear to the true $T_{d}$ values for all gas flow rates measured, with the three plots show the linearity between 0.997 to 0.999 . The equation from the linear regression analysis is used for converting the measured $T_{d}$ value to the actual $T_{d}$ value. The converted $T_{d}$ value s are then used to calculate $P_{H 2 O}$ according to equation (3.3). 


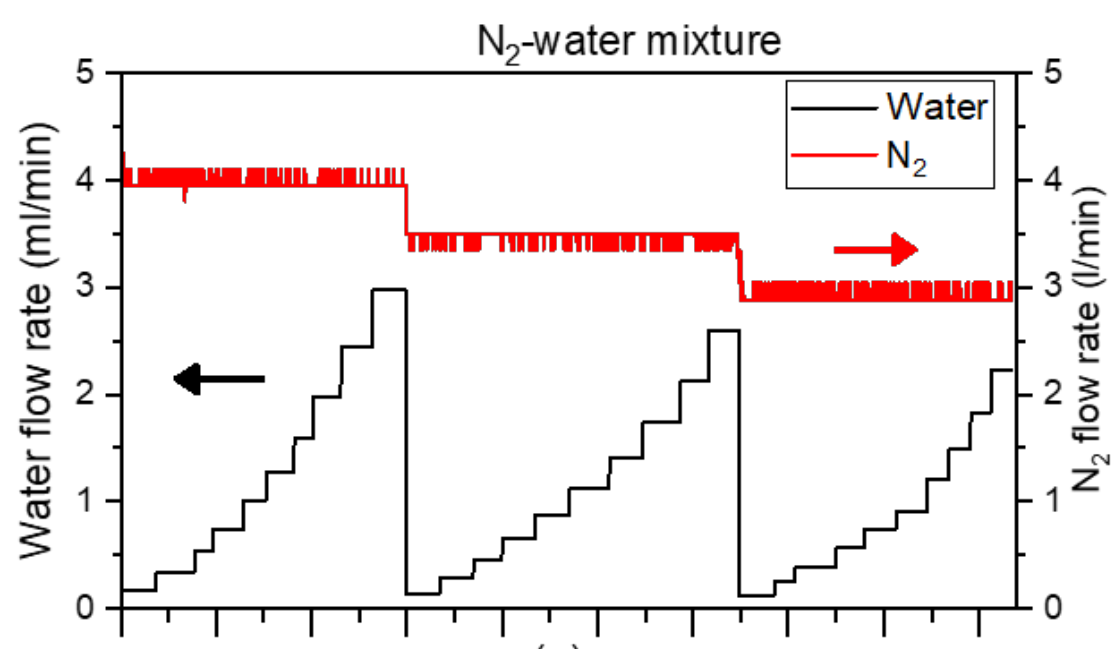

(a)

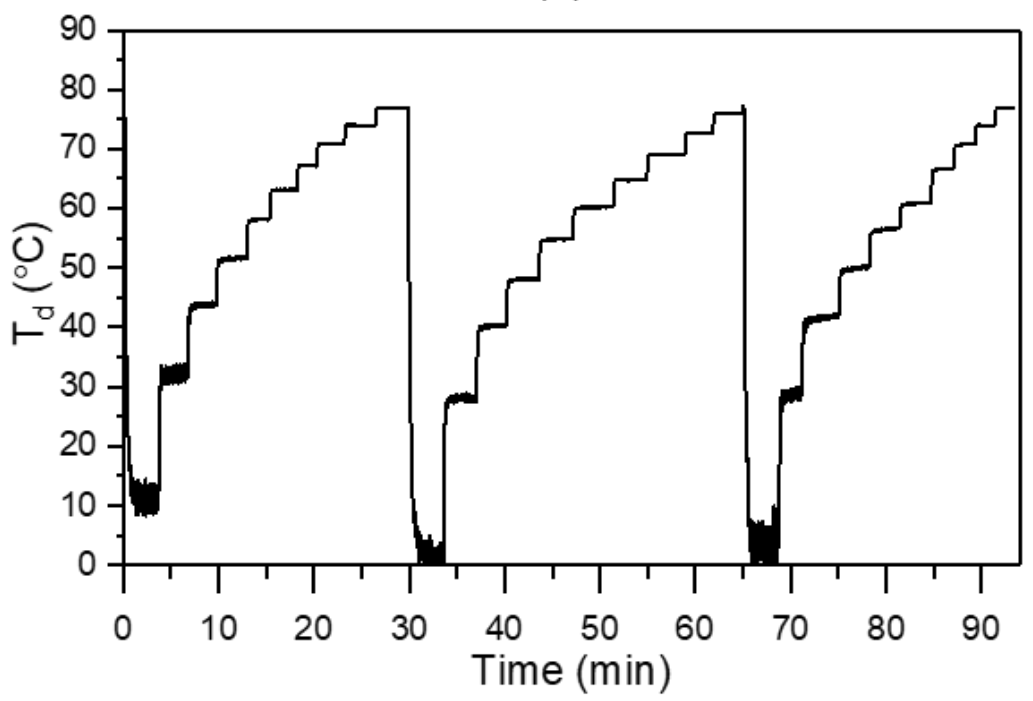

(b)

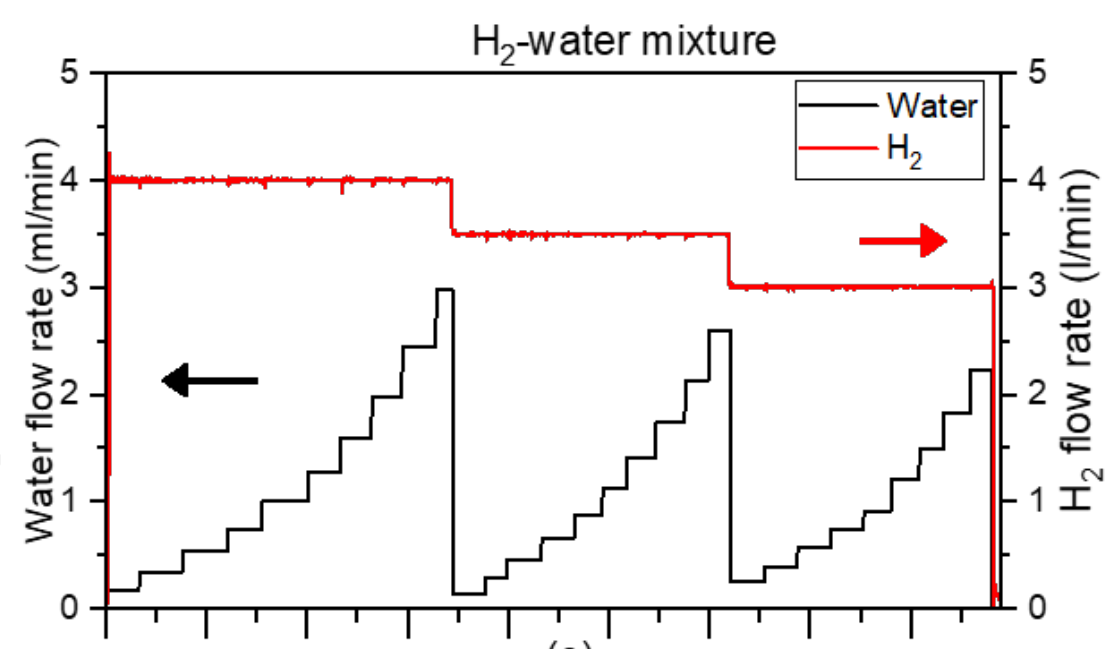

(c)

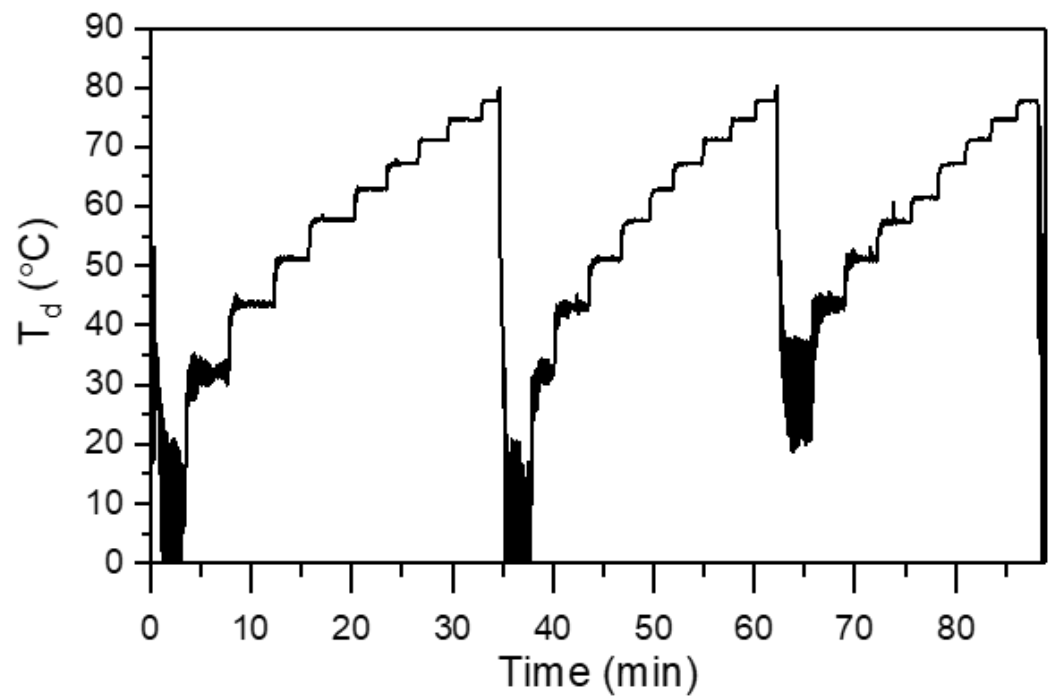

(d)

Figure A.1 Resulted $T_{d}$ measured for different gas and water flow rate in $\mathrm{N}_{2}$-water mixture and $\mathrm{H}_{2}$-water mixture. (a) profile of $\mathrm{N}_{2}$ gas and water flow rate. (b) $\mathrm{T}_{d}$ measured in $\mathrm{N}_{2}$-water mixture. (c) profile of $\mathrm{H}_{2}$ gas and water flow rate. (b) $\mathrm{T}_{d}$ measured in $\mathrm{H}_{2}$-water mixture. 


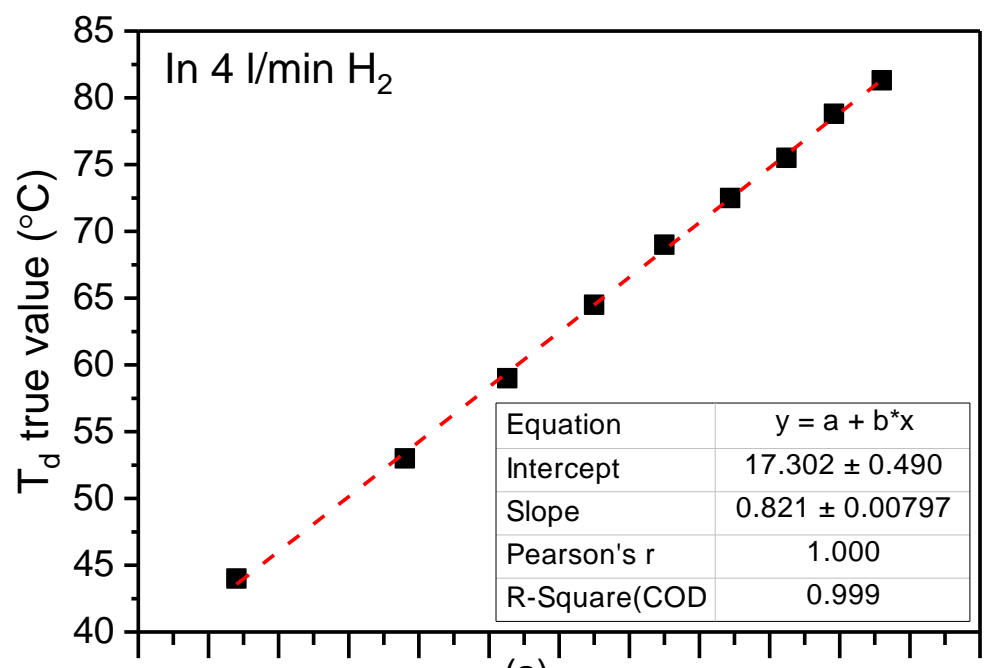

(a)

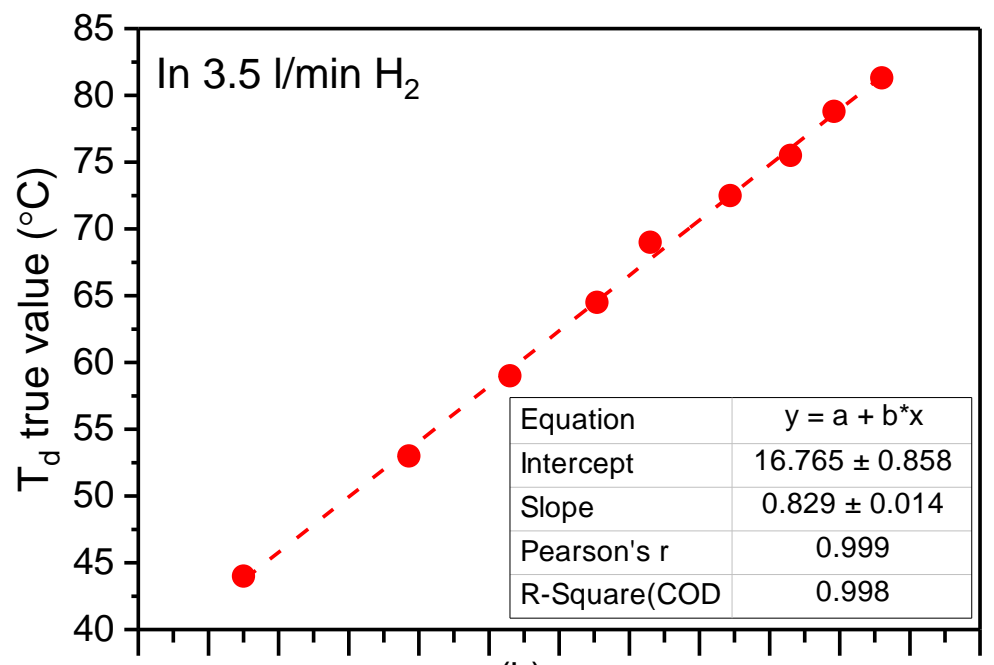

(b)

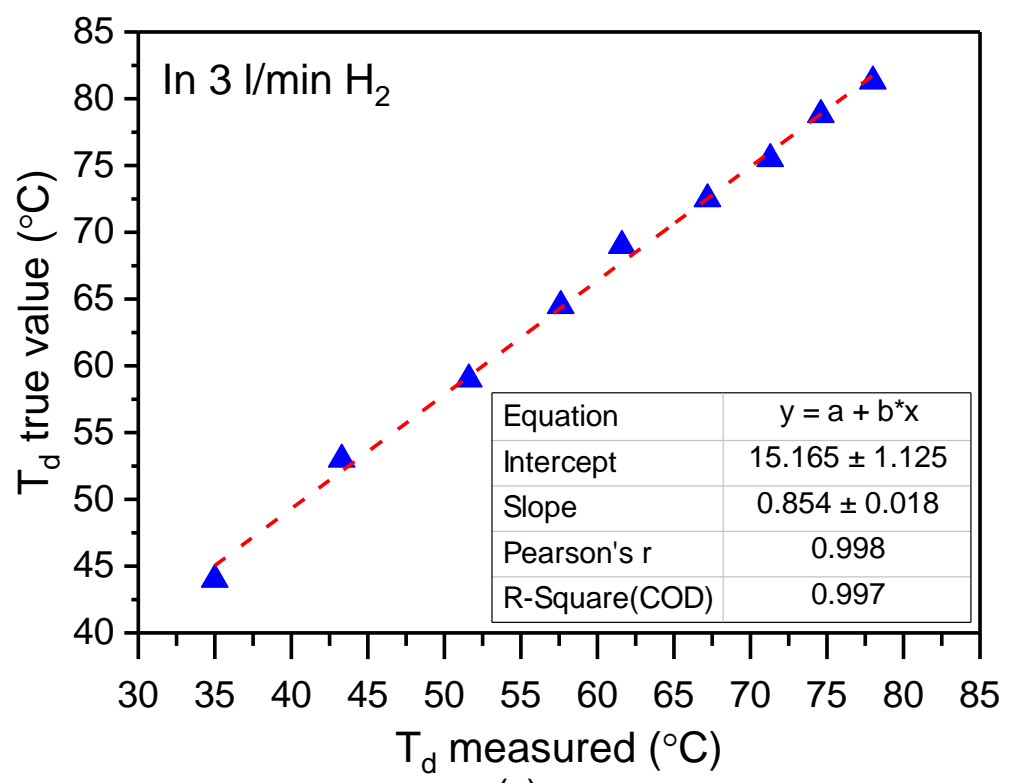

(c)

Figure A.2 Calibration plot of true $T_{d}$ values versus $T_{d}$ measured by the sensor for three different $\mathrm{H}_{2}$ gas flow rate. (a) in $4 \mathrm{l} / \mathrm{min} \mathrm{H}_{2}$. (b) in $3.5 \mathrm{l} / \mathrm{min} \mathrm{H}_{2}$. (c) in $3 \mathrm{l} / \mathrm{min} \mathrm{H}_{2}$. 


\section{Appendix B}

\section{Additional SEM Images for Chapter 6}

\section{B.1 SEM images of the particle reduced by 30 vol. $\% \mathrm{Ar}-70 \mathrm{vol.} \% \mathrm{H}_{2}$ at}

\section{$950^{\circ} \mathrm{C}$ - Section 6.6}

Figures presented here were taken from the published conference paper in Prabowo et al. (2019b). These are reproduced with permission of The Australian Institute of Mining and Metallurgy.
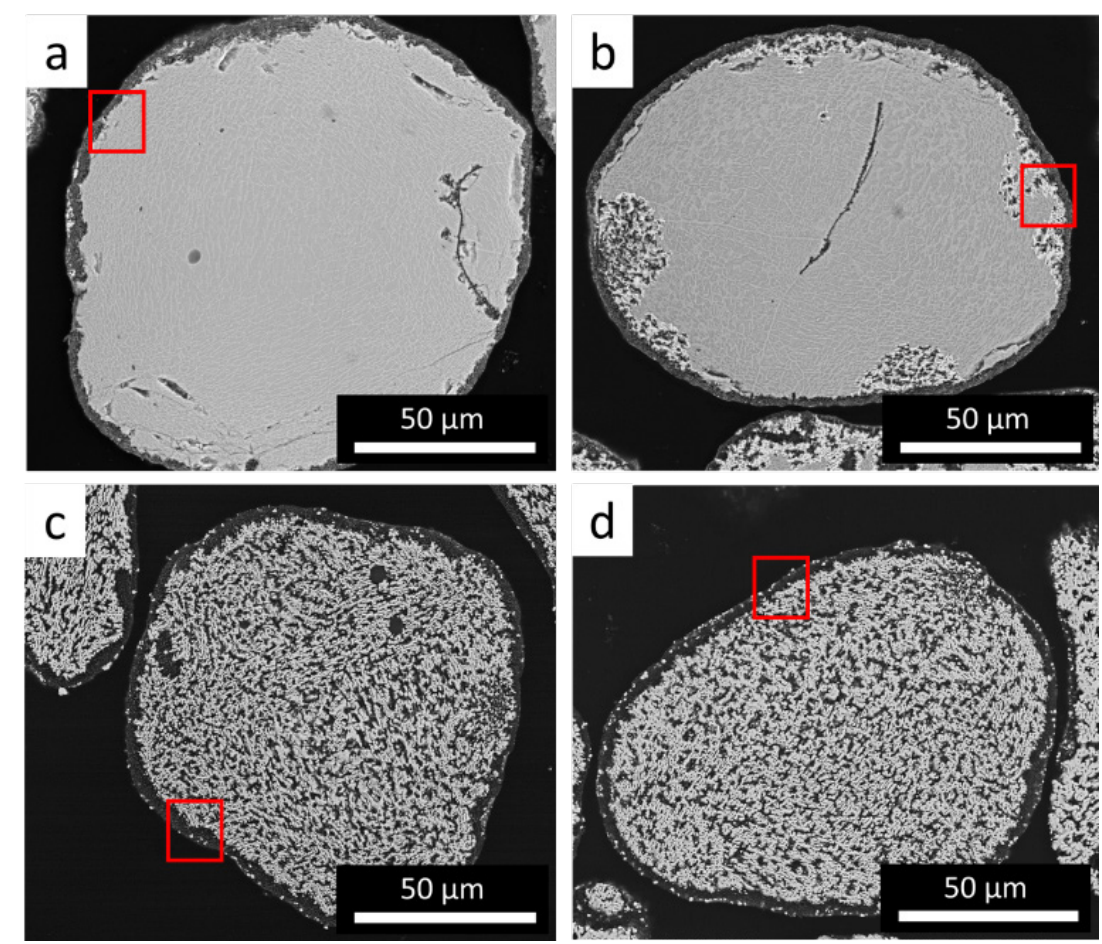

Figure B.1 BSE-SEM image of the ironsand particle during the reduction by $30 \mathrm{vol. \%} \mathrm{Ar}$

- 70 vol.\% $\mathrm{H}_{2}$ at $950^{\circ} \mathrm{C}$ : (a) 5 minutes, (b) 10 minutes, (c) 30 minutes, and (d) 60 minutes.

Red markers indicate the location of magnified image in Figure B.2. 

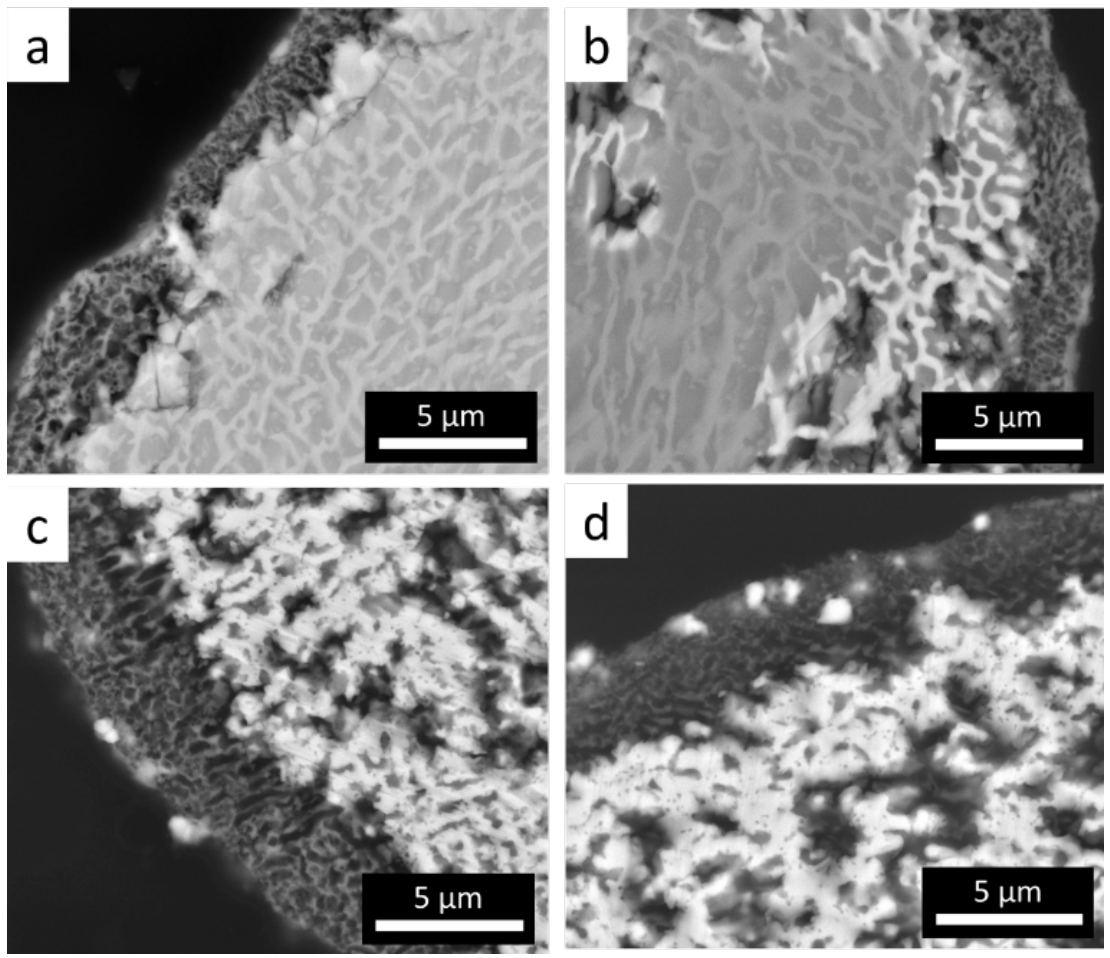

Figure B.2 High magnification BSE-SEM images of ironsand particle (from Figure B.1) during the reduction by 30 vol.\% $\mathrm{Ar}-70$ vol.\% $\mathrm{H}_{2}$ at $950^{\circ} \mathrm{C}$ : (a) 5 minutes, (b) 10 minutes, (c) 30 minutes, and (d) 60 minutes. The magnification is 16,000x. 


\section{B.2 Low magnification images of bulk ironsand particles reduced by 5}

$\mathrm{Nl} / \mathrm{min} \mathrm{H}_{2}$ at $950^{\circ} \mathrm{C}$ - Section 6.6.1

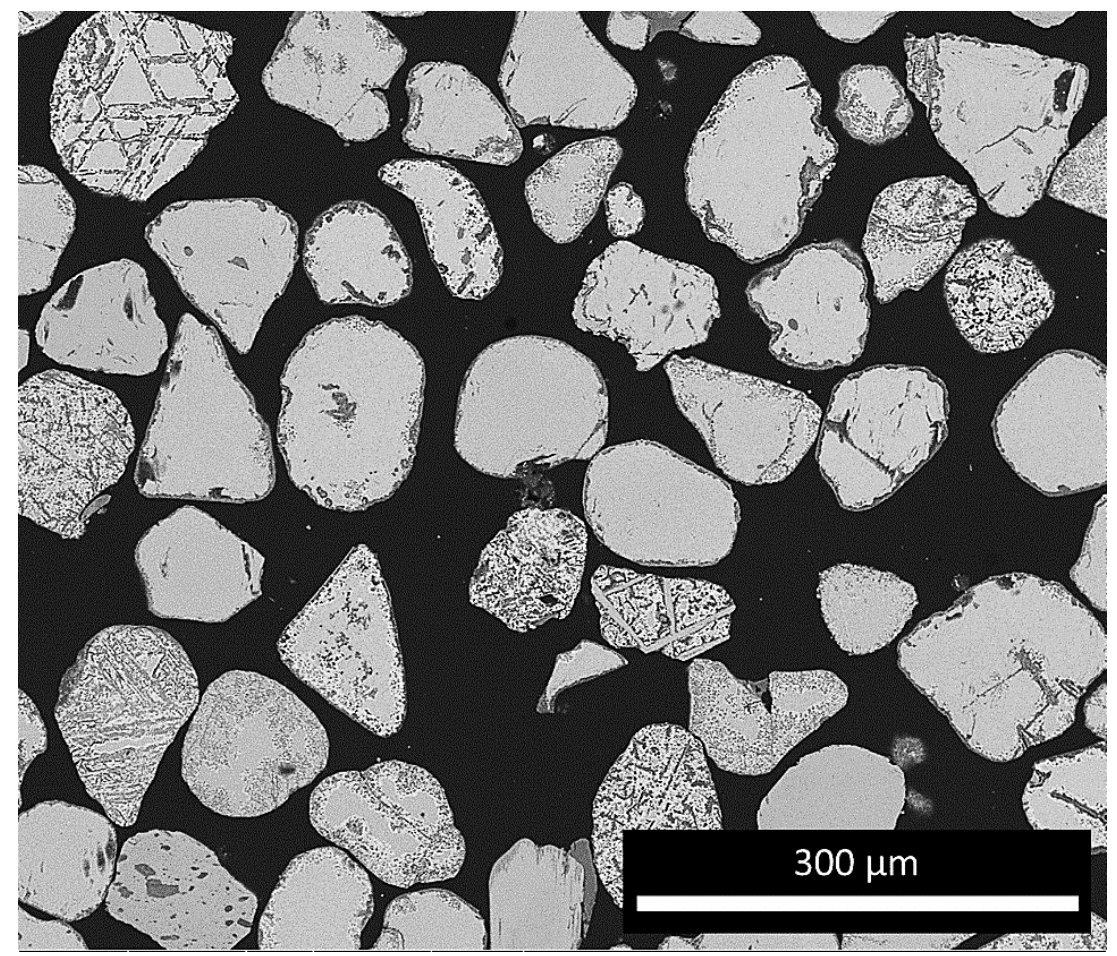

Figure B.3 Low magnification BSE-SEM image showing of bulk ironsand particles reduced by $5 \mathrm{Nl} / \mathrm{min} \mathrm{H}_{2}$ at $950^{\circ} \mathrm{C}$ for 5 minutes. The magnification is $400 \mathrm{x}$

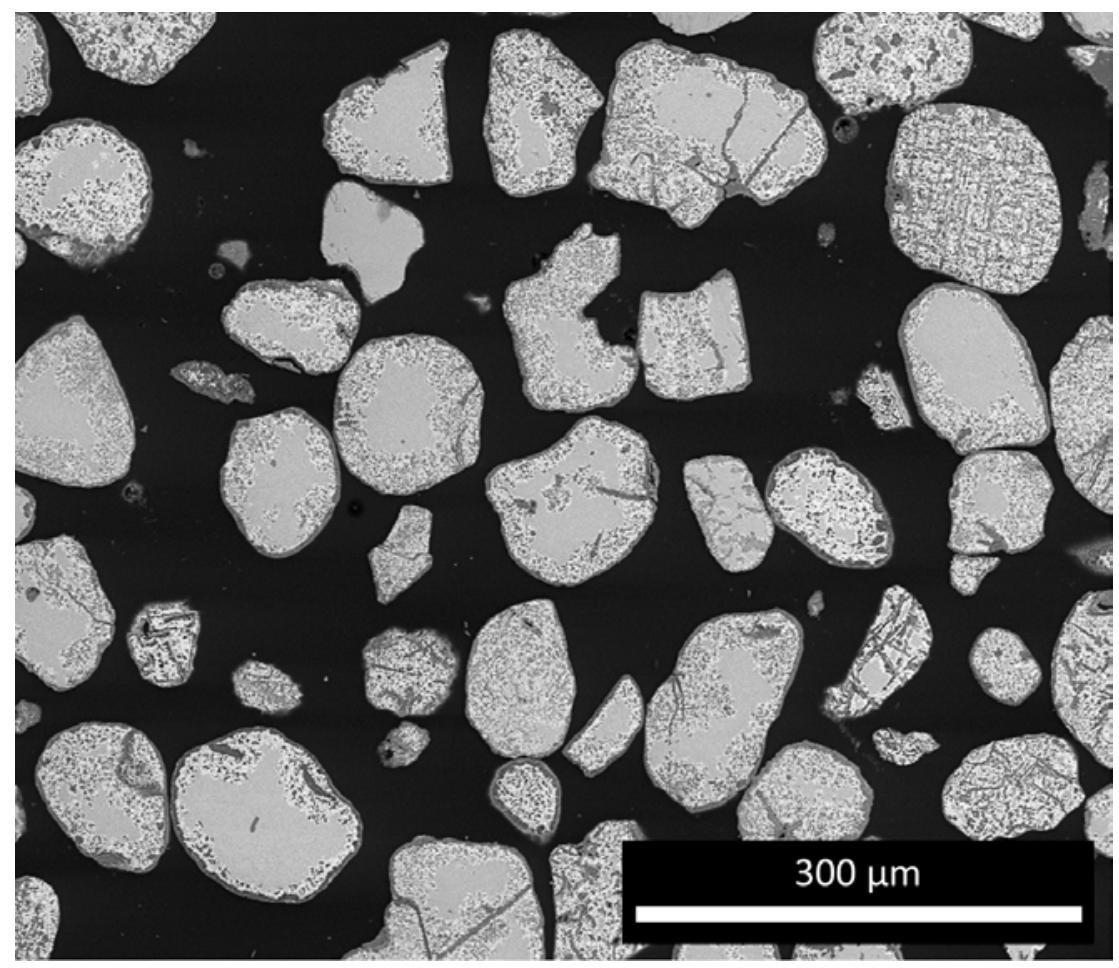

Figure B.4 Low magnification BSE-SEM image showing of bulk ironsand particles reduced by $5 \mathrm{Nl} / \mathrm{min} \mathrm{H}_{2}$ at $950^{\circ} \mathrm{C}$ for 10 minutes. The magnification is $400 \mathrm{x}$ 


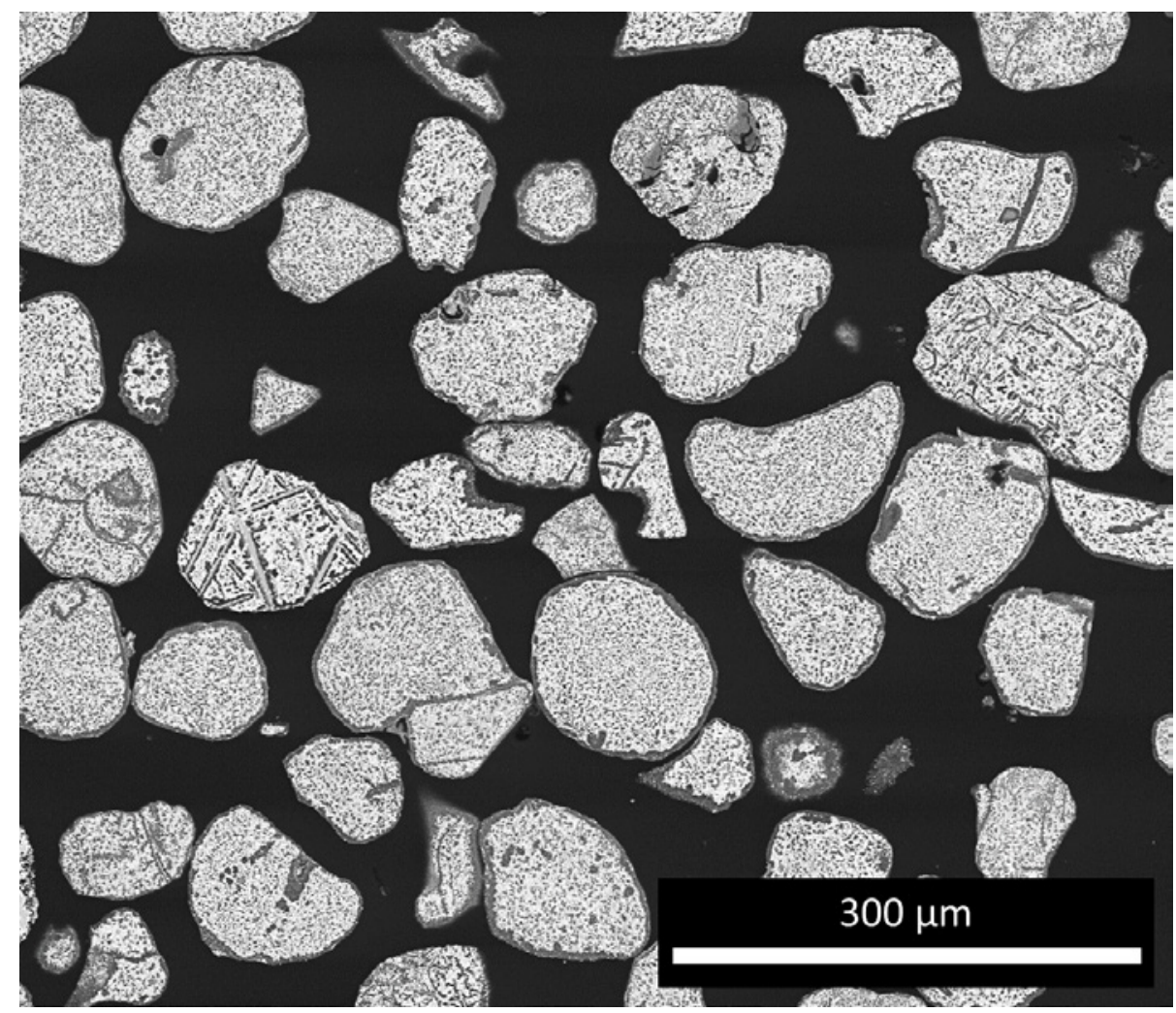

Figure B.5 Low magnification BSE-SEM image showing of bulk ironsand particles reduced by $5 \mathrm{Nl} / \mathrm{min} \mathrm{H}_{2}$ at $950^{\circ} \mathrm{C}$ for 20 minutes. The magnification is $400 x$.

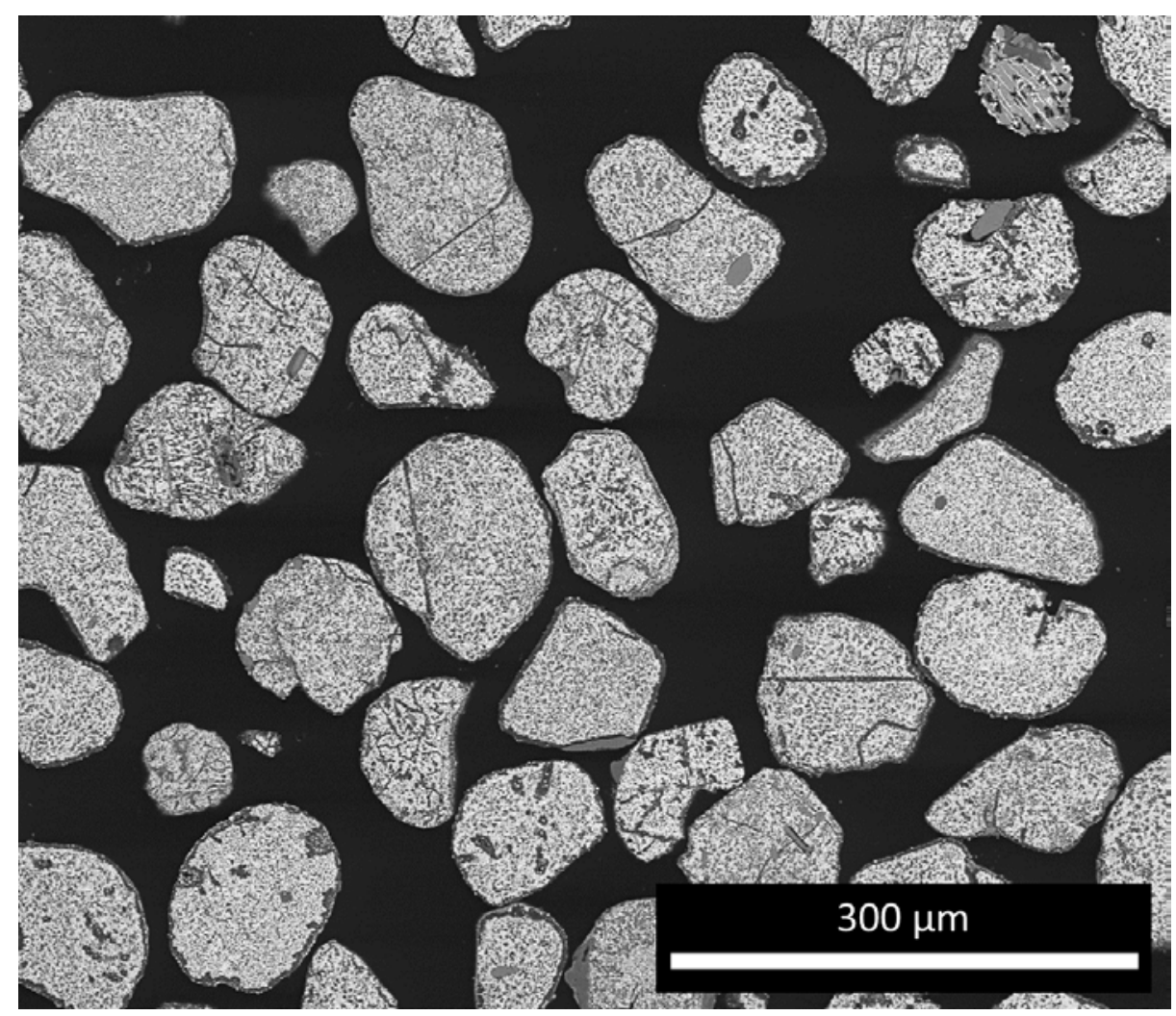

Figure B.6 Low magnification BSE-SEM image showing of bulk ironsand particles reduced by $5 \mathrm{Nl} / \mathrm{min} \mathrm{H}_{2}$ at $950^{\circ} \mathrm{C}$ for 40 minutes. The magnification is $400 \mathrm{x}$ 


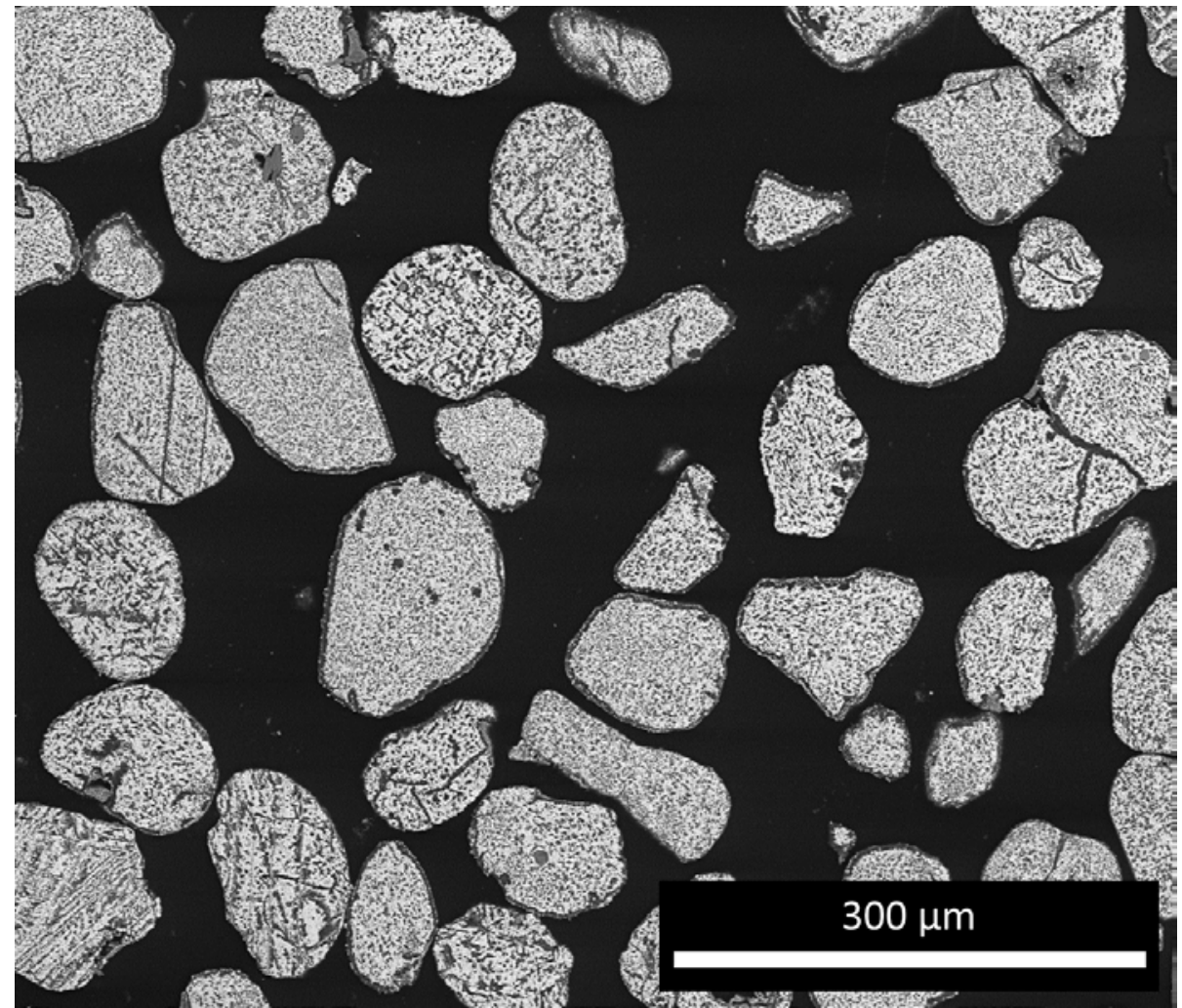

Figure B.7 Low magnification BSE-SEM image showing of bulk ironsand particles reduced by $5 \mathrm{Nl} / \mathrm{min} \mathrm{H}_{2}$ at $950^{\circ} \mathrm{C}$ for 60 minutes. The magnification is $400 \mathrm{x}$ 


\section{Appendix C}

\section{Additional SEM Images for Chapter 7}

\section{C.1 SEM images of the particle reduced by $5 \mathrm{Nl} / \mathrm{min} \mathrm{H}_{2}$ at $800^{\circ} \mathrm{C}$}
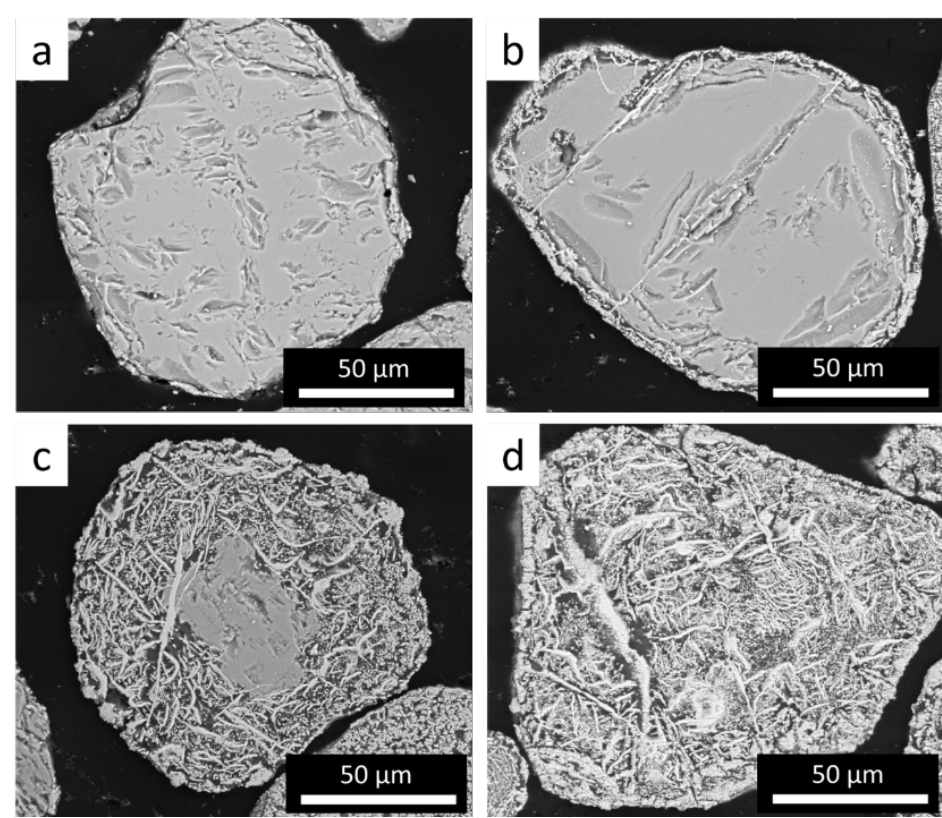

Figure C.1 BSE-SEM images of the ironsand particle during the reduction by $5 \mathrm{Nl} / \mathrm{min} \mathrm{H}_{2}$ at $800^{\circ} \mathrm{C}$ : (a) 5 minutes, (b) 20 minutes, (c) 60 minutes, and (d) 115 minutes.

\section{C.2 SEM images of the particle reduced by $5 \mathrm{Nl} / \mathrm{min} \mathrm{H}_{2}$ at $850^{\circ} \mathrm{C}$}
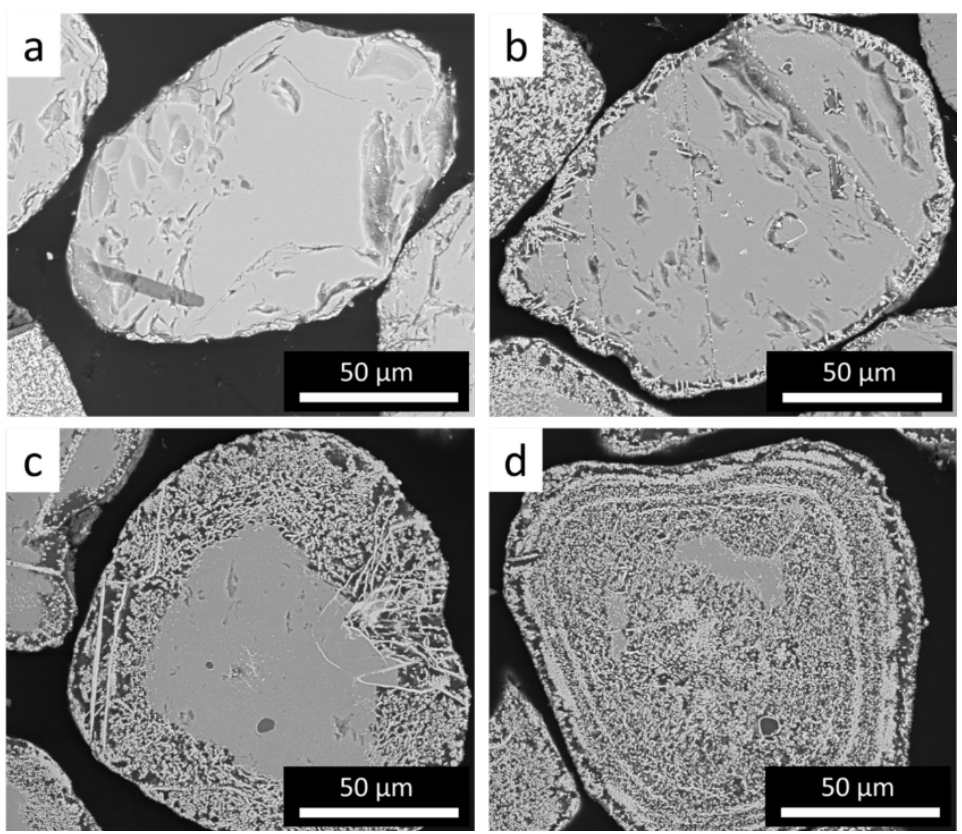

Figure C.2 BSE-SEM images of the ironsand particle during the reduction by $5 \mathrm{Nl} / \mathrm{min} \mathrm{H}_{2}$ at $850^{\circ} \mathrm{C}$ : (a) 5 minutes, (b) 20 minutes, (c) 40 minutes, and (d) 60 minutes. 


\section{Appendix D}

\section{Additional Information for Sticking Cases Described in Section 7.7}

\section{D.1 Sticking case A}

\section{D.1.1 Observation of sticking}

Figure D.1 shows the time profile of $\Delta P$ across the bed during the reduction at $1050^{\circ} \mathrm{C}$. In the figure, a sharp fall of $\Delta P$ is observed after about 17 minutes of reduction (red arrow). After this point, samples can no longer be extracted from the reactor. The experiment was then stopped after about 20 minutes, and the fluidising gas was switched to Ar gas. Again, all attempts at sampling also failed in Ar gas. All of these behaviours indicated the sticking of particles in the reactor. Once the furnace had cooled to room temperature, the samples were taken out from the reactor and examined. The furnace was cooled slowly, with $2 \mathrm{~L} / \mathrm{min}$ of Ar gas flowed to the reactor to prevent oxidation of the bed.

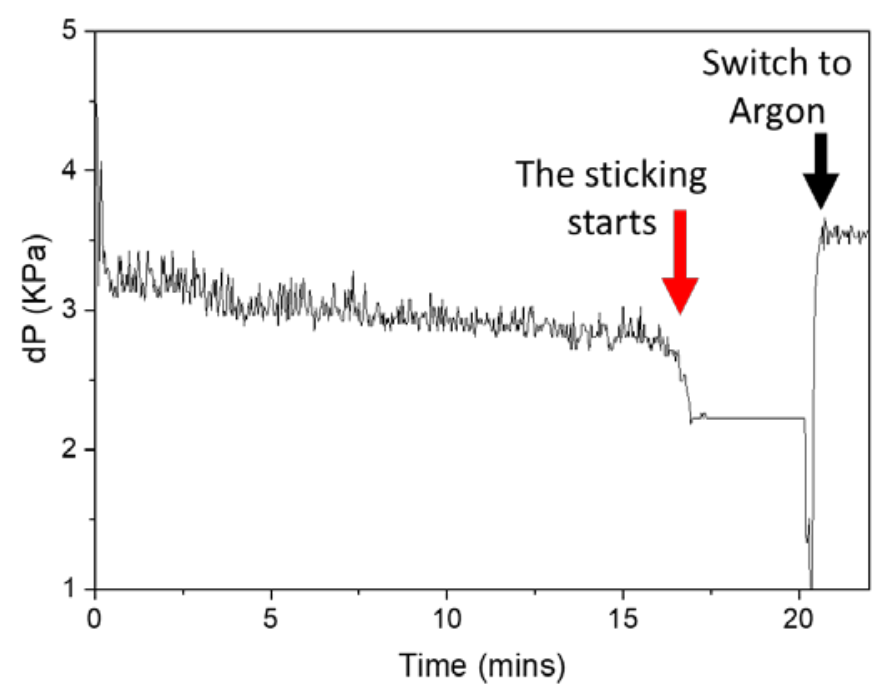

Figure D.1 Pressure drop profile during the reduction of TTM ironsand by $5 \mathrm{~L} / \mathrm{min} \mathrm{H}_{2}$ gas at $1050^{\circ} \mathrm{C}$. Red arrow indicates the start of particle sticking in the bed. Black arrow indicates the time when the hydrogen gas is switched to Ar gas.

Figure D.2 shows the XRD patterns from the two types of sinter and the loose powder part shown in Figure 7.20. Wüstite phase is detected in both types of sinter, as shown in the Figure. In the case of the loose powder part, the majority of the XRD peaks are iron with 
some traces of TTM, ilmenite, and pseudobrookite peaks. This is similar to that of the fully reduced particle (see Chapters 6 and 7), implying that that the un-sintered loose particles are fully reduced by the conclusion of the experiment. The fact that this material remains loose powder, suggests that these particles might be fluidised in the middle part of the reactor throughout the reduction process.

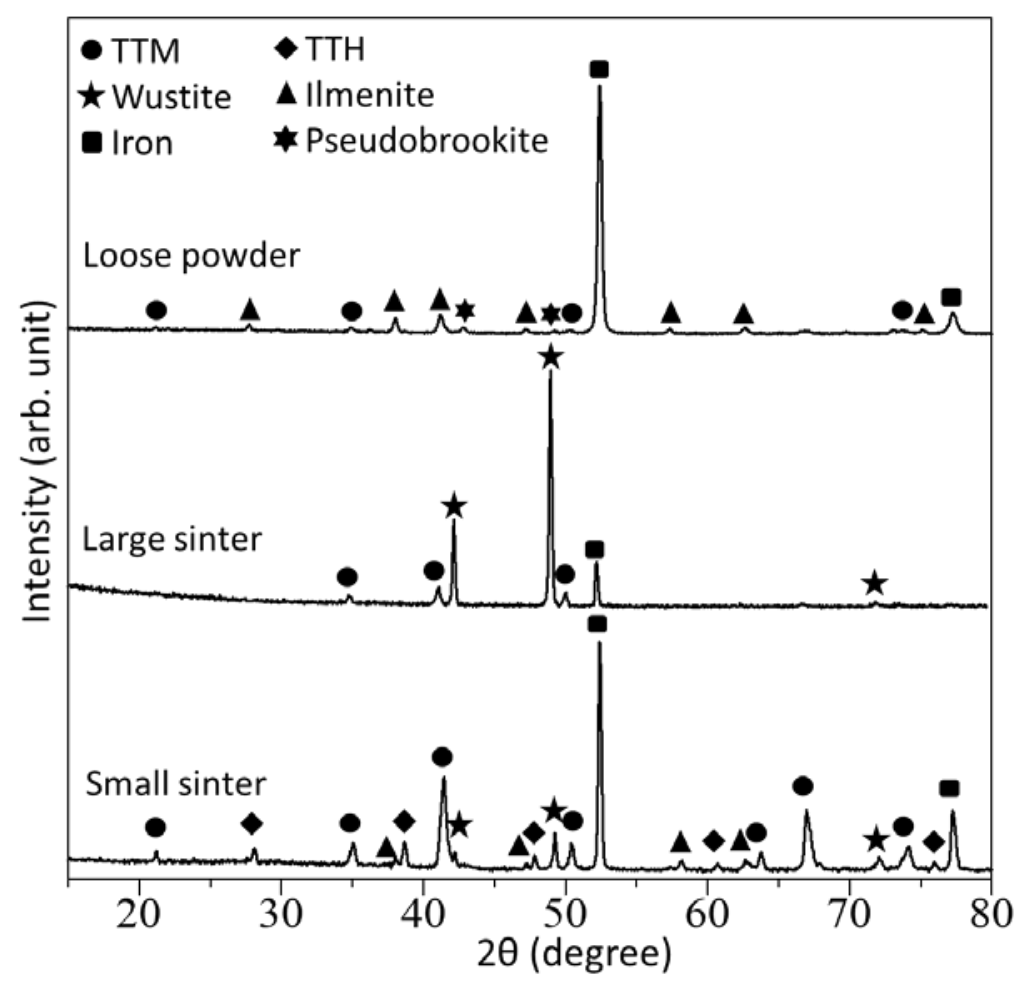

Figure D.2 XRD patterns of the small sinter (point 1 in Figure 7.20), the large sinter (point 2 in Figure 7.20), and lose powder (point 3 in Figure 7.20)

During the first 15 minutes of the reduction experiment, sampling could be carried out normally at 3, 5, 10, and 15 minutes. Figure D.3 shows the resulting plot of \%met and the time evolution of each phase during this period. The data points at 20 minutes correspond to the powder sample, which was removed after slow cooling of the entire reactor to room temperature. 


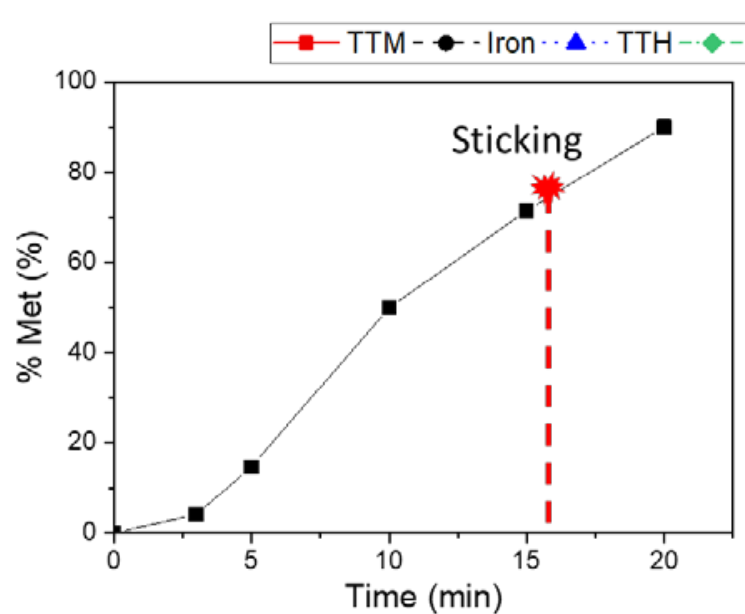

(a)

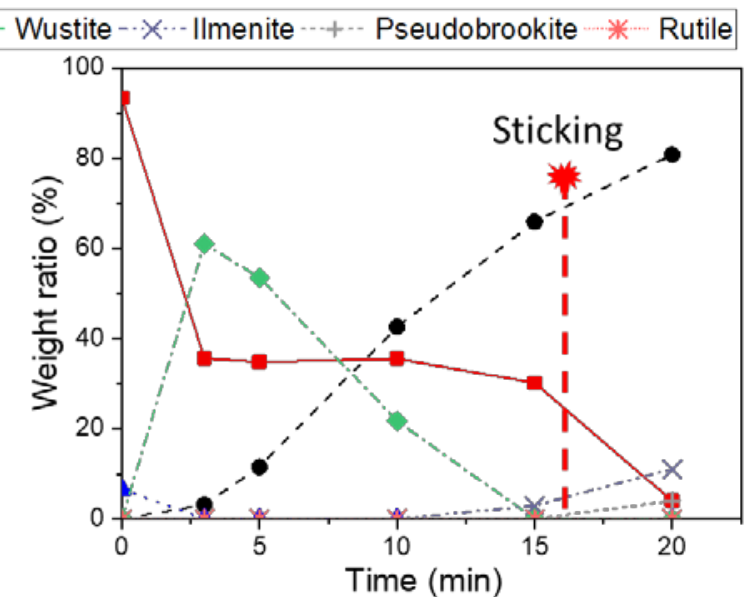

(b)

Figure D.3 \%met curve (a), and the evolution of the amount of phases (b) as a function of time showing the progression of the reduction reaction. Dashed red line and red marker indicate the sticking time.

Figure D.3(a) shows that the onset of particle sticking appears to occur once the reduction process has reached relatively high \%met levels ( 80\%). From Figure D.3(b), it can be seen that particle sticking occurs after wüstite has been fully reduced to metallic iron. This is during reduction stage 3: the reduction of Ti-rich TTM to metallic iron and ilmenite (see Chapter 6, Section 6.4). This result is different from sticking for hematite ores (Komatina and Gudenau, 2004; Shao, Guo and Tang, 2013; Guo et al., 2020) and magnetite ore (shown in Chapter 5), which is reported to occur at the beginning of the reduction of wüstite to metallic iron.

\section{D.1.2 SEM images for the fluidised particle (loose powder)}

Figure D.4 shows BSE-SEM images of cross-section views of particles reduced at $1050^{\circ} \mathrm{C}$ for $5,10,15$, and 20 minutes. In general, the microstructure of the particle is the same as that seen for particles reduced at $950^{\circ} \mathrm{C}$ and $1000^{\circ} \mathrm{C}$ (see Chapter 6 and 7). Here it can be seen that the Ti-rich shell (white arrow) is apparent on the particles in every image, including the particle from the final loose powder part (Figure D.4(d)). This is as expected as the shell most likely prevents the sticking of particles in the loose powder. This is different from that found in the particle sticking case for magnetite ore in Chapter 5. 

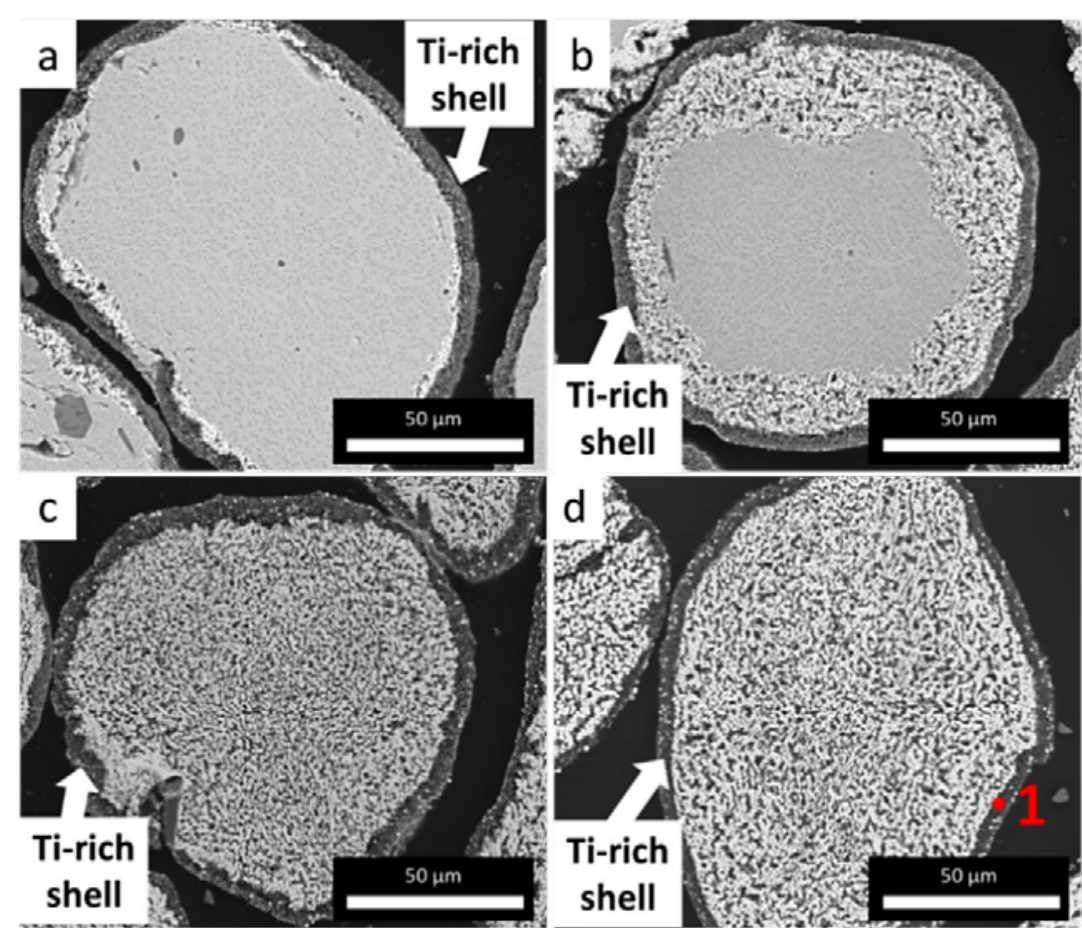

Figure D.4 The microstructural evolution of ironsand particle during the reduction by 5 $\mathrm{L} / \mathrm{min} \mathrm{H}_{2}$ at $1050^{\circ} \mathrm{C}$ : (a) 5 minutes, (b) 10 minutes, and (c) 15 minutes. Image (d) is the particle in powder part (reduced for 20 minutes).

\section{D.1.3 SEM images for the small sinter}

Figure D.5 shows the BSE-SEM images showing the surface morphology of particles in the small sinter. The surface of the sintered particles is covered by cubic crystals. The crystal structure of wüstite is cubic (see Chapter 2, Section 2.3), so these are most likely the wüstite phase detected by XRD. This would indicate the shell disappears during the reduction process, and then wüstite is formed on the surface of the particle.
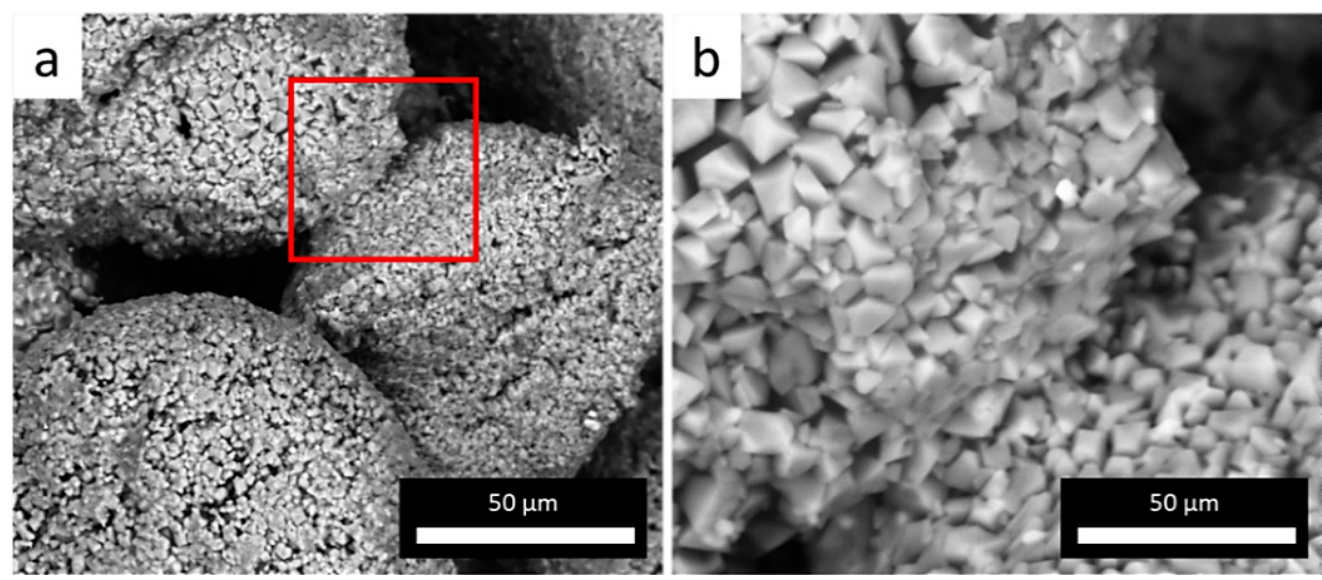

Figure D.5 BSE-SEM micrographs showing the surface morphology of the particle in

sinter type 1. Image (b) is the higher magnification of the red marker in image (a). 
Figures D.6(a, e, i, m) show cross-section BSE-SEM images which illustrate the changing detailed microstructure of particles located at the bottom, middle, and top part of the small sinter. Elemental EDS map of each image are presented on the right side of each image shown in Figures D.6.

An EDS point analysis of a Ti-rich shell from a fluidised particle, and a dense shell found in the sinter is presented in Table D.1. In the table, the Fe/Ti ratio in the dense shell (points 2, 3, 4) is higher than in the Ti-rich shell (point 1), and it increases as the position of the particle gets closer to the reactor wall). The EDS maps in Figure D.6 emphasise that the Ti content of the dense shell is greatly depleted as the position of the particle is getting closer to the wall. These results suggest that the dense shell is converted to an Fe-oxide. The Fe/O ratio in the dense shell (points $2,3,4$ ) does not change significantly across all particles in the sinter, which indicates that the phase in the dense shell is likely to be the same in all locations, and is probably the wüstite phase detected by XRD (see Figure D.2).

Table D.1 Elemental spot EDS analysis of points shown in Figure D.4 and D.6.

\begin{tabular}{cccccc}
\hline & \multicolumn{5}{c}{ Point (At. \%) } \\
\cline { 2 - 6 } Element & $\begin{array}{c}\text { Fluidised } \\
\text { particle }\end{array}$ & bottom part & middle part & middle part & top part \\
\cline { 2 - 6 } & 1 & 2 & 3 & 4 & 5 \\
\hline $\mathrm{O}$ & 55.1 & 48.4 & 47.9 & 51.2 & 54.8 \\
$\mathrm{Mg}$ & 7.9 & 2.6 & 5.6 & 2.5 & 4.1 \\
$\mathrm{Al}$ & 13.5 & 4.2 & 2.6 & 1.5 & - \\
$\mathrm{Ti}$ & 10.6 & 8.9 & 2.4 & 0.6 & - \\
$\mathrm{Mn}$ & - & - & - & 0.8 & 1.3 \\
$\mathrm{Si}$ & - & 2.3 & - & - & - \\
$\mathrm{Fe}$ & 12.9 & 39 & 41.5 & 43.4 & 39.9 \\
$\mathrm{Fe} / \mathrm{Ti}$ & 1.2 & 11.1 & 18.1 & - & - \\
$\mathrm{Fe} / \mathrm{O}$ & 0.2 & 0.8 & 0.9 & 0.8 & 0.7 \\
\hline
\end{tabular}

The hyphen sign in the table means no signal for the respective element. 


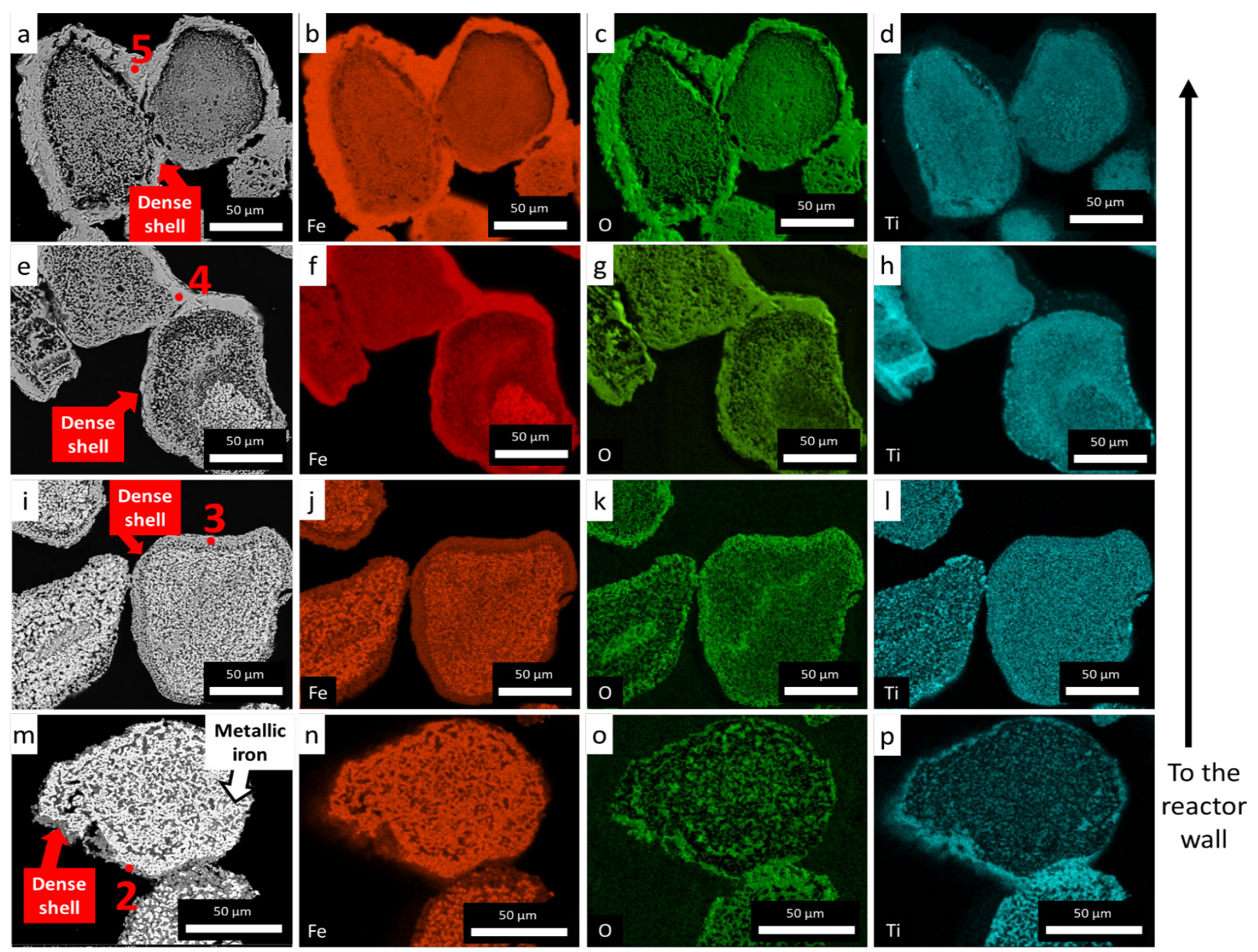

Figure D.6 BSE-SEM micrographs showing the cross-section of particles in the sinter type 1 (a, e, i, m). Black arrow on the right side indicates the location of the particle towards the wall. Elemental EDS map of each image are on the right side: $(b-d)$ for (a), (f-h) for (e), (j-l) for (i), and $(n-p)$ for $(m)$. Each element is noted in each image. 


\section{D.1.4 SEM images for large sinter}

Figure D.7(a) shows the photograph of the cross-sectional view of the sinter type 2, which formed around the Inconel sampling tube. The bottom part of the sinter in this image was stuck to the sampling tube at the end of the reaction. A SEM image of the same sinter is shown in Figure D.7(b).
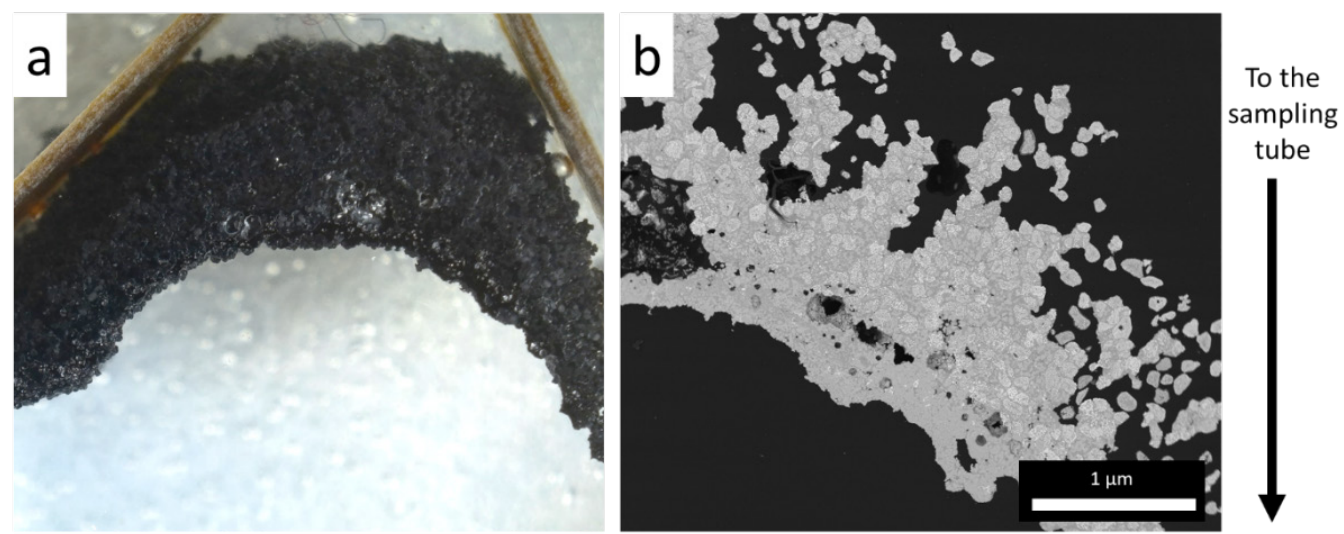

Figure D.7 Photograph of the cross-sectional view of the sinter type $2(a)$. (b) is the BSE-SEM image (80x magnification) at a section of the sinter.

Figure D.8 shows high-magnification SEM images of the bottom, middle, and top part of the sinter. Metallic iron progressively disappears as the particles approach the surface of the sampling tube. However, in the bottom image, the particle still seems to retain a similar shape to the particles in the top and middle images. This suggests that the particles here have also been re-oxidised during the experiment. 

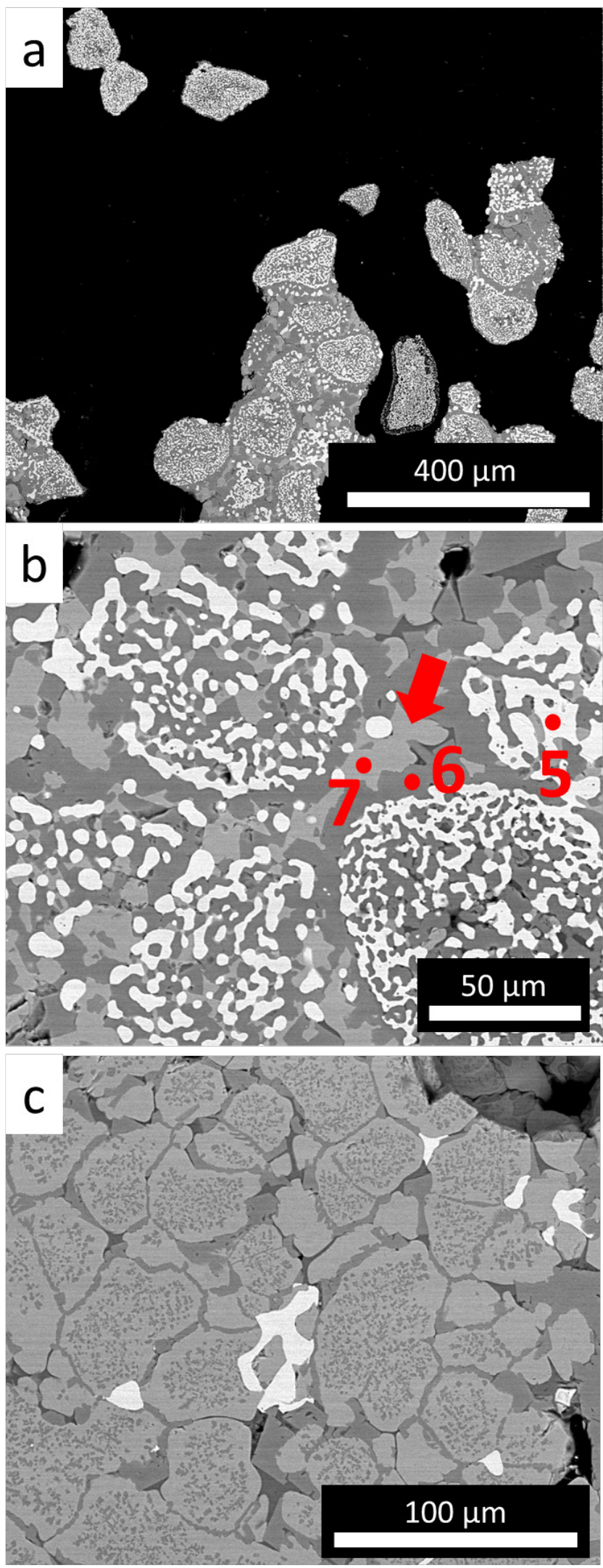

Figure D.8 BSE-SEM micrographs showing the cross-section of particles in the sinter type 1. Images (a-d) refer to the location of the particle towards the wall as indicated by black arrow on the right side. 
Table D.2 presents the EDS analysis for points in Figure D-2. Figure D-3 shows the EDS maps of Figure D-2(b) and (c). The table and the figure reveal that light grey region (red arrow) is depleted in Ti. This suggests that the light grey regions comprise the wüstite phase observed in XRD (Figure D.2).

Table D.2 Elemental spot EDS analysis of points shown in Figure D.8

\begin{tabular}{cccc}
\hline \multirow{2}{*}{ Element } & \multicolumn{3}{c}{ Point (At. \%) } \\
\cline { 2 - 4 } & 5 & 6 & 7 \\
\hline $\mathrm{O}$ & - & 59.5 & 51.4 \\
$\mathrm{Mg}$ & - & 4.4 & 2.7 \\
$\mathrm{Al}$ & - & 6.2 & - \\
$\mathrm{Ti}$ & - & 7.7 & 0.7 \\
$\mathrm{Mn}$ & - & 0.6 & 0.6 \\
$\mathrm{~V}$ & - & - & - \\
$\mathrm{Si}$ & - & - & - \\
$\mathrm{Fe}$ & 100 & 21.7 & 44.6 \\
$\mathrm{Fe} / \mathrm{Ti}$ & - & 2.8 & 59.5 \\
$\mathrm{Fe} / \mathrm{O}$ & - & 0.4 & 0.9 \\
\hline
\end{tabular}

The hyphen sign in the table means no signal for the respective element. 

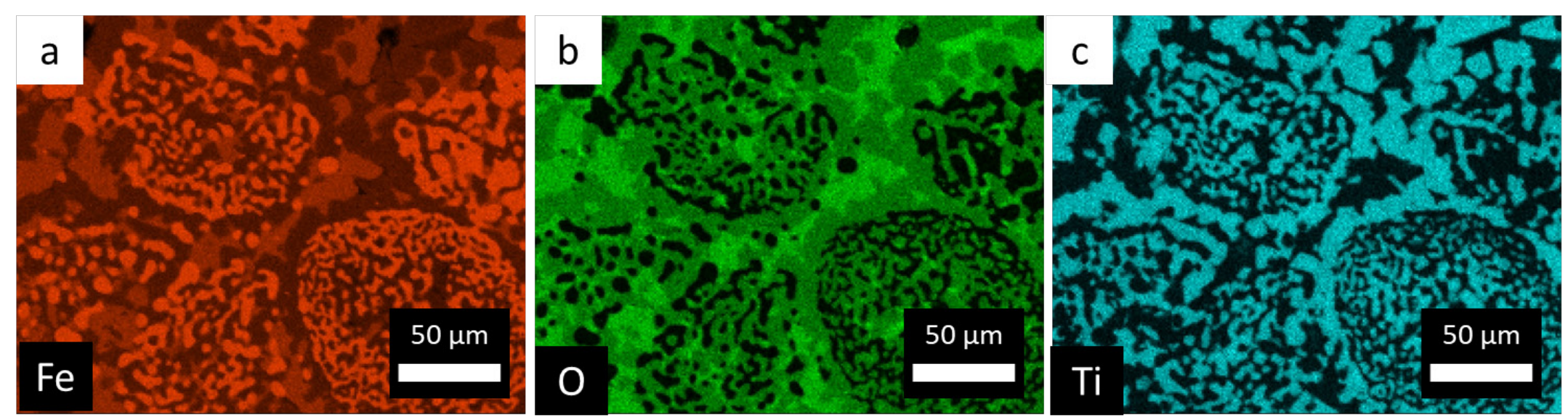

\section{To the sampling tube}
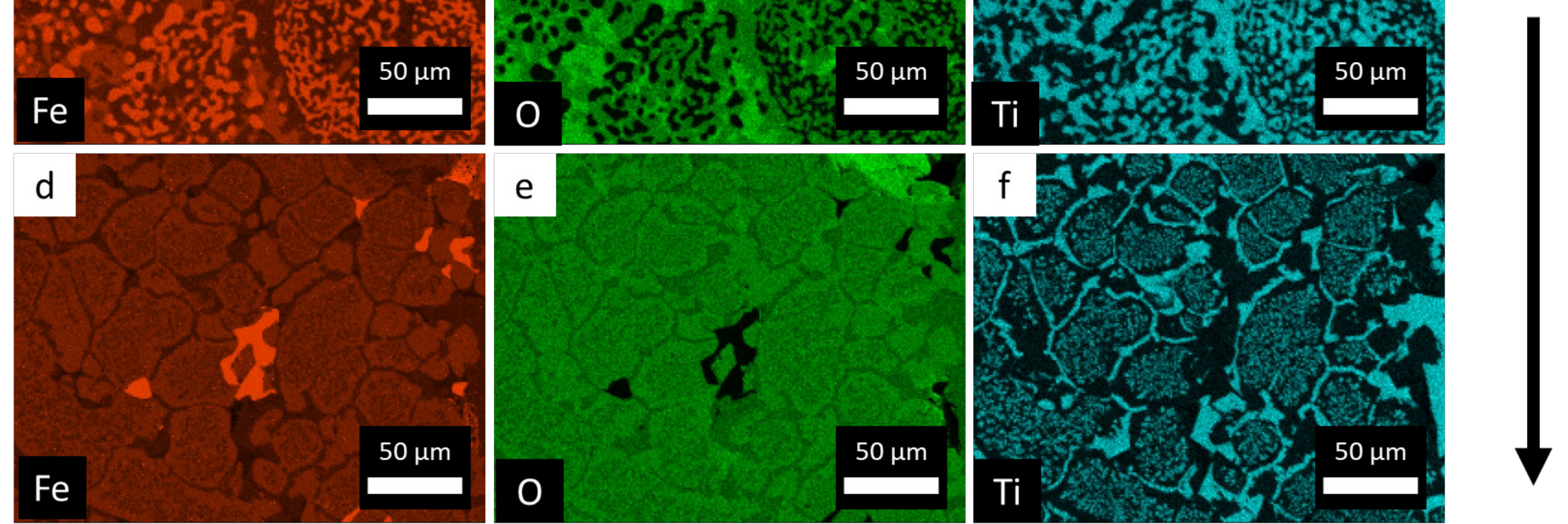

Figure D.9 Elemental EDS map of the particle in the sinter type 2. Images (a-c) are the middle part, Images (d-f) are the bottom part. Each element is noted in each image. The black arrow indicates the location of particle towards the sampling tube. 


\section{D.2 Sticking Case B}

\section{D.2.1 Observation of sticking}

Figure D.10 shows the $\Delta P$ profile and the partial pressure of $\mathrm{H}_{2} \mathrm{O}\left(X p_{\mathrm{H} 2 \mathrm{O}}\right)$ in the outlet gas during the reduction at $950^{\circ} \mathrm{C}$. Throughout the reduction experiment, there was no sign of a sharp fall in $\Delta P$ (Figure D.10 (a)). The reduction experiment was stopped at 70 minutes, after the $P_{H 2 O}$ in the outlet gas became steady at $\sim 7 \%$ (see Figure D.10(b)). Although there was no sudden drop of $\Delta P$, it was not possible to extract samples using the venturi sampler at any time after 30 minutes of reduction (several attempts at sampling were carried out between 30 and 70 minutes). After 70 minutes, Ar was switched into the reactor and it was slowly cooled to room temperature. Final samples were then taken out from the cold reactor. The photograph of the sample is presented in Figure 7.22. Figure D.11 shows the photograph of the sampling tube after the experiment. As mentioned in Section 7.7.2, no deformation observed in the tube.

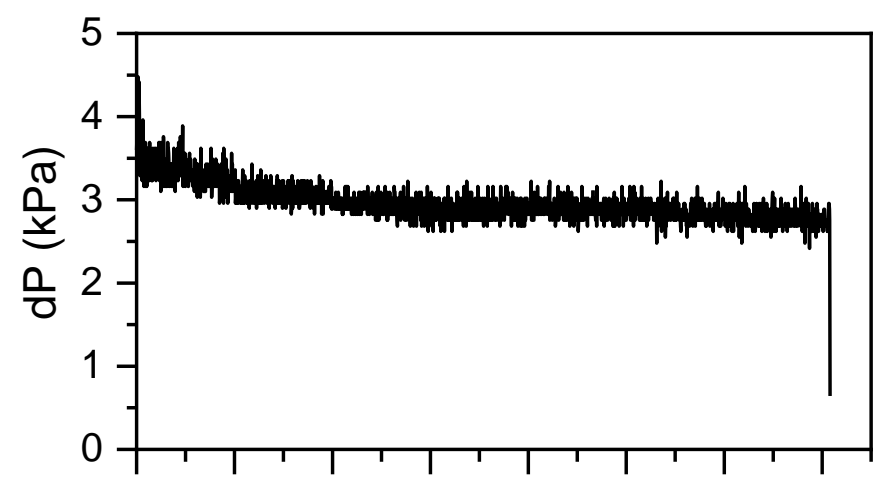

(a)

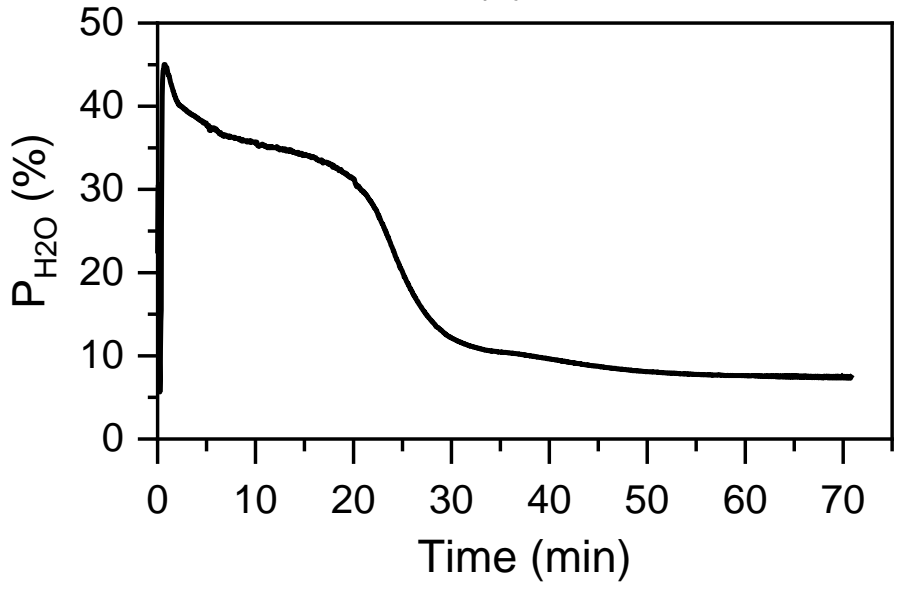

(b)

Figure D.10 Plots of $\triangle P(a)$ and $P_{H 2 O}$ (b) during the reduction of TTM ironsand by 7.5 mol.\% $\mathrm{H}_{2} \mathrm{O}-92.5 \mathrm{~mol} . \% \mathrm{H}_{2}$ at $950^{\circ} \mathrm{C}$. 


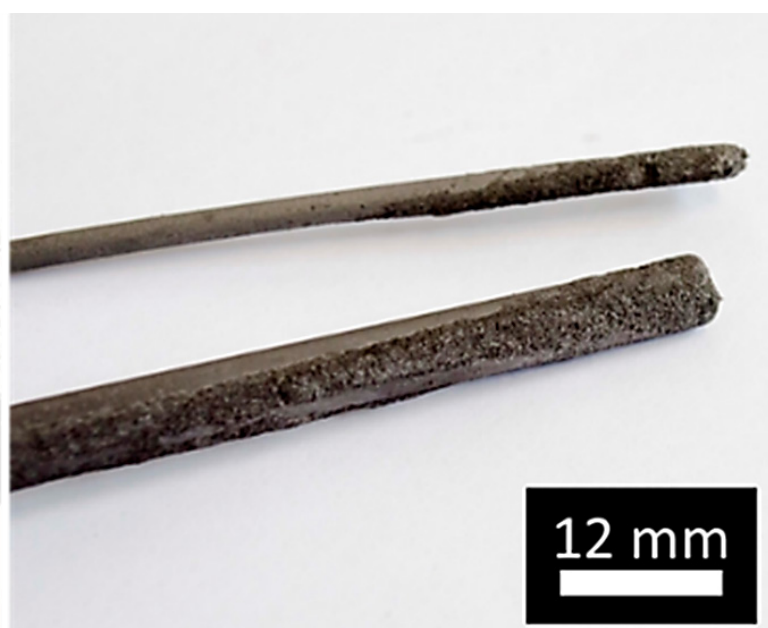

Figure D.11 the photograph of the sampling tube showing a small quantity adhered particles to the tube.

Sampling of the bed was able to be carried out normally at 5, 10, and 20 minutes. Figure D.12 shows the resulted plot of \%met and the time evolution of each phase over this period. The data at 70 minutes corresponds to the final sample in powder form, which was removed after slow cooling of the entire reactor to room temperature. As before, the Figure indicates that particle sticking must have occurred just after the conversion of wüstite to metallic iron. This result is similar to the case A.

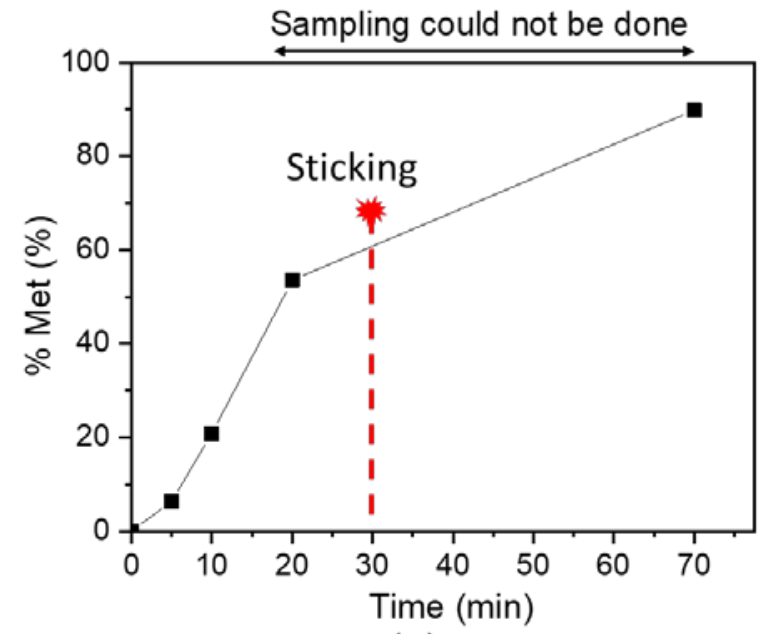

(a)

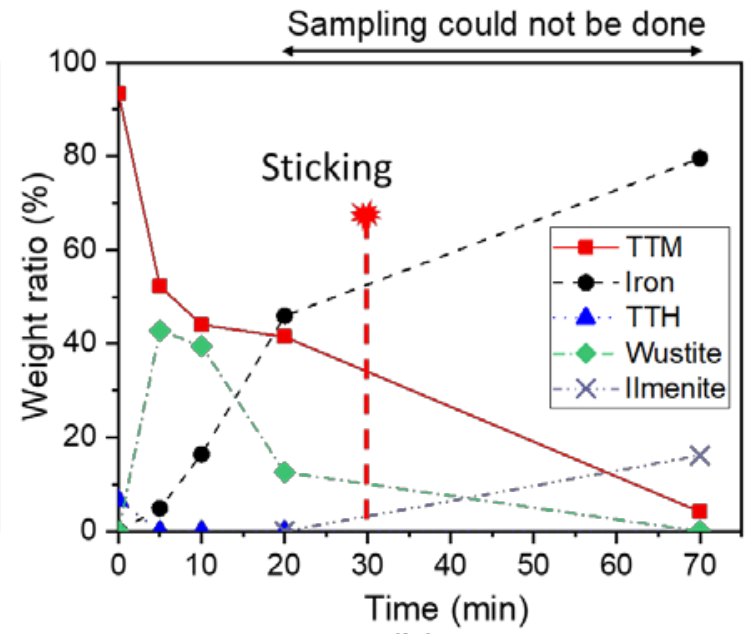

(b)

Figure D.12 \%met curve (a), and q-XRD evolution of the crystalline phases (c) as a function of time, showing the progression of the reduction reaction. The dashed red line and red marker indicate the sticking time.

Figure D.13 shows the XRD patterns of the sinter and the powder part shown in Figure 7.22. These are close to identical. Iron XRD peaks are dominant in both samples 
with some traces of TTM, ilmenite, and pseudobrookite peaks. This is different to what was found in the sticking case A. Here in case B, there is no wüstite XRD peak in the sinter. As the experiment was continued until 70 minutes under reducing gas (92.5 mol.\% $\mathrm{H}_{2}$ ), it is possible that any re-oxidised parts in the sinter might have been reduced again to metallic iron.

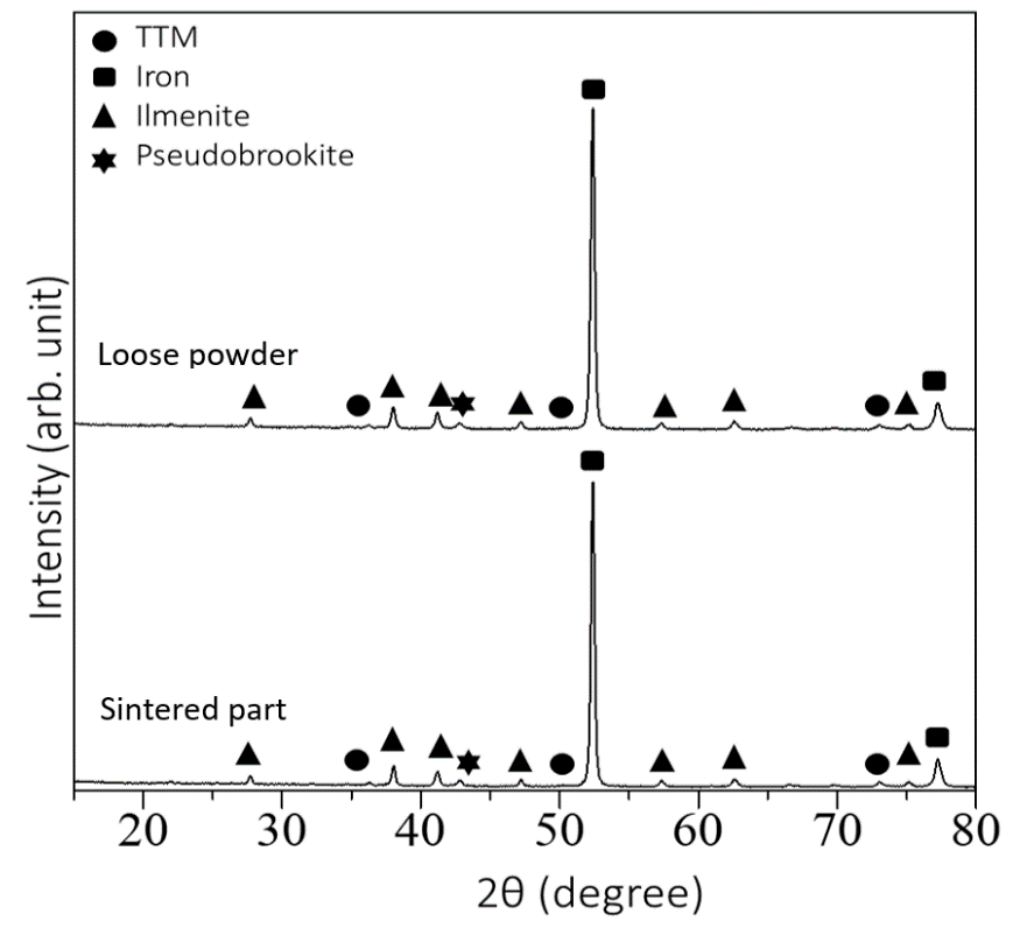

Figure D.13 XRD patterns of a small piece of the sinter (point 1 in Figure 7.23) and the powder part of the final sample obtained from sticking case B (point 2 in Figure 7.23)

\section{D.2.2 SEM images for fluidised particle (loose powder)}

Figure D.14 shows a comparison between the microstructural evolution of particles sampled during reductions at $7.5 \mathrm{~mol} \% \mathrm{H}_{2} \mathrm{O}$ and $100 \% \mathrm{H}_{2}$. The Figure compares the microstructure for samples at similar reduction stages. In general, the particle reduced by 7.5 mol. $\% \mathrm{H}_{2} \mathrm{O}$ display similar microstructural features to the particle reduced in $100 \% \mathrm{H}_{2}$ for each reduction stage. The Ti-rich shell had formed from reduction stage 1 (Figure D.14(a)) and remained up to the point that sampling could no longer be performed (Figure D.14(b)). In particular, the Ti-rich shell is also present in the outer part of the particle in the powder part (Figure D.14(c)). This indicates that these particles were fluidised as the shell most likely prevents the sticking of particles. 


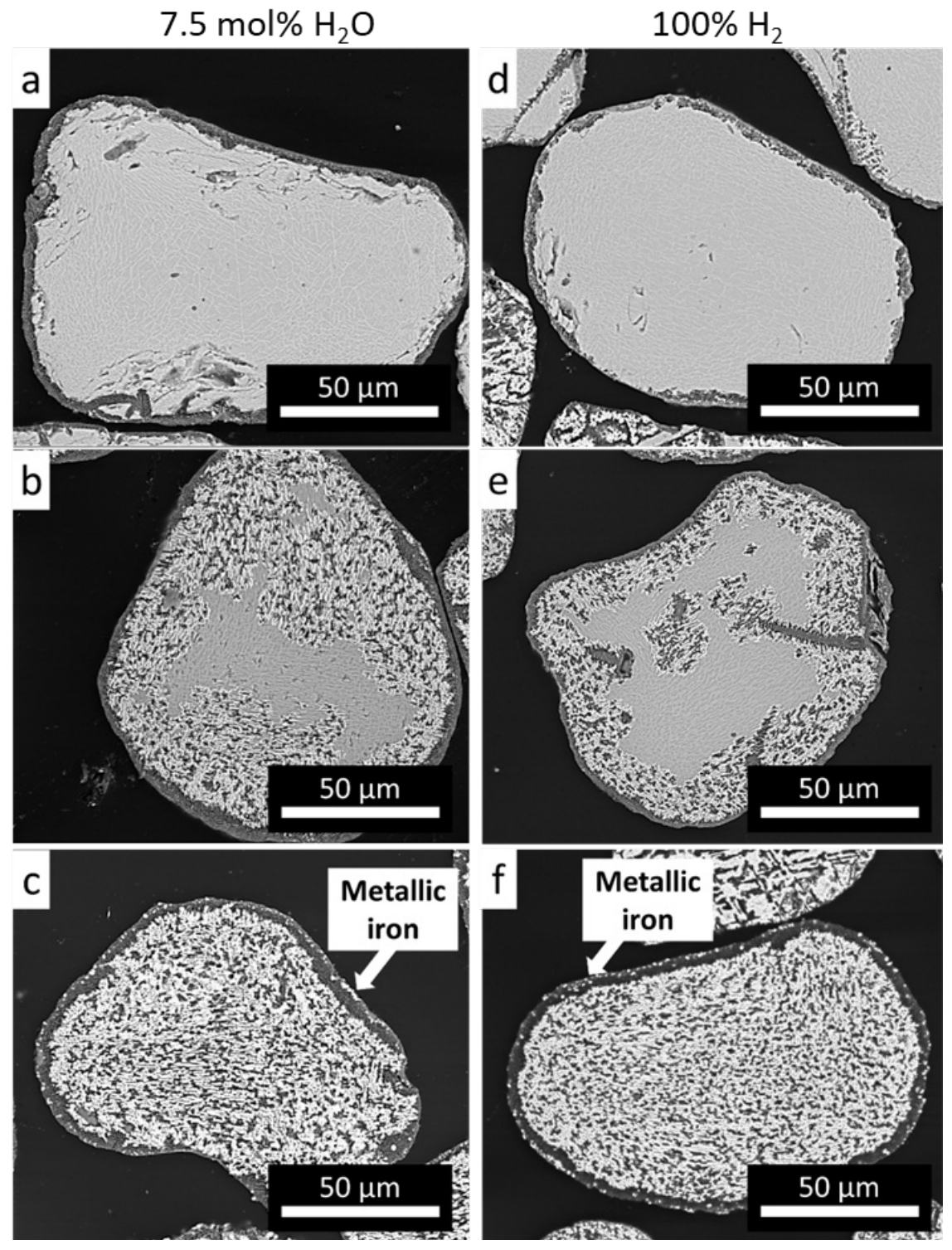

Figure D.14 Comparison of microstructure for the particle reduced in $7.5 \mathrm{H}_{2} \mathrm{O}$ mol.\% (ac) and $100 \% \mathrm{H}_{2}(\mathrm{~d}-\mathrm{f})$ at $950^{\circ} \mathrm{C}$. The figure compares left-side images to the respective right-side images with a similar reduction stage: ( $a \& b)$ for stage 1 , (b \& e) for stage 2 , and ( $c$ \& f) for the fully reduced particle.

\section{D.2.3 SEM images for sintered part}

Figure D.15 shows cross-section BSE-SEM images of particles located at the bottom, middle, and top part of the sinter. The figure clearly shows that the particles in the final sinter mostly comprise metallic iron, which is consistent with the XRD result (Figure D.13). 


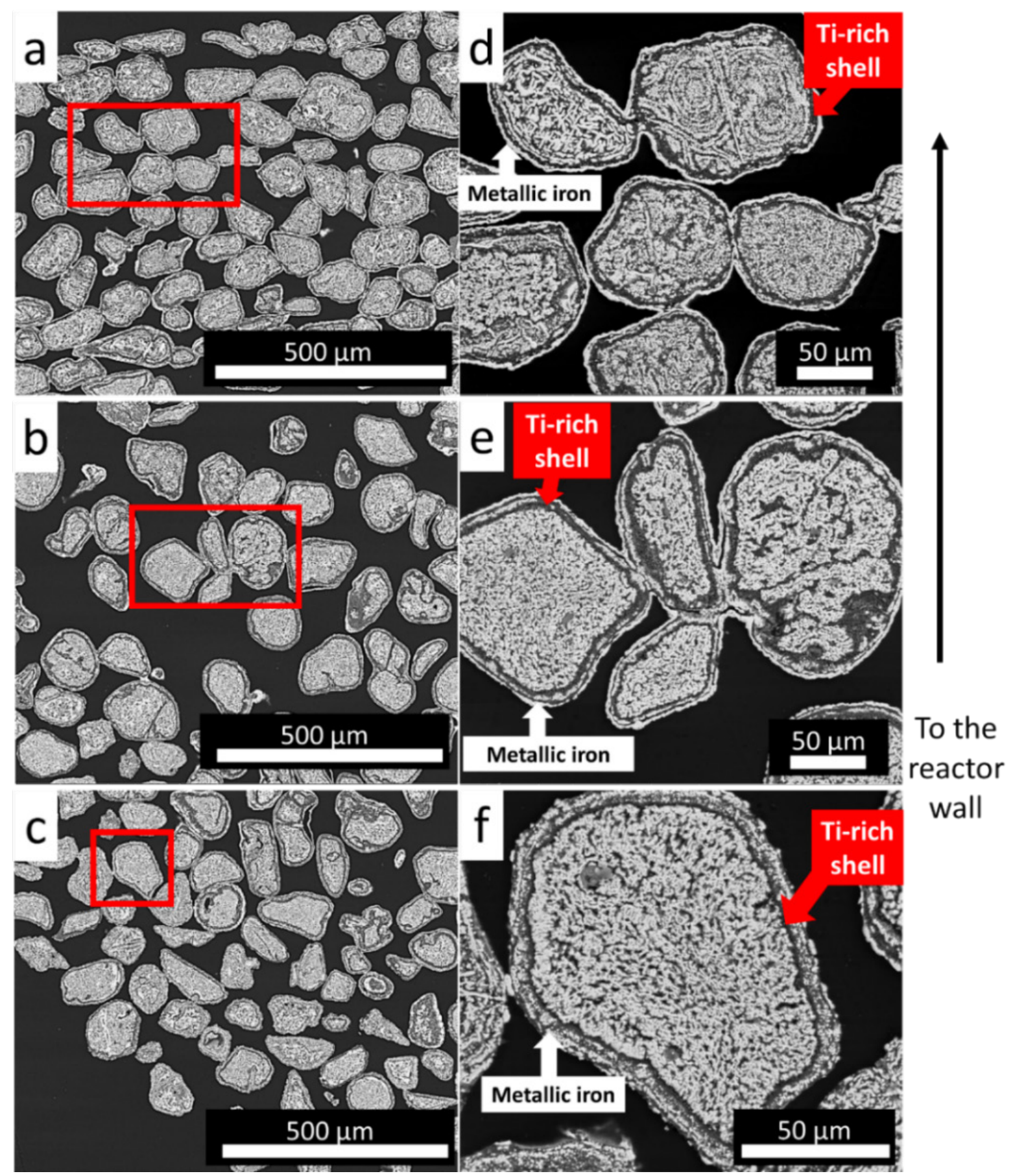

Figure D.15 BSE-SEM micrographs showing the cross-sectional view of particles in the sinter. Images $(a-c)$ refer to the location of the particle towards the wall as indicated by black arrow on the right side. Images ( $d-f)$ on the right side are respective high magnification images of the red markers.

In Figure D.15(d, e, f), it can be seen the outer shell (red arrow) of each particle appears to quite uniformly coated in metallic iron (white arrow). This is different from what was found in the sinter for sticking case A. It is not clear why the formation of metallic iron becomes uniform in the sinter. 